US Army Corps

of Engineers

Prepared for the U.S. Army Corps of Engineers, Portland District

Under an Interagency Agreement with the U.S. Department of Energy

Contract DE-AC05-76RLO 1830

\title{
Evaluating Cumulative Ecosystem Response to Restoration Projects in the Lower Columbia River and Estuary, 2008
}

\author{
FINAL ANNUAL REPORT
}

Prepared by:

Pacific Northwest National Laboratory, Marine Sciences Laboratory National Marine Fisheries Service, Pt. Adams Biological Field Station Columbia River Estuary Study Taskforce University of Washington

December 2009

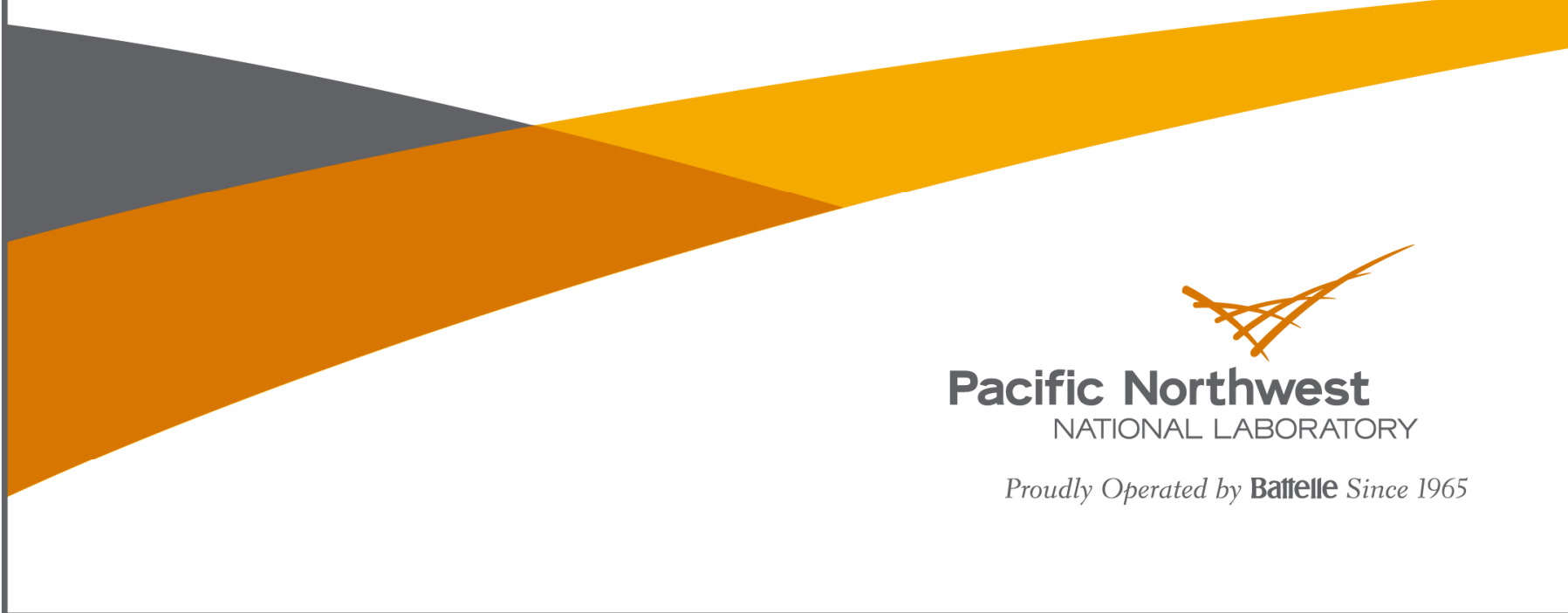




\title{
DISCLAIMER
}

This report was prepared as an account of work sponsored by an agency of the United States Government. Neither the United States Government nor any agency thereof, nor Battelle Memorial Institute, nor any of their employees, makes any warranty, express or implied, or assumes any legal liability or responsibility for the accuracy, completeness, or usefulness of any information, apparatus, product, or process disclosed, or represents that its use would not infringe privately owned rights. Reference herein to any specific commercial product, process, or service by trade name, trademark, manufacturer, or otherwise does not necessarily constitute or imply its endorsement, recommendation, or favoring by the United States Government or any agency thereof, or Battelle Memorial Institute. The views and opinions of authors expressed herein do not necessarily state or reflect those of the United States Government or any agency thereof.

\author{
PACIFIC NORTHWEST NATIONAL LABORATORY \\ operated by \\ BATTELLE \\ for the \\ UNITED STATES DEPARTMENT OF ENERGY \\ under Contract DE-AC05-76RL01830
}

Printed in the United States of America
Available to DOE and DOE contractors from the Office of Scientific and Technical Information,
P.O. Box 62, Oak Ridge, TN 37831-0062;
ph: (865) 576-8401
fax: $(865)$ 576-5728
email: reports@adonis.osti.gov

\begin{abstract}
Available to the public from the National Technical Information Service, U.S. Department of Commerce, 5285 Port Royal Rd., Springfield, VA 22161 ph: (800) 553-6847 fax: $(703) 605-6900$ email: orders@ntis.fedworld.gov online ordering: http://www.ntis.gov/ordering.htm
\end{abstract}

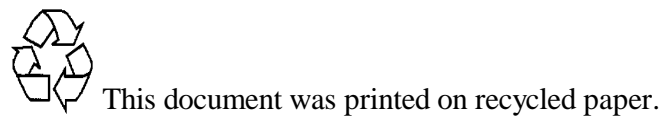


PNNL-18677

\section{Evaluating Cumulative Ecosystem Response to Restoration Projects in the Lower Columbia River and Estuary, 2008}

Edited by Gary E. Johnson and Heida L. Diefenderfer ${ }^{\mathrm{a}}$

Amy B. Borde ${ }^{a}$

Earl M. Dawley ${ }^{\mathrm{b}}$

Blaine D. Ebberts ${ }^{c}$

G. Curtis Roegner ${ }^{\mathrm{d}}$

Micah T. Russell ${ }^{\mathrm{e}}$

John R. Skalski ${ }^{\mathrm{f}}$

Ronald M. Thom ${ }^{\mathrm{a}}$

John Vavrinec III ${ }^{\mathrm{a}}$

Shon A. Zimmerman ${ }^{\text {a }}$

FINAL ANNUAL REPORT

December 2009

Prepared for the

U.S. Army Corps of Engineers, Portland District

Under a Government Order with the U.S. Department of Energy

Contract DE-AC05-76RLO 1830

Prepared by:

Pacific Northwest National Laboratory, Marine Sciences Laboratory National Marine Fisheries Service, Pt. Adams Biological Field Station Columbia River Estuary Study Taskforce University of Washington

\footnotetext{
${ }^{a}$ Pacific Northwest National Laboratory, Richland, Washington

b NOAA Fisheries (retired)

c U.S. Army Corps of Engineers, Portland District, Portland, Oregon

d NOAA Fisheries, Hammond, Oregon

e Columbia River Estuary Study Taskforce, Astoria, Oregon

${ }^{\mathrm{f}}$ University of Washington, Seattle, Washington
} 



\section{Executive Summary}

This is the fifth annual report of a seven-year project (2004 through 2010) to evaluate the cumulative effects of habitat restoration actions in the 235-km-long Columbia River estuary. The project, called the Cumulative Effects Study, is being conducted for the U.S. Army Corps of Engineers, Portland District (CENWP), by the Marine Sciences Laboratory of the Pacific Northwest National Laboratory (PNNL), the Pt. Adams Biological Field Station of the National Marine Fisheries Service (NMFS), and the Columbia River Estuary Study Taskforce (CREST).

The goal of the Cumulative Effects Study is to develop a methodology to evaluate the cumulative effects of multiple habitat restoration projects intended to benefit ecosystems supporting juvenile salmonids in the lower Columbia River and estuary (LCRE). Literature review in 2004 revealed no existing methods for such an evaluation and suggested that cumulative effects could be additive or synergistic. From 2005 through 2008, annual field research involved intensive, comparative studies paired by habitat type (tidal swamp versus marsh), trajectory (restoration versus reference site), and restoration action (tide gate versus culvert versus dike breach).

During 2008, the specific objectives for the Cumulative Effects Study were to do the following:

1. Summarize the adaptive management framework for LCRE habitat restoration activities.

2. Finalize the levels-of-evidence approach and ecological theory underpinning the analysis, synthesis, and evaluation of the cumulative effects of multiple habitat restoration projects in the LCRE.

3. Summarize new results from analyses from 2005-2008 project research for the purpose of cumulative effects evaluation in the LCRE.

4. Initiate a synthesis and evaluation of cumulative effects in the LCRE.

5. Assess management implications, lessons learned, decision-making, 2009-2010 research, and final project deliverables.

6. Provide a hydrodynamic model assessment of synergistic effects, analysis summaries of the additive modeling pilot study, natural breach and habitat creation sites, wetted area, hydrology and fish, monitoring summaries for Julia Butler Hanson Wildlife Refuge and Crims Island, and a preliminary meta-analysis of effectiveness monitoring ${ }^{1}$ data.

An adaptive management framework has been designed to capture learning from ecosystem restoration projects conducted under the Federal LCRE Habitat Restoration Program. This framework can be used to improve future projects conducted by the Corps and others in the LCRE, or as a model for larger-scale ecosystem restoration adaptive management. Successful implementation of adaptive management in the estuary will require the additional choices and commitments that would best be defined through a decision-making process that includes the other major sponsors of ecosystem restoration and stakeholders in the LCRE. The overarching purpose of adaptive management is to provide a framework to fulfill the goal of the Federal LCRE Habitat Restoration Program to understand, conserve, and restore the estuary ecosystem to improve the performance of listed salmonid populations. The framework is depicted in Figure ES.1.

\footnotetext{
${ }^{1}$ Effectiveness monitoring specifically pertains to monitoring at restoration and reference sites for the purpose of evaluating the effects of the restoration action.
} 


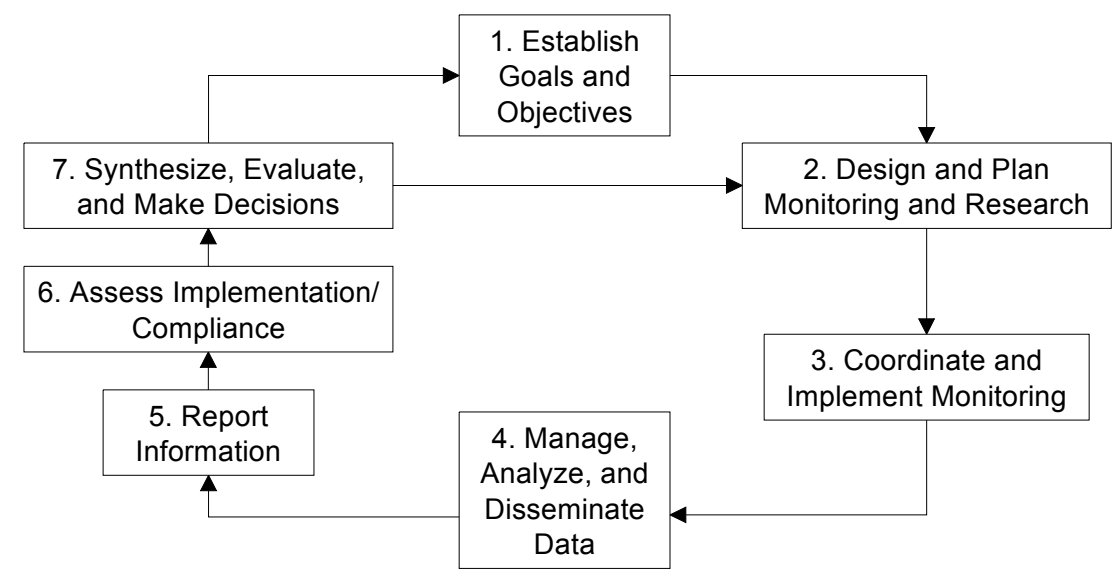

Figure ES.1. Schematic of the Adaptive Management Framework

The technical approach to evaluate the cumulative effects of habitat restoration in the LCRE is based on levels of evidence. A methodology for cumulative effects needs to be able to predict outcomes, provide a rationale to prioritize those projects likely to have the strongest effect on ecosystems, and thus function as a guide for identifying the efficient expenditure of restoration funding. We use levels of evidence to construct an inferential case for evaluating the cumulative response of an ecosystem to the large Federal LCRE Habitat Restoration Program. This case uses causal criteria, which are standard for levels-of-evidence approaches, as a guide from the initial experimental design for field data collection, for modeling and meta-analyses, and finally for the synthesis and evaluation of cumulative effects. Through this effort, we established that a levels-of-evidence approach is a potentially valuable tool for assessing the cumulative effects of ecological restoration actions, although the tool needs to be modified to account for uncertainties in outcomes, particularly if it is applied in an understudied ecosystem such as the LCRE. The technical approach for a cumulative effects evaluation is shown in Figure ES.2

Analyses from field research conducted from 2005 through 2008 addressed ecological relationships, restoration action effectiveness monitoring data, net ecosystem improvement, and synergies (Figure ES.2). In this 2008 annual report, we present preliminary data pertinent to the evaluation of the cumulative effects of habitat restoration in the LCRE. Some key results to date include the following:

- Water Elevation and Wetted Area Relationship - Frequency of floodplain inundation at a restoration site, the Kandoll Farm, was 54\% compared with $18 \%$ at the associated Kandoll Reference site. This was because the mean floodplain elevation of the restoration site was $0.7 \mathrm{~m}$ lower than the adjacent reference swamp; further, the microtopography was greater at the reference swamp. This implies that the area inundated on a particular recurrence interval will decrease as land surfaces rise due to sediment accretion. Thus the typical use of wetted area as an indicator of the effective size of tidal floodplain restoration projects, for the purpose of measuring available fish habitat, is likely to overestimate the areal extent of the inundation that will be seen some decades after implementation.

- Water Temperature and Fish Abundance Relationship - Chinook salmon catch per unit effort (CPUE) was greatest at temperatures 11 to $16^{\circ} \mathrm{C}$, although Chinook salmon were present in water up to $20^{\circ} \mathrm{C}$. CPUE for chum salmon was highest during temperatures 9 to $12{ }^{\circ} \mathrm{C}$. Coho salmon CPUE peaked at 12 to $18{ }^{\circ} \mathrm{C}$. Water temperature is a key indicator to monitor at habitat restoration sites. 


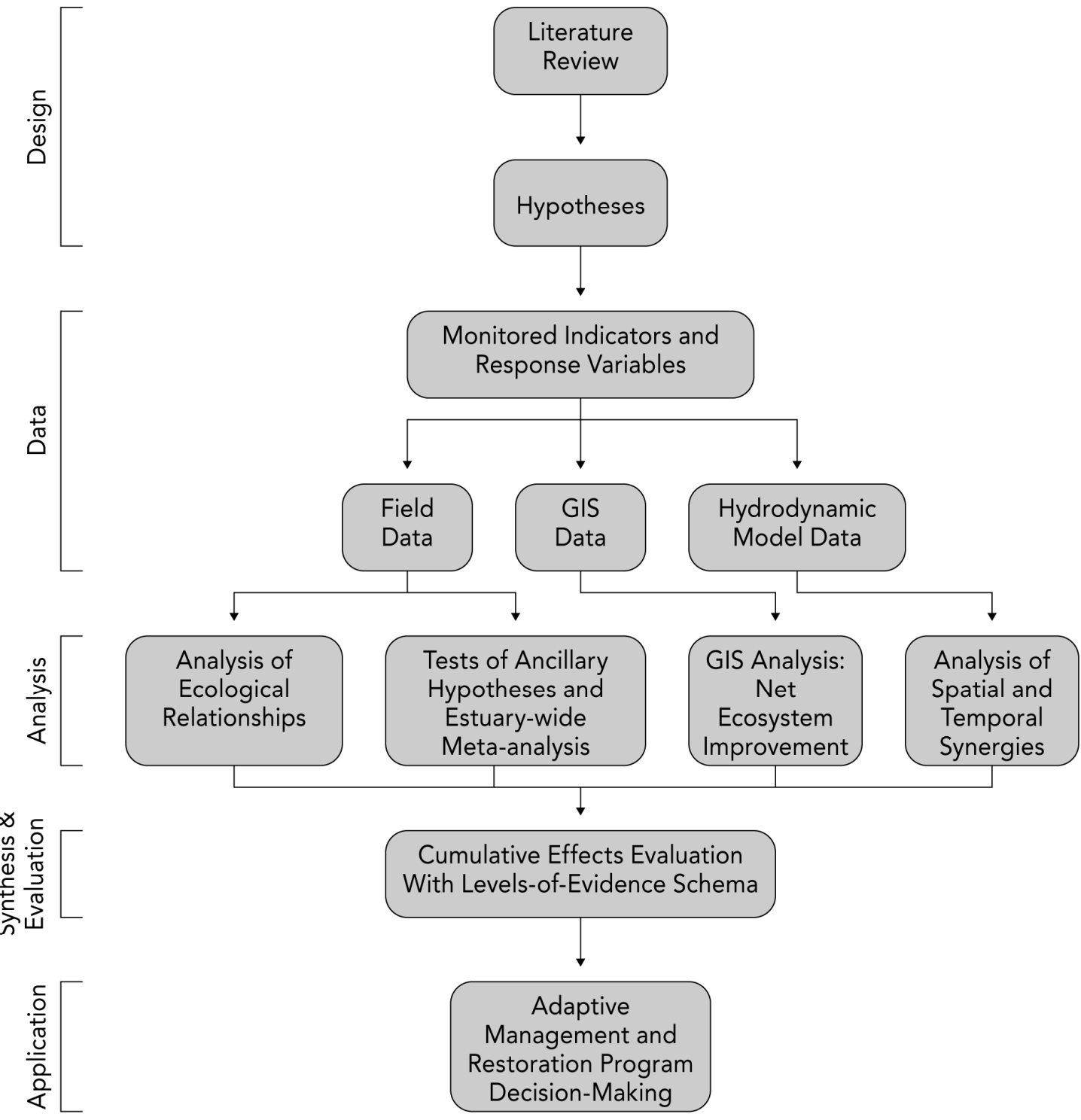

Figure ES.2. Assessment of the Cumulative Effects of Ecosystem Restoration by a Levels-of-Evidence Approach. GIS stands for geographical information system.

- Habitat Type and Fish Stock Relationship - There was no clear relationship between fish stock and habitat type, as represented by the different sampling locations in the lower Grays River. Salmon stock management practices over the past 50 years or more have resulted in ambiguity in assigning natal origin based on the genetic group.

- Effectiveness Monitoring: Preliminary Meta-Analysis - The preliminary data indicate that the restored sites are responding measurably to the restoration actions. The fact that water temperature, sedimentation, vegetation, and fish access have changed since prior to restoration indicates that the actions have restored ecological processes that form and maintain habitats. These changes were detectable within 2 years after restorative actions. 
- Net Ecosystem Improvement: Modeling Additive Effects - This preliminary assessment, using the export of macrodetritis as an example, uncovered significant weaknesses in the available data for additive modeling from wetlands on the LCRE. For example, the use of reprocessed light detection and ranging (LiDAR) data showed that the digitized boundary of the floodplain and the floodplain boundary that is in common use by agencies on the LCRE contain substantial errors due to the 10-m digital elevation models used for digitizing them. Thus, reprocessing the existing 2005 LiDAR data is crucial for wetted area and floodplain delineation in the LCRE.

- Synergy: Hydrodynamic Modeling Synergistic Effects - The effect of upstream breaches on wetted area per breach is negligible, while the effect of midstream breaches is somewhat greater and downstream breaches the largest at $23 \mathrm{ha} / \mathrm{breach}$. The effect of the same number of breaches (11) evenly spaced throughout the study area was in all three runs equivalent to or greater than the effect of downstream breaches. The average incremental change in wetted area per breach that is produced by different numbers of dike breaches appeared to be a nonlinear function, rising steeply from a single dike breach to the 25 th percentile (11 breaches) and falling more gradually thereafter.

To continue development of the levels-of-evidence approach of the Cumulative Effects Study, we recommend the following study objectives for 2009-2010:

1. Issue final, peer-reviewed monitoring protocols for habitat restoration evaluations, including examples of data analysis and presentation.

2. Collect and analyze existing field data to support the 2008 cumulative effects pilot-scale study and the final estuary-wide cumulative effects analysis by continuing existing time series and assessing larger spatial and temporal scales.

3. Implement the levels-of-evidence cumulative effects analysis methodology at a pilot scale in the tidal Grays River area, including geographic information system (GIS) assessments, hydrodynamic modeling, and meta-analyses, and develop management recommendations for estuary-wide assessment based on the results.

4. Support implementation of the adaptive management framework to inform decisions by the Corps and others regarding LCRE habitat restoration activities.

When the Cumulative Effects Study concludes in the 2010-2011 project year, we will provide three main deliverables to the USACE: a peer-reviewed, scientific method to evaluate the cumulative effects of multiple habitat restoration projects in the LCRE; an adaptive management framework and specific recommendations for infrastructure to periodically implement a comprehensive LCRE cumulative effects evaluation; and, an initial LCRE cumulative effects evaluation based on available data and information. After any necessary data-sharing agreements are reached, data sources for the cumulative effects evaluation will include monitoring and GIS analysis performed by state and federal agencies and nongovernmental organizations. Conversely, regional entities will be able to use GIS layers developed or improved by the Cumulative Effects Study and the levels-of-evidence approach to synthesize and evaluate their restoration effectiveness monitoring data. In total, these efforts will advance the mission of ecosystem restoration in the LCRE. 


\section{Preface}

This research was performed under the auspices of the U.S. Army Corps of Engineers (USACE) Anadromous Fish Evaluation Program (study code EST-P-02-04). The study was funded by the U.S. Army Corps of Engineers Portland District (CENWP) (Ref. No. AGRW66QKZ80031101) under agreements with the U.S. Department of Energy and the U.S. Department of Commerce for work by Pacific Northwest National Laboratory (PNNL) and the National Marine Fisheries Service (NMFS), respectively. Subcontractors to PNNL included the Columbia River Estuary Study Taskforce, the University of Washington, and Mr. Earl Dawley (National Marine Fisheries Services-retired). Mr. Blaine D. Ebberts was the CENWP's technical lead for the study.

Technical reports and peer-reviewed publications, essential mechanisms to disseminate scientific findings, are products of this project. Previous technical reports for the Cumulative Effects Study are described in the introduction. The project's publications and potential publications are as follows:

- Diefenderfer HL and DR Montgomery. 2008. "Pool Spacing, Channel Morphology, and the Restoration of Tidal Forested Wetlands of the Columbia River, U.S.A.” Restoration Ecology 17:158-168.

- Diefenderfer HL, AM Coleman, AB Borde, and IA Sinks. 2008. "Hydraulic geometry and microtopography of tidal freshwater forested wetlands and implications for restoration, Columbia River, U.S.A.” International Journal of Ecohydrology and Hydrobiology 8:339-361.

- Diefenderfer HL, RM Thom, GE Johnson, JR Skalski, KA Vogt, BD Ebberts, GC Roegner, and EM Dawley. "Assessing Cumulative Ecosystem Response to Estuary and River Restoration Programs Using a Levels-of-Evidence Approach.” Ecological Restoration. (In Review).

- Diefenderfer HL, GE Johnson, JR Skalski, SA Breithaupt, and AM Coleman. "Diminishing Returns of Dike Breaching in the Restoration of Tidal Floodplain Habitat Area." Journal of Ecological Restoration (In Review).

- Roegner GC, EW Dawley, M Russell, AH Whiting, and DJ Teel. "Juvenile salmon use of newly reconnected tidal freshwater wetland habitats in the Grays River tributary of the lower Columbia River." Transactions of the American Fisheries Society (In Review).

Scientific conferences, symposia, and workshops are also important ways to transfer knowledge gained from this research. Project scientists presented papers concerning various aspects of the study at the following events during 2008:

- Pacific Estuarine Research Society, February 2008, Newport, Oregon

- Columbia River Estuary Conference, April 2008, Astoria, Oregon

- USACE Hydrologic Engineering Center, April 2008, Davis, California

- Ecohydrological Processes and Sustainable Floodplain Management, May 2008, Lodz, Poland

- American Fisheries Society, Oregon Chapter Meeting, May 2008, Portland, Oregon

- Anadromous Fish Evaluation Program Annual Review, December 2008, Portland, Oregon. 
Recommended citation for the entire report: Johnson GE and HL Diefenderfer (eds.). 2009. "Evaluating Cumulative Ecosystem Response to Restoration Projects in the Lower Columbia River and Estuary, 2008.” PNNL-18677, prepared by Pacific Northwest National Laboratory, Richland, Washington, and the National Marine Fisheries Service, Seattle, Washington, for the U.S. Army Corps of Engineers, Portland District, Portland, Oregon.

Recommended citation for a chapter in the report: Roegner GC, M Russell, and EM Dawley. 2009. "Hydrology and Fish - Monitoring Data Summary." Appendix E, in: Evaluating Cumulative Ecosystem Response to Restoration Projects in the Lower Columbia River and Estuary, 2008, eds. GE Johnson and HL Diefenderfer. PNNL-18677, prepared by Pacific Northwest National Laboratory, Richland, Washington, and the National Marine Fisheries Service, Seattle, Washington, for the U.S. Army Corps of Engineers, Portland District, Portland, Oregon; pp. E1-E12. 


\section{Acknowledgments}

We gratefully acknowledge contributions to this study from the following contributors:

- Scott McEwen and Ian Sinks of the Columbia Land Trust

- April Silva, Harry Rectenwald, and April Cameron of the Columbia River Estuary Study Taskforce

- Catherine Corbett and Krista Jones of the Lower Columbia River Estuary Partnership

- Dennis Dauble, Dick Ecker, Susan Ennor, Val Cullinan, Kate Hall, Chaeli Judd, and Mike Parker of the Pacific Northwest National Laboratory

- Allan Whiting of PC Trask and Associates, Inc.

- Kristiina Vogt, David Montgomery, Kern Ewing of the University of Washington

- Mike Ott of the U.S. Army Corps of Engineers

- Jeff Johnson of the U.S. Fish and Wildlife Service. 



\section{Acronyms and Abbreviations}

\begin{tabular}{|c|c|c|c|}
\hline AFEP & Anadromous Fish Evaluation & D8 & Deterministic 8 (method) \\
\hline \multirow{4}{*}{$\begin{array}{l}\text { AGOM } \\
\text { AH } \\
\text { ALTMS }\end{array}$} & Program & DB & dike breach \\
\hline & above-ground organic matter & DEM & Digital Elevation Model \\
\hline & ancillary hypothesis & DLS & Duck Lake Slough \\
\hline & $\begin{array}{l}\text { airborne laser terrain mapping } \\
\text { system }\end{array}$ & DO & dissolved oxygen \\
\hline \multirow{2}{*}{ ArcGIS } & ArcInfo Geographic & DR & Deep River \\
\hline & Information System & $\mathrm{EAB}$ & Environmental Advisory Board \\
\hline \multirow{3}{*}{$\begin{array}{l}\text { BGOM } \\
\text { BP } \\
\text { BPA }\end{array}$} & below-ground organic matter & ELS & Ellison Slough \\
\hline & before present & EPA & U.S. Environmental Protection \\
\hline & $\begin{array}{l}\text { Bonneville Power } \\
\text { Administration }\end{array}$ & ERT & Estuary-Wide Restoration Team \\
\hline \multirow{6}{*}{$\begin{array}{l}{ }^{\circ} \mathrm{C} \\
\mathrm{CC} \\
\mathrm{CD} \\
\mathrm{CE} \\
\mathrm{CEA} \\
\text { CENWP }\end{array}$} & degrees Celsius & ESU & Evolutionarily Significant Unit \\
\hline & Crooked Creek & ESA & Endangered Species Act \\
\hline & coded wire tag & $\mathrm{FAC}+$ & $\begin{array}{l}\text { facultative wetland species (plus } \\
\text { indicating dryer than normal) }\end{array}$ \\
\hline & cumulative effects & FACU & facultative upland \\
\hline & cost-effectiveness analysis & FACW & facultative wetland \\
\hline & $\begin{array}{l}\text { U.S. Army Corps of Engineers, } \\
\text { Portland District }\end{array}$ & FCRPS & $\begin{array}{l}\text { Federal Columbia River Power } \\
\text { System }\end{array}$ \\
\hline CET & $\begin{array}{l}\text { Cumulative Effects Assessment } \\
\text { Team }\end{array}$ & FL & fork length \\
\hline $\mathrm{cfs}$ & cubic feet per second & $\mathrm{GF} / \mathrm{C}$ & glass filter, grade $\mathrm{C}$ \\
\hline CI & confidence interval & GIS & geographic information system \\
\hline \multirow{5}{*}{$\begin{array}{l}\text { CLT } \\
\mathrm{cm} \\
\mathrm{cms} \\
\text { CNEI }\end{array}$} & Columbia Land Trust & $\mathrm{g} / \mathrm{m}^{2}$ & gram(s) per square meter \\
\hline & centimeter(s) & GPS & global positioning system \\
\hline & centimeter(s) per second & GR & Grays River \\
\hline & cumulative net ecosystem & ha & hectare(s) \\
\hline & improvement & $\mathrm{H}^{\prime}$ & Shannon-Wiener species \\
\hline \multirow{4}{*}{$\begin{array}{l}\text { CPUE } \\
\text { CR } \\
\text { LCRE }\end{array}$} & catch per unit effort & & diversity index \\
\hline & culvert replacement & $\mathrm{HU}$ & hydrologic unit \\
\hline & lower Columbia River and & HUC & hydrologic unit code \\
\hline & estuary (rkm 0-235) & ICA & incremental cost analysis \\
\hline \multirow[t]{2}{*}{ CREST } & Columbia River Estuary Study & IDW & inverse distance weighting \\
\hline & Taskforce & IRI & index of relative importance \\
\hline CTD & conductivity-temperature-depth & IWR & Institute of Water Resources \\
\hline $\mathrm{CV}$ & coefficient of variation & JBH & Julia Butler Hansen \\
\hline $\mathrm{D} \infty$ & Deterministic Infinity & $\mathrm{kg}$ & kilogram(s) \\
\hline
\end{tabular}




\begin{tabular}{|c|c|c|c|}
\hline $\mathrm{km}$ & kilometer(s) & OTO & otolith branding \\
\hline $\mathrm{KR}$ & Kandoll Reference & PAT & Project Assessment Team \\
\hline LiDAR & light detection and ranging & PDT & Product Delivery Team \\
\hline $\mathrm{m}$ & meter(s) & PNNL & Pacific Northwest National \\
\hline MHHW & mean higher high water & & Laboratory \\
\hline MOU & memorandum of understanding & $\mathrm{PO}_{4}$ & phosphate \\
\hline MS-222 & tricaine methane sulfonate & PVC & polyvinyl chloride \\
\hline $\mathrm{m}^{3} / \mathrm{s}$ & cubic meter(s) per second & $\mathrm{rkm}$ & river kilometer \\
\hline NAIP & $\begin{array}{l}\text { National Agricultural Imagery } \\
\text { Program }\end{array}$ & RMA2 & $\begin{array}{l}\text { a depth-averaged, finite element } \\
\text { hydrodynamic model }\end{array}$ \\
\hline \multirow{4}{*}{$\begin{array}{l}\mathrm{N}: \mathrm{P} \\
\mathrm{N} \\
\mathrm{NA} \\
\mathrm{NAVD} 88\end{array}$} & nitrogen-to-phosphate ratio & \multirow[t]{2}{*}{ RME } & Research, Monitoring, and \\
\hline & number of individuals & & Evaluation (Plan) \\
\hline & not applicable & RPA & $\begin{array}{l}\text { Reasonable and Prudent } \\
\text { Alternative }\end{array}$ \\
\hline & $\begin{array}{l}\text { North American Vertical Datum } \\
\text { of } 1988\end{array}$ & RTK & real-time kinematic \\
\hline NCER & $\begin{array}{l}\text { National Council on Ecosystem } \\
\text { Restoration }\end{array}$ & $\begin{array}{l}\text { s.d. } \\
\text { S }\end{array}$ & $\begin{array}{l}\text { standard deviation } \\
\text { number of species; or swamp }\end{array}$ \\
\hline NEI & net ecosystem improvement & SAV & submerge aquatic vegetation \\
\hline \multirow[t]{2}{*}{ NEPA } & National Environmental Policy & SEC & site evaluation card \\
\hline & Act of 1969 & SHT & Stakeholders Team \\
\hline $\mathrm{NH}_{4}$ & ammonium & $\mathrm{SiO}_{4}$ & silicate \\
\hline \multirow[t]{2}{*}{ NMFS } & National Marine Fisheries & SS & Seal Slough \\
\hline & Service & SSE & Seal Slough East \\
\hline NNS & No Name Slough & SSW & Seal Slough West \\
\hline NOAA & $\begin{array}{l}\text { National Oceanic and } \\
\text { Atmospheric Administration }\end{array}$ & TIN & $\begin{array}{l}\text { total inorganic nitrogen, or } \\
\text { Triangulated Irregular Network }\end{array}$ \\
\hline \multirow{2}{*}{ NOAA Fisherie } & NOAA National Marine & TOC & total organic carbon \\
\hline & Fisheries Service (formerly & $\mathrm{TR}$ & tide gate replacement \\
\hline \multirow{4}{*}{$\begin{array}{l}\mathrm{NO}_{2} \\
\mathrm{NO}_{3} \\
\mathrm{NPCC}\end{array}$} & NIVIFS) & USACE & U.S. Army Corps of Engineers \\
\hline & Hitiate & US & Unnamed Slough \\
\hline & nitrite & USFWS & U.S. Fish and Wildlife Service \\
\hline & Conservation Council & USGS & U.S. Geological Survey \\
\hline NRC & National Research Council & UW & University of Washington \\
\hline NWI & National Wetlands Inventory & VS & Vera Slough \\
\hline NWR & National Wildlife Refuge & WDFW & Washington Department of Fish \\
\hline \multirow{2}{*}{$\begin{array}{l}\mathrm{O} \& \mathrm{M} \\
\mathrm{OBL}\end{array}$} & Operations and Maintenance & & W \\
\hline & obligate & WRDA & $\begin{array}{l}\text { Water Resources Development } \\
\text { Act }\end{array}$ \\
\hline ODFW & $\begin{array}{l}\text { Oregon Department of Fish and } \\
\text { Wildlife }\end{array}$ & & \\
\hline
\end{tabular}




\section{Contents}

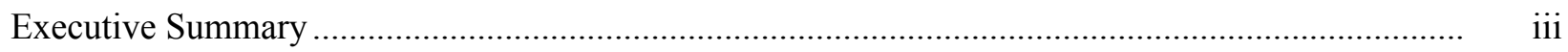

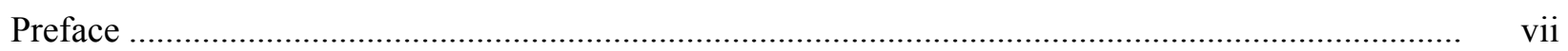

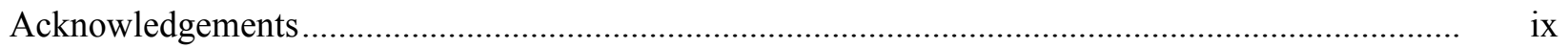

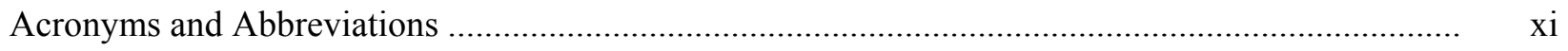

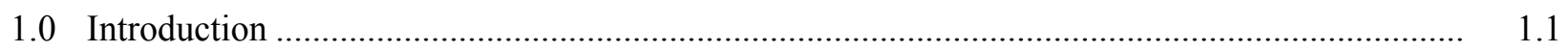

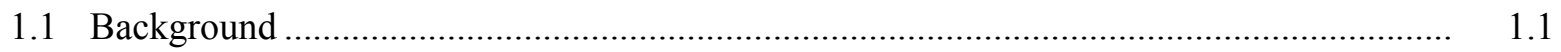

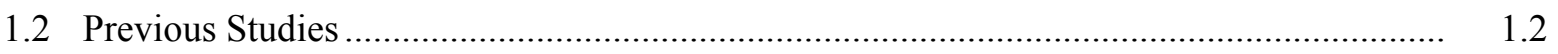

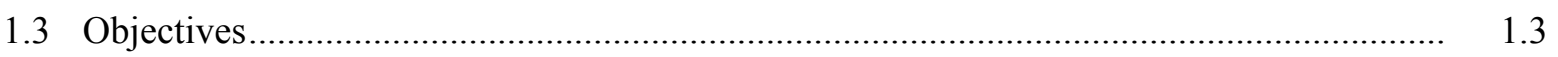

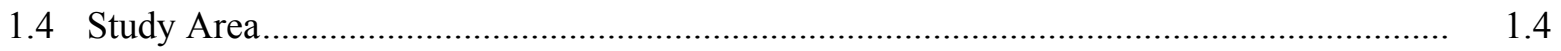

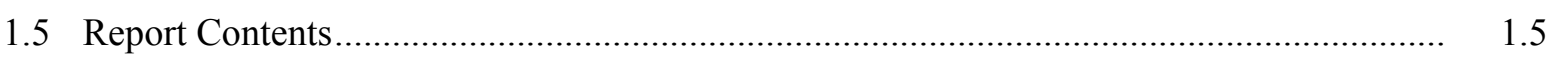

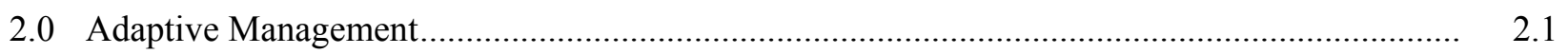

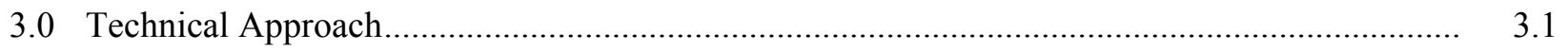

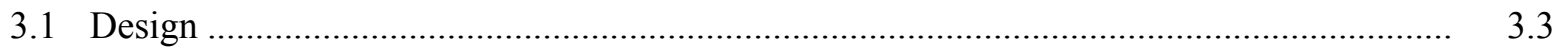

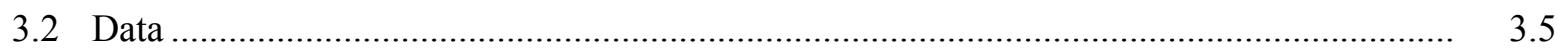

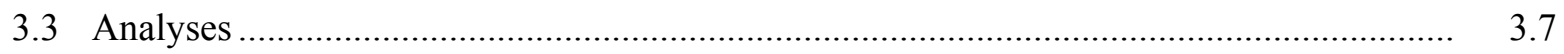

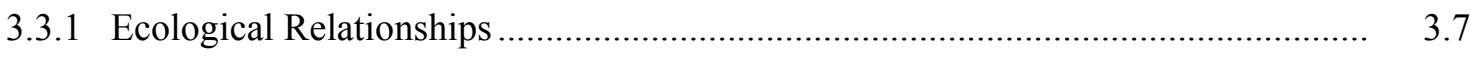

3.3.2 Effectiveness Monitoring Data................................................................... 3.8

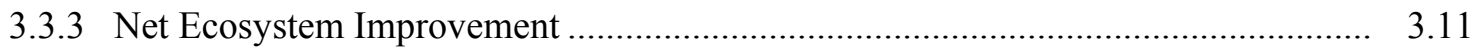

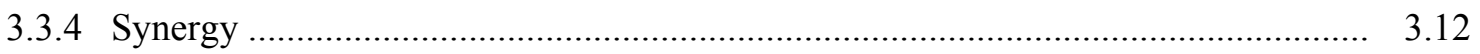

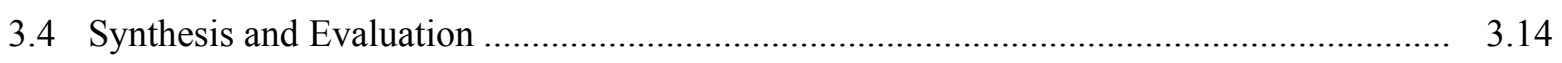

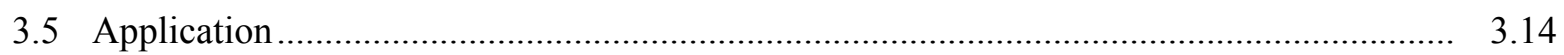

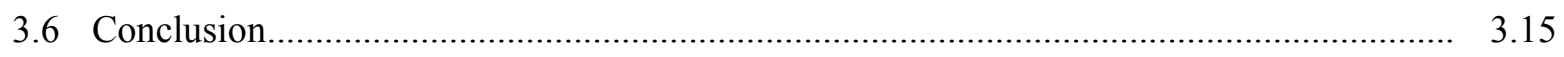

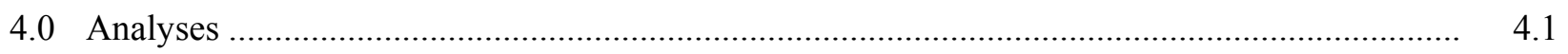

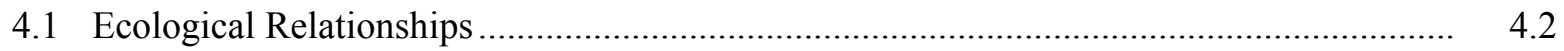

4.1.1 Water Surface Elevation vs. Floodplain Wetted Area............................................ 4.2

4.1.2 Water Temperature vs. Fish Abundance ........................................................... 4.4

4.1.3 Habitat Type vs. Fish Stock .......................................................................... 4.5

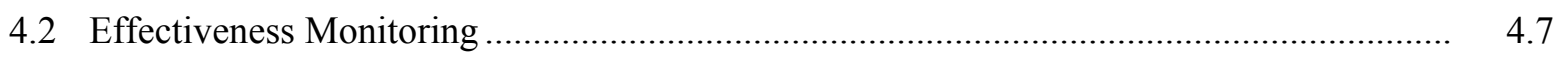

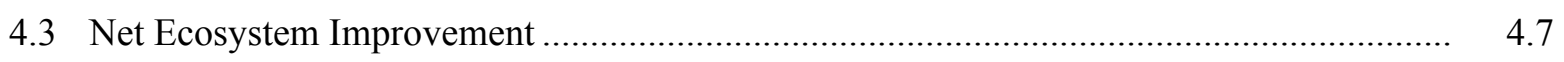

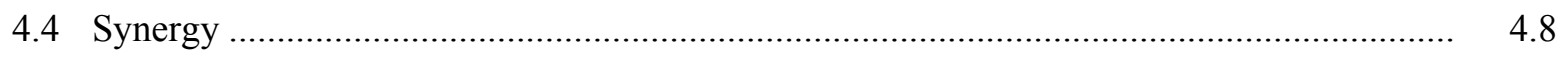

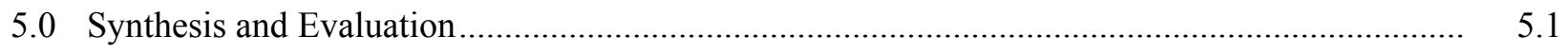

5.1 Elements of Levels of Evidence .............................................................................. 5.1

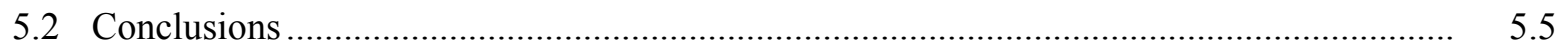

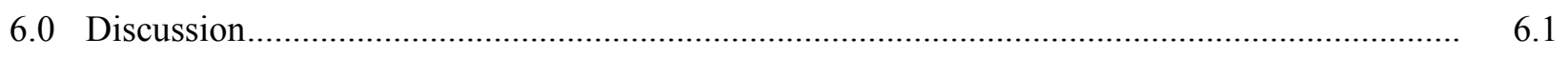

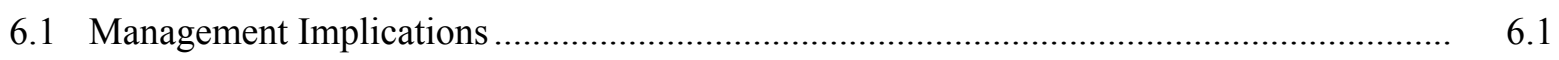

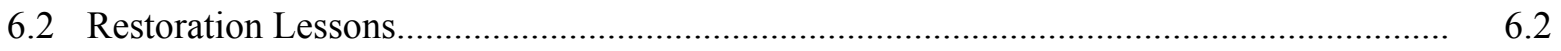




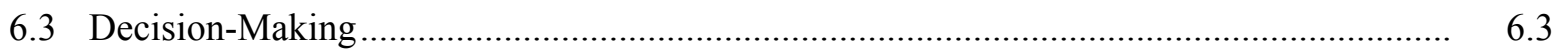

6.3.1 Components of Adaptive Management ............................................................ 6.4

6.3.2 Scales of Analysis, Decisions, and Application ..................................................... 6.5

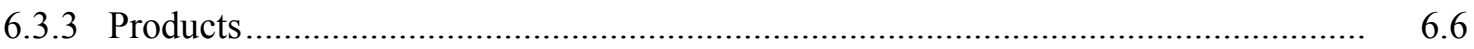

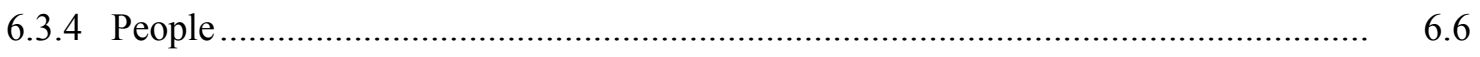

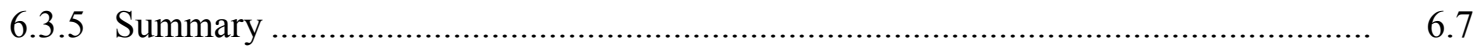

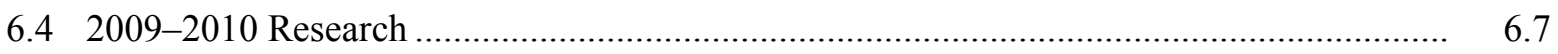

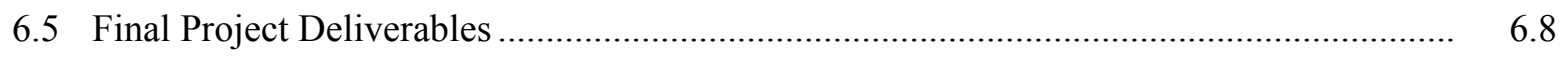

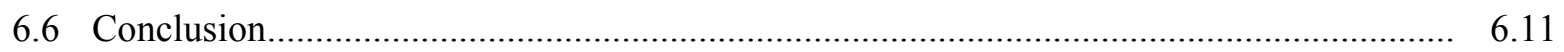

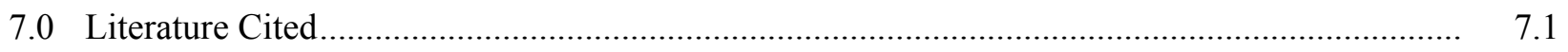

Appendix A - Synergistic Modeling Pilot Study - Draft Manuscript ............................................. A. A

Appendix B - Additive Modeling Pilot Study - Analysis Summary ….......................................... B. 1

Appendix C - Assessment of Previously Breached and Created Sites - Analysis Summary.............. C. C.1

Appendix D - Wetted Area - Analysis Summary ................................................................ D. 1

Appendix E - Hydrology and Fish - Analysis Summary ............................................................ E. 1

Appendix F - Julia Butler Hansen - Monitoring Data Summary ................................................. F. F.

Appendix G - Crims Island - Monitoring Activities Summary ................................................. G. 1

Appendix H - Effectiveness Monitoring Data - Preliminary Meta-Analysis .................................... H.1 


\section{Figures}

1.1 The Lower Columbia River and Estuary - Bonneville Dam to the Pacific Ocean..................... 1.1

1.2 Field Sites for the Cumulative Effects Study...................................................................... 1.4

2.1 Schematic of an Adaptive Management Framework ........................................................... 2.3

3.1 Assessment of the Cumulative Effects of Ecosystem Restoration by a Modified Levels-ofEvidence Approach

3.2 Conceptual Diagram of the Hypothetico-Deductive Method Illustrating the Overarching Working Hypothesis and the Testable Ancillary Hypotheses................................................... 3.5

3.3 Conceptual Framework for Monitoring Restoration Effectiveness ............................................. 3.9

3.4 Illustration of Control Chart Methods Used to Monitor Recovery Success ............................. 3.10

3.5 Hypothetical Relationships Related to Habitat Restoration.................................................... 3.13

4.1 Approach for the Evaluation of Cumulative Effects with Emphasis on 2008 Data and Analysis

4.2 Total Wetted Area Produced by Water Levels at Kandoll Farm and Kandoll Reference ............ 4.3

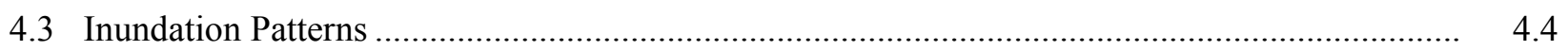

4.4 Juvenile Salmon Catch per Unit Effort versus Temperature for the Kandoll Restoration Site .... $\quad 4.5$

4.5 Juvenile Chinook Salmon Stock Identification by Fork Length, Julian Date, and Sample Location

4.6 Change in Wetted Area per Breach ............................................................................

\section{Tables}

3.1 Causal Criteria and Element Schema for a Levels-of-Evidence Approach .............................. 3.2

3.2 Hypothesized Effects of Habitat Restoration Actions ........................................................... 3.4

3.3 Monitored Indicators by Category to Assess the Effectiveness of Tidal Reconnection Restoration

3.4 Ecological Relationships Supporting the Federal LCRE Habitat Restoration Program

3.5 Relationships Between Selected Extensive and Intensive Monitored Indicators and Management Applications.

4.1 Summary Meta-Analysis Table

5.1 Trial Application of the Causal Criteria with "High" Applicability to the Cumulative Effects Evaluation for Water Temperature and Fish Presence.

5.2 Example Sources of Variability for Monitored Indicators.................................................... 5.3

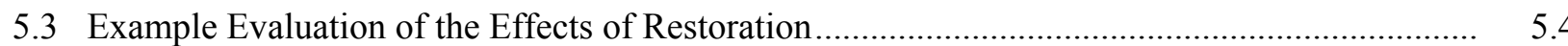

6.1 Summary of Decision Types, Decision Schedules, and Information Needs Arranged by the Scale of Actions 



\subsection{Introduction}

This is the fifth annual report of a 7-year project (2004-2010) to evaluate the cumulative effects of habitat restoration actions in the 235-km-long lower Columbia River and estuary (LCRE ${ }^{1}$; Figure 1.1). The project, called the Cumulative Effects Study, is being conducted for the U.S. Army Corps of Engineers, Portland District (CENWP), by the Marine Sciences Laboratory of the Pacific Northwest National Laboratory, the Pt. Adams Biological Field Station of the National Marine Fisheries Service (NMFS), and the Columbia River Estuary Study Taskforce (CREST).

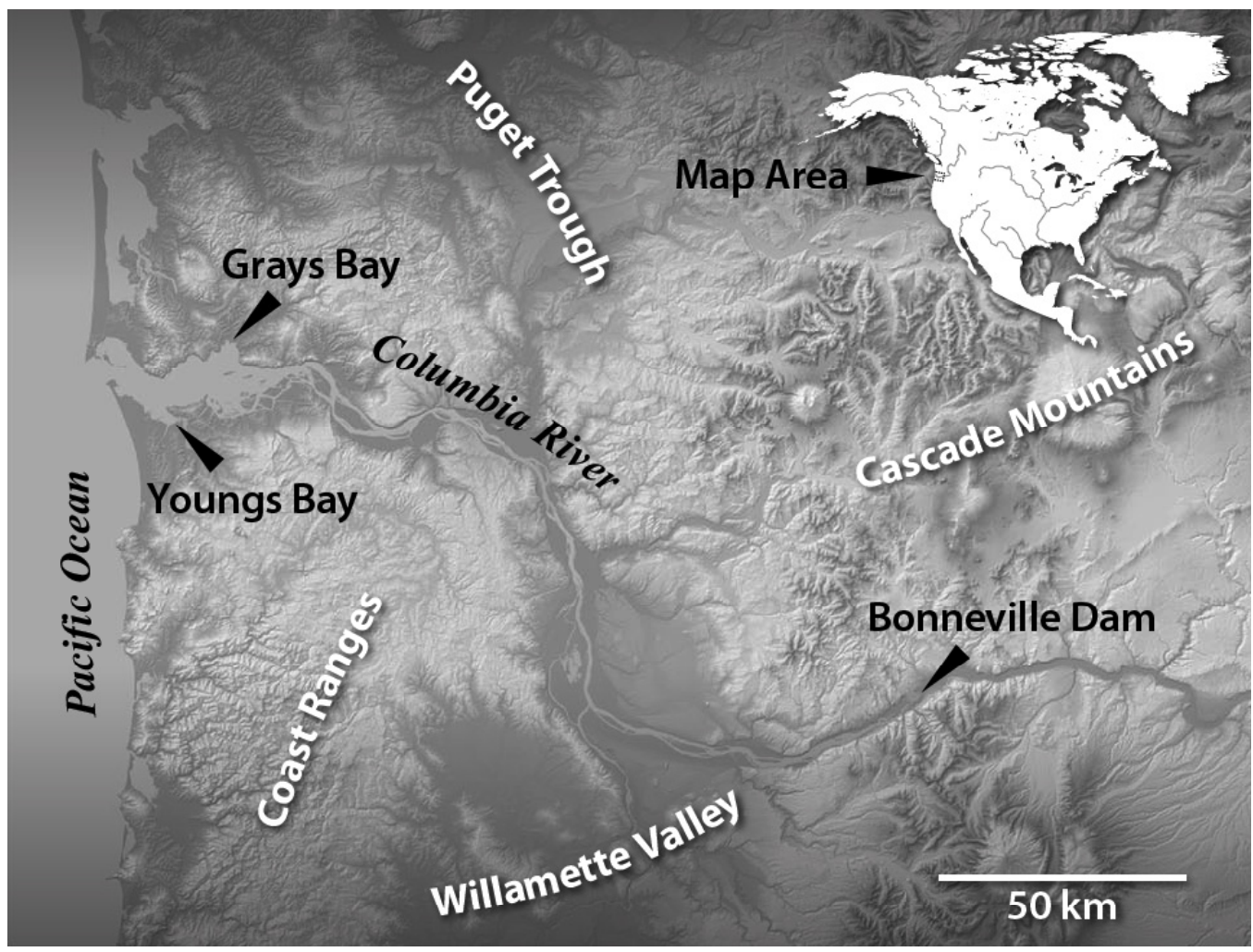

Figure 1.1. The Lower Columbia River and Estuary - Bonneville Dam to the Pacific Ocean

\subsection{Background}

The Corps is working with federal, state, and local agencies and nongovernmental organizations to restore estuarine habitats in the LCRE. The restoration effort, herein called the Federal Columbia River Estuary Restoration Program, is driven by various Water Resources Development Acts and the Biological Opinion (BiOp) on operation of the Federal Columbia River Power System (FCRPS) (NMFS 2008). Overall, the goal for the Federal LCRE Habitat Restoration Program is to understand, conserve, and restore the estuary ecosystem to improve the performance of listed salmonid populations (Johnson et al. 2008).

\footnotetext{
${ }^{1}$ By definition, the Columbia River estuary includes the river and its floodplain from Bonneville Dam to the mouth of the river.
} 
Many LCRE restoration activities involve the hydrologic reconnection of portions of the estuarine system currently isolated by dikes, tide gates, culverts, and other barriers. The intent is to improve the functionality of the LCRE ecosystem through habitat restoration efforts (Johnson et al. 2003). This will aid in rebuilding salmonid stocks of the Columbia River basin that are currently listed under the Endangered Species Act (ESA) (NMFS 2008). In addition, cumulative effects methodology will be useful in guiding the design and monitoring of individual LCRE habitat restoration projects, fulfilling actions authorized in Water Resources Development Acts, implementing offsite mitigation measures called for in the FCRPS BiOp, and evaluating the success of the overall LCRE Restoration Program. Essentially, managers want to know the following:

- Are protection and restoration resulting in continued loss, no net loss, or net ecosystem improvement in the context of continuing land conversion?

- What suite of projects results in an increase in habitat opportunity and capacity for juvenile salmon?

- What suite of projects produces increased habitat connectivity, maximum flood attenuation, sediment trapping, nutrient processing, return of marsh macrodetritis, and other ecosystem functions?

- What are the survival benefits to juvenile salmonids from LCRE habitat restoration actions?

Understanding the cumulative effects of ecological restoration projects in the LCRE is a formidable task because of the size and complexity of the LCRE landscape (Small 1990). Despite the challenges presented by this system, developing and implementing appropriate indicators and methods to evaluate cumulative effects is possible and will enable estuary managers to assess and improve the overall effectiveness of investments in estuary restoration projects. This study is intended to both develop methods for quantifying the effects of restoration projects and lay a foundation for future effectiveness ${ }^{1}$ evaluation and validation ${ }^{2}$ of cumulative restoration activities in the LCRE.

\subsection{Previous Studies}

The Cumulative Effects Study started in 2004 with a comprehensive literature review that found no published formal methods to quantify the cumulative effects of multiple restoration projects across one estuary (Diefenderfer et al. 2005). We initiated development of protocols for monitoring restoration activities with a meeting open to all estuary restoration project managers, which is an important step toward achieving a cumulative assessment of restoration effects (e.g., Neckles et al. 2002). The following definition of cumulative effects was adopted: "the impact on the environment which results from the incremental impact of the action when added to other past, present, and reasonably foreseeable future actions regardless of what agency (Federal or non-Federal) or person undertakes such other actions" (40 CFR $\S 1508.7$ ). And, most importantly, a levels-of-evidence approach (Downes et al. 2002) to evaluate cumulative effects was proposed.

During 2005, Diefenderfer et al. (2006) developed hypotheses regarding the effects of hydrologicalreconnection restoration methods, refined the selection of measurable metrics, tested restoration effectiveness monitoring protocols, continued to develop a sampling design supporting an estuary-wide

\footnotetext{
${ }^{1}$ Effectiveness monitoring involves activities designed and undertaken to assess how well a particular restoration project performs relative to reference site(s).

${ }^{2}$ Validation monitoring involves activities directed at testing cause-and-effect relationships between management activities and monitoring indicators (Busch and Trexler 2003).
} 
cumulative effects analysis, and initiated development of an adaptive management framework for the LCRE Restoration Program. The effectiveness monitoring methodology was applied in 2005 before restoration actions at two restoration sites and two reference sites in the Columbia River estuary-Vera Slough and Kandoll Farm — as paired site studies of marsh and swamp habitats, respectively.

Post-restoration research at the selected study sites continued in 2006 to support the ongoing development of a technical approach to assess the cumulative effects of multiple aquatic habitat restoration projects in the LCRE (Johnson 2007). Overall, field research in 2005 and 2006 contributed three sources of data for cumulative effects analysis using the levels-of-evidence approach proposed by Diefenderfer et al. (2005): in-depth paired site studies (marsh and swamp), selected core indicators at all monitored restoration project and reference sites, and cumulative effects indicators.

During the 2007 study, we released draft monitoring protocols, developed a detailed adaptive management framework for the LCRE Restoration Program, continued development of the scientific approach for cumulative effects assessment, provided monitoring data summaries for Julia Butler Hanson, Crims Island, hydrology, material flux, and the natural breach assessment. Manuscripts for the analyses of the fish data and hydraulic geometry were presented. Key results summarized in the 2007 annual report (Johnson and Diefenderfer, eds., 2008) concerned hydraulic geometry and channel morphology relationships, elevation-vegetation relationships, invasive plant species at restoration sites, sediment accretion rates in tidal wetlands, similarity indices of vegetation, and juvenile salmon use of tidal reconnection sites.

Progressing to 2008, we are using the results from 2005-2008 field research and modeling to develop predictive structure/function relationships as indicators of fundamental processes, acquire intensive and extensive effectiveness monitoring data from restoration and reference sites, analyze for cumulative effects based on the concept of net ecosystem improvement, and apply hydrodynamic modeling to assess synergies. These data will be synthesized in future study years in a levels-of-evidence approach to evaluate cumulative effects within an adaptive management framework. As part of this effort, other agencies and nongovernmental organizations are using the project protocols to intensively monitor projects throughout the estuary, creating the basis for a standardized database that can be evaluated to meet out-year reporting requirements. Thus, adaptive management provides a means for the Corps' Portland District to systematically capture and disseminate learning from the Federal LCRE Habitat Restoration Program now and after the Cumulative Effects Study is complete.

\subsection{Objectives}

During 2008, the specific objectives for the Cumulative Effects Study were to do the following:

1. Summarize the adaptive management framework for LCRE habitat restoration activities.

2. Finalize the levels-of-evidence approach and ecological theory underpinning the analysis, synthesis, and evaluation of the cumulative effects of multiple habitat restoration projects in the LCRE.

3. Summarize new results from analyses from 2005-2008 project research for the purpose of cumulative effects evaluation in the LCRE.

4. Initiate a synthesis and evaluation of cumulative effects in the LCRE. 
5. Assess management implications, lessons learned, decision-making, 2009-2010 research, and final project deliverables.

6. Provide a hydrodynamic model assessment of synergistic effects, analysis summaries of the additive modeling pilot study, natural breach and habitat creation sites, wetted area, hydrology and fish, monitoring summaries for Julia Butler Hanson and Crims Island, and a preliminary meta-analysis of effectiveness monitoring data.

\subsection{Study Area}

For the general purpose of the cumulative effects project, Diefenderfer et al. (2005) described the lower LCRE study area. A number of publications also provide useful descriptive information about the study area, including Salmon at River's End (Bottom et al. 2005), Role of the Estuary in the Recovery of Columbia River Basin Salmon and Steelhead (Fresh et al. 2004), and Ecosystem-Based Approach to Habitat Restoration Projects (Johnson et al. 2003).

During 2005-2008, field studies for the Cumulative Effects Study occurred at selected sites in the LCRE: Vera Slough, Kandoll Farm, Julia Butler Hanson Wildlife Refuge, and Crims Island (Figure 1.2). Plant communities representing the salmon habitat types that were historically most common in each of these regions and most likely to be restored today were chosen for field studies: tidal freshwater swamps in the tidal freshwater region and tidal brackish marsh in the brackish water region. Within each of the habitat types, studies were conducted in at least one natural reference site and at least one restoration site. Site selection was based in part on the timing of planned restoration, because the monitoring protocols recommend collecting data before and after implementation of restoration actions.

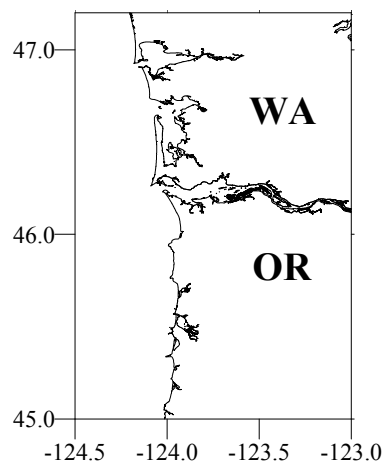

$\underline{\text { Tide gate removal }}$

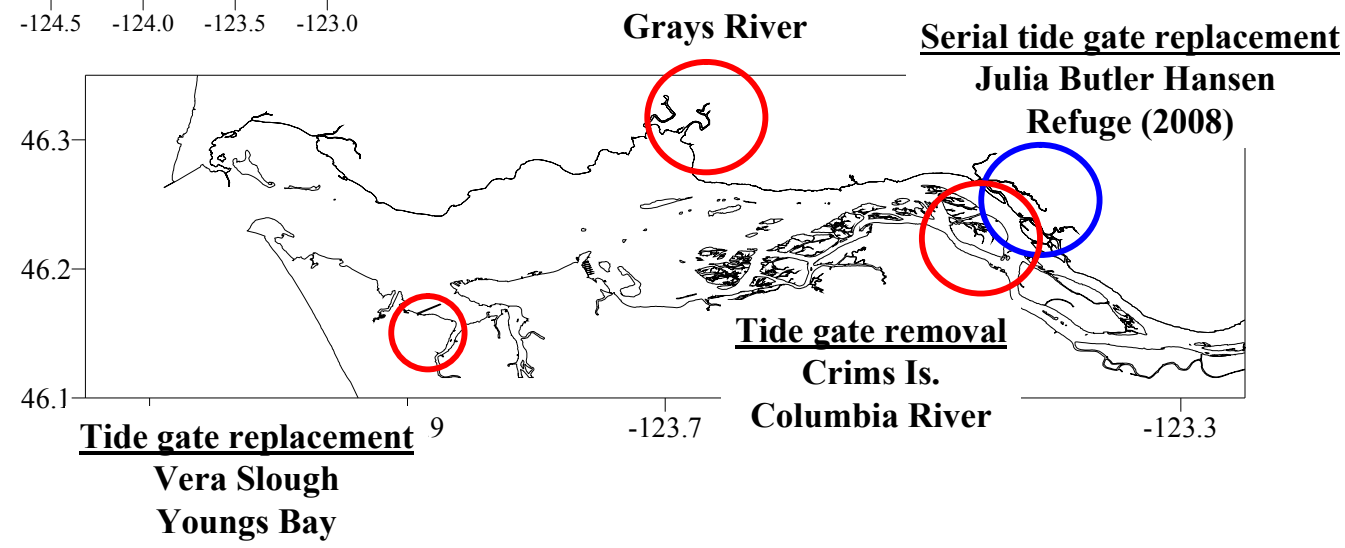

Figure 1.2. Field Sites for the Cumulative Effects Study 


\subsection{Report Contents}

This report contains seven main sections and eight appendices corresponding to the 2008 objectives. Section 2.0 summarizes the adaptive management process (Objective 1); Section 3.0 describes the scientific approach and theoretical underpinnings of the cumulative effects methodology (Objective 2); Section 4.0 provides results from analyses to date (Objective 3); Section 5.0 initiates the synthesis and evaluation of cumulative effects in the LCRE (Objective 4); Section 6.0 discusses lessons learned, management implications, and projections from the Cumulative Effects Study (Objective 5); and Section 7.0 contains literature cited. The appendices contain a draft manuscript on synergistic modeling (Appendix A); summary analyses of the additive modeling pilot study (Appendix B), natural breach and habitat creation sites (Appendix C), wetted area (Appendix D), hydrology and fish (Appendix E); monitoring summaries for Julia Butler Hanson Wildlife Refuge (Appendix F) and Crims Island (Appendix G); and a preliminary meta-analysis of effectiveness monitoring data (Appendix H). 



\subsection{Adaptive Management}

This section outlines the basis of an adaptive management framework for capturing learning from ecosystem restoration projects conducted under the Federal LCRE Habitat Restoration Program. A comprehensive presentation of the framework was presented in Chapter 3 of Evaluating Cumulative Ecosystem Response to Restoration Projects in the Columbia River Estuary, Annual Report 2007 (Thom et al. 2008). This framework can be used to improve future projects conducted by the CENWP and others in the LCRE, or as a model for larger-scale ecosystem restoration adaptive management. Successful implementation of adaptive management in the estuary will require the additional choices and commitments outlined in that chapter that would best be defined through a decision-making process that includes the other major sponsors of ecosystem restoration and stakeholders in the LCRE. The overarching purpose of adaptive management is to provide a framework within which to fulfill the goal of the LCRE Restoration Program: understand, conserve, and restore the estuary ecosystem to improve the performance of listed salmonid populations.

Congress has provided the USACE the authority to develop ecosystem restoration projects in the LCRE under national authorities including Section 1135 of the Water Resources Development Act (WRDA) of 1986, Project Modification for Improvement of the Environment; Section 206 of WRDA 1996, Aquatic Ecosystem Restoration; Section 536 of WRDA 2000, Lower Columbia River Ecosystem Restoration; and Section 306 of WRDA 1990, General Investigation Studies for Environmental Restoration. Work under these authorities and mandates in the FCRPS BiOp (NMFS 2008) would benefit from an adaptive management system tailored to the Portland District's organizational structure and needs, due to significant uncertainties associated with planning and implementing ecosystem restoration in dynamic and varied LCRE environments.

Both the science of restoration ecology in general and the practice of tidal ecosystem restoration in particular are fundamentally experimental, and generally lack information on outcomes, thereby inhibiting improvement in project performance (Cairns 1995; Palmer et al. 2006). Examples of uncertainties or risks identified in LCRE ecosystem restoration projects that would drive monitoring research and lessons learned in an adaptive management program include the following: the lack of juvenile salmon use of a wetland behind a newly installed tide gate; colonization of an excavated site by an invasive, non-native plant species; poor documentation of elevation distributions of major tidal wetland plant species; and disproportionate coverage of invasive non-native plant species in the LCRE.

In recent years, many high-level reviews have focused on adaptive management of ecosystem restoration, including recommendations to the Chief of Engineers by the Corps of Engineers' Environmental Advisory Board (EAB 2005, 2006a, 2006b), reports of the Corps of Engineers' Institute of Water Resources (IWR) (Thom and Wellman 1996; Yozzo et al. 1996; Diefenderfer et al. 2005), reports of the National Research Council (NRC 2003; 2004), and memoranda from the Corps leadership.

Additionally, reports by the National Research Council on the restoration of wetlands and marine habitats in general have recommended adaptive management (NRC 1994, 2001). Moreover, a USACE circular (No. 1105-2-210) entitled Ecosystem Restoration in the Civil Works Program (Department of the Army 1995) states that adaptive management should be considered for inclusion in restoration projects with potential for uncertainty in achieving objectives: "At the heart of adaptive management, and the cornerstone for its success, is a carefully designed monitoring program that begins during [before] construction and continues for a specific period after the project has been completed...Improving the knowledge base regarding a 
particular restoration approach or ecosystem component is a significant subset of the overall goal of adaptive management." As a rule, these Corps and Environmental Advisory Board documents recommend use of the adaptive management process to improve the performance of existing and planned projects; however, circular No. 1105-2-210 has expired and at this time adaptive management is not a required part of the Corps ecosystem restoration planning process. Furthermore, as the National Research Council identified in 2004, a key impediment has been restrictions on funding restoration project monitoring; it has been consistently difficult for USACE districts to conduct post-project monitoring and accompanying adjustments to projects under the present rules by which the Corps operates.

The Portland District is developing the understanding of the LCRE ecosystem necessary to design and evaluate projects through intensive monitoring of two of its restoration projects-Julia Butler Hansen and Crims Island - and by funding, through the Columbia River Fish Mitigation project under the auspices of the Cumulative Effects Study, intensive monitoring of two other restoration projects representing different fish habitat types - Vera Slough and Kandoll Farm. These strengths, however, are concurrent with limitations that prevent long-term commitments to monitoring and adaptive management. This situation is not unique to the Portland District; national examples are well-described in the documents cited above. The limitations include lack of standardized effectiveness monitoring protocols, until a recent report from the Cumulative Effects Study; a requirement that the USACE deliver projects to local project sponsors; informal data sharing and lessons learned generally remain within project teams; and, ecological data from more than one project are not routinely, systematically analyzed to compare the effectiveness of methods and inform new designs.

Adaptive management needs for the Portland District and the LCRE reflect both the state of the science and national recommendations but have yet to become national policy. As is the case in virtually every aquatic ecosystem in the United States, there is a clear need for focused, performance-based monitoring in all ecosystem restoration programs in the LCRE. Within the LCRE, a complex ecosystem and one for which it is hard to find an analog, there needs to be an effective framework for evaluating restoration projects that maximizes information gain and reduces uncertainties. In order for adaptive management to be effective and long lasting, it must have strong scientific underpinnings, show relevance to cooperating agencies, and be feasible to implement. Thus, the following guiding principles are recommended for general practices within the adaptive management framework:

- Science Based - The adaptive management framework adheres to scientific principles of data acquisition, analysis, and interpretation. It is driven by questions and hypotheses such that the scientific knowledge base is consistently both used and improved.

- Implementable - The adaptive management framework is cost-effective, feasible, and reasonable. It uses existing organizational processes to avoid additional demands on staff or redundancy as advocated by the EAB.

- Corps-Centric in Scope - The adaptive management framework adheres to the USACE planning process and procedures for USACE restoration programs. It serves as a national model for the adaptive management of ecosystem restoration in a tidal riverscape.

- Regional Collaboration - The adaptive management framework captures and complements learning from others' projects, and works collaboratively to raise the success of all restoration projects in the LCRE, in cooperation with others funding projects in the LCRE and other Pacific Northwest estuaries. 
The structure for the CENWP's adaptive management effort for ecosystem restoration in the LCRE is depicted in Figure 2.1. Program goals and objectives (Step 1) and monitoring and research plans (Step 2) were established in the Biological Opinion of Federal Columbia River Power System Operations (NMFS 2008) and the Research, Monitoring, and Evaluation for the Federal Columbia River Estuary Program (Johnson et al. 2008), respectively. The CENWP and other Action Agencies (Bonneville Power Administration and the U.S. Bureau of Reclamation) are currently coordinating with regional agencies and interested parties to implement monitoring (Step 3), develop systems to manage data (Step 4), provide avenues for reporting information (Step 5), and assess compliance (Step 6). The Cumulative Effects Study will provide a means to analyze data (Step 4) and synthesize and evaluate data on ecosystem restoration effectiveness (Step 7) for the CENWP and others to make decisions.

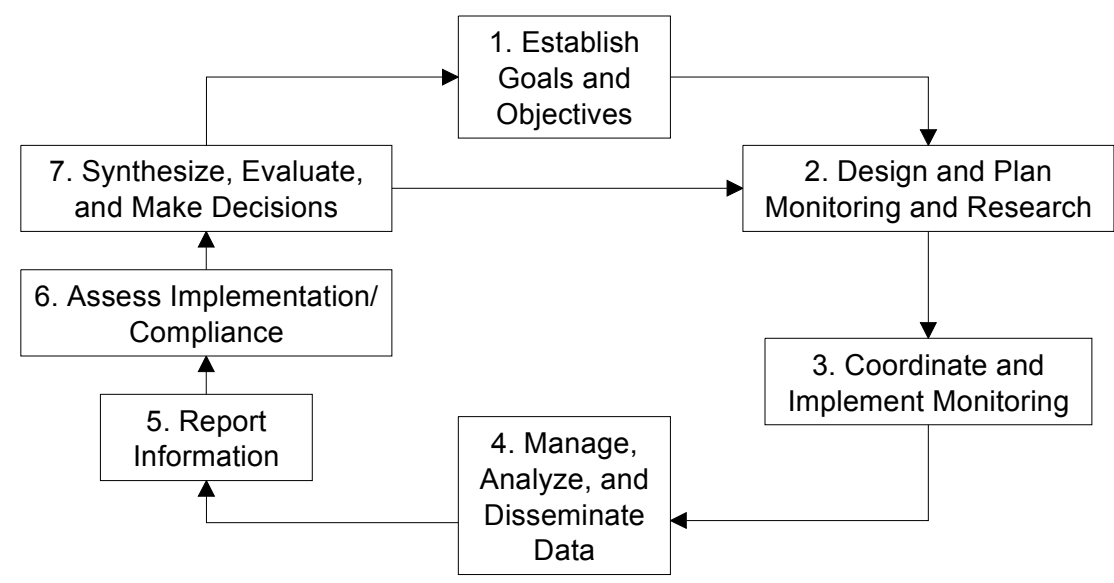

Figure 2.1. Schematic of an Adaptive Management Framework (from Johnson et al. 2008)

Monitoring is an especially important step in adaptive management. Ecosystem restoration monitoring requires spatially extensive sampling to make inferences to broad geographic areas. Consequently, there is usually a trade-off between spatially extensive and locally intensive sampling efforts. Nevertheless, guidance on which recovery end points to measure and when to measure them must be determined from intensively studied reference and treatment (restoration) areas. Integrated within the fabric of an extensive estuary-wide monitoring program must be a few intensively sampled areas where sampling protocols are developed and the trajectories of physical and biological responses to restoration can be mapped. Intensive monitoring should be conducted within "strata" based on a suite of factors that is likely to affect the patterns, rates, and trajectories of results, e.g., gradients in habitat types and types of restoration actions. Furthermore, the methods and metrics used for monitoring should provide efficient and effective feedback on these rates and patterns. The purpose of the extensive monitoring is to be able to infer whether specific sites as wells as the LCRE ecosystem are benefiting from habitat restoration projects; on this basis it should include meta-analysis of indicators estuary-wide and analysis of cumulative effects.

The fundamental driver for adaptive management is to reduce uncertainties in the design and implementation of restoration projects in order to maximize the probability of meeting project goals. The ultimate aim of an adaptive management program is to understand what initial actions efficiently produce optimal, predictable, and repeatable results. Adaptive management will help the Portland District fulfill its mission of providing cost-effective, ecologically successful ecosystem restoration projects in the LCRE. The evaluation of the cumulative effects of the Federal LCRE Habitat Restoration Program will occur within this adaptive management framework. 



\subsection{Technical Approach}

Even though large-scale ecological restoration programs are beginning to supplement isolated projects implemented on rivers and tidal waterways, the effects of restoration success often continue to be evaluated at project scales or integrated in an additive manner. Today our scientific understanding is sufficient for us to begin to apply lessons learned from assessing cumulative impacts of anthropogenic stressors on ecosystems to the assessment of ecological restoration. Integration of this knowledge has the potential to increase the efficacy of restoration projects conducted at several locations but co-managed within the confines of a larger integrative program, such as the Federal LCRE Habitat Restoration Program. We introduce here a framework based on a levels-of-evidence approach that facilitates assessment of the cumulative landscape effects of individual restoration actions taken at many different locations.

A cumulative effects methodology needs to be able to predict outcomes, provide a rationale to prioritize those projects likely to have the strongest effect on ecosystems, and function as a guide for identifying the efficient expenditure of restoration funding. The purpose of this section is to expand on the approach we proposed in 2004 (Diefenderfer et al. 2005) to assess the cumulative effects of multiple restoration projects on the $235-\mathrm{km}$ tidally influenced portion of the LCRE. We demonstrate the construction of an inferential case for evaluating the cumulative response of an ecosystem to the Federal LCRE Habitat Restoration Program. This case uses causal criteria, which are standard for levels-ofevidence approaches (Dorward-King et al. 2001; Downes et al. 2002), as a guide from the initial experimental design for field data collection, for modeling and meta-analyses, and finally for the synthesis and evaluation of cumulative effects (Table 3.1). Through this effort, we established that a levels-of-evidence approach is a potentially valuable tool for assessing the cumulative effects of ecological restoration actions, although the tool needs to be modified to account for uncertainties in outcomes, particularly if applied in an understudied ecosystem such as the LCRE (Clements et al. 2001). In this section, we describe the levels-of-evidence approach and its application and discuss the specific modifications needed for the LCRE.

In viewing the cumulative effects of multiple restoration projects in the LCRE over time, the LCRE itself becomes the experimental unit. From this perspective, there is only one such experimental unitthe estuary as a whole. Consequently, classical forms of statistical analysis based on the experimental principles of replication and randomization are not relevant. Other forms of less direct scientific inference must be used to provide evidence of the benefits of estuary habitat restoration on salmonid populations. Hence, the inferential problem of demonstrating the cumulative effects of habitat restoration on salmon returns is not wholly dissimilar from trying to prove or disprove the "greenhouse" effect on global warming. A single, definitive, indisputable experiment does not exist, nor will it ever exist. Instead, inference will depend on a preponderance of evidence substantial enough to be considered sufficient by reasonable individuals.

A few problems arose while applying the causal criteria (Table 3.1) in the early stages of the Cumulative Effects Study. In particular, the relative absence of existing data suggested that the levels-ofevidence approach should be used with caution in ecological restoration projects. This uncertainty necessitated a greater emphasis on collecting new data to support the levels-of-evidence approach as applied to ecological restoration. Toward this end, we developed a framework for both intensive and extensive data collection that will serve as the basis of future meta-analyses to inform cumulative effects 
assessment. In ecological restoration, there is usually a trade-off between spatially extensive and locally intensive efforts in the allocation of scarce sampling resources. For example, extensive sampling supports inferences across the broad geographic area, while intensive sampling of both restoration and reference sites decreases uncertainties about fundamental ecological processes and thus provides a model of the restoration process and the inferential framework to help assess restoration success from more cursory extensive observations throughout the study area. Furthermore, because the ecological parameters involved are not as tightly linked as toxicological ones, there must be a continual effort to increase the number of places and times restoration is monitored to robustly connect the cause (restoration action) with the effect (restoration outcomes).

The cumulative effects measurement and assessment process is intended to be implemented within an adaptive management framework (Section 2.0) (Thom 1997, 2000). The approach we developed for assessing cumulative effects in the context of ecological restoration in the LCRE is based on levels-ofevidence reasoning and consists of five stages: design, data, analysis, synthesis and evaluation, and application (as illustrated in Figure 3.1 and described in the ensuing sections).

Table 3.1. Causal Criteria and Element Schema for a Levels-of-Evidence Approach (from Downes et al. 2002). Applicability pertains to assessing the cumulative effects of ecosystem restoration.

\begin{tabular}{lc}
\hline Causal Criterion & Applicability \\
\hline Experimental studies - controlled, manipulative experiments show evidence of an effect & Medium \\
Analogous cases - effects from factors may be supported by other analogous cases & High \\
$\begin{array}{l}\text { Coherence of evidence - a cause-and-effect interpretation is not in conflict with the known biology } \\
\text { of the factor }\end{array}$ & High \\
$\begin{array}{l}\text { Strength and consistency of association - relative to other factors, there is a particularly strong } \\
\text { response for the factor in question or the effect has been observed repeatedly in different } \\
\text { places }\end{array}$ & High \\
$\begin{array}{l}\text { Specificity of cause and effect - whether or not the effect is limited to a specific location, time, or } \\
\text { other condition }\end{array}$ & Medium \\
$\begin{array}{l}\text { Temporal relationship - whether or not the effect follows exposure } \\
\text { Biological or ecological gradient - whether or not there is a gradient in the effect } \\
\text { Biological plausibility - there is a plausible explanation even if no direct evidence of a mechanism } \\
\text { exists }\end{array}$ & High \\
\hline Element Schema & High
\end{tabular}

1. Define each causal criterion and decide how it will be examined and measured.

2. Use the literature to review all of the effects of the human activity and to extract information required to evaluate each effect on response variables, using each of the causal criteria.

3. For each response variable identified under element 2, conduct a separate literature review examining the main natural sources of variability in the absence of the human activity.

4. List the effects associated with the human activity and evaluate the amount and kind of evidence supporting each effect.

5. Consider whether the monitoring design could be improved by factoring in natural influences on monitoring variables into the design and removing these as potential explanations.

6. Decide how evidence will be used to draw inferences about human impacts. 


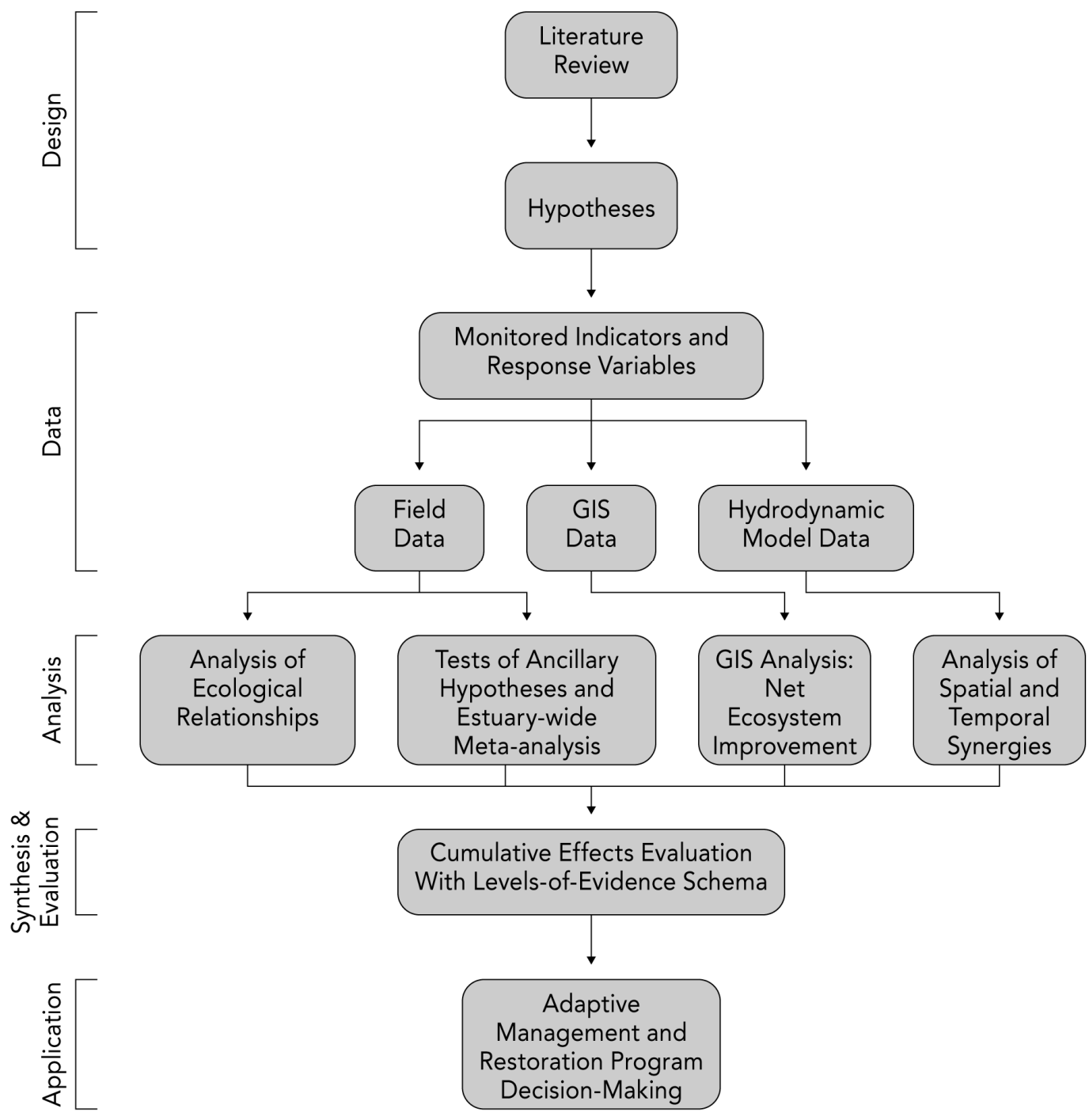

Figure 3.1. Assessment of the Cumulative Effects of Ecosystem Restoration by a Modified Levels-ofEvidence Approach

\subsection{Design}

Due to the paucity of literature on the effects of the human activity, a nonquantitative, descriptive meta-analysis of existing ecosystem restoration data was performed at the outset of the Cumulative Effects Study (Diefenderfer et al. 2005). This process consisted of attempting to separate direct effects, typically short-term, from longer-term or indirect effects at the site scale. Further, a cumulative effects category was assigned for those effects that occurred at larger spatial scales or that might be described as being emergent properties relative to the biological hierarchy. In addition, hypotheses at multiple scales (Table 3.2) were developed to guide the selection of indicators (Figure 3.1, "Design"). The descriptive meta-analysis of existing ecosystem restoration data may be summarized as follows (see Diefenderfer et al. 2005 for citations for each effect):

- Restoration Measures - dike breach, dike removal, tide gate/culvert installation, tide gate/culvert replacement, channel excavation, and site grading 
- Direct Effects - water surface elevation (i.e., tidal inundation), temperature, salinity, fish presence

- Indirect or Long-Term Effects - channel cross-sectional area, sediment accretion, plant composition, plant percent cover, plant biomass, macro-invertebrates, and fish abundance, species, size structure, diet, growth, and fitness

- Cumulative Effects - floodplain wetted area, wetted channel edge length, hydroperiod, materials fluxes, and fish residence time, diet, and growth.

Table 3.2. Hypothesized Effects of Habitat Restoration Actions. Based on a literature review by Diefenderfer et al. (2005) and Diefenderfer et al. (in review).

\begin{tabular}{|c|c|}
\hline Hypothesis & Effect \\
\hline $\begin{array}{l}\text { Working } \\
\text { Hypothesis }\end{array}$ & The habitat restoration activities in the estuary have a cumulative beneficial effect on salmon. \\
\hline $\begin{array}{l}\text { Landscape-Scale } \\
\text { Hypothesis }\end{array}$ & $\begin{array}{l}\text { Restoration actions in the LCRE will produce an increasing number of hectares and } \\
\text { connectivity of floodplain wetlands trending toward historical levels present prior to land } \\
\text { conversion for agriculture and the construction of dams. }\end{array}$ \\
\hline \multirow[t]{7}{*}{$\begin{array}{l}\text { Ancillary } \\
\text { Hypotheses }\end{array}$} & $\begin{array}{l}\text { The following monitored indicators (organized by category) will trend toward reference site } \\
\text { conditions (measured by the control chart method): }\end{array}$ \\
\hline & Hydrology - area-time inundation index \\
\hline & Water quality - temperature \\
\hline & Topography/bathymetry - average land elevation, sediment accretion rate \\
\hline & Vegetation - percent cover by species \\
\hline & Fish - presence, abundance, residence time, diet, growth rate, fitness \\
\hline & Flux - plant biomass, total organic carbon, nutrients, macro-invertebrates \\
\hline
\end{tabular}

Based on the literature review (Diefenderfer et al. 2005), hydrological reconnection restoration actions proposed throughout the LCRE were hypothesized to produce 1) site-scale controlling factors and ecological structures and processes that are increasingly similar to those of reference sites, and 2) estuarywide, landscape-scale ecological functions (emergent properties) that are increasingly similar to conditions prior to land conversion for agriculture and the construction of dams. Furthermore, if available tidal wetland habitats increase, it could be concluded that the fitness of outmigrating juvenile salmonids would likely increase. The predictions made during this phase of the assessment were qualified by the lack of specific information concerning the background variability of salmon outmigration patterns, gradients in plant community types, and other factors. As a result, the following working hypothesis was developed: the cumulative effects of the habitat restoration activities in the estuary are benefiting salmon recovery in the Columbia River basin. All hypotheses concerning the specific changes to wetland habitats and to the use of those habitats by fishes are ancillary to this hypothesis (Figure 3.2).

Evidence is being built by compiling positive indicators to support the working hypothesis and the absence of indicators for its rejection. The hypothetico-deductive method (Popper 1962; Harvey 1969; Romesburg 1981) provides a conceptual framework for such investigations. The approach begins with a research hypothesis which makes predictions about observable facts that should be true if the research hypothesis is true; these ancillary hypotheses are directly testable, which allows the predictions to be confirmed or refuted. In this way, the hypothetico-deductive method builds support for or against the 
working hypothesis. The hypothetico-deductive method is an excellent approach to gauge the preponderance of evidence for a hypothesis that itself is not directly testable. In this way, the working hypothesis that the cumulative effects of habitat restoration are benefiting salmon recovery may be tested using a necessary and sufficient set of ancillary tests of hypotheses.

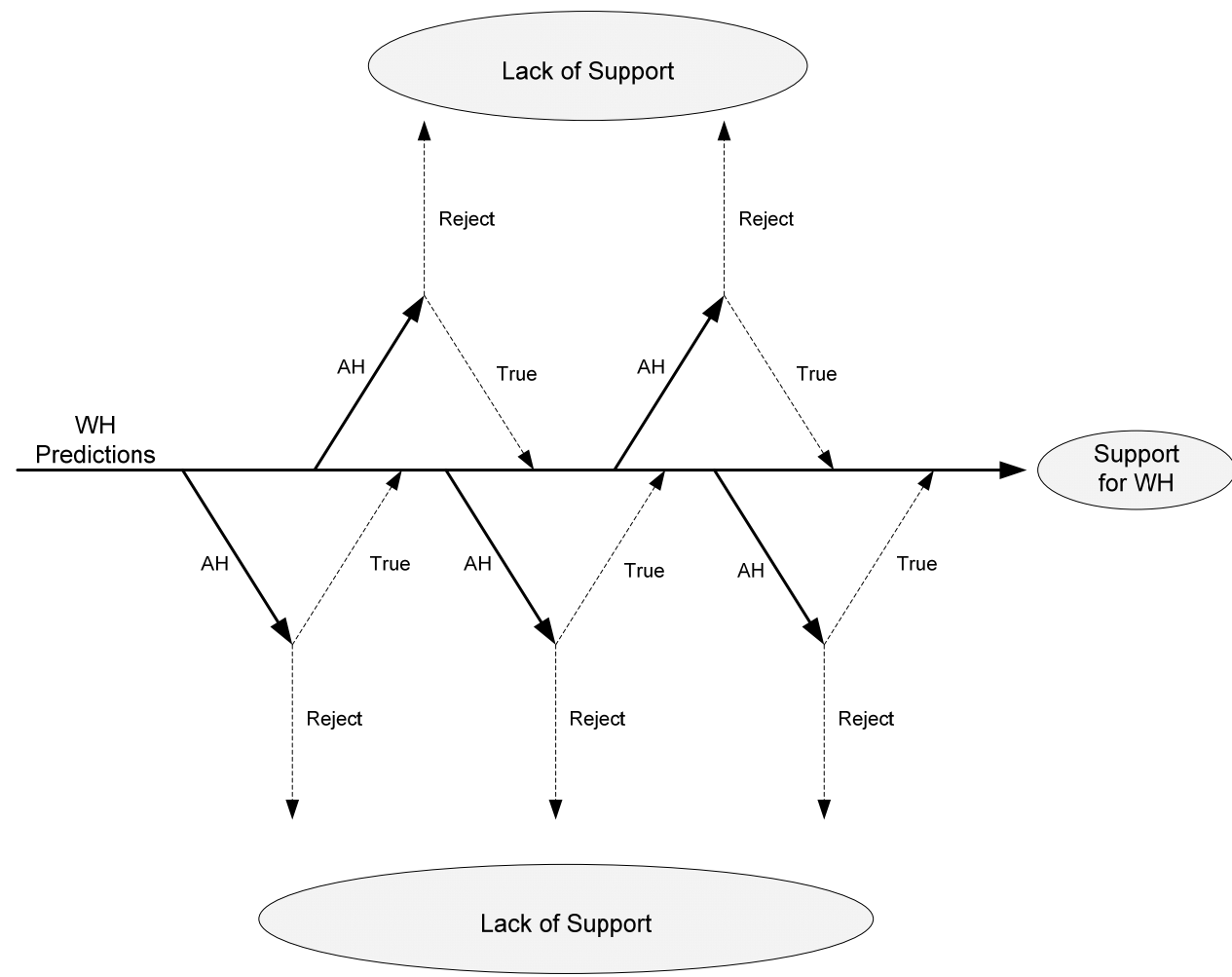

Figure 3.2. Conceptual Diagram of the Hypothetico-Deductive Method Illustrating the Overarching Working Hypothesis (WH) and the Testable Ancillary Hypotheses (AHs)

The purpose of the design therefore was to quantify both background variability and ecological changes in the estuary using the indicators in Table 3.3. In each case, the conditions on the pasturelands prior to tidal reconnection were hypothesized to converge on conditions found in the paired reference sites; for example, the site-scale hydrologic regime indicated by water surface elevation would begin to reflect that of the tidal regime and river flows; sediments would accrete in the compacted areas to raise land elevations; and plant communities would become more similar to existing remnant communities in nondiked areas. The fish community structure in restored sites was surveyed under this design (Roegner et al. [In Review]), while the realized function of habitat usage by salmon (residence time, growth rate, survival rate) will be derived from analogous cases in West Coast North American estuaries in the temperate zone, and from concurrent studies in the LCRE. At larger spatiotemporal scales, the material flux from restored tidal wetlands was predicted to affect the food web of the main stem river, and the increase in cluster size of reconnection projects to have a nonlinear effect on floodplain wetted area.

\subsection{Data}

A dataset sufficient for cumulative effects assessment has been lacking on the LCRE. Therefore, consistent with the requirements of element 2 of the levels-of-evidence approach (Table 3.1), data were 
generated from field collection, publicly available spatial data in GISs, and hydrodynamic model predictions (Figure 3.1, "Design"). To test the hypotheses developed in the design stage (Table 3.2), monitored indicators were identified and protocols were developed for collecting data in the field (Roegner et al. 2009) (Table 3.3). Some of these indicators are quantitative, while others provide supporting information for the qualitative interpretation and confirmation of outcomes. These core indicators include salmon habitat usage in the estuary by juveniles or spawning adults - not population size or status because these would reflect much larger spatiotemporal influences. While the core monitored indicators are measured at the site scale, higher order indicators are measured or derived at both the site and landscape scales (Figure 3.1, "Data"). To reduce ecological uncertainty, we conducted research in fundamental ecosystem controlling factors, structures, processes, and realized functions in the LCRE.

Table 3.3. Monitored Indicators by Category to Assess the Effectiveness of Tidal Reconnection Restoration. Organized by ecosystem controlling factors, structure, processes, and functions of the LCRE Ecosystem Conceptual Model (Thom et al. 2005).

\begin{tabular}{ll}
\hline Category & Indicator \\
\hline Core Indicators - Ecosystem & Controlling Factors and Structures \\
\hline Hydrology & Water surface elevation, catchment area, tidal exchange volume, wetland delineation \\
Water quality & Temperature, salinity, dissolved oxygen \\
Topography/ bathymetry & Elevation, sediment accretion rate, channel cross-sectional area \\
Landscape & Photo points, aerial photos \\
Vegetation & Percent cover by species, plant community composition \\
Fish & Presence, abundance, species composition, size structure \\
Higher Order Indicators - Ecosystem Processes and Realized Functions \\
\hline $\begin{array}{l}\text { Habitat Size } \\
\text { Material Flux }\end{array}$ & Area-time inundation, wetted-channel edge length, floodplain wetted area \\
& Flux rates for nutrients, chlorophyll, dissolved organic matter, plant biomass, total \\
Fish Usage & organic carbon, macro-invertebrates \\
\hline
\end{tabular}

Intensive monitoring of higher order indicators of changes (e.g., habitat size, material flux, and fish usage) at selected sites on the LCRE is strongly recommended (Table 3.3). A focus on habitat-forming processes has become the accepted approach for evaluating the effects of watershed restoration (Beechie and Bolton 1999). This focus is particularly relevant to a spatially complex region such as the LCRE and to spatially and temporally complex populations such as salmon. It shifts the focus of restoration objectives and prioritization to identifying disruptions of processes and building an understanding of the mechanisms by which historical dynamics have been changed through land uses (Beechie and Bolton 1999). It also may help to avoid pitfalls such as performance measures suited to some but not all parts of a study area, the restoration of stable structures at the expense of dynamic functions that maintain a mosaic of habitats, or the restoration of habitat for one species at the expense of another (Roni et al. 2002).

For example, floodplain wetted area represents the active floodplain area in each reach; the floodplain wetted area is produced by the combination of hydrologic controls such as local tributaries, direct rainfall, groundwater, and mainstem flow and tides (Naiman et al. 2005). We have developed a time-area 
inundation model for restoration sites under study by combining data collected on topography and water levels, which allows for calculation of the hectare-hours of available habitat during any time period of interest (e.g., the outmigration of a specific endangered salmon population) (Appendix D; Diefenderfer et al. [In Press]). The total edge length of tidal channels hydrologically connected to the main stem also represents habitat opportunity for salmonids and other species (Simenstad and Cordell 2000), and a nexus of terrestrial and aquatic ecosystems where materials flux can occur. On the restoration sites located in the LCRE, channel density is a poor indicator because it can remain unchanged before and after restoration due to the relict channel networks existing behind some dikes (Diefenderfer et al. [In Press]). Habitat capacity can be quantified through materials flux - the productivity and export of macrophytic organic matter, nutrients, and invertebrates - which represents the primary link from the marshes and swamps to the broader aquatic ecosystem and affects the food web for higher organisms (Kremer et al. 2000). The realized function of the habitats for the fishes - measured as fish residence time, growth rate, and survival rate_-provides the necessary link between habitat restoration and salmonid fitness.

\subsection{Analysis}

The levels-of-evidence approach to cumulative effects assessment involves four main areas of analysis: ecological relationships, effectiveness monitoring data, net ecosystem improvement, and spatial and temporal synergies (Figure 3.1, "Analysis"). Due to the relative lack of existing literature at the outset of most ecosystem restoration programs, meta-analyses can be conducted during the implementation phase on both intensive and extensive field-collected monitoring data. This allows a restoration ecologist or manager to assess the effectiveness of practices being implemented and, if necessary, alter implementation practices to improve success in an adaptive management framework.

\subsubsection{Ecological Relationships}

Predictive ecological relationships can be developed by intensively monitoring the indicators (Table 3.3) before and after restoration at types of sites identified in the monitoring design-paired sites for restoration and reference representing target habitat types (in this case, swamps and marshes); and sequenced sites. An example of this "Before-After-Restoration-Reference" (BARR) design (Diefenderfer et al. [In Review]) is the use of the Czekanowski index in plant community analysis to estimate similarity in species composition and cover (e.g., Bray and Curtis 1957; Thom et al. 2002) before and after restoration at paired restoration and reference sites. Examples of ecological relationships relevant to tidal wetland restoration are listed in Table 3.4. Some, but not all, of these relationships will be used directly to test the ancillary hypotheses listed in Table 3.2. These relationships all have important explanatory power that in some cases involves effects at multiple geographic scales and will be useful in evaluating the trends in monitored variables at restoration sites relative to reference sites. 
Table 3.4. Ecological Relationships Supporting the Federal LCRE Habitat Restoration Program

\begin{tabular}{lll}
\hline Id. & Independent Variable(s) & Dependent Variable(s) \\
\hline 1 & Water surface elevation, land elevation & Floodplain wetted area, area-time inundation \\
2 & Water surface elevation, lateral and longitudinal location & Sediment accretion rate \\
& in floodplain & \\
3 & Catchment area & Channel cross sectional area at outlet \\
4 & Catchment area & Wetted-channel edge length \\
5 & Wetland delineation & Floodplain wetland area \\
6 & Land elevation, lateral and longitudinal location in & Plant community composition \\
& floodplain, sediment accretion rate & \\
7 & Water temperature & Fish presence, species composition, abundance \\
8 & Area-time inundation & Fish presence and residence time \\
9 & Prey availability & Juvenile salmon diet, growth, and fitness \\
10 & Tidal exchange volume & Chlorophyll, dissolved organic matter, and \\
& & nutrient fluxes \\
11 & Tidal exchange volume & Macro-invertebrate flux \\
12 & Tidal exchange volume (annually) & Annual plant biomass export \\
13 & Plant community composition & Fish stock (genetic identification) \\
\hline
\end{tabular}

\subsubsection{Effectiveness Monitoring Data}

The purpose of effectiveness monitoring is to assess whether restoration measures achieve project and program goals and objectives. Testing for a simple change in ecosystem structures or processes is usually not necessary because a physical change was intentionally performed, although measurement of outcomes may be of ecological or programmatic interest. Instead, the purpose is to assess whether the restoration activity produced the desired shift from some state A (impacted; restoration site) to state B (desired; reference site). Auxiliary questions may include how rapidly the shift occurred and the relative costs of alternative restoration activities.

During intensive effectiveness monitoring, we take the view that incorporating control sitesreplicate locations with habitat traits similar to those of the subject site prior to restoration-in the monitoring design is an unnecessary luxury if the difference between states A and B is great (Figure 3.3). In other words, if the ranges of characteristics at restoration and reference sites do not overlap, then there should be little or no risk of falsely concluding restoration success (i.e., reaching state B) when the site is still within the range of the initial state A. In this case, only reference sites-replicate areas considered representative of the desired outcome of the restoration action are needed to assess the status of recovery. These replicate areas are used to characterize the spatial heterogeneity of the target habitat and any temporal shift in the target over time due to climate shift, maturation, etc. Hence, the habitat goal of the restoration may be best viewed as a range of conditions, itself subject to natural change over time (Thom 1997). Restoration success is defined in this situation as the subject site merging into the range of reference conditions and tracking reference site responses over time. 


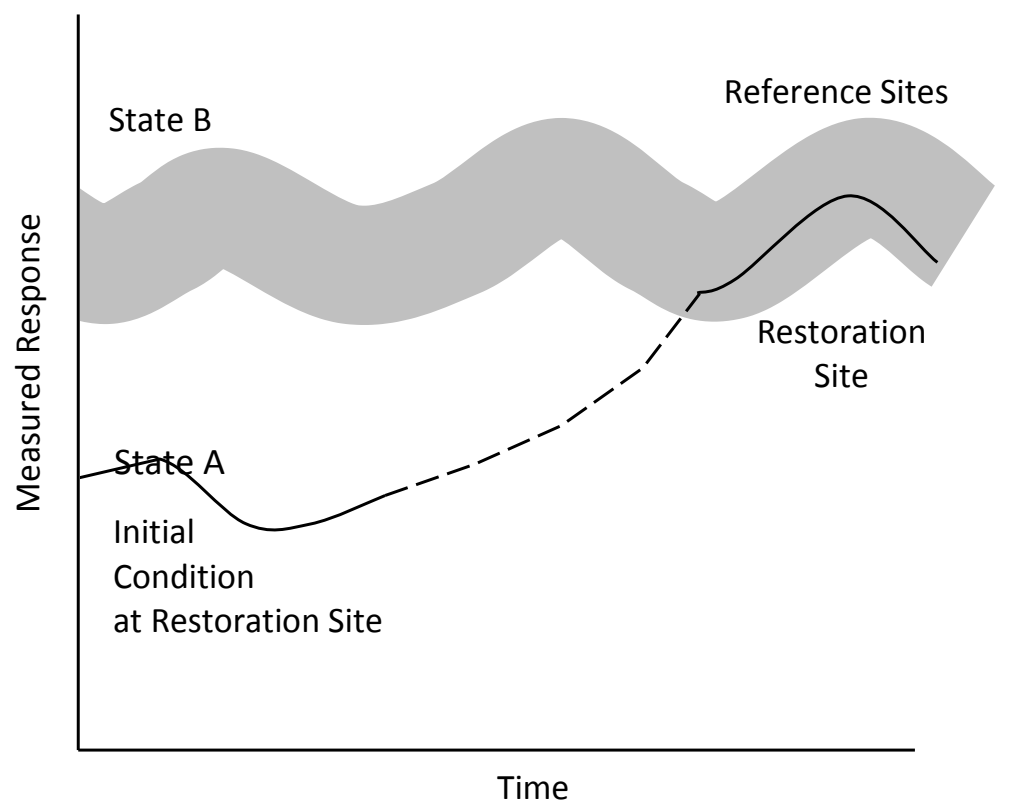

Figure 3.3. Conceptual Framework for Monitoring Restoration Effectiveness. It uses only reference sites (State B) as a target for recovery of restorations sites (State A).

Using only reference sites as part of an effectiveness monitoring design is analogous in many ways to accident assessment designs (Skalski 1995). In these designs, typically there are multiple reference sites and multiple potentially affected sites in the evaluation. Recovery of affected sites after some environmental accident is defined by the affected site approaching the range of reference conditions and subsequently sharing their same temporal trajectory over time. Skalski and Robson (1992) suggested using repeated measures analysis in conjunction with a test for parallelism to assess recovery. Recovery was achieved when the reference and impact sites began tracking each other through time, i.e., parallelism (Skalski et al. 2001). However, in monitoring the restoration of a single site, standard tests of parallelism cannot be performed. There is no between-site, within-treatment variance, only within-site measurement error at the restoration site. Thus, a control-chart method can be useful.

For cumulative effects assessment in the LCRE, trends in core monitored indicators at restoration sites and at a network of corresponding reference and status monitoring sites can be analyzed using a control chart method. From the repeated sampling at the reference sites, upper and lower control limits for reference responses can be constructed. Control limits describe a range of population responses, such that a prescribed proportion of the population falls within their bounds. For example, the limits

$$
\mu \pm 3 \sigma
$$

contain approximately $99.7 \%$ of a normally distributed population. Shewhart control charts (Grant and Leavenworth 1972; Duncan 1974; Burr 1976) use this principle to establish control limits to monitor production processes in manufacturing. A variation of this concept could be used to assess whether a restoration site merges into the range of reference conditions (Figure 3.4). Wheeler (1995, pp. 205-225) provides statistical power calculations for control charts. 


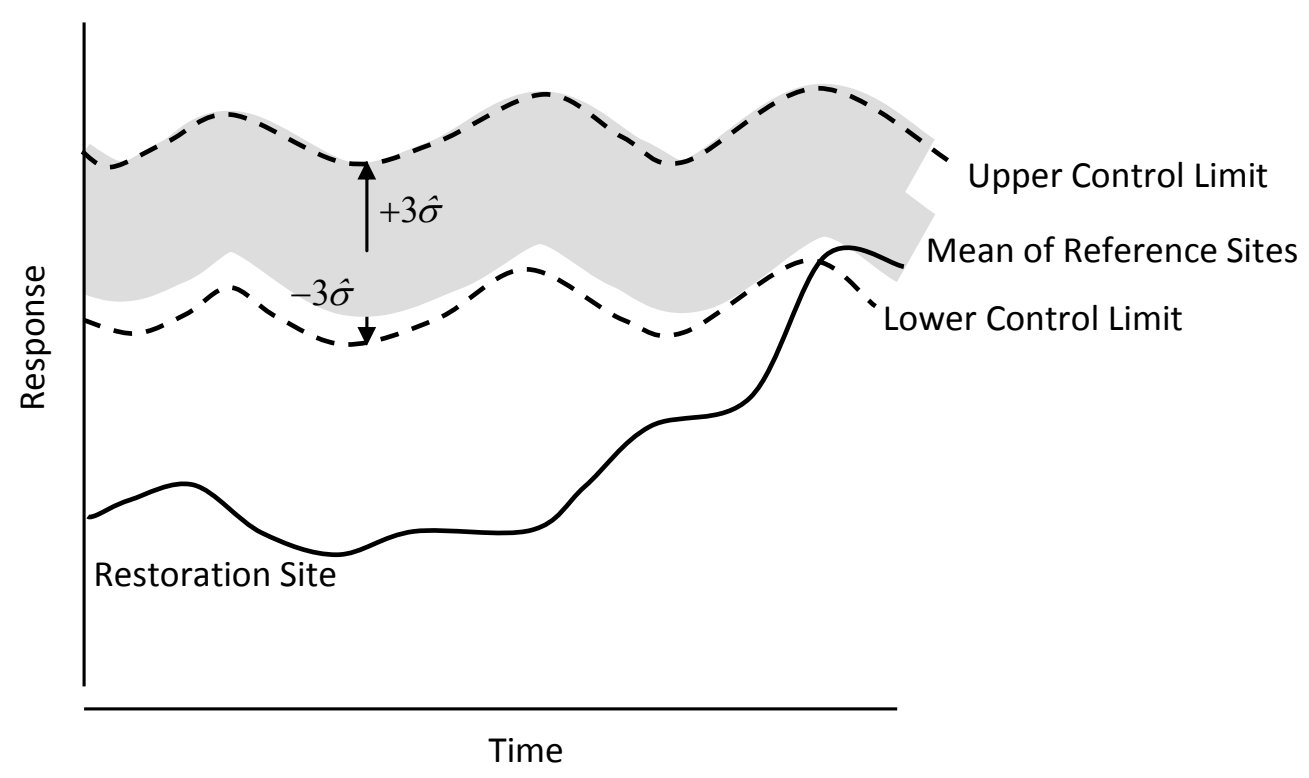

Figure 3.4. Illustration of Control Chart Methods Used to Monitor Recovery Success

A potentially powerful complement to control charts is the Cumulative Sum or cusum technique. The cusum technique consists of a sequential test of hypotheses that can be presented graphically. Unlike control chart methodology, which examines the data for the existence of stability, the cusum method sequentially tests whether a target value has been achieved. In restoration activities, a reasonable value for the target is the mean from reference sites. The cusum plot is more difficult to produce than a control chart and "is so homely that only its parent could love it" (Wheeler 1995), but it can be focused on the objectives of restoration sites achieving a new state. Therefore, we recommend the use of both a control chart and cusum technique, because when conducting a site restoration there is usually a goal of transforming the site from State A to some new State B. The control chart method examines stability and the cusum method actually tests whether the new State B has been achieved or not over time (i.e., year after year, etc.). In other words, have the site-specific goals of the restoration been achieved?

To complement intensive monitoring at selected restoration sites, extensive monitoring of several key indicators is recommended at many if not all other restoration sites. The extensive indicators include a rapid assessment of whether or not the project is on track for meeting its goals, e.g., a wetland delineation for tidal reconnection projects and a survey of planting success for revegetation projects. The extensive monitoring data will be collected using "site evaluation cards," the purpose of which is to succinctly summarize the performance of restored sites relative to key metrics. The site evaluation card (SEC), from which data can be easily summarized and extracted, reports short-term performance of restored sites and often represents the basic set of information needed for accounting by project sponsors and supporting programs (see Thom et al. 2008 for a detailed explanation of site evaluation cards). The SECs will include quantitative indicators, not just qualitative. This will allow extrapolations from extensive to intensive indicators using statistical relationships between the two types of indicators. The ultimate goal is to quantitatively describe the relationship between the cumulative effects of ecosystem restoration (independent variable) and benefits to salmon population (dependent variable).

There is a continuum from extensive monitoring for general needs of adaptive management, to sitespecific action effectiveness monitoring, to intensive action effectiveness research (Table 3.5). The 
choice of extensive indicators may necessarily depend on the type of restoration and the needs of the sponsors. However, extensive indicators will be most useful for estuary-wide accounting purposes if they are standardized for each restoration action, e.g., hydrological reconnection, riparian revegetation. Cost estimates for the final suite of extensive indicators will be required. The indicators will help define success for a restoration action (passage barrier removed, hydrology reconnected, vegetation reestablished, etc.) and provide the basis for periodic meta-analyses of effectiveness within the adaptive management framework.

The SEC also can be used to report information in support of the cumulative effects analysis, including direct input into the calculation of net ecosystem improvement. Critical to the meta-analysis is clearly identifying the linkage between the intensive metrics used to assess performance at individual sites, the metrics used for extensive sampling at all sites, and values for emergent properties at the landscape scale (Table 3.5). Thus, instead of the meta-analysis of existing literature common to levels-ofevidence approaches (Downes et al. 2002; Glasziou et al. 2004), meta-analyses of the intensive and extensive monitoring data specific to the LCRE are conducted under the modified levels-of-evidence framework that is shown in Figure 3.1 ("Analysis").

Table 3.5. Relationships Between Selected Extensive (independent) and Intensive (dependent) Monitored Indicators and Management Applications.

\begin{tabular}{|c|c|c|c|}
\hline Id. & Extensive Indicator(s) & Intensive Indicator(s) & Management Application \\
\hline 1 & Wetland delineation & Floodplain wetland area & $\begin{array}{l}\text { Measurement of wetland } \\
\text { area restored }\end{array}$ \\
\hline 2 & Water surface elevation, land elevation & Area-time inundation & $\begin{array}{l}\text { Assessment of habitat } \\
\text { opportunity for salmon }\end{array}$ \\
\hline 3 & Water temperature & $\begin{array}{l}\text { Fish presence, species } \\
\text { composition, abundance }\end{array}$ & $\begin{array}{l}\text { Assessment of habitat } \\
\text { opportunity for salmon }\end{array}$ \\
\hline 4 & $\begin{array}{l}\text { Land elevation, lateral and longitudinal } \\
\text { location in floodplain, sediment accretion rate }\end{array}$ & $\begin{array}{l}\text { Plant community } \\
\text { composition }\end{array}$ & $\begin{array}{l}\text { Evaluation of restoration } \\
\text { trajectory }\end{array}$ \\
\hline 5 & Photo points & Not applicable & Evaluation of trajectory \\
\hline
\end{tabular}

\subsubsection{Net Ecosystem Improvement}

Assessing cumulative effects presupposes the existence of a set of restoration projects within a landscape. The condition of the set of landscape units is dynamic in response to natural and anthropogenic disturbance processes; thus, not all units can be expected to be in an optimal condition. For this reason, the analysis of frequency distributions to document changes in targeted habitat types has been recommended (Naiman et al. 1992; Reeves et al. 1995; Hemstrom et al. 1998; Reeves et al. 2004). For instance, on the Columbia River the geographic information system (GIS) facilitates examining multiple stressors and land cover at three scales; in ascending order, these are 2100 sites, 60 hydrologic unit code (HUC) 6 watershed units, and the historical floodplain from the river mouth to rkm 235 (see Thom et al. [In Review]).

Stressors included in this GIS analysis (Figure 3.1, "Analysis") are the anthropogenic modifications that act on controlling factors and in turn on ecosystem structures, processes, and functions, as described in our ecosystem conceptual model of the Columbia (Borde et al. 2005) and for which geographically complete datasets exist. The base model also makes use of cumulative effects landscape indicators with 
some promise of nonlinear relationships to aquatic communities and ecosystems, such as frequency and size distributions of habitat types or land cover (Gosselink et al. 1990; Leibowitz et al. 1992; Spies and Turner 1999; Gergel et al. 2002). Indices of fragmentation, one mode of accumulation of effects, also can be calculated in GIS. A simple equation allows us to sum the cumulative net ecosystem improvement (CNEI) from restoration sites across the landscape (Thom et al. 2005, Diefenderfer et al. [In Review]).

$$
\mathrm{CNEI}=\sum(\Delta \text { function } \mathrm{X} \text { area } \mathrm{X} \text { probability })
$$

An additive model of cumulative net ecosystem improvement is a function of the change in ecological function (delta), the project size, and probability of success of the restoration action. Any indicators of function and area can be used, while the probability of success reflects the initial levels of disturbance, restoration strategy applied, stochastic events, and past results in the system. A GIS base model permits the additive calculation of changes in landscape pattern, the frequency distributions of habitat types, and stressors. However, depending on response and in the presence of positive synergistic effects, Equation 3.1 will tend to underestimate actual benefits. Its advantage is in the relative ease of calculation (see Thom et al. [In Review]).

\subsubsection{Synergy}

Several features of large-scale restoration programs have the potential to contribute to a cumulative response by the ecosystem, among them the spatial configuration and number of restoration projects, temporal trends in restoration events, the physical size of restoration sites, and the total restored area in a landscape (Figure 3.1, "Analysis"). Theoretically, these have the potential to produce 1) additive effect; 2) positive synergy, i.e., a total effect greater than the sum of effects from individual actions; or 3) the reverse or negative synergy, known as an antagonistic or countervailing effect. While a single restoration event has little or no opportunity to benefit from interactions with disturbed neighboring sites, neighboring restoration activities may be affected by mutual feedback. If this is the case and there is a positive synergy, then the average response per restoration project should increase as the cluster size of the projects increases (Figure 3.5a). In this scenario, the experimental design would consist of restoration clusters of size 1,2,3, and more, replicated and randomized within the landscape, and initiated concurrently to eliminate confounding size with duration or time.

If cumulative effects based on project area exist, the magnitude of the response should be disproportionately larger at larger restoration sites (Figure 3.5b). The study design would consist of multiple restoration sites of different sizes restored at the same time and monitored over time. Log-linear regression of response versus size could then be used to test the significance of the slope term (i.e., $\beta$ ) some years post-restoration. Because multiple hydrological restoration scenarios cannot be implemented on the same river reach, hydrodynamic modeling of alternative sets of spatially configured sites is used to quantify compounding, indirect, and cross-boundary effects of projects on the fundamental controlling factor on estuary biota, the hydrologic regime (Diefenderfer et al. [In Preparation]).

As an isolated restoration site is joined by others, the temporal pattern of site response may be altered, and cumulative effects may be evident if the equilibrium state of a biological response variable at early restored sites increases (Figure 3.5c). The experimental design would consist of a set of isolated replicate restoration events, where restoration processes are allowed to reach a new level of equilibrium response. A random sample of these sites would then be selected for nearby intervention; the rest would remain in 
a

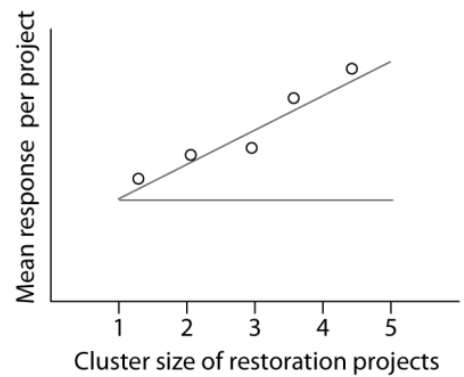

b

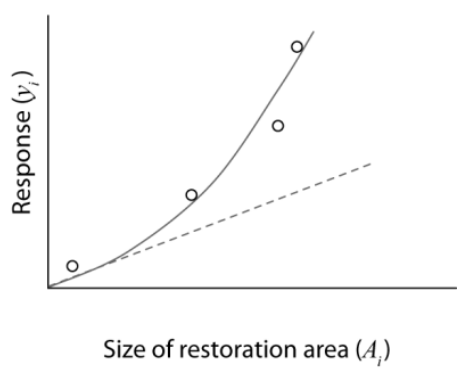

C

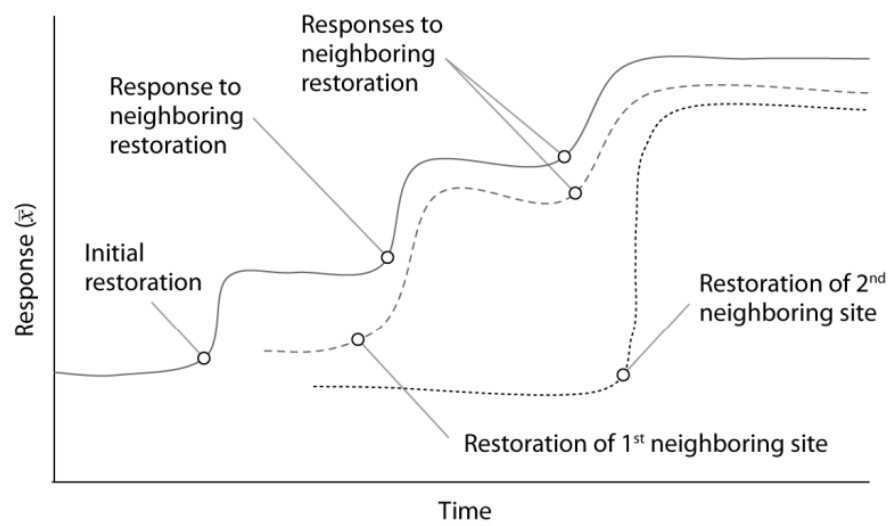

d

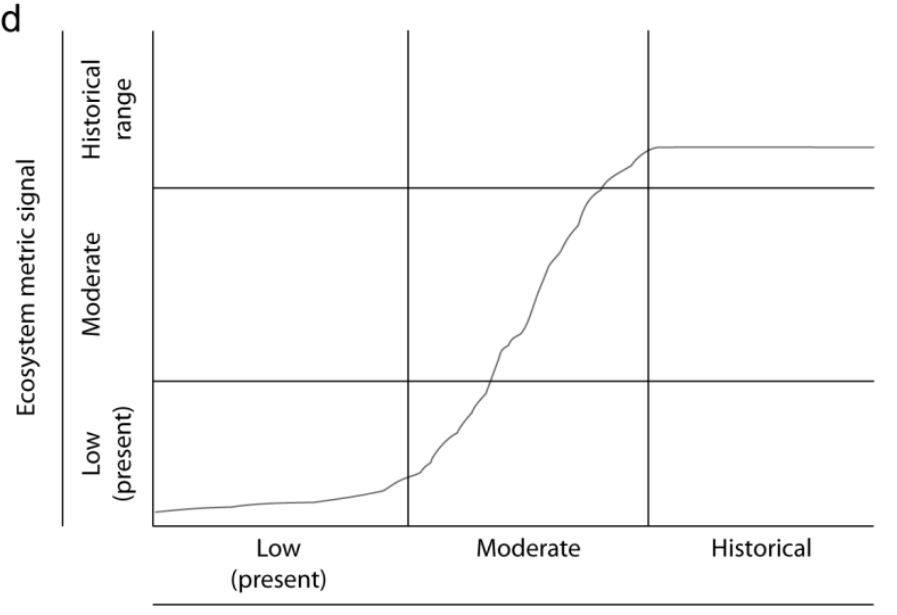

Area of viable habitats

Figure 3.5. Hypothetical Relationships Related to Habitat Restoration. The figure shows the hypothetical relationships between (a) number of restoration projects in a cluster and mean response per project under the null $\left(\mathrm{H}_{\mathrm{o}}\right.$ : no relationship) and alternative $\left(\mathrm{H}_{\mathrm{a}}\right.$ : cumulative effects) hypotheses; (b) the magnitude of environmental response and size of the restoration area under the null $\left(\mathrm{H}_{\mathrm{o}}\right.$ : proportionality) and alternative $\left(\mathrm{H}_{\mathrm{a}}\right.$ : cumulative effects) hypotheses; (c) temporal patterns of site response and one or more interventions at nearby restoration sites; and (d) ecosystem response and area of viable habitats. 
isolation. The working hypothesis is that response output from the sites with a nearby restoration would increase compared to sites in isolation. The statistical test of cumulative effects would be based on a time-by-treatment interaction. The design could be augmented with additional restoration activities over the course of time. Temporally sequenced sites facilitate the analysis of large-scale and long-term outcomes at 1) sets of spatially conjoined sites on which restoration actions are implemented or modeled in sequence, and 2) a set of sites representing a decades-long time series of accidental dike breaches before the present time.

At a program scale, it is possible to test for the effect of the total area of viable sites on ecosystem metrics (Figure 3.5d). The shape of this curve could be influenced by direct relationships between structure and function (e.g., Bradshaw 1987) or asymptotic functions such as the effect of biodiversity on some ecosystem function metrics (e.g., Naeem 2006). Assessing and predicting the cumulative effects of restoration requires a means to document the trajectory of net ecosystem improvement, ideally from a prerestoration baseline toward historical conditions, although in fact multiple states may occur (Thom et al. 2005; Suding and Gross 2006). Therefore, system state and development are best tracked by monitoring a set of predictive biological and physical metrics (Thom 1997) over time as successful restoration projects throughout a landscape increase the total functioning area while continuing impacts decrease it.

Practically, restoration program funding often limits the ability to implement designs such as these because they require the existence of a large number of projects where field collection has been designed to provide before-and-after monitoring data over large spatial scales. Therefore, researchers need to use all available resources to draw evidence from the literature, from targeted field data collection, and from modeling resources, within a defensible inferential framework.

\subsection{Synthesis and Evaluation}

The purpose of this stage (Figure 3.1, "Synthesis and Evaluation") is to assemble the results of all analyses and examine each result as indicated by its role within the larger design to determine whether the additive, synergistic, and countervailing effects of all habitat restoration projects in the LCRE produce 1) site-scale ecological structure and function that are more similar to those of reference sites, and 2) estuary-wide scale ecological structure and function that are more similar to conditions prior to land conversion for agriculture and the construction of dams. Broadly, this makes up our definition of "ecosystem restoration" in the LCRE. To make this determination, results of all analyses are synthesized and evaluated relative to the causal criteria (Table 3.1).

\subsection{Application}

Cumulative effects methodology is intended to be applied at project, reach, and estuary-wide scales. The approach will be useful for decision-making relative to LCRE habitat restoration projects, evaluation of the overall LCRE habitat restoration effort, interpretations of WRDAs pertaining to the LCRE, and implementation of protection and offsite mitigation measures for listed salmonids in the Columbia River basin that are affected by the operation of the FCRPS. Examples from the field research supporting our cumulative effects assessment include 1) specification of the role of large wood in the reference condition pool spacing of spruce swamps (Diefenderfer and Montgomery 2009), 2) determination of suitable indicators of habitat opportunity through elimination of channel density and development of a method to index the continuously changing amount of wetted area (Diefenderfer et al. [In Press]), and 3) survey 
results for fish community structure in tidal channels recently reconnected to the main stem river by restoration actions (Roegner et al. [In Review]).

In general, managers want to know the following: What suite of projects results in an increase in habitat opportunity and capacity for juvenile salmon? What suite of projects reproduces increased habitat connectivity, maximum flood attenuation, sediment trapping, nutrient processing, return of marsh macrodetritis, and other ecosystem functions? What are the survival benefits from habitat restoration? Are protection and restoration resulting in continued loss, no net loss, or net ecosystem improvement in the context of continuing land conversion? These types of questions are integrated through adaptive management into regional ecosystem restoration planning processes and lessons learned are disseminated within the LCRE and beyond. The approach to monitoring salmon habitat restoration actions in the tributaries of the upper Columbia River basin also is based on levels of evidence (USACE et al. 2007); use of the same causal criteria throughout the Columbia River basin will facilitate assessment of salmon recovery at larger scales.

\subsection{Conclusion}

The continuing goal for scientists is to elucidate relationships among monitored indicators in order to effectively measure ecosystem response with limited data on the river-floodplain system. Newly emerging analytical methods and technologies will improve our ability to measure the cumulative effects of restoration. Scientists have been developing methods to assess the cumulative impacts of anthropogenic stressors on ecosystems for decades; however, during this same time period a net loss of coastal and wetland ecosystems has simultaneously occurred in the United Stated (Jackson et al. 2001; NRC 2001). Perhaps the knowledge generated here can still be applied to return some of these systems to more resilient states. Monitoring on a project-by-project or additive basis is unlikely to reflect the interactions produced in nature during the process of restoration. The framework introduced here should be tested for its applicability to other understudied systems where restoration projects are being implemented. 



\subsection{Analyses}

This section contains some results for the four avenues of analysis of the cumulative effects approach described in Section 3.0: ecological relationships, effectiveness monitoring data, net ecosystem improvement, and synergies (Figure 4.1). These analyses include data from 2005 through 2008 field research and 2008 modeling and GIS work conducted, in part, as part of the Cumulative Effects Study. The purpose of this section is to present preliminary data that are pertinent to the evaluation of the cumulative effects of habitat restoration in the LCRE.
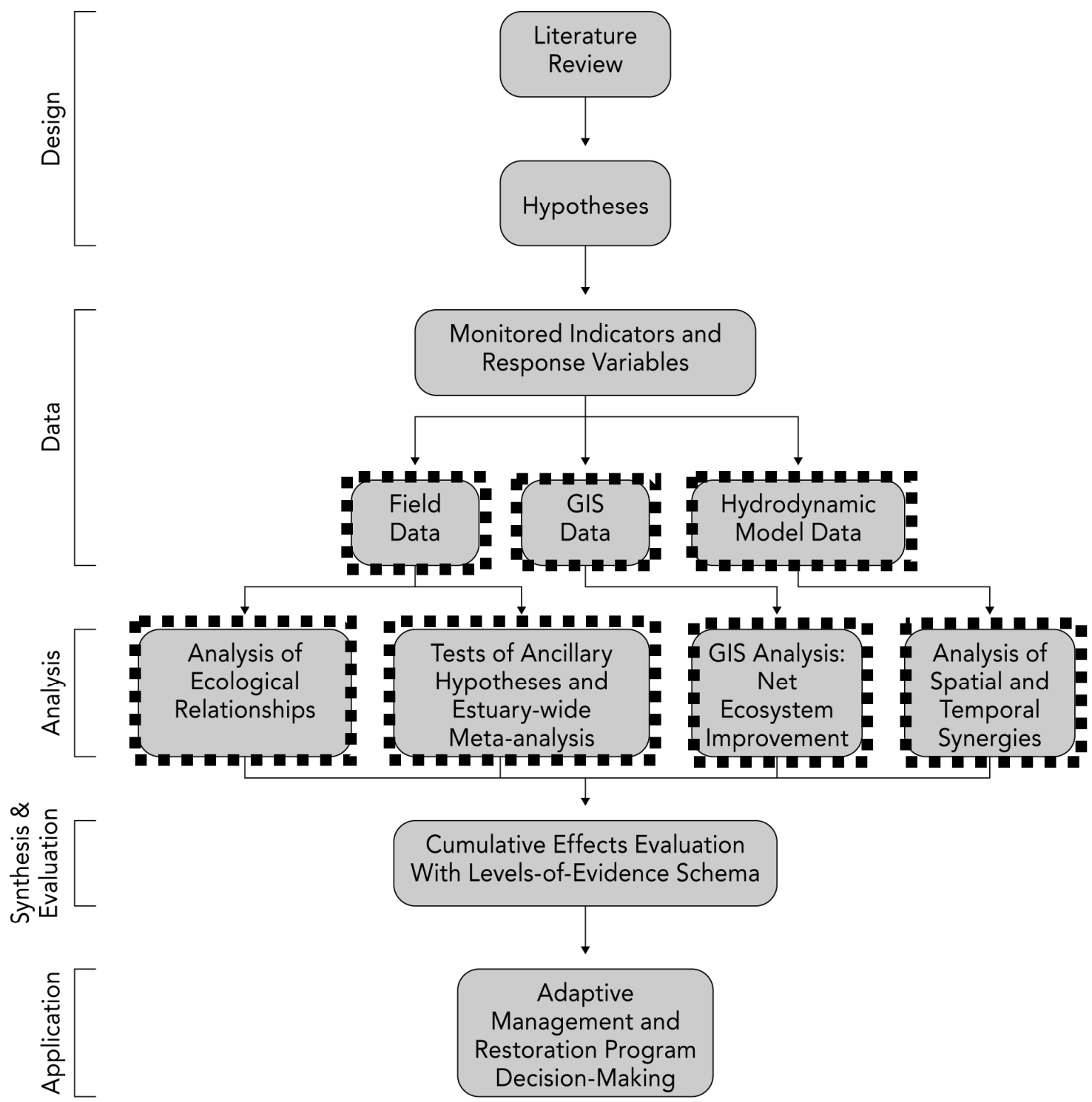

Cumulative Effects Evaluation With Levels-of-Evidence Schema
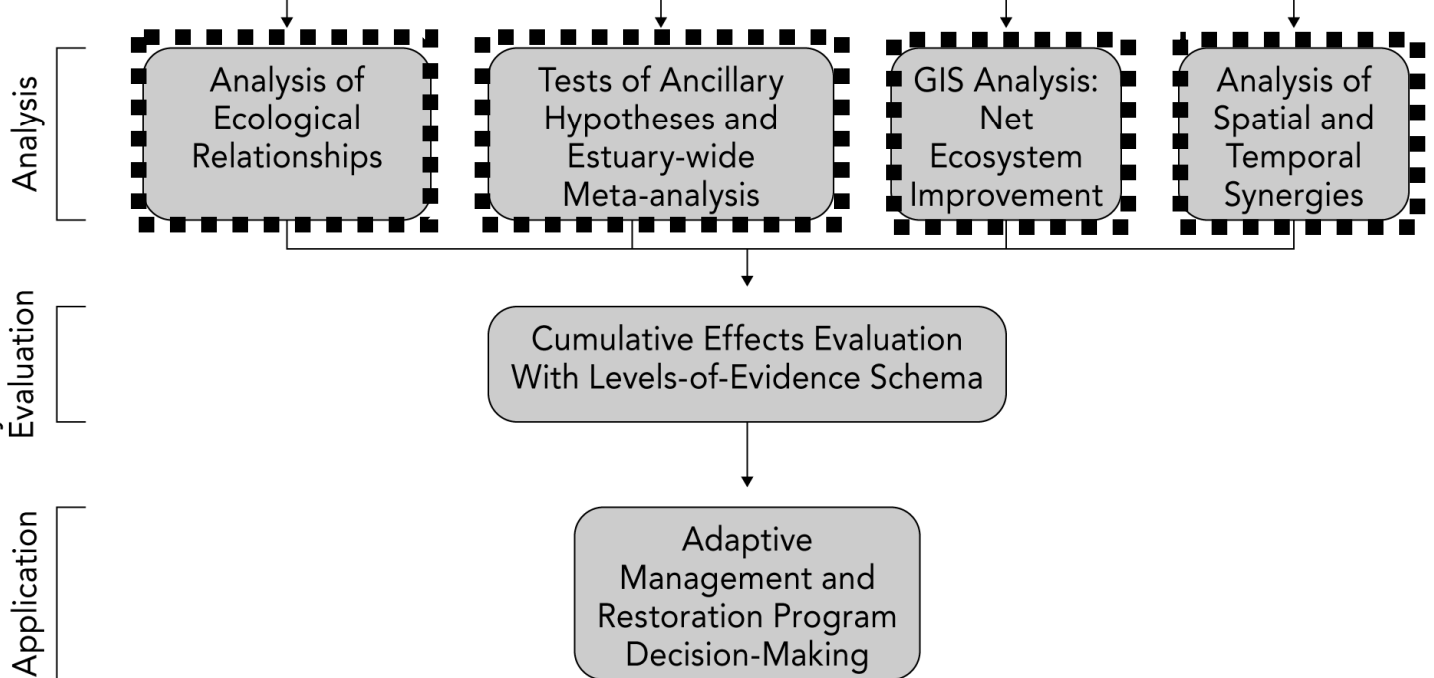

Figure 4.1. Approach for the Evaluation of Cumulative Effects with Emphasis (black dashed boxes) on 2008 Data and Analysis 
Recall that we presented the following preliminary key results in the 2007 Annual Report:

- Hydraulic Geometry and Channel Morphology Relationships - There were strong, positive correlations between the three monitored indicators: catchment area, total channel length, and crosssectional area at outlet. Measurement of these indicators in hydraulic geometry and channel morphology at restoration sites may now be compared with these established relationships to assess the trajectory and, hence, the success of a project.

- Elevation-Vegetation Relationships - Data from several locations in the estuary reveal differences between habitat types (e.g., marsh versus swamp), as well as locations in the floodplain (e.g., island versus tributary floodplain area). Information about plant species tolerances in a given region of the estuary floodplain, coupled with pre-restoration data about elevations in restoration sites, provides managers with the ability to forecast the plant communities that may develop based on existing conditions or to elect to alter existing elevations to support desired plant communities.

- Invasive Plant Species at Restoration Sites - As an example, reed canary grass increased at sampling locations at the Kandoll restoration site. On the other hand, Himalayan blackberry decreased after restoration inundated the pasture land. The prediction of invasions may help in planning project designs to avoid them.

- Sediment Accretion Rates in Tidal Wetlands - The sediment accretion rate was $2.4 \mathrm{~cm} / \mathrm{yr}$ for the Johnson and Kandoll sites combined over 2005 through 2007. Comparison of sediment accretion rates with the initial elevation of restoration sites and with the elevations of reference sites supporting target plant communities can help restoration managers predict the length of time it will take for ecological processes in a watershed to increase land elevations sufficiently to achieve project goals; if necessary, the process can be augmented through adaptive management with active restoration techniques.

- Similarity Indices of Vegetation - An example shows very little similarity between indices of vegetation at restoration and reference sites (13.1-53.2\%) before and in the first year after restoration. Managers can assess the rate of change and whether change is occurring in the direction of the plant community target using similarity indices.

- Juvenile Salmon Use of Tidal Reconnection Sites - At Kandoll sites, Chinook salmon were eating Chironomidae. Chum and coho diets included Chiromonidae, Heteroptera, and other insects. Species collected in insect traps and benthic cores at the sites included Chironomidae and Corophium, respectively. This key result supports management decisions to restore tidal wetlands and supports future restoration actions of this kind.

\subsection{Ecological Relationships}

This section contains preliminary 2008 results related to the relationships between 1) channel crosssection vs. plant composition at natural breach sites, 2) water elevation vs. floodplain wetted area, 3) fish abundance vs. water temperature, and 4) fish genetic identification vs. plant composition.

\subsubsection{Water Surface Elevation vs. Floodplain Wetted Area}

An area-time inundation index was calculated for two sites, Kandoll Reference and Kandoll Farm, for the water year 2006 (1 October 2005-30 September 2006), which immediately followed hydrological 
reconnection. The area-time inundation index was calculated as the number of hectare-hours of inundation, including both in-channel and floodplain area, summed at 10-cm increments and divided by the total possible hectare-hours for each site. The area-time inundation index was $34 \%$ at Kandoll Farm in contrast to $9 \%$ at Kandoll Reference. Frequency of floodplain inundation at Kandoll Farm was 54\% compared with $18 \%$ at Kandoll Reference. This was due to the fact that the mean floodplain elevation of the restoration site was $0.7 \mathrm{~m}$ lower than the adjacent reference swamp; further, the microtopography was greater at the swamp.

Based on these conclusions, in the early years after hydrologic reconnection, the area inundated on a particular recurrence interval will change as land surfaces rise (Figure 4.2). Thus the typical use of wetted area as an indicator of the effective size of tidal floodplain restoration projects, for the purpose of measuring available fish habitat, is likely to overestimate the areal extent of the inundation that will be seen some decades after implementation. The 34\% area-time inundation index seen at Kandoll Farm in the year following hydrologic reconnection, for example, may be expected to decline toward the $9 \%$ seen at Kandoll Reference, as sediment accretes at a mean rate of $2.4 \mathrm{~cm} \mathrm{yr}^{-1}$ (Diefenderfer et al. [In Press]). Inundation frequency, too, would be expected to decline from $54 \%$ toward $18 \%$. Based on these findings, it would be worthwhile to consider active modification of elevation during implementation for some restoration designs. See Appendix D for more information and Figure 4.3 for example inundation patterns.
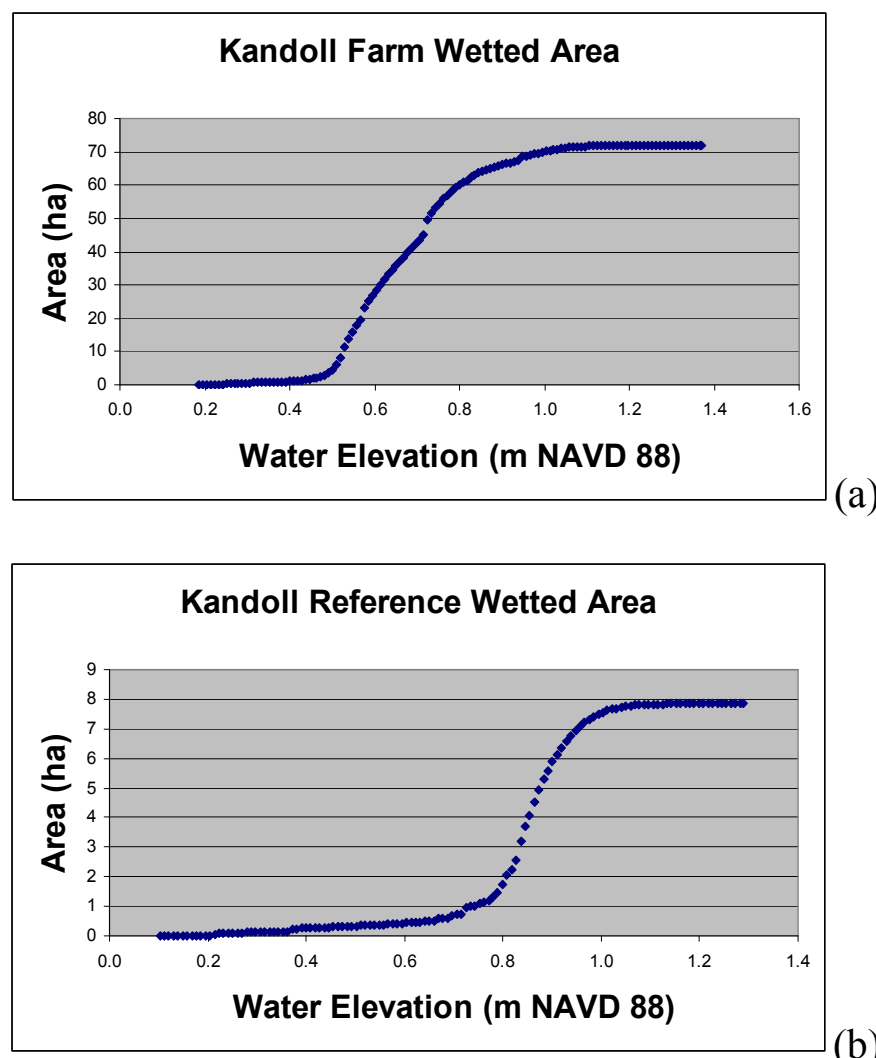

(b)

Figure 4.2. Total Wetted Area Produced by Water Levels at (a) Kandoll Farm and (b) Kandoll Reference 


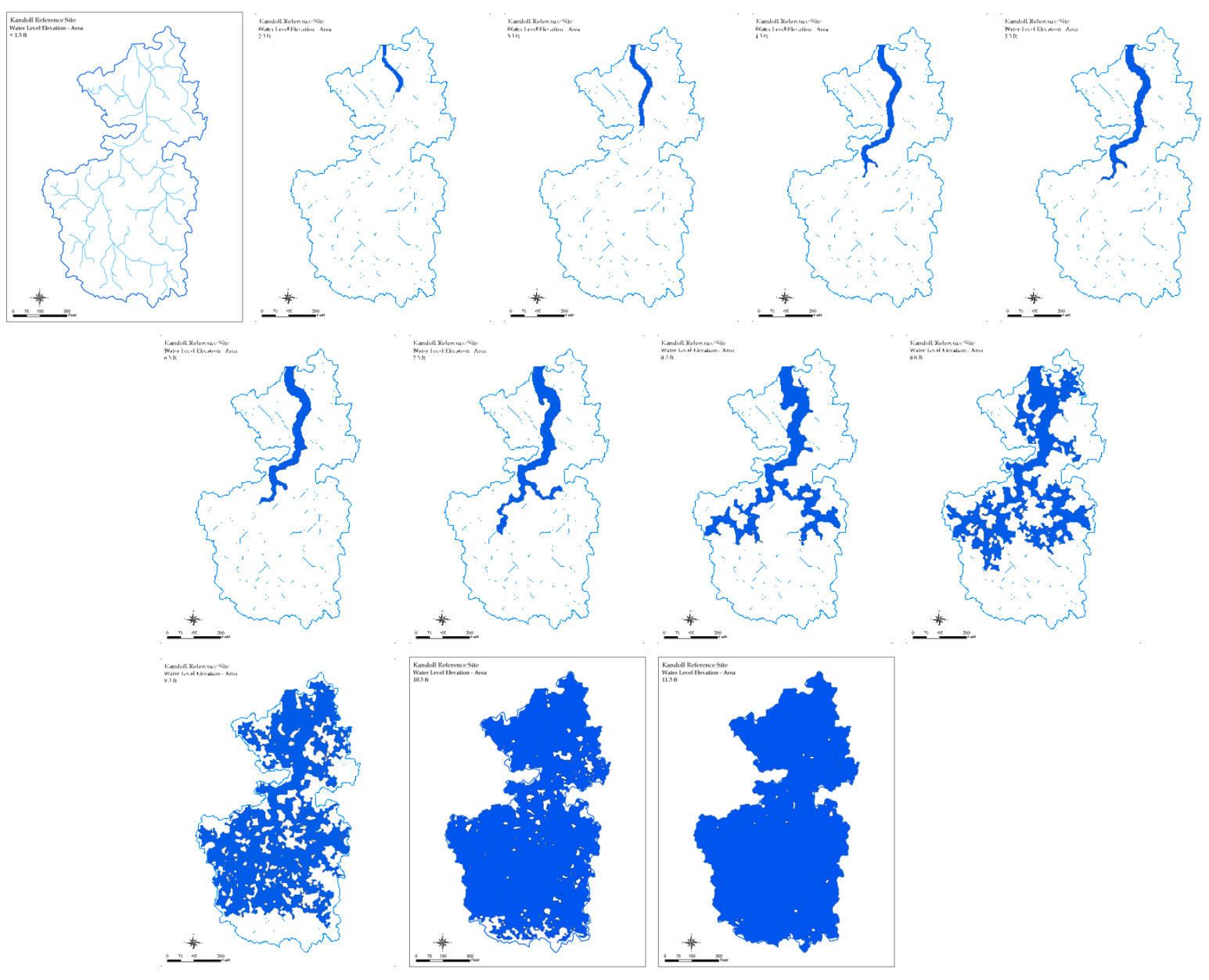

Figure 4.3. Inundation Patterns. The typical inundation pattern as the tide rises in a forested wetland, beginning at the top row left position with zero wetted area at $<1.3 \mathrm{ft}$ NAVD88 (North American Vertical Datum of 1988), and continuing to the right with $2.3 \mathrm{ft}, 3.3 \mathrm{ft}$ etc. at $1 \mathrm{ft}$ water-level intervals through $11.3 \mathrm{ft}$. One $0.5 \mathrm{ft}$ increment is shown (bottom row, left position, $8.8 \mathrm{ft}$ ) due to the large change in wetted area between water elevations of $8.3-\mathrm{ft}$ and 9.3 -t NAVD88.

\subsubsection{Water Temperature vs. Fish Abundance}

The capacity of restored wetlands to support juvenile salmon depends in part on water temperature, and improving the thermal regime is a key goal for restoration activities in the CRE. Salmonids are cold water species and in general prefer temperatures below about $16{ }^{\circ} \mathrm{C}$ for optimum growth (McCullough 1999). Many studies have linked water temperature to physiological stress in salmonids (Richter and Kolmes 2005), and as temperatures increase, salmonids attempt to migrate to more thermally suitable environments. However, behavioral responses to temperature are species-specific. For example high temperatures may induce downstream migration in species such as chum and fall Chinook that have fry and subyearling life histories, but species that have an extended freshwater rearing strategy, such as coho, may migrate upstream (Sauter et al 2001; Miller and Sadro 2003). The thermal regime of a site is dependent on many factors, including the source of input water, residence time within the site (local hydrology), exposure versus shading (riparian cover), and seasonal/interannual variations in solar input. Note that these factors are sometimes beyond the control of restoration designers, which underscores the 
need for adequate monitoring. Thus, the thermal regime is an important determinant of the timing of fish habitation of a site, and indeed is one measure of habitat restoration success.

We investigated the temporal distribution of salmon at Kandoll Farm based on thermal regime by plotting salmon abundance (catch per unit effort, CPUE) by the 7-day average maximum temperature (7DAM temperature, EPA 2003; Richter and Kolmes 2005) (Figure 4.4). In 2007 and 2008, few Chinook salmon were captured in trap net samples, which likely reflects the low abundance of adults returning to the system. CPUE was greatest at temperatures from 11 to $16^{\circ} \mathrm{C}$, although in previous years Chinook salmon were present in water up to $24^{\circ} \mathrm{C}$ (Roegner et al. [In Review]). CPUE for chum salmon was highest during temperatures from 9 to $12^{\circ} \mathrm{C}$, and coho salmon CPUE peaked at 12 to $18{ }^{\circ} \mathrm{C}$. These latter thermal ranges are similar to patterns from previous years. Salmon abundance and performance in Kandoll Farm are likely influenced by the tolerance of each species to high temperatures, with migration from the site occurring as temperatures reach specific thresholds. See Appendix E for more information.
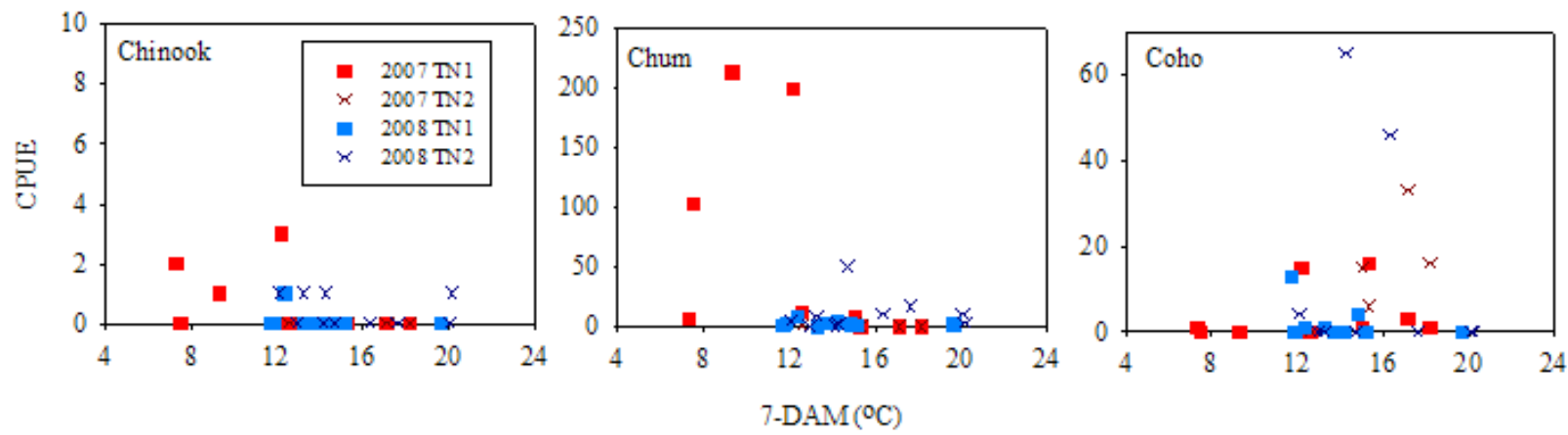

Figure 4.4. Juvenile Salmon Catch per Unit Effort (CPUE) versus Temperature (7-DAM $\left.{ }^{\circ} \mathrm{C}\right)$ for the Kandoll Restoration Site

\subsubsection{Habitat Type vs. Fish Stock}

The relationship between fish stock (genetic identification) and habitat type is important because such data can inform strategic restoration of particular habitat types for the benefit of specific Evolutionarily Significant Units. During 2007, Chinook salmon juveniles were captured at and in the vicinity of the Kandoll restoration site and fin-clipped for genetics analysis to identify the stock of origin. The 37 fish in the sample represented four genetic reporting groups: West Cascade Fall, West Cascade Spring, Spring Creek Group Fall, and Rogue (Roegner et al. [In Review; Figure 4.5). West Cascade Fall and West Cascade Spring are ESA-listed. There was no clear relationship between fish stock and habitat type, as represented by the different sampling locations in the lower Grays River (Figure 4.5). Salmon stock management practices over the past 50 years or more, however, have resulted in ambiguity in assigning natal origin based on the genetic group (Sather et al. 2009). The Rogue River fish at the Kandoll site in the lower Grays River are a good example of this. Nonetheless, genetic stock identification might provide important data to understand juvenile salmon ecology in restored tidal wetlands, especially when data from multiple studies estuary-wide are synthesized. 
All sampled Chinook $(\mathrm{n}=37)$
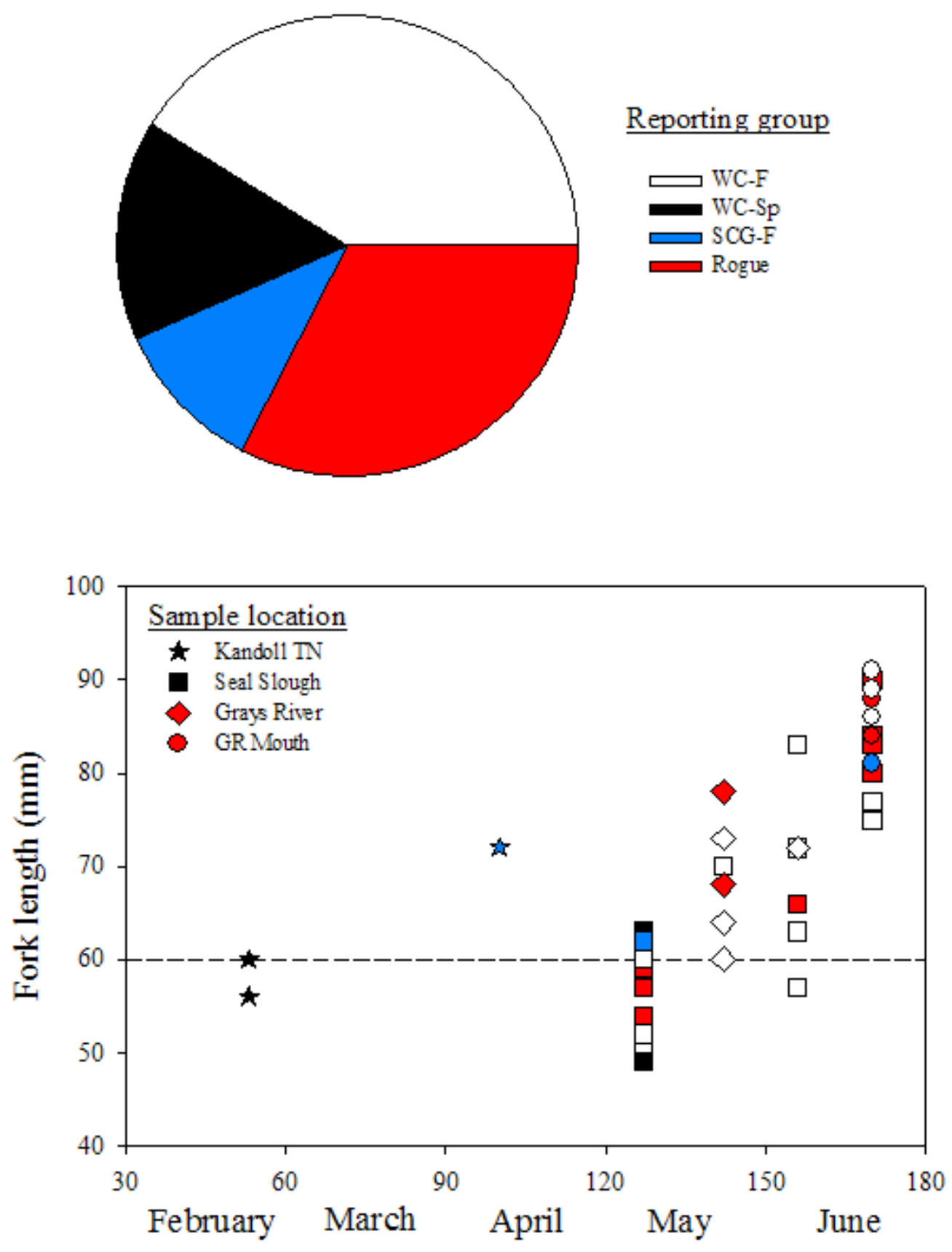

Figure 4.5. Juvenile Chinook Salmon Stock Identification (reporting group) by Fork Length, Julian Date, and Sample Location during 2007. The reporting groups are West Cascade Fall (WCF), West Cascade Spring (WC-Sp), Spring Creek Group Fall (SCG-F), and Rogue. 


\subsection{Effectiveness Monitoring}

Extensive and intensive effectiveness monitoring data using the monitoring protocols (Roegner et al. 2009) currently are being collected from at least eight restoration sites in the LCRE as part of the Cumulative Effects Study and other studies. We performed a preliminary meta-analysis of the results from this suite of projects, although not all indicators are being monitored at all sites. The meta-analysis entailed compiling the available data and presenting them to examine whether conditions at restoration sites were trending in the desired direction, i.e., toward conditions at reference sites.

The data indicate that the restored sites are responding measurably to the restoration actions (Table 4.1). The fact that water temperature, sedimentation, vegetation, and fish access have changed since prior to restoration indicates that the actions have restored ecological processes that form and maintain habitats, and that biological resource species are able to benefit from any processes like prey production and refuge afforded by these newly opened habitats. These changes have been detectable within 2 years following restorative actions.

Table 4.1. Summary Meta-Analysis Table -- Is the response variable trending in the desired direction? The double dashes mean data were not available.

\begin{tabular}{lcccc}
\hline & Photo Point & $\begin{array}{c}\text { Water } \\
\text { Temperature }\end{array}$ & $\begin{array}{c}\text { Sediment } \\
\text { Accretion Rate }\end{array}$ & $\begin{array}{c}\text { Juvenile Salmon } \\
\text { Presence }\end{array}$ \\
\hline Crims Island & Yes & -- & Yes & Yes \\
Ft. Clatsop & -- & Cooler in Summer & -- & Yes \\
Johnson Property & Yes & -- & -- & Yes \\
Kandoll Farm & Yes & Cooler in Summer & Yes & Yes \\
Vera Slough & Yes & -- & -- & No \\
\hline
\end{tabular}

This first attempt to summarize the results from a suite of projects illustrated several points. First, variability in level of effort, lack of pre-restoration sampling, and other factors significantly reduced the number of sites that could be compared. That said, sites that were excluded here do have data that can be used for planning and evaluation purposes, but they are less useful in drawing general inference about the success or failure and direction of response of the restored sites. Second, the level of effort in terms of the metrics sampled limited comparisons to four metrics. However, these metrics were relatively robust for determining the response in processes and functions. Having a greater number of metrics commonly collected and sampled would improve the power of comparisons. Third, the duration of assessment was probably not long enough to more fully evaluate the long-term (e.g., greater than 10 years) condition of the site. We expect the vegetation to change rapidly over at least 5 to 6 years following tidal reconnection. Channel morphology should change due to sedimentation and erosion, and this may affect temperature and fish access.

\subsection{Net Ecosystem Improvement}

One approach to assessing net ecosystem improvement is through GIS additive modeling. We performed a pilot study using macrodetritus flux as the ecological function of interest. In terms of evaluating cumulative effects, key factors to consider include the area of marsh or swamp restored, rate of organic matter production, rate and pattern of development of the systems from present state to restored 
state, and the exchange rate and capacity between these restored systems and the LCRE. At the outset of this study, we hypothesized that increases in all of these factors would result in an increase in the contribution of marsh macrodetritus and other forms of marsh-derived organic matter to the broader ecosystem.

During the period from 2005 through 2008, we evaluated this prediction on a pilot scale on 1) Vera Slough and Vera Reference on Youngs Bay and 2) a tributary of the LCRE, the lower Grays River. We monitored tidally influenced sites that were reconnected to tidal inundation during that period for the purpose of habitat restoration to evaluate macrodetritis export outcomes. We used the data together with an assessment of plant community cover at different historical periods in GISs to examine the potential for macrodetritis flux and to predict future flux along the temporal restoration trajectory under partial and complete restoration scenarios. The data reported are at this stage preliminary and will be finalized following collection of 2009-2010 macrodetritis flux data at these sites. See Appendix B for more information.

These results permit coarse preliminary calculations of macrodetritis flux conditions at the landscape scale for the lower Grays River watershed. For example, the historical condition of continuous spruce swamps may have produced little flux of nonwoody materials. The 96 ha of currently restoring sites on the Grays River could be exporting as much as 398 metric tons per year of macrodetritis. The rate of production for a tide gate enhancement on Youngs Bay is similarly high. This assessment, however, uncovered significant weaknesses in the available data for such additive modeling of the export of macrodetritis from wetlands on the LCRE. For example, the use of reprocessed LiDAR data (see Diefenderfer et al. 2008 for methods) showed that the digitized boundary of the floodplain reported by Evans et al. (2006) and the floodplain boundary that is in common use by agencies on the LCRE contain substantial errors due to the 10-m Digital Elevation Models (DEMs) used for digitizing them. Thus, reprocessing of the existing $2005 \mathrm{LiDAR}$ data is crucial for wetted area and floodplain delineation in the LCRE. Furthermore, for the purpose of additive modeling, biomass flux data need to be collected according to topography to adequately account for subtle elevational differences between emergent wetlands and wet meadows such as those identified in National Wetlands Inventory in the landscape assessment. Thus, more fine-grained spatial assessment of flux is needed in field data collection and more intensive sampling of forested areas is needed to address variability. Additive modeling for the purpose of assessing net ecosystem improvement is planned for future studies.

\subsection{Synergy}

We examined synergistic relationships in dike-breach restoration scenarios on the tidal portion of the Grays River. We used a hydrodynamic model and a statistical design to test the hypothesis that the cluster size of hydrological reconnection projects has a nonlinear effect on the area of floodplain inundation and available habitat, under both even and uneven spatial configuration scenarios. An RMA2 model (a depth-averaged, finite element hydrodynamic model) of the lower Grays River was used to run multiple randomized sets of dike breaches from Highway 4 to near the river mouth at Grays Bay.

Analysis of the simulations indicated that the effect of upstream breaches on wetted area per breach is negligible, while the effect of midstream breaches is somewhat greater and downstream breaches the largest at $23 \mathrm{ha} /$ breach (Figure 4.6a). The effect of the same number of breaches (11) evenly spaced throughout the study area was in all three runs equivalent to or greater than the effect of downstream 
breaches (Figure 4.6b). The average incremental change in wetted area per breach that is produced by different numbers of dike breaches appeared to be a nonlinear function, rising steeply from a single dike breach to the 25 th percentile ( 11 breaches) and falling more gradually thereafter (Figure 4.6c).
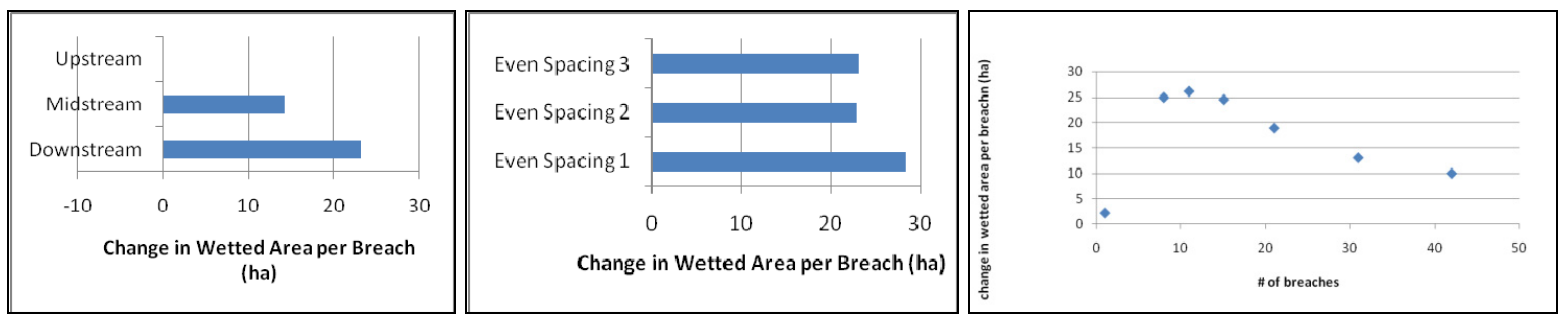

Figure 4.6. Change in Wetted Area per Breach. (a) The average change in wetted area produced per breach for upper, middle and lower segments of the river in the study area, (b) the change in wetted area per breach resulting from three runs of randomly selected dike breaches evenly spaced through the river corridor, and (c) the average incremental change in wetted area.

The implications of these findings for the design of restoration projects and programs depend on the ecological goals and need for cost efficiency. For instance, if wetting the entire floodplain on the high tides is the goal and cost efficiency is imperative, then breaching only half of the channels may be sufficient. Under this scenario, determination of the spatial configuration of these breaches should consider that breaching only the downstream breaches may produce a change in wetted area per breach (Figure 4.6a) equivalent to evenly spacing them throughout the river corridor in most cases (Figure 1b, even spacing runs two and three). It is possible, however, that evenly spacing the breaches throughout the corridor may produce even greater change in wetted area per breach than breaching only downstream channels through the dike (Figure 4.6b, even spacing run one). 



\subsection{Synthesis and Evaluation}

This section contains a preliminary synthesis and evaluation of cumulative effects results to date for two monitored indicators hypothesized (Table 3.2) to be affected at the site scale by ecosystem restoration: water surface elevation and fish presence. We do this by addressing the elements of the levels-of-evidence approach described in Section 3.0 (Table 3.1), adapting each to the specific requirements of the Cumulative Effects Study. This step congregates pertinent findings to argue for or against a cumulative effect from multiple habitat restoration projects in the estuary.

\subsection{Elements of Levels of Evidence}

Element 1. Define each causal criterion and decide how it will be examined and measured.

The definitions of causal criteria (Table 3.1) by Dorward-King et al. (2001) and Downes et al. (2002) are consistent and we accepted them at the outset of this study (element 1). We found, however, that although all causal criteria were applicable to the study some were likely to be more useful than others. For example, our literature review (Diefenderfer et al. 2005) revealed that no experimental evidence existed on whether hydrological reconnection actually restored habitats in the LCRE. Thus, a study was designed and carried out to generate the necessary data. Also, we chose not to carry forward the causal criterion for exposure pathway (Table 3.1) because it has low applicability to ecosystem restoration because its original intent was for ecotoxicology. We assumed that any ecological restoration action would not result in specificity of effect, i.e., a single effect, even though the sudden reconnection to tidal dynamics could relatively easily be tied to a specific cause such as dike breaching. Due to the paucity of data on LCRE restoration actions and background ecological variability, it became clear that analogous cases, i.e., data from other systems, were going to be important elements of the preponderance of evidence in this approach.

Element 2. Use the literature and results from the Cumulative Effects Study to compile data on the effects of the LCRE Restoration Program and to extract information required to evaluate effects on selected monitored indicators using the causal criteria.

The restoration activity being measured in the LCRE is expected to catalyze a series of ecological changes assumed to be beneficial to the LCRE ecosystem and juvenile salmon. A common, site-specific action being implemented in the LCRE is hydrological reconnection, such as dike breach and removal, tide gate and culvert removal and replacement, and grading and channel excavation. Hydrological reconnection restores tidal inundation to increase the availability to juvenile salmon of the habitats most reduced in area by the historical construction of dikes and the alteration of the hydrograph. For example, in the lower $74 \mathrm{~km}$ of the estuary alone, the initial literature review (Diefenderfer et al. 2005) suggested that $77 \%$ of the tidal forested wetlands (swamps) and $65 \%$ of the native tidal marshes have been lost and an estimated $150 \mathrm{~km}^{2}$ of estuary habitat has been converted to diked floodplain, uplands, and nonestuarine wetlands (Thomas 1983). Several stressors particular to the LCRE involve logging, stump removal, and grading, followed by cattle grazing and associated compaction of the soils, fertilization, excavation of drainage ditches, and colonization by non-native species (Allan 2004; Martin 1997; Diefenderfer and Montgomery 2009; Diefenderfer et al. [In Press]). Therefore, the aim of restoration actions is to ameliorate multiple land-use stressors that have impacted the LCRE for a century or more and altered its hydrologic regime, temperature regime, microtopography, and processes linked to the fate and transport of sediments and large wood. 
The selection of monitored indicators of restoration effects poses a challenge as well as an opportunity for understanding the ecosystem better (Walters and Holling 1990). It also requires the synthesis of what is known about the system, application of the state of the science concerning similar systems, and on-the-ground ecological investigation of potential indicators. Furthermore, the consistent application of restoration monitoring protocols (e.g., Neckles et al. 2002) is fundamental to regional assessments. Therefore, we developed such protocols for the core biological and physical indicators for the LCRE (Roegner et al. 2009). In particular for the LCRE, salmon population status is not a suitable indicator of the cumulative effects of habitat restoration in the estuary because of numerous confounding influences during the complex life history of salmon. Modeling, however, has shown that salmon populations would benefit from improved survival in the estuary (Kareiva et al. 2000). Fisheries scientists have documented synergies between anthropogenic impacts on the environment that produce detrimental effects on fish populations by mechanisms such as hypoxia (Jackson et al. 2001), or augmentative effects through, for example, marine protected areas or harvest restrictions (Russ et al. 2004). Salmon populations are sensitive to basin-wide and oceanic conditions as well as estuary habitats due to complex life histories and migration patterns (Kareiva et al. 2000). Their status, in essence, represents compounding effects from multiple sources. In contrast, ecological indicators with clear cause-and-effect relationships provide the clearest predictive ability (NRC 2000). As our study attempts to link the changing pattern and quality of habitats in the estuary with the changing viability of salmon populations, it deals with the topic of "biocomplexity." This requires assessing how site-specific changes following restoration affect habitat availability and quality relative to the multiple life-history strategies of salmon that exhibit differing spatial and temporal scaling. Because it is not possible to measure every feature of the study area, the challenge is to identify key measurable linkages (i.e., ecological relationships) between habitats and salmon that are sensitive to proposed restoration. Those emergent properties of the estuarine ecosystem that support salmon need to be monitored during recovery. Therefore, researchers at restoration and references sites are measuring channel cross-sections, plant composition and percent cover, materials fluxes, and fish presence, etc. For this preliminary synthesis and evaluation of cumulative effects of ecosystem restoration, we evaluated water temperature and fish presence using the causal criteria (Table 5.1).

Table 5.1. Trial Application of the Causal Criteria with "High" Applicability to the Cumulative Effects Evaluation (see Table 3.1) for Water Temperature and Fish Presence. The context is the general ancillary hypothesis that, for a given monitored indicator, conditions at the restoration site are trending toward those at the reference site (see Table 3.2).

\begin{tabular}{|c|c|c|}
\hline $\begin{array}{c}\text { Causal } \\
\text { Criterion }\end{array}$ & Water Temperature & Fish Presence \\
\hline $\begin{array}{l}\text { Analogous } \\
\text { cases }\end{array}$ & $\begin{array}{l}\text { Other water-quality parameters, such as salinity and } \\
\text { dissolved oxygen, likely show similar trends between } \\
\text { restoration and reference sites as water temperature. }\end{array}$ & $\begin{array}{l}\text { Juvenile salmon are found at natural breach } \\
\text { sites (Appendix F), which can be considered } \\
\text { analogous cases. }\end{array}$ \\
\hline $\begin{array}{l}\text { Coherence of } \\
\text { evidence }\end{array}$ & $\begin{array}{l}\text { The findings about water temperature are coherent with } \\
\text { known and expected trends. }\end{array}$ & $\begin{array}{l}\text { The findings make sense; the site with few fish } \\
\text { (Vera) was isolated from sources of juvenile } \\
\text { salmon to begin with. }\end{array}$ \\
\hline $\begin{array}{l}\text { Strength and } \\
\text { consistency of } \\
\text { association }\end{array}$ & $\begin{array}{l}\text { The association between restoration and reference sites for } \\
\text { water temperature is strong and consistent across sites. }\end{array}$ & $\begin{array}{l}\text { Juvenile salmon are consistently present at } \\
\text { restoration and reference sites if access and a } \\
\text { source of fish exist. }\end{array}$ \\
\hline $\begin{array}{l}\text { Temporal } \\
\text { relationship }\end{array}$ & $\begin{array}{l}\text { Water temperature at both restoration and reference sites } \\
\text { follows seasonal weather and runoff conditions. }\end{array}$ & $\begin{array}{l}\text { Juvenile salmon presence follows seasonal } \\
\text { patterns. }\end{array}$ \\
\hline $\begin{array}{l}\text { Biological } \\
\text { plausibility }\end{array}$ & $\begin{array}{l}\text { Very plausible because sources of water are similar between } \\
\text { the restoration and reference sites. }\end{array}$ & $\begin{array}{l}\text { Perfectly plausible because juvenile salmon } \\
\text { are known to use shallow water, tidal channel } \\
\text { habitats (Roegner et al. 2009) }\end{array}$ \\
\hline
\end{tabular}




\section{Element 3. For each monitored indicator identified under element 2, conduct a separate review examining the main sources of variability in the absence of the Federal LCRE Habitat Restoration Program.}

In general, based on our literature review (Diefenderfer et al. 2005) three key elements stand out concerning background variability in the LCRE system. First, spatial and temporal variability of salmon outmigrations is extremely high and is complicated by multiple life-history patterns and hatchery operations. Second, plant community composition on the LCRE varies according to elevation of the floodplain relative to water levels - from highest to lowest being forested wetlands (swamps), shrubdominated wetlands, and emergent marshes. Thus, plant communities vary on ecological gradients longitudinally along the main stem Columbia River and laterally away from the main stem. Third, the floodplain hydrologic regime is governed by the intersection of regulated Columbia River flows originating in snow pack during parts of the year, flows from tributaries of the estuary many of which have heavily logged watersheds, and oceanic tides and sea level. Based on these three key elements, the Columbia River historically exhibited a "polymodal unpredictable" hydrologic regime as defined by Junk (Junk and Piedade 2005; Junk 2008) and its hydrograph varies on multiple spatial and temporal scales. In summary, the primary sources of background variability in the absence of the LCRE habitat restoration effort are fish hatchery outputs, hydrosystem operations, and climate change. These sources affect all of the Cumulative Effects Study monitored indicators and response variables, including water temperature and fish presence (Table 5.2).

However, it is almost impossible to measure the variability in ecological functions in the absence of human activity, because humans have modified and altered their environments for millennia. The environment is continuing to respond to these changes, and therefore it is difficult to identify the threshold at which a particular land use will decrease the system's resiliency, which complicates measuring element 3. Like in many threatened yet understudied systems worldwide, projects to restore tidal ecosystems are proceeding simultaneously with research attempting to reduce uncertainties (Lee and Lawrence 1986) so that the risk of repercussions from restoration practices can be minimized. For example, in the LCRE, the ecology of the plant communities inhabiting the riverscapes and their contributions to salmon population viability is an uncertainty (Small et al. 1990; Bottom et al. 2005), but is currently being studied.

Table 5.2. Example Sources of Variability for Monitored Indicators

\begin{tabular}{lll}
\multicolumn{1}{c}{$\begin{array}{c}\text { Source of } \\
\text { Variability }\end{array}$} & \multicolumn{1}{c}{ Water Temperature } & \multicolumn{1}{c}{ Fish Presence } \\
\hline $\begin{array}{l}\text { Fish Hatchery } \\
\text { Outputs }\end{array}$ & Not applicable & $\begin{array}{l}\text { Hatchery fish can comprise a significant proportion of } \\
\text { juvenile salmon in the LCRE at a given time. Hatchery } \\
\text { and wild fish may use resources in restored wetlands at } \\
\text { differing degrees. }\end{array}$ \\
$\begin{array}{l}\text { Hydrosystem } \\
\text { Operations }\end{array}$ & $\begin{array}{l}\text { Selective water withdrawals for temperature } \\
\text { control from high head, upstream dams; reservoir } \\
\text { heating; controlled runoff-all can affect water } \\
\text { temperature in the LCRE. }\end{array}$ & $\begin{array}{l}\text { Hydrosystem operations and the fish transportation } \\
\text { program affect juvenile fish passage survival at main } \\
\text { stem dams and, hence, fish presence in the LCRE. }\end{array}$ \\
$\begin{array}{l}\text { Numerous studies of the effects of climate change } \\
\text { identify warmer water temperatures. }\end{array}$ & $\begin{array}{l}\text { Climate change could cause higher water temperatures } \\
\text { and lower stream flows in the LCRE and, thereby affect } \\
\text { juvenile salmon presence. }\end{array}$ \\
\hline
\end{tabular}




\section{Element 4. List the effects expected from the habitat restoration effort and evaluate the amount and kinds} of evidence supporting each effect.

For the example response variables, water temperature, and fish presence, data are available from field studies and the literature to evaluate the hypothesized effects (Table 5.3). In general, the evidence supports the hypothesized effects, although the data are preliminary. Element 4 will be a critical piece in the levels-of-evidence approach, especially as more data about more hypothesized effects are disseminated.

Table 5.3. Example Evaluation of the Effects of Restoration. The hypothesized effects were listed in Table 3.2.

\begin{tabular}{lll}
\hline Hypothesized Effect & Evidence & Evaluation \\
\hline $\begin{array}{l}\text { Water temperature at the } \\
\text { restoration site will trend } \\
\text { toward reference site } \\
\text { conditions. }\end{array}$ & $\begin{array}{l}\text { Data about the ecological } \\
\text { relationship between water } \\
\text { temperature and fish abuyndance } \\
\text { (Roegner et al. [In Review]). } \\
\text { Literarure review. }\end{array}$ & $\begin{array}{l}\text { Yes, water temperature changes should be expected, but } \\
\text { they will be a function of the temperatures in the adjacent } \\
\text { waterbodies. Predictions of the quantitative changes in } \\
\text { water temperature must consider adjacent waterbodies. }\end{array}$ \\
$\begin{array}{l}\text { Fish presence at the } \\
\text { restoration site will trend } \\
\begin{array}{l}\text { toward reference site } \\
\text { conditions. }\end{array}\end{array}$ & $\begin{array}{l}\text { Review]); natural breach seine data } \\
\text { Revine data (Roegner et al. [n }\end{array}$ & $\begin{array}{l}\text { Yes, tidal reconnection can increase habitat capacity if } \\
\text { fish are available to the area. }\end{array}$ \\
\hline
\end{tabular}

Element 5. Consider whether the monitoring design could be improved by factoring natural influences on monitoring variables into the design and removing these as potential explanations (alternative hypotheses).

Based on our literature review at the outset of the study, an established monitoring design (element 5) for evaluation of the cumulative effects of ecosystem restoration did not exist. Therefore, we considered variations of two basic sampling designs, the Before-After-Control-Impact (BACI; Green 1979) and the Accident Recovery (hereafter Recovery; Skalski et al. 2001) for restoration monitoring in the LCRE. BACI incorporates before and after sampling at control and restoration ("impact") sites, while the Recovery method incorporates after-only sampling at reference and restoration sites. We settled on the BARR (see Section 3.2).

One measure of restoration "success" is for values of post-restoration monitored indicators to converge with those of the reference site (Kentula et al. 1992; Simenstad and Thom 1996; Raposa 2002). The Recovery model tests the "parallelism hypothesis" (Skalski et al. 2001): how a treatment site recovers in comparison to a relatively undisturbed reference site, as opposed to comparison to "before" conditions at a control (Hood 2002; Miller and Simenstad 1997; Skalski et al. 2001; Steyer et al. 2003; Thom et al. 2002). While the Recovery model does not require multiple data collection times before implementation of restoration actions, data collected prior to restoring a site are highly desirable for documenting the initial response of the system to the restoration process as well as for assessing interannual or seasonal variability in the reference and restoration sites (Skalski et al. 2001). The rationale for the design we used for restoration monitoring in the LCRE was developed in Section 3.0. 
Element 6. Use the evidence to draw inferences about the cumulative effects of habitat restoration.

To make inferences about the cumulative effects of restoration (element 6), a principle from the weight-of-evidence approach articulated by Dorward-King et al. (2001) was followed: initiate analysis of effects with the simplest of models, assuming zero interaction, additive accumulations, and only necessary and sufficient causes. Upon this foundation, statistical tests will be applied to experimentally sequenced projects with the potential to detect nonlinear effects from time and space crowding or increased project size. Our semi-quantitative approach to developing evidence regarding cumulative ecosystem response to multiple restoration projects includes 1) the development of predictive ecological relationships through sampling at project and reference sites to increase the validity of spatial and temporal extrapolations from the preponderance of evidence; 2) the detection of synergies at scales larger than the project through statistical tests and hydrodynamic modeling of paired, clustered, and sequenced sites; and 3) an additive model of publicly available spatial data. Preliminary results from these analyses were presented in Section 4.0. It is too early to make inferences.

\subsection{Conclusions}

The preliminary synthesis and evaluation for the purpose of cumulative effects revealed that it is too early in the data collection process to produce meaningful information. The material provides an indication of the content for future synthesis and evaluation efforts. 



\subsection{Discussion}

In this section we discuss the management implications of the Cumulative Effects Study, its role in informing decision-making in the adaptive management of the LCRE Restoration Program, lessons learned to date for restoration planners and designers, recommendations for cumulative effects research in 2009-2010, and considerations for implementation of the cumulative effects methodology after the study ends in the 2010-2011 project year.

\subsection{Management Implications}

Cumulative effects methodology will be useful to guide the design and monitoring of individual LCRE habitat restoration projects, fulfill actions pertaining to the LCRE in WRDAs, implement offsite mitigation measures called for in the FCRPS BiOp, and, most importantly, evaluate the overall LCRE Restoration Program. As mentioned previously, managers generally want to know the following:

- Are protection and restoration resulting in continued loss, no net loss, or net ecosystem improvement in the context of continuing land conversion?

- What suite of projects results in an increase in habitat opportunity and capacity for juvenile salmon?

- What suite of projects produces increased habitat connectivity, maximum flood attenuation, sediment trapping, nutrient processing, return of marsh macrodetritis, and other ecosystem functions?

- What are the survival benefits to juvenile salmonids from LCRE habitat restoration actions?

To address these questions, development and implementation of appropriate indicators and methods are critical. These efforts will enable estuary managers to track the effectiveness of their large investments in estuary habitat restoration projects and to improve conservation and restoration measures over time. Restoration of habitat complexes in the LCRE can have direct and indirect effects on key ecosystem processes and functions, such as organic matter production, biodiversity, and juvenile salmon fitness. The cumulative effects methodologies we are developing are intended to give managers the capability to measure the effects of the LCRE habitat restoration effort on a collective basis.

Similarly, analysis methods for cumulative effects are currently being developed for upper Columbia River tributary watersheds. The objectives of these efforts are analogous to those of the Cumulative Effects Study in the LCRE in that both intend to establish the effects of habitat restoration actions on salmon. However, because of inherent differences in the ecological systems (i.e., tidal vs. nontidal, main stem floodplain versus upland tributaries, aquatic versus terrestrial, marsh and swamp wetlands versus riparian zones), the statistical sampling designs and the sampling methods will necessarily differ.

Nevertheless, by producing comparable scientific results describing the cumulative effects of restoration actions, managers will be able to assess the relative benefits of monies spent among various habitats from freshwater streams to the estuarine wetlands, and better evaluate efforts and progress toward recovery of ESA-listed Columbia River basin salmonids. Furthermore, with the Cumulative Effects Study, the Portland District has begun to demonstrate the implementation of national-level recommendations of the USACE Environmental Advisory Board and the National Research Councillarge-scale systems planning, adaptive management, post-project evaluation, and a collaborative approach - on the LCRE, the estuary of one of the largest rivers in the nation (National Research Council 
1994, 2001, 2003, 2004). The bottom-line is that standardizing effectiveness monitoring data throughout the LCRE and evaluating cumulative effects are essential to analyzing changes resulting from habitat restoration actions.

Enormous potential exists to establish effective habitat restoration strategies, as well as management of the LCRE ecosystem as a whole, using a comprehensive dataset obtained from using the effectiveness monitoring protocols (Roegner et al. 2009). Given standard data, their application in an adaptive management framework with a definitive programmatic infrastructure will be instrumental in 1) coordinating among groups conducting habitat restoration projects; 2) compiling and analyzing data at various spatial and temporal scales; 3) synthesizing data to develop specific management recommendations for the ecosystem restoration program in the LCRE as well as specific existing and planned projects; and 4) promulgating the protocols to encourage continuing standardized data collection. Parties interested in LCRE ecosystem restoration encompass nongovernmental organizations, universities, and state and federal agencies. In short, the analyses produced by this study, and through the associated adaptive management program, may be expected to provide insight into the effects of restoration actions on ecosystem processes that will inform resource managers and regulators in many arenas. If transparent and well-understood mechanisms are in place, managers can apply this information as important lessons learned for future restoration treatments and regulatory guidance.

\subsection{Restoration Lessons}

Based on restoration effectiveness monitoring from 2005 through 2008 in the LCRE, we learned the following lessons for design, monitoring, and adaptive management for the Federal LCRE Habitat Restoration Program.

\section{$\underline{\text { Design }}$}

- Potential sites for restoration are limited, even in an area as large as the LCRE floodplain, because of land-use practices, accessibility, suitability, among other reasons (Johnson and Sutherland 2008).

- Restoration project designs need to be informed by reach-scale data and research on pool-forming factors in forested reference areas subject to similar hydrodynamics, because large wood in forested tidal channels can produce a forced step-pool channel type, regulating pool spacing as well as associated habitat functions, hydrodynamics, and bidirectional material fluxes. Furthermore, pool spacing and large wood can serve as monitoring indicators after restoration actions are accomplished (Diefenderfer and Montgomery 2009).

- Alternative sources of large wood might need to be considered to meet restoration goals, even though some wood can become available to previously diked restoration sites through tree fall and reexposure of previously buried wood due to changing hydrodynamics (Diefenderfer and Montgomery 2008). This is worth considering because ecohydrological processes that provide large wood and produce ecosystem structures in tidal channels could be important in the restoration of hitherto uninvestigated, historically or prehistorically forested tidal environments (Diefenderfer and Montgomery 2008). 
- Designing for the desired outcome of an emergent marsh may be warranted because emergent marsh systems significantly alter water properties compared to the adjacent stream or river. And, in the long-term (greater than 50 years), forested swamps differ dramatically in the flux of materials compared to emergent marshes.

- The new automated tide gates can significantly alter tidal flows into a diked wetland, as well as affect water properties behind a dike.

- Opening a system does not necessarily mean fish will access the site (Roegner et al. [In Review]). For sites designed to directly benefit juvenile salmon, practitioners need to consider whether there are juvenile salmon in reasonably close proximity to the area.

- Design should be informed by preconstruction topography and/or bathymetry because historical channels can reform following hydrological re-connection.

\section{Monitoring}

- It is critically important to apply the effectiveness monitoring protocols (Roegner et al. 2009) when and wherever possible because this will allow valid analysis across multiple restoration sites and times. Applying the protocols, however, may require onsite adjustments in many cases to adapt to the conditions of the site.

- Access to sites for pre- and post-monitoring can be very difficult. Water-level variations affect the ability to sample sites at times.

- Hydrology is critically important to monitor, as is vegetation, because these parameters are a primary ecosystem controlling factor and structure, respectively.

- Changes happen rapidly within the first few years following tidal reconnection; therefore, sampling should be designed accordingly.

- Subsidence seems to be common in the diked former wetlands in the LCRE. This means more than one sediment accretion station per site will be necessary.

\section{Adaptive Management}

- Annual meetings of restoration designers and monitoring practitioners, either jointly or separately, are useful to learn and adapt lessons so that restoration and monitoring efforts can be optimized to improve LCRE ecosystem conditions. The Action Agencies should institutionalize these meetings.

\subsection{Decision-Making}

This section describes the recommended framework for making decisions critical to the success of ecosystem restoration in the LCRE. Decision-making is integral to adaptively managing a restoration program toward its overall goal, and below we present how decision-making could be carried out in the adaptive management program described earlier (Section 2).

This general framework for decision-making summarizes the integrated processes, products, and people potentially involved in LCRE ecosystem restoration. Our goal is to clearly describe the basic steps in the process, and how, by whom, and when decisions will be made. Thus, the framework will 
serve as a road map for decision-making that is intended to produce the best results with the least uncertainty and cost.

\subsubsection{Components of Adaptive Management}

The framework uses the standard adaptive management flow as illustrated in Figure 2.1. Three major components form the essence of the process: goals, models, and a decision framework. The three components are described below.

1. Goals - A goal is the explicit purpose of a project. It is imperative that the goal be clearly stated, defined at the correct scale (see scale discussion below), and measureable.

2. Models - Both conceptual and numerical models play an integrative role in compiling and synthesizing data, and predicting outcomes of suites of actions at the various scales to meet a goal.

They also play an integral role in prioritizing actions, relative to the goal, over all scales. The models are continually refined as new monitoring data and understanding become available. At times, experimental efforts are required to answer some critical questions. Again, the models must be developed for the appropriate scales of analysis and application of actions. Model output is used in the consequence table described below.

3. Decision framework - The decision framework is the suite of "tools" used for making critical decisions about future actions. It is here that the performance of actions as assessed through monitoring is compared against the goal. The tools include the following:

a. Decision criteria - The criteria for making a decision must be specified. Criteria usually include 1) meeting the goal in the shortest amount of time, 2) at the lowest cost, and 3) with minimal disruption.

b. Consequence table - These criteria are evaluated in what is termed a consequence table. The consequence table is a simple tool that provides quantitative values or qualitative ranks of the range of possible project actions within each criterion. Thus, the consequences, tradeoffs, and costs among various possible actions are directly comparable. The consequence table uses model output.

c. System development matrix - Decisions are needed if actions are not producing predicted results. Basic alternative decisions include do nothing, do something, or change the goal. A tool useful for summarizing and assessing the progress of the actions toward the goal is a system development matrix. The system development matrix uses information about the following:

i. Performance metrics - parameters used to indicate effects of actions (e.g., vegetation assemblage similarity)

ii. Performance criteria - threshold values for the performance metrics indicating the goal is achieved (e.g., vegetation assemblage 70\% similar to reference condition)

iii. Triggers - threshold values that indicate a decision needs to be made (e.g., vegetation assemblage only $30 \%$ similar to reference condition after year three following restoration) to improve performance toward the goal. 


\subsubsection{Scales of Analysis, Decisions, and Application}

There are five scales at which decisions are potentially made. The role and composition of decisionmakers, frequency and specificity of decisions, and the role of social and economic drivers varies by scale. The scales are briefly described as follows:

1. Individual structure/actions (Structure scale). These are actions where an engineer and construction contractor may decide the optimal design for creating shallow-water habitat that is specific to the conditions at a specific site. As guidance, they need biological information regarding the size, shape, depth, etc. of habitat that would produce the optimal benefit to the target resource species.

2. Cumulative actions within a reach (Reach scale). This is a set of actions within the riverscape of a reach that, taken together, produce the most beneficial conditions for target resource recovery. Again, engineers need biological information that guides the structural design, such as the number, type, size, and distribution of structures that are optimal for the species. Engineers also need physical and hydrodynamic data and models to best design the actions in that particular reach.

3. Cumulative actions in multiples reaches within an estuarine hydrological unit (HU scale). Like cumulative actions in a reach, this biological information identifies and prioritizes the reaches within the three HUs that compose the estuary where actions would provide the most cumulative benefit to the target species.

4. Cumulative actions in the entire estuary (Estuary scale). Finally, biological information is needed to identify and prioritize the HUs where actions would provide the most cumulative benefit to the target species. This scale is the most appropriate for incorporating flow manipulations because of the influence of flow on the entire river. Flow manipulation involves potential impingement on land as well as authorized uses of the river for such things as navigation. Also, this scale may be the most appropriate for actually assessing the cumulative effects of multiple actions on species recovery over the entire estuary.

5. Program direction (Program scale). This is a very high-level scale that addresses whether the overall program is being effective in all performance aspects including social and economic.

Obviously there are many uncertainties associated with optimizing the design, location, distribution, size, arrangement, etc. of structures and actions relative to the scale of analysis. Monitoring, targeted research, and experimental studies and modeling provide the mechanisms by which engineering and biological information is developed and refined. The engineering design is based on hydrodynamic studies, modeling, and experience with the performance of various actions under various physical conditions. The biological guidance comes from studies of populations, their preferred habitats, the mechanisms and life-history stage support provided by the habitats, and empirical data about the performance of actions to produce responses by the species. Coupling the physical performance of the engineering actions (e.g., the formation and maintenance of habitats) with the biological outcomes (e.g., the increase in survival of juvenile pallid sturgeon, net increase in piping plover population size) provides the empirical evidence that verifies actions are having the desired effect relative to the program goal. 


\subsubsection{Products}

Several products are required to make timely progress toward the goals for the restoration of the LCRE. The aim is to minimize the effort in compiling and publishing reports while maximizing the efficient transfer of the most relevant information. To accomplish this aim, decision-makers must specify the type (e.g., general qualitative summaries, model output, number of projects completed), specificity (e.g., spatial and temporal scales), area (e.g., area of habitat) of information that is critical to their decisions and when this information is required. At the present time, decision-making teams have not been developed for the LCRE, other than those internal to the CENWP that routinely plan, implement and manage projects. Development of these teams is critical at some point. The Summary Section below and Table 6.1 provide a first assessment of the teams, and products and schedules required for each decisionmaking team.

\subsubsection{People}

To accomplish the goals of the LCRE Restoration Program, decisions must be made at various times and various levels. The "suite of teams" is responsible for the design and implementation of actions, investigating key uncertainties, summarizing progress, making recommendations for next steps, and making decisions. These teams include managers, stakeholders, scientists, and engineers. The recommended teams are as follows:

- Product Delivery Team (PDT) - This group of engineers, project managers, and scientists develops the final design for specific projects in specific sites and implements the projects.

- Project Assessment Team (PAT) - This team is responsible for monitoring the performance of the projects relative to the performance metrics, criteria, and targets. This team implements protocols for monitoring, accumulates and manages data, and produces reports to be used by other teams.

- Cumulative Effects Assessment Team (CET) - This team is responsible for assessing monitoring data, refining models, and producing science-based recommendations for restoration actions at all scales.

- Estuarine-Wide Restoration Team (ERT) - This team coordinates monitoring and research activities associated with the LCRE Restoration Program and provides technical assessments of restoration activities. It is home to science, research, monitoring, data management, analysis, and synthesis. It is also responsible for effective coordination and communication among all teams.

- Stakeholders Team (SHT) - This team might include representatives from federal agencies, states, Water Management Agencies, Fish and Wildlife Agencies, Native American Tribes, and nongovernmental stakeholders. It is tasked with providing guidance to the program with regard to LCRE restoration, including changes to the implementation strategy from the use of adaptive management and "the coordination of the development of consistent policies, strategies, plans, programs, projects, activities and priorities" for the program. This team could also include an independent science review team.

To design the program and projects, and to effectively adjust and refine actions to better meet the program goals, it is critical that these teams know their roles and responsibilities and interact and communicate clearly, accurately, and in a timely manner. Because the ERT has the responsibility of fostering communication, it should designate an Information Transfer Specialist who assures that 
information is communicated effectively among the various teams. This specialist should rely on selected members of each team to, as appropriate, be involved in the communication process.

\subsubsection{Summary}

The decision types, decision-makers, products required, and schedules are interdependent (Table 6.1). This is only a preliminary attempt to identify the role of each team in the process and the types and timing of information required. Critical products are developed to be as relevant as possible for each scale. For example, action effectiveness at scale I might include a two-page summary of monitoring results for tidal wetlands developed following levee breaches within a reach. In contrast, action effectiveness at scale $\mathrm{V}$ might include a two-page summary of the amount of tidal wetlands created over the entire river each year and cumulatively over the program with a comparison to program goals. The consequence table is the result of analysis of monitoring and research data as well predictions based on refined models. Each product should highlight any new information and learning that has taken place as a result of the actions, as well as uncertainties that have developed that need further study because they will impact decisions.

Table 6.1. Summary of Decision Types, Decision Schedules, and Information Needs Arranged by the Scale of Actions. This is a first assessment of products and schedules required by each decision-making team, and requires refinement by each team. See the sections on Products and Summary of Decisions for more information.

\begin{tabular}{|c|c|c|c|c|}
\hline Scale & Decision Types & $\begin{array}{l}\text { Decision } \\
\text { Period }\end{array}$ & $\begin{array}{l}\text { Critical Products (developed at } \\
\text { appropriate scale) }\end{array}$ & $\begin{array}{l}\text { Decision } \\
\text { Team(s) }\end{array}$ \\
\hline I. Structure & Specific actions at sites & Summer & $\begin{array}{l}\text {-Action effectiveness summary } \\
\text {-Consequence table }\end{array}$ & $\begin{array}{l}\text { PDT } \\
\text { PAT }\end{array}$ \\
\hline II. Reach & $\begin{array}{l}\text { Action types and locations and types } \\
\text { within reaches }\end{array}$ & Summer & $\begin{array}{l}\text {-Action effectiveness summary } \\
\text {-Consequence table }\end{array}$ & $\begin{array}{l}\text { PDT } \\
\text { PAT } \\
\text { CET }\end{array}$ \\
\hline III. HU & $\begin{array}{l}\text { Action types and locations and types } \\
\text { within HUs }\end{array}$ & Summer & $\begin{array}{l}\text {-Action effectiveness summary } \\
\text {-Consequence table }\end{array}$ & $\begin{array}{l}\text { PDT } \\
\text { PAT } \\
\text { CET }\end{array}$ \\
\hline IV. Estuary & $\begin{array}{l}\text { Priorities for actions in the entire } \\
\text { LCRE including structures and flow } \\
\text { regulation }\end{array}$ & Winter & $\begin{array}{l}\text {-System development matrix } \\
\text {-Action effectiveness summary } \\
\text {-Consequence table }\end{array}$ & $\begin{array}{l}\text { CET } \\
\text { ERT }\end{array}$ \\
\hline V. Program & $\begin{array}{l}\text { Direction toward program goals and } \\
\text { stakeholder needs }\end{array}$ & Winter & $\begin{array}{l}\text {-System development matrix } \\
\text {-Action effectiveness summary } \\
\text {-Consequence table }\end{array}$ & $\begin{array}{l}\text { ERT } \\
\text { SHT }\end{array}$ \\
\hline
\end{tabular}

\section{$6.4 \quad 2009-2010$ Research}

To continue development of the levels-of-evidence approach of the Cumulative Effects Study, we recommend the following study objectives for 2009-2010:

1. Issue final monitoring protocols for habitat restoration evaluations, including examples of data analysis and presentation.

2. Collect and analyze existing field data to support the 2008 cumulative effects pilot-scale study and the final estuary-wide cumulative effects analysis by continuing existing time series and assessing larger spatial and temporal scales. 
3. Implement the levels-of-evidence cumulative effects analysis methodology at a pilot scale in the tidal Grays River area, including GIS assessments, hydrodynamic modeling, and meta-analyses; and develop management recommendations for estuary-wide assessment based on the results.

4. Support implementation of the adaptive management framework presented in Section 2.0 to support decisions by the CENWP and others regarding LCRE habitat restoration activities.

The duration of the Cumulative Effects Study is 7 years with completion in the 2010-2011 project year. The underlying purpose of all project activities is to leave the Portland District and the region with a valid scientific approach, an infrastructure for adaptive management, and initial datasets with guidance for future data collection and analysis to evaluate the cumulative effects of habitat restoration in the LCRE. Emphasis in the later years will be on analysis, although a major field effort is planned for 2009 - the 4-year anniversary of the restoration actions at Vera Slough and Kandoll Farm. Research in 2010 will include minimal or no field work (only if gaps are identified in the preliminary meta-analysis) in order to concentrate on synthesis and close-out.

\subsection{Final Project Deliverables}

When the Cumulative Effects Study concludes in the 2010-2011 project year, our deliverables to the CENWP will include the monitoring protocols (Roegner et al. 2009) and peer-reviewed papers that address uncertainties fundamental to successful restoration project design and evaluation, such as 1) fish use of restored habitats in the LCRE (Roegner et al. [In Review]), 2) tidal channel morphology in the LCRE (Diefenderfer et al. 2009), and 3) hydraulic geometry and microtopography in the LCRE (Diefenderfer et al. [In Press]). In addition, the following three main deliverables will be provided:

- a peer-reviewed, scientific method to evaluate the cumulative effects of multiple habitat restoration projects in the LCRE

- an adaptive management framework and specific recommendations for infrastructure to periodically implement a comprehensive LCRE cumulative effects evaluation

- an initial LCRE cumulative effects evaluation based on all available existing data and information.

After any necessary data-sharing agreements are reached, data sources for the cumulative effects evaluation will include monitoring and GIS analysis performed by state and federal agencies and nongovernmental organizations. Conversely, regional entities will be able to use GIS layers developed or improved by the Cumulative Effects Study, and use the cumulative effects approach to synthesize and evaluate their own effectiveness monitoring data to meet reporting needs and to further the mission of ecosystem restoration. The cumulative effects approach should help predict benefits during the prioritization and project-selection stage of the habitat restoration effort. This will be useful to the USACE and others for cost-benefit analyses. The cumulative effects approach will also be applicable to the new regional expert panel on salmon benefits called for by Reasonable and Prudent Alternative 37 of the 2008 FCRPS Biological Opinion. In fact, while direct survival measurements for a restored site are ideal, assessment of ecosystem services and functions can also be used to determine level of benefit. 
The following considerations for implementation of the cumulative effects approach after the project ends in the 2010-2011 project year are organized by elements of the adaptive management framework (Figure 2.1). The considerations are only outlined here; they will be detailed in the closing synthesis report for the Cumulative Effects Study.

\section{Establish Program Goal and Objectives}

The goal of the CREST is to understand, conserve, and restore the estuary ecosystem to improve the performance of listed salmonid populations. Five general objectives address the program goal: 1)

- Understand the primary stressors affecting ecosystem controlling factors, such as ocean conditions and invasive species.

- Conserve and restore factors controlling ecosystem structures and processes, such as hydrodynamics and water quality.

- Increase the quantity and quality of ecosystem structures, i.e., habitats juvenile salmonids use during migration through the estuary.

- Maintain the food web to benefit salmonid performance.

- Improve salmonid performance in terms of life-history diversity, foraging success, growth, and survival.

Progress toward meeting the goals and objectives of the LCRE Restoration Program, and decisionmaking within it, will be addressed by a specially designed research, monitoring, and evaluation effort (see Johnson et al. 2008) being conducted within an adaptive management framework.

An adaptive management framework for the LCRE Restoration Program was designed by Thom et al. (2008) and summarized in Section 2.0 of this report. To succeed, adaptive management requires active and constructive participation and support from the key parties - funding agencies, estuary managers, and restoration implementers, and researchers.

A workshop should be held in the 2010-2011 project year to coordinate, plan, and describe the Federal LCRE Habitat Restoration Program and future implementation of the cumulative effects approach. A matrix of roles and responsibilities will be useful to clarify respective elements of the restoration program. A steering committee could be warranted.

\section{Design and Plan Monitoring and Research}

The final report for the Cumulative Effects Study will include a detailed plan and design for intensive and extensive monitoring to support cumulative effects analysis. The report will list the remaining critical uncertainties and recommend research to resolve them.

We will develop an activity matrix of what, when, and where to monitor during the out-years 20112017. We will include a schedule for monitoring, analysis, reporting, and evaluation of cumulative effects of the LCRE Restoration Program. At this step, if not above, responsible parties should be identified and their participation confirmed. The measured monitored indicators for site-scale structures and processes and the derived response variables for landscape-scale emergent properties should become engrained. 


\section{Coordinate and Implement Monitoring}

An annual meeting of managers, practitioners, and analysts to discuss and coordinate monitoring and research could be scoped and recommended; outcomes of this meeting could include synthesis of research results for the purposes of input to restoration design and the prioritization of restoration projects.

Suggestions for topics for contracting officials to include in monitoring contracts should be considered. This could help ensure consistent implementation of monitoring.

A template to track which parties are doing what monitoring, and where and when they are scheduled to do it would be useful to coordinate and implement monitoring.

\section{Manage and Analyze Data}

The data are the engine for the cumulative effects assessment. In coordination with the Portland District data group, we will recommend database design criteria and data maintenance and management procedures. The data archive, including meta-data, from the Cumulative Effects Study (2005-2009) will be transferred to the Portland District. This transition will require close coordination.

The Cumulative Effects Study will not be complete without an instruction manual detailing the methods and procedures to perform the levels-of-evidence approach for cumulative effects assessment. Much like the protocols manual for restoration project effectiveness monitoring (Roegner et al. 2009), the cumulative effects instruction manual will describe the methods in sufficient detail that an analyst unacquainted with the approach can successfully implement it.

Meta-analysis of intensive and extensive effectiveness monitoring data is an integral step in the levels-of-evidence approach. A formal meta-analysis based on available data will be included in the final report for the Cumulative Effects Study. This will serve as an example for future meta-analyses.

The final Cumulative Effects Study report will contain an estimate to date of the cumulative effects of habitat restoration in the LCRE. Furthermore, we will make projections of future effects based on potential restoration actions.

\section{Disseminate Data and Report Information}

To disseminate data and report information for the LCRE Restoration Program, we recommend periodic meetings, an annual or biennial conference, technical and nontechnical publications, and a wellmaintained, professionally designed website.

This report will include, as appropriate based on the amount of new data, the results of periodic cumulative effects assessments.

\section{Assess Implementation and Compliance}

The SECs could be useful in assessing implementation and compliance.

\section{Synthesize, Evaluate, and Make Program Decisions}

Periodic reports about the LCRE Restoration Program will be outlined and possibly scheduled to coincide with requirements for Comprehensive Reports under the $2008 \mathrm{BiOp}$. The reports should include 
a synthesis of available information, a rigorous evaluation of the information, and recommendations for program improvements, direction, and strategy. The reports should be one of several primary resources for decision-makers.

\subsection{Conclusion}

This study is developing and implementing appropriate indicators and methods to evaluate cumulative effects to enable estuary managers to track the overall effectiveness of investments in estuary restoration projects. Further, it is developing methods to quantify the effects of restoration projects and lay a foundation for future the effectiveness, evaluation, and validation of cumulative restoration activities in the LCRE. 



\subsection{Literature Cited}

Allan, JD. 2004. Landscapes and riverscapes: the influence of land use on stream ecosystems. Annual Review of Ecology Evolution and Systematics 35:257-84.

Beechie, T and S Bolton. 1999. An approach to restoring salmonid habitat-forming processes in Pacific Northwest watersheds. Fisheries 24:6-15.

Borde, AB, RM Thom, and N Evans. 2005. "An interactive conceptual model tool for coastal management." In Proceedings of the 18th Biennial Conference of the Estuarine Research Federation, Estuarine Research Federation, Norfolk, Virginia, and Port Republic, Maryland. October 16-20.

Bottom, DL, CA Simenstad, J Burke, AM Baptista, DA Jay, KK Jones, E Casillas, and MH Schiewe. 2005. Salmon at River's End: the Role of the Estuary in the Decline and Recovery of Columbia River Salmon. National Oceanic and Atmospheric Administration (NOAA) Technical Memorandum. NMFS-NWFSC-68, NOAA National Marine Fisheries Service, Seattle, Washington.

Bottom, DL, KK Jones, and JJ Herring. 1984. Fishes of the Columbia River Estuary. Columbia River Data Development Program, Columbia River Estuary Study Taskforce, Astoria, Oregon.

Bradshaw, AJ. 1987. "The reclamation of derelict land and the ecology of ecosystems." Pp. 53-74 in WR Jordan III, ME Gilpin, and JD Aber (eds), Restoration Ecology: A Synthetic Approach to Ecological Research. Cambridge University Press, Cambridge, England.

Bray, J and J Curtis, 1957. "An ordination of the upland forest community of southern Wisconsin." Ecological Monographs 27:325-349.

Burr, IW. 1976. Statistical Quality Control Methods. Marcel Dekker, New York.

Busch, DE and JC Trexler (eds). 2003. Monitoring Ecosystems- Interdisciplinary Approaches for Evaluating Ecoregional Initiatives. Island Press, Washington, D.C.

Cairns, J. Jr. 1995. Restoration ecology: protecting our National and global life support systems. Chapter 1, pages 1-12, in John Cairns, jr., editor. Rehabilitating Damaged Ecosystems, second ed. Lewis Publishers.

Clements, WH, SN Luoma, J Gerritsen, A Hatch, P Jepson, T Reynoldson, and RM Thom. 2001. "Stressor interactions in ecological systems." Pp. 215-232, in Baird DJ and Burton Jr GA (eds), Ecological Variability: Separating Natural from Anthropogenic Causes of Ecosystem Impairment. SETAC Press, Pensacola, Forida.

Department of the Army. 1995. Water Resources Policies and Authorities: Ecosystem Restoration in the Civil Works Program. Circular No. 1105-2-210, Department of the Army, U.S. Army Corps of Engineers, Washington, D.C. 
Diefenderfer, H.L., G.E. Johnson, J.R. Skalski, R.M. Thom, S.A. Breithaupt and A.M. Coleman. In Review. Synergistic effects of hydrological reconnection on tidal channel and floodplain habitats of juvenile salmon. Columbia River, U.S.A.

Diefenderfer, HL and DR Montgomery. 2009. "Pool spacing, channel morphology, and the restoration of tidal forested wetlands of the Columbia River, U.S.A.” Restoration Ecology 17:158-168.

Diefenderfer, HL, AM Coleman, AB Borde, and IA Sinks. In Press. "Hydraulic geometry and microtopography of tidal freshwater forested wetlands and implications for restoration, Columbia River, U.S.A.” International Journal of Ecohydrology and Hydrobiology.

Diefenderfer, HL, GC Roegner, RM Thom, EM Dawley, AH Whiting, GE Johnson, KL Sobocinski, MG Anderson, and BD Ebberts. 2005. Evaluating Cumulative Ecosystem Response to Restoration Projects in the Columbia River Estuary, Annual Report 2004. PNNL-15102, prepared by Pacific Northwest National Laboratory, Richland, Washington, for the U.S. Army Corps of Engineers, Portland District, Portland, Oregon.

Diefenderfer, HL, RM Thom, AB Borde, GC Roegner, AH Whiting, GE Johnson, EM Dawley, JR Skalski, J Vavrinec, and BD Ebberts. 2006. Evaluating Cumulative Ecosystem Response to Restoration Projects in the Columbia River Estuary, Annual Report 2005. PNNL-15934, prepared by Pacific Northwest National Laboratory, Richland, Washington, for the U.S. Army Corps of Engineers, Portland District, Portland, Oregon.

Diefenderfer, HL, RM Thom, and KD Hofseth. 2005. "A framework for risk analysis for ecological restoration projects in the U.S. Army Corps of Engineers." Pp. 57-105 in RJF Bruins and MT Heberling (eds.) Economics and Ecological Risk Assessment: Applications to Watershed Management. CRC Press, Boca Raton, Florida.

Dorward-King, EJ, GW Suter II, LA Kapustka, DR Mount, DK Reed-Judkins, SM Cormier, SD Dyer, MG Luxon, R Parrish, and GA Burton Jr. 2001. "Distinguishing among factors that influence ecosystems.” Pp. 1-26 in DJ Baird and GA Burton Jr. (eds), Ecological Variability: Separating Natural from Anthropogenic Causes of Ecosystem Impairment. SETAC Press, Pensacola, Florida..

Downes, BJ., LA Barmuta, PG Fairweather, DP Faith, MJ Keough, PS Lake, BD Mapstone, and GP Quinn. 2002. Monitoring Ecological Impacts: Concepts and Practice in Flowing Waters. Cambridge University Press, Cambridge, UK.:

Duncan, AJ. 1974. Quality Control and Industrial Statistics. Fourth edition, Richard D. Irwin, Inc., Homewood, Illinois,

EAB (Chief of Engineers Environmental Advisory Board). 2005. "Restoration Authorities of the U.S. Army Corps of Engineers." A Discussion Paper adopted by the Chief of Engineers Environmental Advisory Board, Washington, D.C.

EAB. 2006a. Integrating Ecosystem Restoration into Programs of the U.S. Army Corps of Engineers. Report of the EAB to the Chief of Engineers, Washington D.C. (September 25, 2006). 
EAB. 2006b. "Environmental Benefits and Performance Measures: Defining National Ecosystem Restoration and How to Measure Its Achievement." A Discussion Paper adopted by the Chief of Engineers Environmental Advisory Board, Washington, D.C. (December 2006).

EPA (U.S. Environmental Protection Agency). 2003. EPA Region 10 Guidance for Pacific Northwest State and Tribal Temperature Water Quality Standards. EPA 910-B-03-002, Region 10 Office of Water, Seattle, Washington.

Evans, NR, R.M. Thom, G.D. Williams, J. Vavrinec, K.L. Sobocinski, L.M. Miller, A.B. Borde, V.I. Cullinan, J.A. Ward, C.W. May, C. Allen. 2006. "Lower Columbia River Restoration Prioritization Framework." Report submitted to the Lower Columbia River Estuary Partnership by Battelle Marine Sciences Laboratory, Sequim, Washington.

Fresh KL, E Casillas, LL Johnson, and DL Bottom. 2004. Role of the Estuary in the Recovery of Columbia River Basin Salmon and Steelhead: An Evaluation of Selected Factors on Population Viability. National Oceanic and Atmospheric Administration (NOAA) Technical Memorandum, Northwest Fisheries Science Center, National Marine Fisheries Service, NOAA, Seattle, Washington (May 2004).

Gergel, SE, Turner MG, Miller JR, Melack JM, and Stanley EH. 2002. "Landscape indicators of human impacts to riverine systems." Aquatic Science 64:118-28.

Glasziou, P, J Vandenbroucke, and I Chalmers. 2004. "Assessing the quality of research.” British Medical Journal 328:39-41.

Gosselink, J.G., G.P. Shaffer, L.C. Lee, D.M. Burdick, D.L. Childers, N.C. Leibowitz, S.C. Hamilton, R. Boumans, D. Cushman, S. Fields, M. Koch and J.M. Visser. 1990. Landscape conservation in a forested wetland watershed: can we manage cumulative impacts? BioScience 40:588-600.

Grant, EL and RS Leavenworth. 1972. Statistical Quality Control. McGraw-Hill, New York.

Green, RH. 1979. Sampling Design and Statistical Methods for Environmental Biologists. Wiley, New York.

Harvey, D. 1969. Explanation in Geography. Edward Arnold, London.

Hemstrom, M, T Spies, C Palmer, R Kiester, J Teply, P McDonald, and R Warbington. 1998. Latesuccessional and old-growth forest effectiveness monitoring plan for the Northwest Forest Plan. USDA Forest Service General Technical Report PNW-GTR-438, Pacific Northwest Research Station, Portland, Oregon. Hood, WG. 2002. "Application of landscape allometry to restoration of tidal channels." Restoration Ecology 10(2):213-222.

Jackson, JBC, MX Kirby, WH Berger, KA Bjorndal, LW Botsford, BJ Bourque, RH Bradbury, R Cooke, J Erlandson, JA Estes, TP Hughes, S Kidwell, CB Lange, HS Lenihan, JM Pandolfi, CH Peterson, RS Steneck, MJ Tegner, and RR Warner. 2001. "Historical overfishing and the recent collapse of coastal ecosystems." Science 293:629-37. 
Johnson GE, and HL Diefenderfer (eds.). 2008. Evaluating Cumulative Ecosystem Response to Restoration Projects in the Columbia River Estuary, Annual Report 2007. PNNL-17437, prepared by Pacific Northwest National Laboratory, Richland, Washington, for the U.S. Army Corps of Engineers, Portland District, Portland, Oregon.

Johnson, GE and GB Sutherland (eds.). 2008. Proceedings of the Columbia River Estuary Conference on Ecosystem Restoration. Compiled by Pacific Northwest National Laboratory, Richland, Washington. Available at http://cerc.labworks.org/.

Johnson, GE, HL Diefenderfer, BD Ebberts, C Tortorici, T Yerxa, J Leary, and J Skalski. 2008. Research Monitoring and Evaluation for the Federal Columbia River Estuary Program. PNNL-17300, final report by the Pacific Northwest National Laboratory, Richland, Washington, for the Bonneville Power Administration, Portland, Oregon.

Johnson GE, RM Thom, AH Whiting, GB Sutherland, T Berquam, BD Ebberts, NM Ricci, JA Southard, and JD Wilcox. 2003. An Ecosystem-Based Approach to Habitat Restoration Projects with Emphasis on Salmonids in the Columbia River Estuary. PNNL-14412, prepared by Pacific Northwest National Laboratory, Richland, Washington, for the Bonneville Power Administration, Portland, Oregon.

Johnson, GE (ed.). 2007. Evaluating Cumulative Ecosystem Response to Restoration Projects in the Columbia River Estuary, Annual Report 2006. PNNL-16561, prepared by Pacific Northwest National Laboratory, Richland, Washington, for the U.S. Army Corps of Engineers, Portland District, Portland, Oregon.

Junk, W. 2008. "Role of flood pulses in shaping river systems." Presentation at the Conference, Ecohydrological Processes and Sustainable Floodplain Management, Lodz, Poland (May 19-23).

Junk, WJ and MTF Piedade. 2005. "The Amazon River basin.” Pp. 63-117 in LH Fraser, PA Keddy (eds), The World's Largest Wetlands: Ecology and Conservation. Cambridge University Press Cambridge, UK.

Kareiva, P, M Marvie, and M McClure. 2000. "Recovery and management options for spring/summer Chinook salmon in the Columbia River basin." Science 290:977-79.

Kentula, ME, RP Brooks, SE Gwin, CC Holland, AD Sherman, and JC Sifneos. 1992. "An approach to improving decision making in wetland restoration and creation.” EPA/600/R-92/150, U.S. Environmental Protection Agency Environmental Research Laboratory, Corvallis, Oregon..

Kremer, JN, WM Kemp, AE Giblin, I Valiela, SP Seitzinger, and EE Hofmann. 2000. "Linking biogeochemical processes to higher trophic levels.” Pp. 299-341 in JE Hobbie (ed), Estuarine Science: A Synthetic Approach to Research and Practice. Island Press, Washington, D.C.

Lee, KN and J Lawrence. 1986. "Adaptive management: learning from the Columbia River Basin Fish and Wildlife Program.” Environmental Law 16:431-460. 
Leibowitz, SG, B Abbruzzese, PR Adamus, LE Hughes, and JT Irish. 1992. A Synoptic Approach to Cumulative Impact Assessment: A Proposed Methodology. EPA/600/R-92/167, U.S. Environmental Protection Agency, Environmental Research Laboratory, Corvallis, Oregon.

Marine, K.R. and J.J. Cech, Jr. 2004. Effects of high water temperature on growth, smoltification, and predator avoidance in juvenile Sacramento River Chinook salmon. North American Journal of Fisheries Management 24: 198-210.

McCullough, D.A. 1999. A review and synthesis of the effects of alterations to the water temperature regime on freshwater life stages of salmonids, with special reference to Chinook salmon. EPA report EPA 910-R-99-010.

Miller, B.A. and Sadro, S. 2003. Residence time and seasonal movements of juvenile coho salmon in the ecotone and lower estuary of Winchester Creek, South Slough, Oregon. Transactions of the American Fisheries Society 132: 546-559.

Miller, JA and CA Simenstad. 1997. "A comparative assessment of a natural and created estuarine slough as rearing habitat for juvenile Chinook and Coho salmon.” Estuaries 20(4):792-806.

Naeem, S. 2006. "Biodiversity and ecosystem functioning in restored ecosystems: extracting principles for a synthetic perspective.” Pp. 210-237 in DA Falk, MA Palmer, and JB Zedler (eds), Foundations of Restoration Ecology. Island Press, Washington, D.C.

Naiman, RJ, H Décamps, and ME McClain. 2005. Riparia: Ecology, Conservation, and Management of Streamside Communities. Elsevier Academic Press, Amsterdam, The Netherlands..

Naiman, RJ, TJ Beechie, LE Benda, DR Berg, PA Bisson, LH MacDonald, MD O’Connor, PL Olson, and EA Steel. 1992. "Fundamental elements of ecologically healthy watersheds in the Pacific Northwest coastal ecoregion.” Pp. 127-188 in RJ Naiman (ed), Watershed Management: Balancing Sustainability and Environmental Change. Springer-Verlag, New York.

Neckles, HA, M Dionne, DM Burdick, CT Roman, R Buchsbaum, and E Hutchins. 2002. "A monitoring protocol to assess tidal restoration of salt marshes on local and regional scales." Restoration Ecology 10:556-63.

National Oceanic and Atmospheric Administration (NOAA) Fisheries. 2008. Biological OpinionConsultation on Remand for Operation of the Federal Columbia River Power System, 11 Bureau of Reclamation Projects in the Columbia Basin and ESA Section 10(a)(1)(A) Permit for Juvenile Fish Transportation Program. National Marine Fisheries Service (NOAA Fisheries) - Northwest Region. Seattle, Washington.

NRC (National Research Council). 2003. Adaptive Monitoring and Assessment for the Comprehensive Everglades Restoration Plan. National Academies Press, Washington, D.C.

NRC (National Research Council). 2004. Adaptive Management for Water Resources Project Planning. National Academies Press, Washington, D.C. 
Palmer, MA, DA Falk, and JB Zedler. 2006. "Ecological theory and restoration ecology." Pp. 1-10 in Falk, DA, MA Palmer, and JB Zedler (eds.) Foundations of Restoration Ecology. Island Press, Washington D.C.

Popper, K R. 1962. Conjectures and Refutations. Basic Books, New York.

Raposa, K. 2002. Early responses of fishes and crustaceans to restoration of a tidally restricted New England salt marsh. Restoration Ecology 10: 665-676.

Reeves, GH, DB Hohler, DP Larsen, DE Busch, K Kratz, K Reynolds, KF Stein, T Atzet, P Hays, and M Tehan. 2004. Effectiveness Monitoring for the Aquatic and Riparian Component of the Northwest Forest Plan: Conceptual Framework and Options. Technical Report PNW-GTR -577, USDA Forest Service, General Pacific Northwest Research Station, Portland, Oregon. Reeves, GH, LE Benda, KM Burnett, PA Bisson, and JR Sedell. 1995. "A disturbance-based ecosystem approach to maintaining and restoring freshwater habitats of evolutionarily significant units of anadromous salmonids in the Pacific Northwest.” American Fisheries Society Symposium 17:334-49.

Richter, A. and S.A. Kolmes. 2005. Maximum temperature limits for Chinook, coho, and chum salmon, and steelhead trout in the Pacific Northwest. Reviews in Fisheries Science 13: 23-49.

Roegner, GC, EW Dawley, M Russell, AH Whiting, and DJ Teel. In Review. Juvenile salmon use of newly reconnected tidal freshwater wetland habitats in the Grays River tributary of the lower Columbia River.

Roegner, GC, HL Diefenderfer, AB Borde, RM Thom, EM Dawley, AH Whiting, SA Zimmerman, and GE Johnson. 2009. Protocols for monitoring habitat restoration projects in the lower Columbia River and estuary. Prepared by NOAA Fisheries and Pacific Northwest National Laboratory for the U.S. Army Corps of Engineers, Portland District. NOAA Technical Memorandum NMFS-NWFSC-97. Seattle, Washington.

Romesburg, HC. 1981. "Wildlife science: gaining reliable knowledge.” Journal of Wildlife Management 45:293-313.

Roni, P, TJ Beechie, RE Bilby, FE Leonetti, MM Pollock, and GR Pess. 2002. "A review of stream restoration techniques and a hierarchical strategy for prioritizing restoration in Pacific Northwest Watersheds." North American Journal of Fisheries Management 22:1-20.

Russ, GR, AC Alcala, AP Maypa, HP Calumpong, and AT White. 2004. "Marine reserve benefits local fisheries." Ecological Applications 14(2):597-606.

Simenstad, CA and JR Cordell. 2000. "Ecological assessment criteria for restoring anadromous salmonid habitat in Pacific Northwest estuaries." Ecological Engineering 15:283-302.

Simenstad, CA and RM Thom. 1996. "Functional equivalency trajectories of the restored Gog-Le-Hi-Te estuarine wetland." Ecological Applications 6:38-56.

Skalski, JR and DS Robson. 1992. Techniques for Wildlife Investigations: Design and Analysis of Capture Data. Academic Press, San Diego, California. 
Skalski, JR, DA Coats, and AK Fukuyama. 2001. "Criteria for oil spill recovery: a case study of the intertidal community of Prince William Sound, Alaska, following the Exxon Valdez oil spill." Environmental Management 28(1):9-18.

Skalski, JR. 1995. "Statistical considerations in the design and analysis of environmental damage assessment studies." Journal of Environmental Management 43:67-85.

Small, LF (ed.). 1990. "Columbia River: Estuarine System.” In Progress in Oceanography, Vol. 25, no. 1-4. Cairns J. (Ed.). 1995. Rehabilitating Damaged Ecosystems. 2nd edition, Lewis Publishers, Boca Raton, Florida.

Small, LF, CD McIntire, KB MacDonald, JR Lara-Lara, BE Frey, MC Amspoker, and T Winfield. 1990. "Primary production, plant and detrital biomass, and particle transport in the Columbia River Estuary." Progress in Oceanography 25:175-210.

Small, LF. 1990. “Columbia River: Estuarine system.” Special Issue. Progress in Oceanography $25: 1-4$.

Spies, TA and MG Turner. 1999. "Dynamic forest mosaics." Pp. 95-160 in ML Hunter (ed), Maintaining Biodiversity in Forest Ecosystems. Cambridge University Press, Cambridge, England.

Steyer, GD, CE Sasser, JM Visser, EM Swenson, JA Nyman, and RC Raynie. 2003. "A proposed coastwide reference monitoring system for evaluating wetland restoration trajectories in Louisiana." Environmental Monitoring and Assessment 81:107-117.

Suding, KN and KL Gross. 2006. "The dynamic nature of ecological systems: multiple states and restoration trajectories.” Pp. 190-209 in DA Falk, MA Palmer, and JB Zedler (eds), Foundations of Restoration Ecology. Island Press, Washington, D.C.

Thom, RM. 1997. "System-development matrix for adaptive management of coastal ecosystem restoration projects." Ecological Engineering 8:219-32.

Thom, RM. 2000. "Adaptive management of coastal ecosystem restoration projects." Ecological Engineering 15:365-372.

Thom, RM, and KF Wellman. 1996. Planning aquatic ecosystem restoration monitoring programs. PNNL-11459. IWR Report 96-R-23. U.S. Army Corps of Engineers, Institute for Water Resources, Alexandria, Virginia.

Thom, RM, R Zeigler, and AB Borde. 2002. "Floristic development patterns in a restored Elk River estuarine marsh, Grays Harbor, Washington.” Restoration Ecology 10(3):487-496.

Thom RM, GW Williams, and HL Diefenderfer. 2005. "Balancing the need to develop coastal areas with the desire for an ecologically functioning coastal environment: Is net ecosystem improvement possible?" Restoration Ecology 13:193-203.

Thom, RM, HL Diefendefer, BD Ebberts, GE Johnson, DA Putman, and JR Skalski. 2008. “Adaptive Management." Chapter 3 in Evaluating Cumulative Ecosystem Response to Restoration Projects in 
the Columbia River Estuary, Annual Report 2007. Eds. GE Johnson and HL Diefenderfer, PNNL17437, prepared by Pacific Northwest National Laboratory, Richland, Washington, and the National Marine Fisheries Service, Seattle, Washington for the U.S. Army Corps of Engineers, Portland District, Portland, Oregon (pp. 3.1-3.21).

Thom, RM, E Haas, NR Evans, and GD Williams. In review. "Lower Columbia River and estuary habitat restoration prioritization framework." Ecological Restoration.

Thomas, DW. 1983. Changes in the Columbia River Estuary Habitat Types over the Past Century. Report of the Columbia River Estuary Data Development Program, Columbia River Estuary Study Taskforce, Astoria, Oregon.

United States Army Corps of Engineers, Bonneville Power Administration, and United States Bureau of Reclamation. 2007. Biological Assessment for Effects of Federal Columbia River Power System and Mainstem Effects of Other Tributary Actions on Anadromous Salmonid Species Listed Under the Endangered Species Act. Appendix B, Section B.2.6, Attachment B.2.6-3: Tributary Habitat Research, Monitoring, and Evaluation Action, Portland, Oregon.

Walters, CJ and CS Holling. 1990. "Large-scale management experiments and learning by doing." Ecology 71:2060-2068.

Wheeler, DJ. 1995. Advanced Topics In Statistical Process Control. SPC Press, Knoxville, Tennessee.

Yozzo D, J Titre, and J Sexton (eds.). 1996. Planning and Evaluating Restoration of Aquatic Habitats from an Ecological Perspective. IWR Report 96-EL-4, U.S. Army Corps of Engineers, Waterways Experiment Station, Vicksburg, Mississippi, and Institute for Water Resources, Alexandria, Virginia. 


\section{Appendix A}

\section{Synergistic Modeling Pilot Study - Draft Manuscript}





\section{Appendix A}

\section{Synergistic Modeling Pilot Study - Draft Manuscript}

\section{Hydrological Modeling of Synergistic Processes in Restoration of the Columbia River Estuary}

Heida L. Diefenderfer, Gary E. Johnson, John R. Skalski, Stephen A. Breithaupt, and Andre M. Coleman

The preponderance of nonlinear processes affecting the degradation of coastal and riverine ecosystems remains undetermined, and the significance of such effects for ecological restoration is perhaps understood even less. Rarely are synergistic effects evaluated to quantify net ecosystem improvement from restoration programs. Hydrological processes, in particular, are a determinate factor in floodplain and wetland restoration, influencing plant community types and habitat functions. In the LCRE, for example, juvenile salmonids rear during outmigration so managed hydrological cycles affect fish opportunity to enter tidal wetlands as well as the capacity of these habitats to contribute to fitness. Currently, there is a need to improve the efficacy of suites of projects designed to provide habitat for these endangered anadromous fishes. Meeting this need requires an ability to predict whether management actions will affect hydrological processes in a linear or synergistic manner.

In the study reported here, PNNL and UW examined synergistic relationships in dike-breach restoration scenarios on the tidal portion of the Grays River, a tributary of the Columbia River estuary. We used a hydrodynamic model and a statistical design to test the hypothesis that the cluster size of hydrological reconnection projects has a nonlinear effect on the area of floodplain inundation and available habitat, under both even and uneven spatial configuration scenarios.

\section{A.1 Methods}

An individual ecosystem restoration project was defined as a single breach in the dike abutting the Grays River, located at an existing or previously existing channel, with standardized breach geometry at the channel outlet. The statistical design for the model runs (see 2005 Cumulative Effects Annual Report [Ref]) was intended to assess synergistic effects on total wetted area and available channel edge from a range of project cluster sizes (i.e., number of breaches).

\section{A.1.1 Experimental Design}

The experimental design consisted of restoration clusters of size 1,2,3, and more, replicated and randomized within the landscape, and initiated concurrently to eliminate confounding size with duration or time. The test of cumulative effects would be based on the null hypothesis

$$
\mathrm{H}_{\mathrm{o}}: \beta \leq 0
$$

versus

$$
\mathrm{H}_{\mathrm{a}}: \beta>0,
$$


where, $\beta$ is the slope of the relationship

$$
\bar{y}_{i}=\alpha+\beta n_{i}
$$

and, where

$$
\begin{aligned}
& \bar{y}_{i}=\text { mean response per project within the } i \text { th cluster, } \\
& n_{i}=\text { number of restoration projects in the } i \text { th cluster. }
\end{aligned}
$$

A significant positive slope would be evidence of cumulative effects.

\section{A.1.2 Model}

This study used a modified version of a depth-averaged finite element hydrodynamic model RMA2 (version 7.4g) (King 1998, 2005; Breithaupt and Khangaonkar 2007). This two-dimensional model of the lower Grays River was used to run multiple randomized sets of dike breaches from Highway 4 to near the river mouth at Grays Bay. It was modified by improving nodal network resolution over some areas and by incorporating field-surveyed gradients and water levels. Some local features were extracted such that the model represents a generic river, as described in the following sections. The hydrodynamic behavior of the lower Grays River is controlled by river flows and tidal forcing. Thus, the model was run using the average flow for April and May from 2005 through 2007, a steady flow of $12.29 \mathrm{~m}^{3} / \mathrm{s}$ (434 cfs), from data from the Washington State Department of Ecology for the Grays River (Pers. Comm., H. Christensen, Washington State Department of Ecology, April 21, 2008). The model was run over a spring tide, based on the tidal prediction from Harrington Point (Flater 1996) and water elevation data at Astoria, Oregon (NOAA 2006, station 9439040).

\section{A.1.3 Runs}

Model stability was tested using only a few breaches, after which the model was run in two phases: 1) range-finding across the suite of available channels, and 2) targeted investigation of uncertainties in the output from the range-finding. The three uncertainties were 1) the shape of the curve in nonlinear portions of the curve, 2) the effect of the uneven spacing of the randomly selected runs versus evenly spaced breaches through the dike, and 3) the relative effects of upstream versus downstream breaches. A total of 42 channels were available for breaching, therefore the effects of breaching through the dike were tested for the following scenarios:

Range-finding

- Run 1, 0 channels breached

- Run 2,42 channels breached

- Runs 3-5, 1 channel breached

- Runs 6-8, 25\% of channels (11) breached

- Runs 9-11,50\% of channels (21) breached

- Runs $12-14,75 \%$ of channels (32) breached.

Targeted

(Non-linear areas) 
- Runs 15-17, 4 channels breached

- Runs 18-20, 8 channels breached

- Runs 21-23, 15 channels breached (Even spacing)

- Runs 24-26, 11 channels breached (Upstream-downstream effect)

- Runs 27-29, 11 channels breached.

The channels to breach for runs 24-26 were selected by dividing the study area into reaches such that each reach contained 3-4 channels, and randomly selecting one channel from each reach. Run 27 consisted of breaching the 11 most downstream channels through the dike, run 28 included channels numbered 16-26 near the middle of the study area, and run 29 included channels numbered 32-42 at the upstream end of the study area.

\section{A.1.4 Topographic Surface}

A base topographic surface was derived from last return, or "bare earth" light detection and ranging (LiDAR) data collected January-February 2005 with a 40-kHz airborne laser terrain mapping system (ALTMS) at $1070 \mathrm{~m}$ (LiDAR Bare Earth DEM 2005). The point data for ground surface elevations were processed into a continuous 1-m resolution raster-based dataset using a finite difference and Inverse Distance Weighting (IDW) method (Hutchinson 1989, 1996). Road infrastructure and irrigation ditch features were removed from the model based on the rationale that roads would interfere with testing for the hydrological effect of each dike breach on a "level playing field." Channels in currently undiked areas (only two patches along the lower river) were not included in the simulation because 1) this would have required erecting dikes on the topographical surface where they were not currently located; 2) the land behind real dikes is subsided (Diefenderfer et al. In Press), so effects there would be different than on land behind artificially created dikes unless modifications (lowering) of the topographical surface behind the artificial dikes were also made; and 3) in the two patches in question, no channels were large enough to cross the floodplain and connect to the surrounding hills so their effects were likely to be small.

\section{A.1.5 Channels}

The statistical population of 42 potential dike breaches was developed by assessing the following required features from the LiDAR using ArcGIS (Figure A.1):

- The channel crosses a dike along the bank of the Grays River (road-channel crossings not included, because roads were not present in the simulated topography).

- The channel may be active (i.e., there is a culvert or tide gate), "fossilized" (i.e., it's blocked but still visible on LiDAR), but for the simulations, it was assumed the channel is inactive, i.e., no water was allowed to pass through the dike unless the channel was among those selected to be opened for the run. 


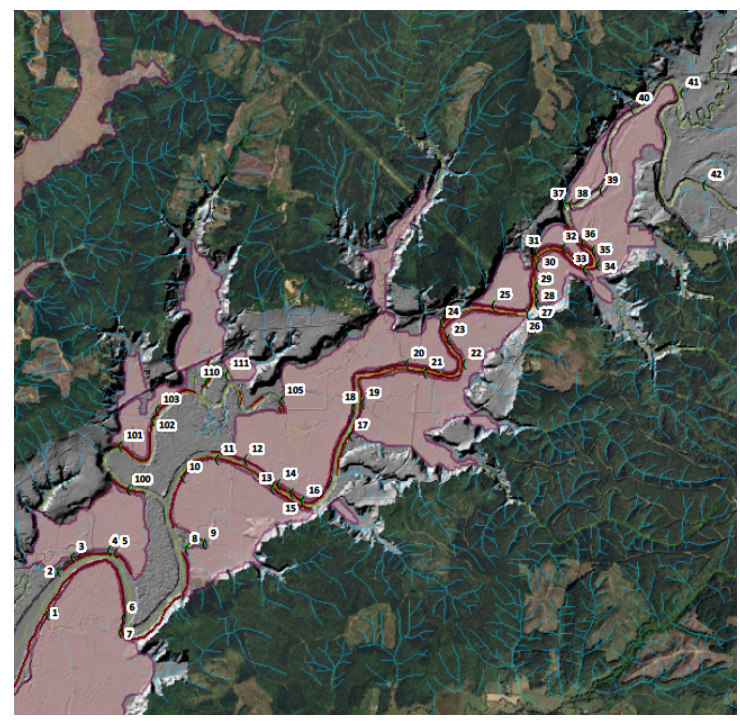

Figure A.1. Channels Identified for Potential Inclusion in the Dike Breach Modeling

- Irrigation ditches were only included in the population of potential dike breaches if they were connected to a stream channel shown in the National Hydrography Dataset (i.e., if a natural channel had been straightened it was included).

- A major side channel, Seal Slough, was not included because the population of potential dike breaches needed to be consistent and the band of floodplain along Seal Slough was narrower and a large channel on Seal Slough would be likely to produce the same effect as a small channel along the Grays River.

A random number generator from EXCEL ${ }^{\mathrm{TM}}$ was used to select the channel identification numbers between one and 42 for each run.

\section{A.1.6 Breaches}

A standard cross-sectional breach geometry was used regardless of differences between channels, on the basis that sufficient time on flood tides occurred during the 2-week simulation to reach in effect an "equilibrium" maximum wetted area, such that the ultimate output variable (wetted area) would be unaffected by breach geometry at the mouth. (If a point is wetted at any time during the simulated period it is counted as wetted.) Breach openings were $27 \mathrm{~m}$ at the top of the dike, with an average of three existing breaches on the river 2 years following breaching such that they have adjusted somewhat to convey existing flows (range $25 \mathrm{~m}-29 \mathrm{~m}$ ). Elevations of the breaches were set to $1 \mathrm{~m}$ below the water surface at low tide, also based on these existing breaches (average $1.063 \mathrm{~m}$ NAVD88, range $.892 \mathrm{~m}$ NAVD88 - 1.23 m NAVD88). Breaches were standardized for comparability between channels for this experiment; in reality, they have different total lengths and drainage areas and will therefore need to convey different amounts of flow and would be expected to develop different cross-sectional areas after breaching. 


\section{A.1.7 Interpolation and Calculation}

The average floodplain wetted area produced by simulated dike breaches was calculated from RMA2 model export files in $\mathrm{x}, \mathrm{y}, \mathrm{z}$ coordinate space, which included maximum water depth during the simulation (see Figure A.2). Using ArcGIS, the model nodes for each of the 29 simulations were assembled into a Triangulated Irregular Network (TIN) using maximum depth for the z-axis. The resulting TINs were converted to a regularly spaced $5 \times 5-\mathrm{ft}$ raster grid and a general conditional filter was applied where nodes with 0.1-m maximum depth and less were screened out of the wetted area calculation based on the possibility that juvenile salmonids could not make use of these shallow floodplain areas. The resulting data yielded a binary dataset indicating a simple presence and/or absence of water during the simulation. The total wetted area was calculated using remaining "presence" flagged data and output to data tables for analysis. Additionally, there are wetted areas in the floodplain that do not drain through the simulation period. These conditions occur in depressions on the landscape and result from the warmup of the model to generate the initial conditions and as such do not become flooded during high tide. The model artifacts were flagged in the geographical information system (GIS) and their areas discounted in the area calculations.

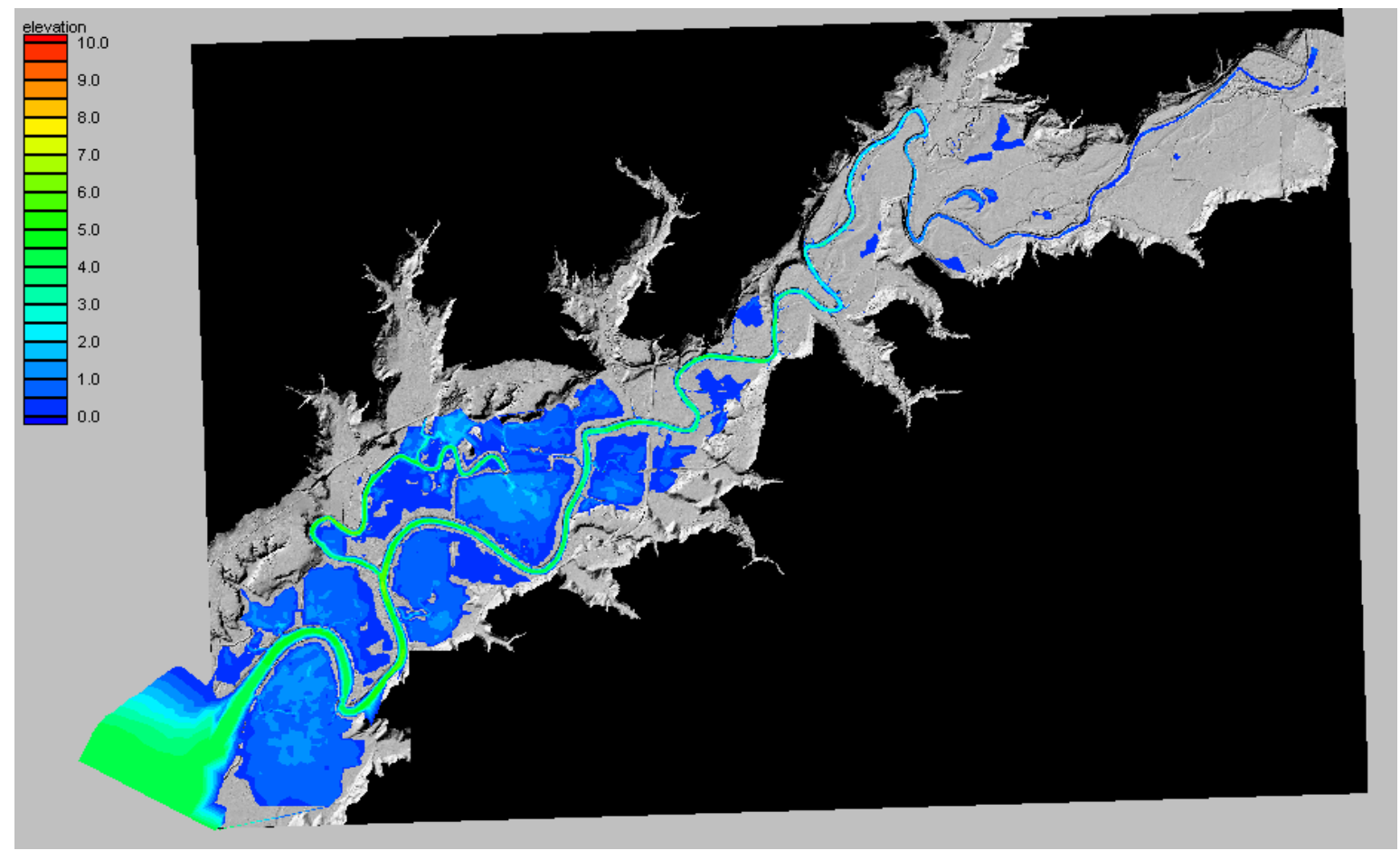

Figure A.2. Modeled Water Depth Used to Calculate Total Wetted Area for 29 Simulations in the Lower Grays River

Following the determination of the total wetted area produced by each model run using interpolation in ArcGIS, an average total wetted area was calculated for each set of three runs corresponding to a given number of dike breaches $(1,4,8,11,15,21$, and 31). The incremental contribution of each breach was then ascertained by 1) subtracting the base wetted area identified from the run with no breaches, and 2) dividing the remaining total wetted area by the number of breaches in that run. 


\section{A.2 Results}

The average wetted area produced by sets of three simulations of various numbers of dike breaches is shown in Figure A.3. With no dike breaching, 355 ha of floodplain were wetted, and this number was subtracted from the results to show only the effects of the simulated breaches. The lack of effectiveness of dike breaches upriver relative to those close to the mouth of the river on Grays Bay as measured by resultant floodplain wetted area is demonstrated in Figure A.4, and as measured by change in floodplain wetted area per breach in Figure A.5.

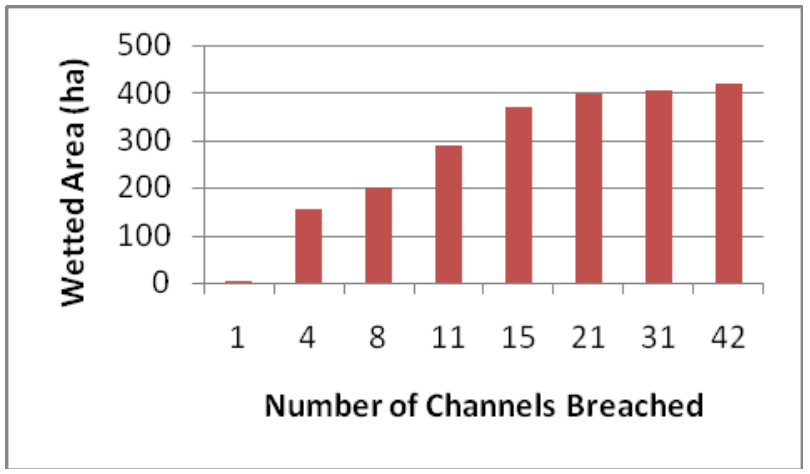

Figure A.3. Average Floodplain Wetted Area Produced by Simulated Dike Breaches. The floodplain area that is wetted without any dike breaching has been subtracted from these averages.
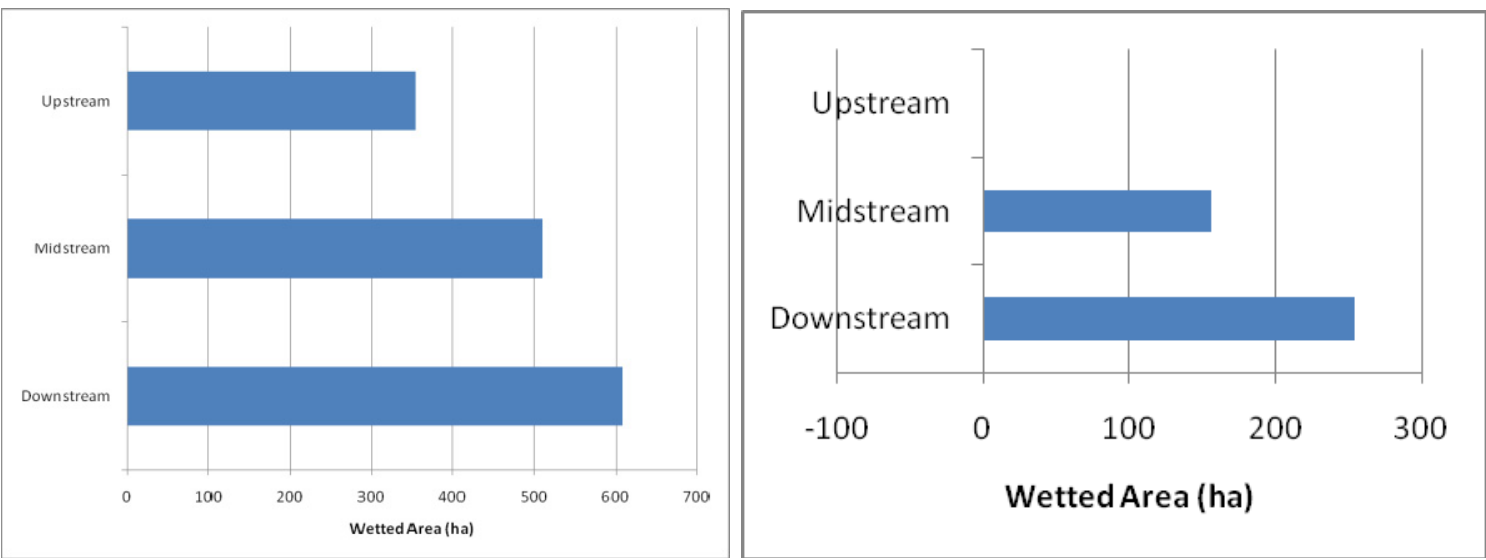

Figure A.4. Effectiveness of Dike Breaches as Measured by Resultant Floodplain Wetted Area. (a) The average floodplain wetted area produced by sets of eleven breaches located on the lower, middle, and upper sections of the study area; and (b) the same results with the floodplain area that is wetted without any dike breaching subtracted. 


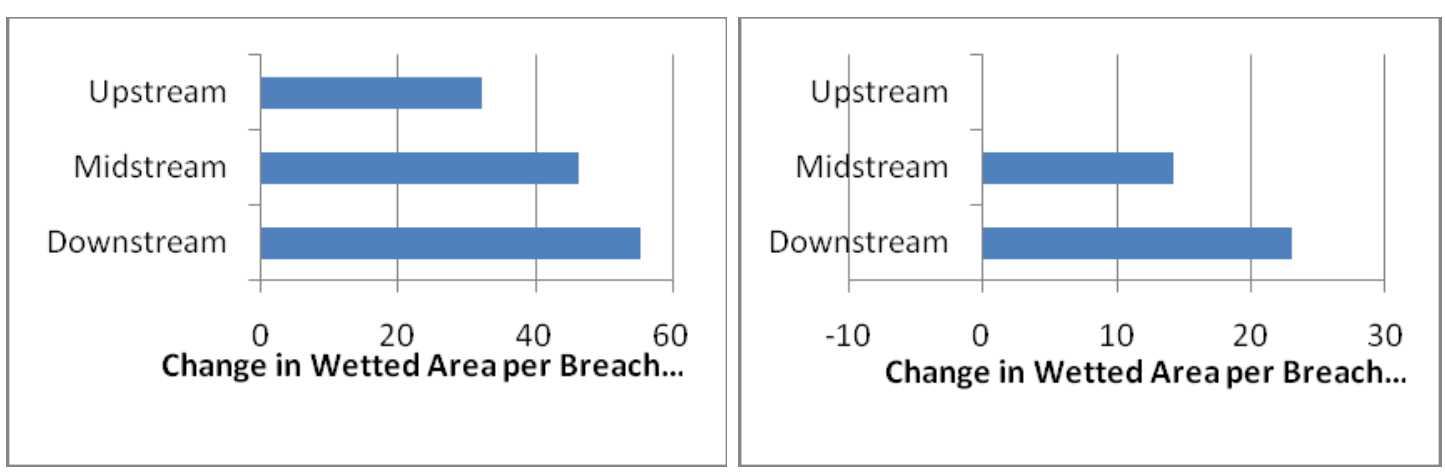

Figure A.5. Effectiveness of Dike Breaches as Measured by the Change in Floodplain Wetted Area. (a) The average change in wetted area produced per breach for upper, middle, and lower segments of the river in the study area; and (b) the same results after subtraction of the floodplain area that is wetted without any dike breaching.

Results of the test of evenly spaced dike breaching along the river corridor are shown in Figure A.6 as the change in wetted area per breach after subtraction of the floodplain area that is wetted without any dike breaching, the same unit shown in Figure A.5b.

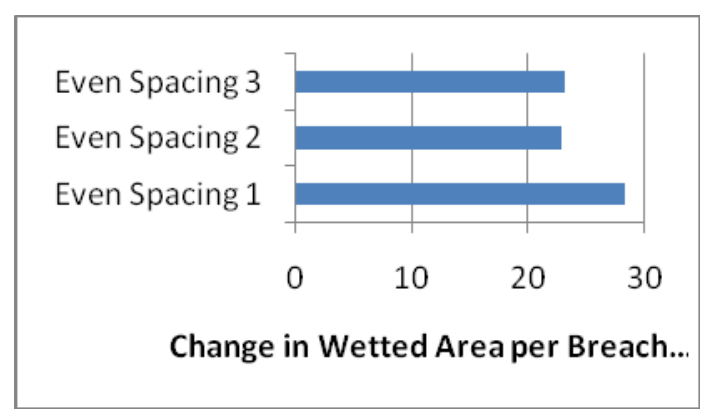

Figure A.6. Change in Wetted Area per Breach Resulting from Three Runs of Randomly Selected Dike Breaches Evenly Spaced Throughout the Lower Grays River Corridor

The incremental change in wetted area that is produced per breach by differently sized sets of dike breaches is shown in Figure A.7a, with Figure A.7b showing the data with the run of four breaches removed.
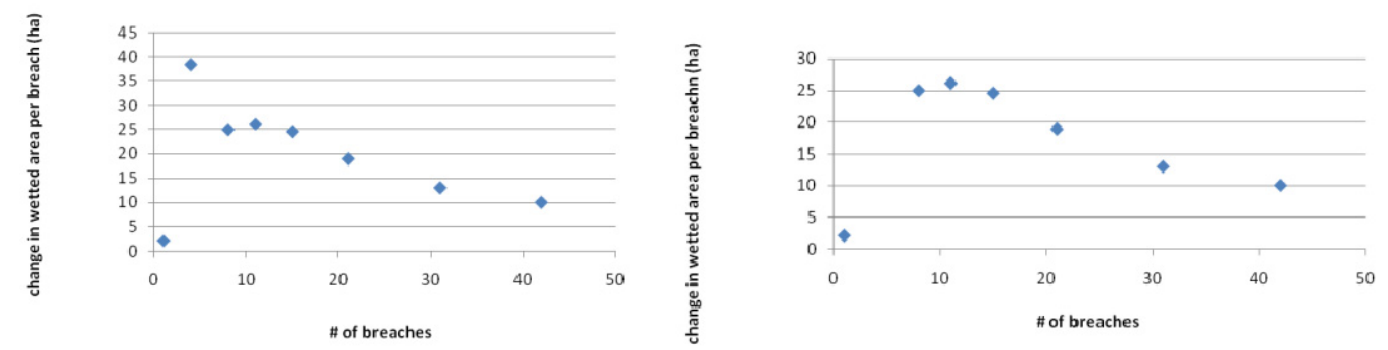

Figure A.7. Incremental Change in Wetted Area that Is Produced per Breach. (a) The average incremental change in wetted area per breach that is produced by different numbers of dike breaches, and (b) the average incremental change in wetted area per breach that is produced by different numbers of dike breaches without the three simulations of four breaches. 


\section{A.4 Discussion}

In this tidal portion of a river system, the effect of upstream breaches on wetted area per breach is negligible, while the effect of midstream breaches is somewhat greater, and downstream breaches the largest at 23 ha/breach (Figure A.5b). The effect of the same number of breaches (11) evenly spaced throughout the study area was in all three runs equivalent to or greater than the effect of downstream breaches (Figure A.6). Thus the influence of river position must be considered in the interpretation of the remaining results.

\section{A.4.1 Nonlinearity}

The average incremental change in wetted area per breach that is produced by different numbers of dike breaches appeared to be a nonlinear function after the first set of simulations, rising steeply from a single dike breach to the 25 th percentile ( 11 breaches) and falling more gradually thereafter. This was confirmed after simulating sets of 4, 8, and 15 breaches (Figure A.7a). However, the randomly selected three runs of four breaches included channels 1 and 2 once each, channel 4 twice, and channel 5 once, or a total of 5 breaches in the lowest portion of the river out of 12 draws. Based on the findings concerning river position, the undue impact of the lower river breaches from the resulting curve was eliminated by removing the three simulations of four breaches (Figure A.7b).

\section{A.4.2 Implications for Design of Restoration Projects}

The implications of these findings for the design of restoration projects and programs depend on the ecological goals and need for cost efficiency. For instance, if wetting the entire floodplain on the high tides is the goal and cost efficiency is imperative, then breaching only half of the channels may be sufficient (Figure A.3). Under this scenario, determination of the spatial configuration of these breaches should consider that breaching only the downstream breaches may produce a change in wetted area per breach (Figure A.5b) equivalent to evenly spacing them throughout the river corridor in most cases (Figure A.6, even spacing runs two and three). It is possible, however, that evenly spacing the breaches throughout the corridor may produce even greater change in wetted area per breach than breaching only downstream channels through the dike (Figure A.6, even spacing run one).

Total wetted area affects the potential for fluxes between the floodplain and channel network, e.g., of nutrients, invertebrates produced on the floodplain vegetation, sediments, and biomass. However, the goals of restoration projects may not be as simple as total wetted area. Flood storage, for example, would depend in addition on the capability of the soils to store water and the duration of wetting, whereas this simulation measured the maximum flood depth reached over the neap to spring tide series. As another example, biomass flux would depend on the relationship between seasonal productivity and seasonal flood cycles.

Total wetted area also to some degree reflects fish habitat opportunity to some degree, which frequently is a goal of river floodplain restoration programs. While opening $50 \%$ of the channels may produce almost complete floodplain inundation, the number of channels reconnected would also be expected to affect access to this floodplain area by animals using the channel corridors. The duration of time during which these channels are connected is another factor that may vary between upstream and downstream areas. For those animals that stay within the channel corridors, measurement of the total length of channels available under the different scenarios, both connected and unconnected to the main 
stem river, may be a more important metric than wetted area. Access, the available wetted floodplain area, and the available length of channel edges are all important components of habitat opportunity and capacity for fishes.

At this time, it is not known whether these findings are applicable in other tidally influenced river systems, or whether they pertain at larger scales in this one; i.e., whether reconnecting habitats in the lower Columbia River would have a greater effect as measured by wetted habitat area than opening habitats further upriver.

\section{A.5 Conclusion}

In this pilot study, a hydrodynamic model was used to experimentally test research questions that could not feasibly have been tested on the ground. For fiscal year 2010, we recommend using the existing, unmodified Grays River model populated with cumulative effects team field-collected data, e.g., 2004-2009 neuston, nutrient, particle, and biomass flux, to model 1) particle import-export from restoration sites to the mouth of Grays River, i.e., effects of transport between tributary restoration sites and the main stem estuary; 2) particle-flux interactions between Columbia Land Trust restoration sites on the lower Grays River, i.e., the cumulative effects resulting from single and multiple restoration sites on other restoration sites; and 3) water velocity and volume ramifications.

\section{A.6 Literature Cited}

Breithaupt, SA and T Khangaonkar. 2007. Hydraulic and Hydrodynamics Modeling of the Grays River and Its Floodplain for the Kandoll Road Restoration Project. PNWD-3780, prepared by BattellePacific Northwest Division, Richland, Washington,, for Ducks Unlimited, Vancouver, Washington.

Flater, D. 1996. “A Brief Introduction to XTide.” Linux Journal 32, 51-57. .http://tbone.biol.sc.edu/tide/ index.html

Hutchinson, MF. 1989. "A new method for gridding elevation and streamline data with automatic removal of pits." Journal of Hydrology 106, 211-232.

Hutchinson, MF. 1996. "A locally adaptive approach to the interpolation of digital elevation models." In: Third international onference/Workshop on Integrating GIS and Environmental Modeling, Santa Fe, 21-25 January 1996. National Center for Geographic Information and Analysis, University of California, Santa Barbara. Available URL: http://www.ncgia.ucsb.edu/conf/SANTA_FE_CD$\mathrm{ROM} /$ program.html

King, IP. 1998. A Finite Element Model for Stratified Flow, RMA-10 User's Guide. Version 6.5. Department of Civil and Environmental Engineering, University of California, Davis.

King, IP. 2005. RMA2, a Two-Dimensional Finite-Element Model for Flow in Estuaries and Streams, Update Documentation. Version 7.4g, Resource Modeling Associates, Sydney, Australia.

LiDAR Bare Earth DEM [computer file]. 2005. "Terrapoint: The Woodlands, Texas.” Puget Sound LiDAR Consortium, Seattle, Washington. Available URL: http://pugetsoundlidar.ess.washington.edu/index.htm

National Oceanographic and Atmospheric Administration. 2006. "Tidal Elevations at Tongue Point (ID\# 9439040).” Available URL: http://tidesandcurrents.noaa.gov/. 



\section{Appendix B}

\section{Additive Modeling Pilot Study - Analysis Summary}





\title{
Appendix B
}

\section{Additive Modeling Pilot Study - Analysis Summary}

\author{
Heida L. Diefenderfer, Amy B. Borde, Ron M. Thom, and Gary E. Johnson
}

This appendix contains a preliminary evaluation of additive modeling needs PNNL performed to calculate historical, present, and potential biomass export from LCRE floodplain wetland habitats. A key function of Pacific Northwest tidal wetlands is the production of organic matter (Eilers 1975; Jefferson 1975; Levings and Moody 1976). Data from the lower portion of the LCRE indicate that marsh and swamp productivity rates are substantial, although the total productivity of these systems has been reduced by the reduction in habitat area (Small et al. 1990). While the relative productivities of various plant types in Pacific Northwest systems are highly variable, in the LCRE, marsh productivity is second only to phytoplankton (Thom 1997). As a whole, Columbia River discharge contains substantially lower carbon concentrations (total, dissolved, and particulate) than the Mississippi (Dahm 1981). Maximum vascular plant above-ground biomass is, however, comparable to that of marshes in the Fraser River estuary in British Columbia (Kistritz et al. 1983; Small et al. 1990.)

The "food web" includes all the species that produce and consume organic matter in the system and the linkages between these species. The food web for the tidal saltwater portion of the LCRE has been diagramed (Weitkamp 1994) and a shift from marsh macrodetrital production to microdetritus favoring zooplankton production over benthic production has been proposed (Simenstad, C. personal communication). Additionally, flow regulation may have created habitats and thermal regimes that are advantageous to non-native plant and animal species, such as Reed canarygrass (Phalaris arundinaceae) and American shad (Alosa sapidissima), which have subsequently altered food web dynamics.

The fate of organic matter produced in marshes and swamps includes respiratory losses, herbivory, burial in the soil, and export to other locations in the system. Burial of organic matter in the soil contributes to both the overall nutrient cycling and maintenance of productivity of the marsh and accretion of the marsh elevation. It is the export process that provides the primary link from the marshes and swamps to the broader aquatic ecosystem (Kistritz et al. 1983). Particulate and dissolved organic matter moves from the sites of production to the flats, channels, and deeper areas of the LCRE. Particulate organic carbon from the Columbia River is dominated by gymnosperm woody and nonwoody angiosperm tissues (Hedges and Mann 1979).

In terms of evaluating cumulative effects, key factors to consider include area of marsh or swamp restored, rate of organic matter production, rate and pattern of development of the systems from present state to restored state, and the exchange rate and capacity between these restored systems and the LCRE. Mechanisms by which macrodetritus flux into the broader estuarine system may be increased include increasing macrodetritus production rates; removing impediments to the flow of materials by enhancing tidal inundation of sites; and reducing respiratory losses, herbivory, and burial. At the outset of this study, we predicted that increases in all of these factors would result in an increase in the contribution of marsh macrodetritus and other forms of marsh-derived organic matter to the broader ecosystem. During 2005 through 2008, we evaluated this prediction on a pilot scale on 1) Vera Slough and Vera Reference on Youngs Bay and 2) a LCRE tributary, the lower Grays River. We monitored tidally influenced sites 
that were reconnected to tidal inundation during that period for the purpose of habitat restoration to evaluate macrodetritis export outcomes. We used the data together with an assessment of plant community cover at different historical periods in geographic information systems to examine the potential for macrodetritis flux and to predict future flux along the temporal restoration trajectory under partial and complete restoration scenarios. The data reported are at this stage preliminary and will be finalized following collection of 2009-2010 macrodetritis flux data at these sites.

\section{B.1 Methods}

We collected above-ground organic matter flux data on the plant community types present in the study area and for one of the study areas we developed scenarios for flux under historical, pre-restoration, present, and future conditions.

\section{B.1.1 Plant Community Types}

Plant community types identified in the Vera Slough study area between the Port of Astoria airport and Youngs Bay were brackish tidal marsh located in the reference slough and diked brackish tidal marsh located behind the dike at the tide gate replacement site.

Four plant community types were defined in the lower Grays River: tidal freshwater forested wetland, freshwater emergent wetland, wet meadow, and restoring site, as discussed below.

- For the Grays River study area, tidal freshwater forested wetland is congruent with the National Wetlands Inventory (NWI) category of "freshwater forested/shrub wetland." While these wetlands have not been well characterized, general descriptions of community composition exist in publications by Christy and Putera (1992) and Kunze (1994).

- Freshwater emergent wetland is an NWI category. While it is not thought that freshwater emergent wetlands occurred in the study area historically, the NWI documents substantial areas, primarily behind dikes, where these systems exist today. The effect of tidal cycles on these wetlands varies depending on their location in the landscape.

- Homesteaders logged the original forests, diked areas along the river, removed the stumps, and initiated agricultural uses of former tidal floodplain lands (Martin 1997). Many of these areas remain in agricultural use today. The NWI defines many of the diked wet meadows in the study area as freshwater emergent wetlands, which is consistent with our observations of seasonal flooding in these areas (Diefenderfer et al. 2008). However, many wet meadows in the study area can be distinguished from emergent wetlands.

- Restoring sites are sites on which hydrological processes have been reconnected to the Grays River through measures such as dike breaching and the replacement of tide gates with culverts, causing changes in the plant communities behind the dikes.

\section{B.1.2 Flux Scenarios}

Temporal scenarios can be developed based on the timeframe of the primary driver for wetland restoration in the LCRE, the Biological Opinion (BiOp) on operation of the Federal Columbia River Power System (NMFS 2000, 2004, 2007). The BiOp (NMFS 2000) called for estuarine restoration as one measure to support outmigrating juvenile salmonids. For example, the Grays River floodplain historically was dominated by tidal freshwater forested wetlands (Metteer 1983; Appelo 1978; Martin 1997; Scott 
2001), so the characteristics of this plant community also affected the selection of the temporal scenarios.

Trees in these tidal forested wetlands grow on poor sites and additionally, the wet meadows being restored exhibit significant alterations of mean elevation, microtopography, and inundation regime (Diefenderfer et al. 2008; Diefenderfer and Montgomery 2009). Therefore, the temporal trajectory for restoration of these plant communities is expected to occur over a period of centuries. To characterize macrodetritis flux throughout this trajectory, we analyzed four periods described here (and listed in Table B.1):

- Period 1, Historical Condition. Logging of areas along the Grays River began in the late 1800s (Appelo 1978) and, following Metteer (1983) and Scott (2001), we assume that the historical condition of the lower Grays River floodplain (downstream of Highway 4) prior to land conversion by settlers was tidal forested wetland with small areas of emergent marsh on both banks of the river at its mouth on Grays Bay.

- Period 2, Biological Opinion (2000). At the time of the BiOp, no hydrological reconnection type restoration actions had occurred in the study area. Thus this period represents the pre-restoration baseline condition.

- Period 3, Present (2009). Two sites on Grays River received restoration treatments in 2004 and 2005 including dike breaching and the replacement of a failed tide gate with culverts (Diefenderfer et al. 2008).

- Period 4, Hypothetical Future "No-Dikes" Scenario. One hypothetical future goal under a "complete restoration" scenario would be restoration to the historical condition (Period 1). This scenario is not realistic given socioeconomic conditions in the Columbia River floodplain, but calculating the maximum potential effect of restoration is important for planning purposes because any actual outcome of restoration efforts in the estuary will be less than that number. Even if this scenario were implemented, it would be unlikely to be realized for centuries due to the timeframe of development of a tidal forested wetland plant community. Therefore, the future scenario of interest in terms of effects on the Grays River and main stem Columbia River food web in the near term is the export from restoring sites, those former pastures that have been reopened to the influence of tidal and riverine hydrology.

Table B.1. Plant Community Types Estimated for the Four Periods Analyzed

\begin{tabular}{|c|c|c|c|c|c|c|}
\hline \multirow[b]{2}{*}{ Period } & \multicolumn{4}{|c|}{ Lower Grays River Watershed } & \multicolumn{2}{|c|}{$\begin{array}{l}\text { Vera Slough area of } \\
\text { Youngs Bay }\end{array}$} \\
\hline & $\begin{array}{c}\text { Tidal } \\
\text { Freshwater } \\
\text { Forested } \\
\text { Wetland }\end{array}$ & $\begin{array}{c}\text { Tidal } \\
\text { Freshwater } \\
\text { Emergent } \\
\text { Wetland }\end{array}$ & $\begin{array}{c}\text { Wet } \\
\text { Meadow }\end{array}$ & $\begin{array}{l}\text { Restoring } \\
\text { Site }^{(a)}\end{array}$ & $\begin{array}{c}\text { Brackish } \\
\text { Emergent } \\
\text { Marsh } \\
\text { (Brackish) }\end{array}$ & $\begin{array}{c}\text { Diked } \\
\text { Emergent } \\
\text { Marsh } \\
\text { (Brackish) }\end{array}$ \\
\hline 1. Historical (mid-1800s) & $\mathrm{X}$ & & & & $\mathrm{X}$ & \\
\hline $\begin{array}{l}\text { 2. Biological Opinion (2000) } \\
\text { Pre-Restoration }\end{array}$ & $\mathrm{X}$ & $\mathrm{X}$ & $\mathrm{X}$ & & $\mathrm{X}$ & $\mathrm{X}$ \\
\hline $\begin{array}{l}\text { 3. Present (2009, Two Sites } \\
\text { Undergoing Restoration) }\end{array}$ & $\mathrm{X}$ & $\mathrm{X}$ & $\mathrm{X}$ & $\mathrm{X}$ & $\mathrm{X}$ & $\mathrm{X}$ \\
\hline $\begin{array}{l}\text { 4. Hypothetical Future } \\
\text { Scenario (No Dikes) }\end{array}$ & $\mathrm{X}$ & $\mathrm{X}$ & $\mathrm{X}$ & $\mathrm{X}$ & $\mathrm{X}$ & $\mathrm{X}$ \\
\hline
\end{tabular}

(a) Following hydrological reconnection, the number of wetland plant species on sites in the lower Grays watershed increased and there was a decrease in the percent cover of non-wetland species. 


\section{B.1.3 Landscape Analysis}

A preliminary landscape analysis was conducted for the Grays River study area. Initially, a database previously developed in ArcGIS for the prioritization of reference sites (Evans et al. 2006) was examined for use as the primary basis for calculating the area from which organic matter was likely to flux outward to the Grays River and potentially to the main stem Columbia River. Evans et al. (2006) delineated the watershed into "sites" of approximately 40 ha in area according to hydrological boundaries using a 10-m digital elevation model (DEM). Our initial approach assumed that the study area should consist of all areas on the Grays River floodplain and within the historical floodplain of the Columbia River that were classified by Evans et al. (2006) as flat. We calculated the total area of the 28 sites immediately adjacent to the Grays River, and the total area of 4 non-riverfront sites adjacent to the Grays River riverfront sites (also classified as "flat") because flooding is expected to be continuous across these floodplain areas.

Examination of the topography of the study area produced by this method together with light detection and ranging (LiDAR) data (LiDAR Bare Earth DEM 2005), aerial imagery (National Agricultural Imagery Program (NAIP) [7/21/2006]), and ground truthing revealed that many of the polygons delineated by Evans et al. (2006) included portions distant from the river or at an elevation that would be unlikely to flood, presumably because of the coarseness of the 10-m DEM relative to the resolution of the LiDAR data. The LiDAR data examined had been collected January-February 2005 and post-processed to accuracies of $\pm 15-25 \mathrm{~cm}$ on soft and/or vegetated surfaces in flat to rolling terrain (LiDAR Bare Earth DEM 2005). Due to the large difference in floodplain area resulting from the two topographic data sources, the final study area boundary used in this research was created as follows: 1) the upper extent of the historical floodplain of the Columbia River on the Grays River (Evans et al. 2006); 2) clipped to the boundary of the available diked-area layer (Evans et al. 2006) to ensure that diking data were available for the entire study area; and 3) modified in finer detail to include only the floodplain based on the LiDAR data, aerial imagery, and ground-truthing. A single elevation contour could not be used to delineate the boundary because the gradient of the Grays River and the intersection of the watershed with hydrologic influence from the main stem Columbia and ocean cause the elevation of overbank flow to vary throughout the study area (Diefenderfer et al. 2008). The upriver boundary of the final study area selected roughly corresponds to the area of the hydrodynamic model pilot study (see Appendix F).

To address the rate and pattern of development of the plant communities from present state to restored state, we examined historical documentation regarding logging by homesteaders in the lower portion of this and an adjacent watershed (Appelo 1978; Martin 1997), maps of habitat types in 18681875 based on U.S. Coast Survey charts (Metteer 1983), and documentation of logging in the watershed throughout the twentieth century (Scott 2001).

We clipped the NWI area to the study area boundary and calculated the areas of NWI categories "freshwater emergent wetland" and "freshwater forested/shrub wetland" within the diked and non-diked areas. Using the NWI data layer and aerial imagery, we identified wet meadows within the study area and calculated the diked and non-diked area of each. The "Other" category includes the following areas: higher elevation areas due to inaccuracies in the floodplain boundary; naturally high areas within the floodplain (e.g., Secret River area); and roads, houses, and developed areas whether higher or not. The diked area layer was used to calculate the "Restoring Site" area, not property boundaries. All area calculations do not include the surface area of the Grays River. Also excluded from the study area were 3 ha at the mouth of the Grays River classified by the NWI as "estuarine and marine wetland." 


\section{B.1.4 Above-Ground Organic Matter Sampling}

Above-ground organic matter was sampled at diked and undiked brackish emergent marshes and a tidegate enhancement site in Youngs Bay on the Oregon side, and in diked wet meadow, a site undergoing restoration, and three tidal forested wetlands, all located in the LCRE on the Washington side. We approximated organic matter flux on a per unit area basis by measuring above-ground live and dead biomass at the peak of productivity in summer and at its lowest in winter. This method does not account for herbivory or burial.

Standing biomass sampling at the restoration site was concentrated on transects proximal to expected changes and sampling at other sites mirrored this design, i.e., sampling was located in close proximity to tidal channels (less than $100 \mathrm{~m}$ ). Within the sampling area, sample plots were randomly selected using systematic sampling from a random start on the transects in the restoration area and wet meadow, and random walk selection in the tidal forested wetland. Sample size was scaled to the vegetation type: $1 \mathrm{~m}^{2}$ in tidal forested wetlands and $0.1 \mathrm{~m}^{2}$ on the herbaceous plant-dominated restoration site, brackish marsh, and wet meadow (Figure B.1a; note that sites on Julia Butler Hansen National Wildlife Refuge and on Youngs Bay are not included in the figure). Sampling on the tidal forested wetlands represented the understory, i.e., trees were not sampled but shrubs were included. The small remnant stands of trees and shrub-dominated patches on the restoration site and wet meadow were not sampled. To collect the samples, a square frame was placed on the ground and all vegetation within the frame was removed at the substrate level. Samples were preserved in plastic bags on ice and shipped to the Battelle Marine Sciences Laboratory in Sequim, Washington, for processing. 

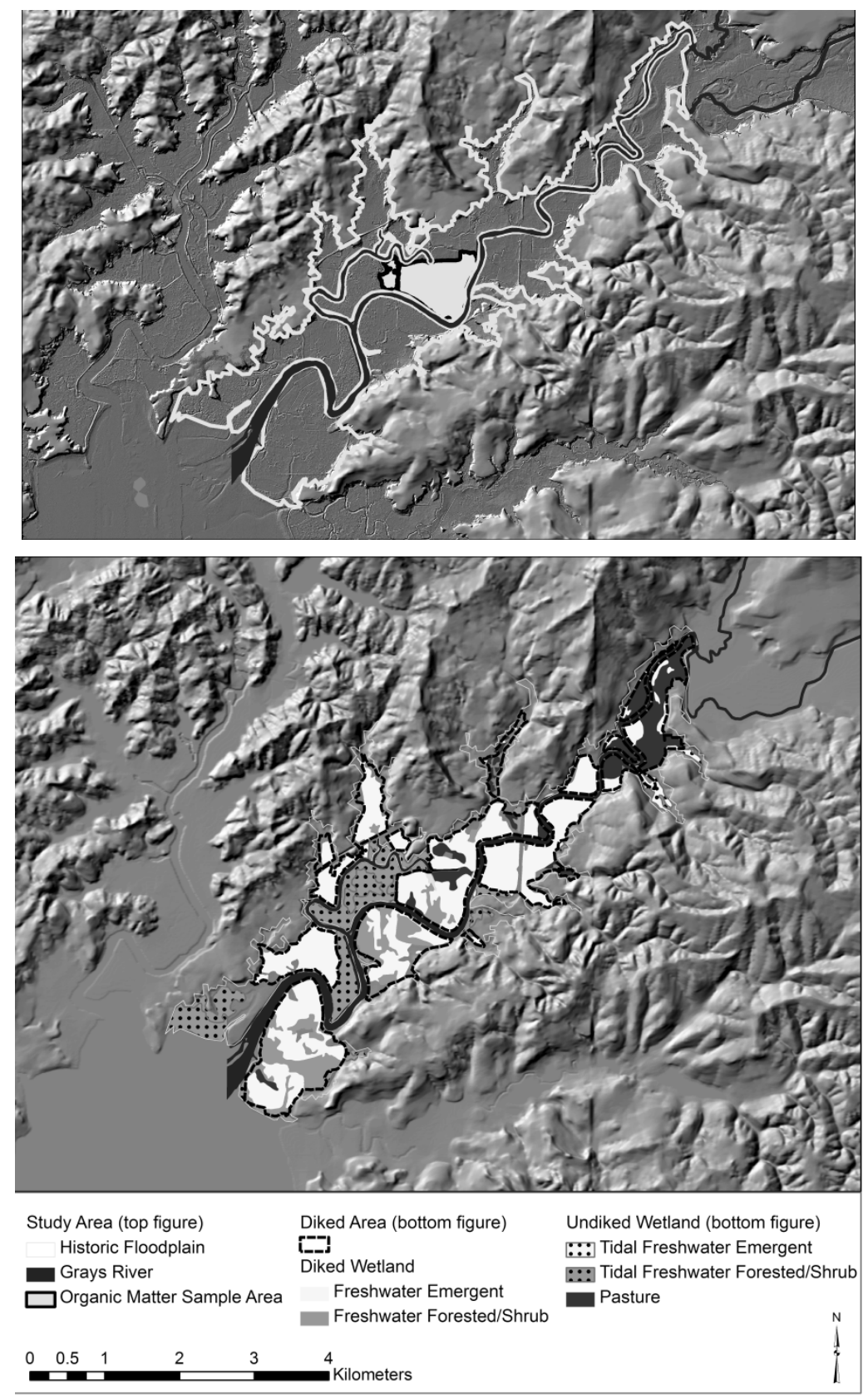

Figure B.1. The Study Area and Land Cover Types. (a) The study area boundary and organic matter sampling area and (b) the land cover types determined in the landscape assessment.

\section{B.1.5 Laboratory Analyses of Organic Matter}

For above-ground organic matter from the restoration sites, brackish marsh, and diked wet meadow, the entire herbaceous sample was rinsed over a 1- or 2-mm mesh in freshwater to remove sediment and anything other than macrovegetation. The dead (brown and flaccid) and live green plant matter were separated, dried in an oven at $\sim 80-90{ }^{\circ} \mathrm{C}$ and weighed after cooling. The percent loss from ignition was then calculated. 
The tidal forested wetland sites had a very low standing biomass of herbaceous plant species and a multilayered canopy. Samples therefore were split into categories suitable for a variety of analyses including this comparison to herbaceous-only samples from other sites, and separated into alive and dead. Following separation, subsamples were dried in an oven at $\sim 80-90{ }^{\circ} \mathrm{C}$ and weighed after cooling. The percent loss from ignition was then calculated. Two simplified categories were used for the purpose of this analysis and calculated by addition: 1) woody twigs, and 2) all remaining matter including shrub parts (e.g., deciduous leaves, evergreen leaves, and reproductive parts), graminoids and aquatics (e.g., grasses, sedges, rushes, cattails), ferns and allies, wildflowers, conifer leaves, and standing dead material.

\section{B.1.6 Calculations}

The idealized general form of the calculation for each period was to 1) subtract winter biomass from summer biomass the previous year, and 2) multiply this difference by the total land area in that plant community type in that period. However, data gaps restricted our ability to complete all calculations for the pilot study years. Specific comments for each period follow:

- Period 1, Historical Condition - The entire study area multiplied by the macrodetritis flux currently observed in forested wetlands or brackish marshes.

- Period 2, BiOp - All wetlands and pasture outside diked areas multiplied by their respective flux numbers.

- Period 3, Present - Same as Period 2, with the addition of restoration and enhancement site areas multiplied by the restoring sites flux numbers.

- Period 4, No Dikes Future Scenario - Change all areas behind dikes (freshwater emergent, wet meadow, brackish marsh) to "Restoring area" category.

\section{B.2 Results}

The lower Grays River was selected for the preliminary analysis of land cover change; Youngs Bay will be added in 2009-2010. Both Grays River and Youngs Bay preliminary organic matter flux results to date are presented here.

\section{B.2.1 Landscape Analysis}

Land cover in five classes and two levels of tidal influence was successfully calculated for two historical periods, the present year, and a hypothetical projected future scenario with no dikes (Table B.2). The trend is from a historical cover of contiguous freshwater tidal forested wetlands to, at the time of the $\mathrm{BiOp}$, a combination of wet meadow and freshwater emergent wetland cover. By the year 2009, some restoring areas had been added through a combination of dike breaching, tide gate removal, and culvert installation. 
Table B.2. Area of Land in Cover Types by Time Period ${ }^{(a)}$

\begin{tabular}{|c|c|c|c|c|c|c|c|c|c|}
\hline \multirow{2}{*}{$\begin{array}{c}\text { Period } \\
\text { Tidal } \\
\text { Influence }\end{array}$} & \multicolumn{2}{|c|}{$\begin{array}{l}\text { Freshwater Tidal } \\
\text { Forested Wetland } \\
\text { (ha) }\end{array}$} & \multicolumn{2}{|c|}{$\begin{array}{c}\text { Freshwater } \\
\text { Emergent Wetland } \\
\text { (ha) }\end{array}$} & \multicolumn{2}{|c|}{$\begin{array}{l}\text { Wet Meadow } \\
\text { (ha) }\end{array}$} & \multicolumn{2}{|c|}{$\begin{array}{l}\text { Other } \\
\text { (ha) }\end{array}$} & \multirow{2}{*}{$\begin{array}{l}\text { Restoring } \\
\text { Site } \\
\text { (ha) }\end{array}$} \\
\hline & Open & Diked & Open & Diked & Open & Diked & Open & Diked & \\
\hline Historical & 1144 & NA & NA & NA & NA & NA & NA & NA & NA \\
\hline 2000 & 158 & 98 & 38 & 399 & 0 & 102 & 274 & 75 & NA \\
\hline 2009 & 168 & 88 & 118 & 329 & 0 & 92 & 282 & 69 & 96 \\
\hline $\begin{array}{l}\text { No-Dikes } \\
\text { Scenario }\end{array}$ & 256 & 0 & 539 & 0 & 0 & 0 & 349 & 0 & 674 \\
\hline \multicolumn{10}{|c|}{$\begin{array}{l}\text { (a) Assumptions: 1) Upon reconnection to tidal flow a forested wetland stays forested wetland, emergent wetland } \\
\text { stays emergent wetland, and wet meadow is converted to emergent wetland; 2) when an area in the "other" } \\
\text { category is inside a diked area, it is considered part of the "restoring site," but it is not included in the wetland } \\
\text { categories because it is not clear what wetland type it would restore to (e.g., forested or emergent), so it is } \\
\text { counted in the "other - open" category. } \\
\mathrm{NA}=\text { not applicable }\end{array}$} \\
\hline
\end{tabular}

\section{B.2.2 Organic Matter Flux}

Organic matter flux from brackish emergent marshes conformed to predictions with high export in the reference slough area (316-596 g/ $\left.\mathrm{m}^{2}\right)$, negative export (i.e., winter growth and lack of circulation) behind the dike $\left(-96 \mathrm{~g} / \mathrm{m}^{2}\right)$, and greatly increased export following tide gate replacement to increase circulation $\left(726 \mathrm{~g} / \mathrm{m}^{2}\right)$ (Table B.3). Nonwoody biomass samples collected from the tidal forested wetland and scrubshrub areas exhibited high variation and in two out of three cases a net negative export; the average for the three sites was a very small net positive export. Diked wet meadows exhibited high flux as measured (441-927 g/ $\mathrm{m}^{2}$ ), which may however not have reached the waterways or exited the site into the estuary because of herbivory and management activities due to cattle grazing and mowing at the Julia Butler Hansen National Wildlife Refuge. A site containing both freshwater emergent wetland and wet meadow went from $226 \mathrm{~g} / \mathrm{m}^{2}$ in the year the dike was breached (i.e., summer growth and cattle grazing pre-breach, fall breaching, and fall-winter export) to $415 \mathrm{~g} / \mathrm{m}^{2}$ the following year. 
Table B.3. Total Flux of Nonwoody Biomass between Summer and Winter at Sites on the Washington and Oregon Sides of the LCRE (Three years of data)

\begin{tabular}{|c|c|c|c|c|c|c|c|c|c|c|c|}
\hline \multirow{3}{*}{$\begin{array}{l}\text { Land } \\
\text { Cover } \\
\text { Type } \\
\text { Unit }\end{array}$} & \multicolumn{8}{|c|}{ Lower Grays River Watershed } & \multicolumn{3}{|c|}{ Vera Slough Area of Youngs Bay } \\
\hline & \multirow{2}{*}{$\frac{\text { Freshwater }}{\left(\mathrm{g} / \mathrm{m}^{2}\right)}$} & \multicolumn{2}{|c|}{ Tidal Forested Wetland } & \multicolumn{2}{|c|}{$\begin{array}{c}\text { Freshwater Emergent } \\
\text { Wetland/Wet } \\
\text { Meadow }\end{array}$} & \multicolumn{2}{|c|}{ Diked Wet Meadow } & \multirow{2}{*}{$\begin{array}{l}\begin{array}{c}\text { Restoring Site (from } \\
\text { diked emergent } \\
\text { wetland/wet meadow) }\end{array} \\
\left(\mathrm{g} / \mathrm{m}^{2}\right)\end{array}$} & \multirow{2}{*}{$\begin{array}{c}\begin{array}{c}\text { Brackish } \\
\text { Emergent } \\
\text { Marsh }\end{array} \\
\left(\mathrm{g} / \mathrm{m}^{2}\right)\end{array}$} & \multirow{2}{*}{$\begin{array}{c}\begin{array}{c}\text { Diked } \\
\text { Brackish } \\
\text { Emergent } \\
\text { Marsh }\end{array} \\
\left(\mathrm{g} / \mathrm{m}^{2}\right)\end{array}$} & \multirow{2}{*}{$\begin{array}{c}\begin{array}{c}\text { Restoring Site } \\
\text { (from diked } \\
\text { brackish emergent } \\
\text { marsh) }\end{array} \\
\left(\mathrm{g} / \mathrm{m}^{2}\right)\end{array}$} \\
\hline & & $\left(\mathrm{g} / \mathrm{m}^{2}\right)$ & $\left(\mathrm{g} / \mathrm{m}^{2}\right)$ & $\left(\mathrm{g} / \mathrm{m}^{2}\right)$ & NA & $\left(\mathrm{g} / \mathrm{m}^{2}\right)$ & $\left(\mathrm{g} / \mathrm{m}^{2}\right)$ & & & & \\
\hline Site & $\begin{array}{c}\text { Crooked } \\
\text { Creek }\end{array}$ & $\begin{array}{l}\text { Secret } \\
\text { River }\end{array}$ & $\begin{array}{c}\text { Kandoll } \\
\text { Reference }\end{array}$ & $\begin{array}{l}\text { (Diked/ } \\
\text { Open) } \\
\text { Kandoll } \\
\text { Farm }\end{array}$ & Open & $\begin{array}{l}\text { Duck } \\
\text { Lake } \\
\text { Slough }\end{array}$ & $\begin{array}{l}\text { Ellison } \\
\text { Slough }\end{array}$ & Kandoll Farm & $\begin{array}{c}\text { Vera } \\
\text { Reference }\end{array}$ & Vera Slough & Vera Slough \\
\hline $\begin{array}{l}2005- \\
2006\end{array}$ & ND & ND & ND & 226 & ND & ND & ND & NA & 316 & -96 & NA \\
\hline $\begin{array}{l}2006- \\
2007\end{array}$ & 115 & -25 & -86 & NA & ND & ND & ND & 407 & 596 & NA & 726 \\
\hline $\begin{array}{l}2007- \\
2008\end{array}$ & ND & ND & ND & NA & ND & 441 & 927 & ND & ND & NA & ND \\
\hline $\begin{array}{l}\mathrm{NA}=\mathrm{nc} \\
\mathrm{ND}=\mathrm{nc}\end{array}$ & $\begin{array}{l}\text { plicable } \\
\text { ta }\end{array}$ & & & & & & & & & & \\
\hline
\end{tabular}


These results permit coarse preliminary calculations of macrodetritis flux conditions at the landscape scale for the lower Grays River watershed. For example, the historical condition of continuous spruce swamps may have produced little flux of nonwoody materials. The 96 ha of currently restoring sites on Grays River could be exporting as much as 391 metric tons per year of macrodetritis. The rate of production for a tide gate enhancement on Youngs Bay is similarly high.

\section{B.3 Discussion}

This assessment uncovered significant weaknesses in the available data for additive modeling of the export of macrodetritis from LCRE wetlands:

1. The use of reprocessed LiDAR data (see Diefenderfer et al. 2008 for methods) showed that the digitized boundary of the floodplain provided by Evans et al. (2006) and the floodplain boundary that is in common use by agencies on the LCRE contain substantial errors due to the 10-m DEMs used for digitizing them. Thus, reprocessing of the existing 2005 LiDAR data is crucial for wetted area and floodplain delineation in the LCRE.

2. For the purpose of additive modeling, biomass flux data need to be collected according to topography to adequately account for subtle elevational differences between emergent wetlands and wet meadows such as those identified in NWI in the landscape assessment. Thus, more fine-grained spatial assessment of flux needed in field data collection and more intensive sampling of forested areas is needed to address variability.

3. Data mining from the literature may serve as a cost-effective substitute for some field data collection. In particular, because this method is simplified and does not account for herbivory, burial, and other forms of biomass loss, a defensible percentage for actual biomass export from the sites may be developed from the literature.

4. Some tributaries, such as the subject of this pilot assessment, were blanketed by tidal forested wetlands right to the water's edge, not emergent wetlands as some early work (e.g., Scott 2001) has suggested.

5. Forested wetlands challenge the traditional paradigm for macrodetritis export in emergent marshes and may require more intensive sampling to address issues of spatial variability in the herbaceous layer, as well as sampling of the multistoried canopy (e.g., litterfall).

6. This assessment does not take into account the change with flux by distance from channel and in fact weights the areas proximal to the channel more heavily than those further away that may have less circulation and/or export.

The export of organic matter produced in the wetlands of the LCRE floodplain affects the food web for juvenile salmon in the estuary and, thus, is important to the management of outmigrating endangered species. Increasing macrodetritus input is not, however, straightforward. For example, in some areas of the estuary, historical conditions may have produced less macrodetritis export than current conditions. To make a site a net exporter of materials, outflows must exceed inflows on average. Some sites available for restoration may be slight net importers of material because of weak outflow rates, so the hydrodynamics of a site and the type and location of restoration actions must be carefully considered. Even marshes that were productive historically may not attain the same level of productivity through 
restoration, because of changes to ecological processes that may not be reengineered. Sites that are more open also may be more susceptible to erosion, and thus would be difficult to maintain.

\section{B.4 Literature Cited}

Appelo, CE 1978. "Deep River: the C. Arthur Appelo story, Wahkiakum County, Washington.” Selfpublished by Carlton E. Appelo, Deep River, Washington, 98618.

Christy, JA and JA Putera. 1992. Lower Columbia River Natural Area Inventory. Report to The Nature Conservancy, Washington Field Office, Seattle, Washington.

Dahm, CN. 1981. "Pathways and mechanisms for removal of dissolved organic carbon from leaf leocheate in streams." Canadian Journal of Fisheries and Aquatic Sciences 38:68-76.

Diefenderfer, HL and DR Montgomery. 2009. "Pool spacing, channel morphology, and the restoration of tidal forested wetlands of the Columbia River, U.S.A.” Restoration Ecology 17:158-168.

Diefenderfer, HL, AM Coleman, AB Borde, and IA Sinks. 2008. "Hydraulic geometry and microtopography of tidal freshwater forested wetlands and implications for restoration, Columbia River, U.S.A.” International Journal of Ecohydrology and Hydrobiology 8:339-361.

Eilers, HP. 1975. "Plants, plant communities, net production and tide levels: the ecological biogeography of the Nehalem Salt Marshes, Tillamook County, Oregon." Ph.D. thesis. Oregon State University, Corvallis, Oregon.

Evans, NR, R.M. Thom, G.D. Williams, J. Vavrinec, K.L. Sobocinski, L.M. Miller, A.B. Borde, V.I. Cullinan, J.A. Ward, C.W. May, C. Allen. 2006. "Lower Columbia River Restoration Prioritization Framework." Report submitted to the Lower Columbia River Estuary Partnership by Battelle Marine Sciences Laboratory, Sequim, Washington.

Hedges, JI and DC Mann. 1979. "The lignin geochemistry of marine sediments from the southern Washington coast." Geochimica et Cosmochimica Acta 43:1809-1818.

Jefferson, CA., 1975. "Plant communities and succession in Oregon coastal salt marshes." Ph.D. Thesis, Oregon State University.

Kistritz, RU, KJ Hall, and I Yesaki, 1983. "Productivity, detritus flux, and nutrient cycling in a Carex lyngbyei tidal marsh.” Estuaries 6(3):227-236.

Kunze, LM. 1994. Preliminary Classification of Native, Low Elevation, Freshwater Wetland Vegetation in Western Washington. Washington State Department of Natural Resources, Olympia, Washington.

Levings, CD and AE Moody. 1976. "Studies of intertidal vascular plants, especially sedge (Carex lyngbei) on the disrupted Squamish River delta.” B.C. Fish. Mar. Serv. Report No. 606.

LiDAR Bare Earth DEM (computer file). 2005. Terrapoint: The Woodlands, Texas. Puget Sound LiDAR Consortium, Seattle, Washington. URL http://pugetsoundlidar.ess.washington.edu/index.htm 
Martin, I. 1997. Beach of Heaven: A History of Wahkiakum County. Washington State University Press, Pullman, Washington.

Metteer, S. 1983. "Habitat types in the Columbia River estuary Map 1: 1868-1875." Pullout map produced by Northwest Cartography, Inc. for DW Thomas: Changes in Columbia River Estuary Habitat Types over the Past Century. Columbia River Estuary Data Development Program, Astoria, Oregon.

NMFS (National Marine Fisheries Service). 2000. "Biological Opinion: Reinitiation of Consultation on Operation of the Federal Columbia River Power System, Including the Juvenile Fish Transportation Program, and 19 Bureau of Reclamation Projects in the Columbia Basin." National Marine Fisheries Service - Northwest Region, Seattle, Washington. Available at: http://www.salmonrecovery.gov/implementation.

NMFS. 2004. "Biological Opinion: Operation of the Federal Columbia River Power System (FCRPS) including 19 Bureau of Reclamation Projects in the Columbia Basin (Revised and reissued pursuant to court order, NWF v. NMFS, Civ. No. CV 01-640-RE [D. Oregon])." National Marine Fisheries Service (NOAA Fisheries) - Northwest Region, Seattle, Washington. Available at: http://www.salmonrecovery.gov/implementation.

NMFS. 2007. "Biological Opinion - Remand Draft. Consultation on Remand for Operation of the Federal Columbia River Power System, 11 Bureau of Reclamation Projects in the Columbia Basin and ESA Section 10(a)(1)(A) Permit for Juvenile Fish Transportation Program (Revised and reissued pursuant to court order, NWF v. NMFS, Civ. No. CV 01-640-RE [D. Oregon])." National Marine Fisheries Service (NOAA Fisheries) - Northwest Region, Seattle, Washington. Available at: http://www.salmonrecovery.gov/implementation.

Scott, MG. 2001. "Forest clearing in the Gray's River watershed 1905-1996." M.S. Thesis, Portland State University, Portland, Oregon.

Small, LF, CD McIntire, KB MacDonald, JR Lara-Lara, BE Frey, MC Amspoker, and T Winfield. 1990. "Primary production, plant and detrital biomass, and particle transport in the Columbia River Estuary.” LF Small (ed.) Columbia River: Estuarine System. Progress in Oceanography 25:1-4.

Thom, RM. 1997. "System-development matrix for adaptive management of coastal ecosystem restoration projects." Ecological Engineering 8:19-232.

Weitkamp, LA. 1994. "A Review of the Effects of Dams on the Columbia River Estuarine Environment, with Special Reference to Salmonids." Prepared by the National Marine Fisheries Service, Seattle, Washington for the Bonneville Power Administration, Portland, Oregon. 


\section{Appendix C}

\section{Assessment of Previously Breached and Created Sites - Analysis Summary}





\title{
Appendix C
}

\section{Assessment of Previously Breached and Created Sites - Analysis Summary}

\author{
Amy B. Borde and Heida L. Diefenderfer
}

Dikes were built throughout the lower Columbia River and estuary (LCRE) floodplain starting in the 1890s with approximately 99,000 acres diked by 1948 (Christy and Putera 1992). Because many of the areas behind the dikes were tidal marshes and swamps, dike breaching offers an opportunity in some situations to restore tidal flow and improve habitat conditions. In the past, some dikes have been breached naturally because of flooding and storm damage. While many accidental breaches are repaired, a few have remained open to tidal flow and provide an opportunity to observe the resulting conditions over time. In addition, several sites have been "created" through the placement of dredge material. Assuming that the time of breaching or creation can be approximated, then the estimated time since "restoration" can be placed in context with other restoration projects for comparison along an ecological trajectory (Figure C.1).

In this appendix we present the methods and results from habitat assessments at three previously breached sites at Karlson Island, Fort Clatsop, and Trestle Bay. The habitat metrics sampled included vegetation, channel cross-section, and sediment. Methods for these metrics were described by Borde et al. (2008). These data will contribute to the formation of a trajectory through time for LCRE tidal reconnection restorations.

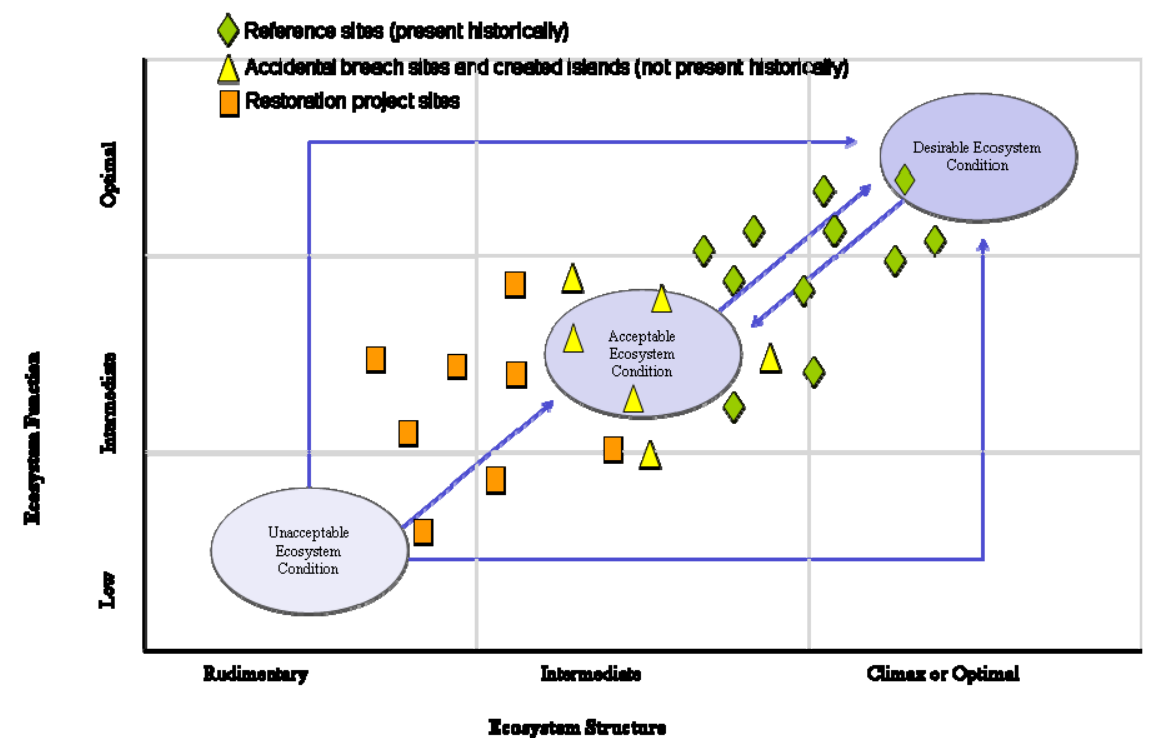

Figure C.1. Conceptual Diagram Showing Location of Active Restoration Sites, Naturally Breached and Created Sites, and Reference Sites Along a Trajectory Toward Functional, Self-Maintaining Ecosystems 


\section{C.1 Site Selection}

Eleven sites were identified from a report published by the U.S. Environmental Protection Agency (EPA) in the mid-1990s that evaluated the restoration potential of diked wetlands along the coast of Oregon and Washington (Simenstad and Feist 1996). Additional sites were added to the list based on communication with local experts. The sites were evaluated remotely using aerial imagery, light detection and ranging (LiDAR), a geographic information system (GIS), and by boat for current status, suitability to the Cumulative Effects Study, and feasibility for access. Some sites could not be located because of a lack of accurate information and many of the sites were found to be repaired and no longer breached.

Six sites were considered to have good potential to evaluate the restoration trajectory (Figure C.2). These sites were further narrowed down based on their location relative to the mainstem of the Columbia River and their potential to provide habitat along the migration route of juvenile salmonids. The Walluski Loop Dike was deemed too far from salmonid migration routes to be evaluated for fish use. The sites evaluated in 2008 (and described in the following sections) were Karlson Island, Lewis and Clark River Bend (Fort Clatsop), and Trestle Bay. Miller Sands, Goat Island, and Walluski Loop Dike will be monitored in 2009.

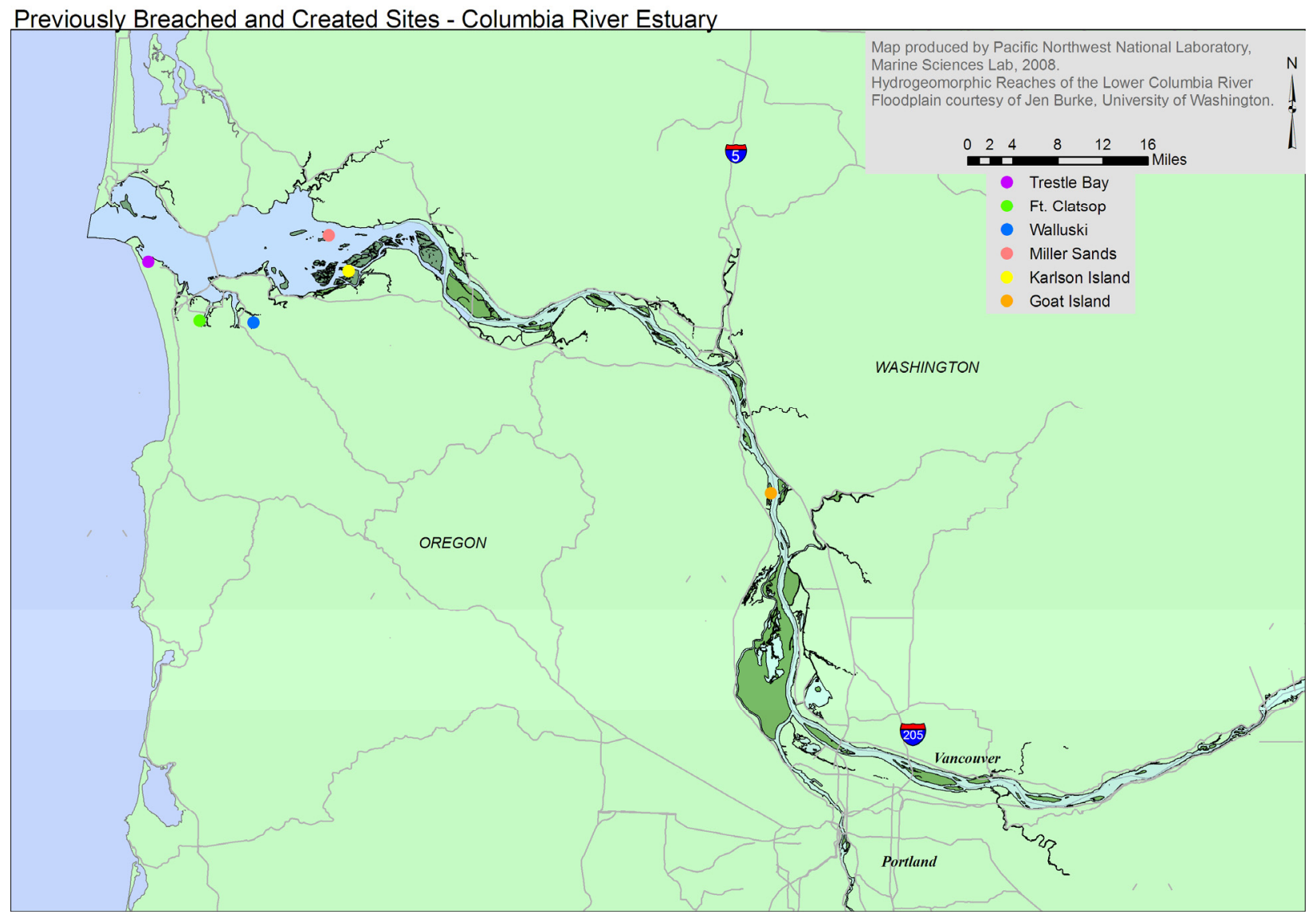

Figure C.2. Location of Previously Breached and Created Sites Monitored in 2008 and Scheduled for Monitoring in 2009 


\section{C.1.1 Karlson Island}

This island is located in the east side of Cathlamet Bay and is part of the Lewis and Clark National Wildlife Refuge. A portion of the island had been diked "prior to 1936" according to Christy and Putera (1992). The dike has been breached for at least 25 years (Borde et al. 2008). The site currently is fully open to tidal flow as shown in the LiDAR image and recent aerial image (Figure C.3). In 2007, a waterlevel sensor was deployed inside the diked area near the mouth of the breach. The sensor was surveyed and downloaded in 2008. This information will be used to relate the hydrology of the site to the vegetation, channel morphology, and fish use, which will be monitored in 2009.

\section{Karlsen Island Natural Breach Site}

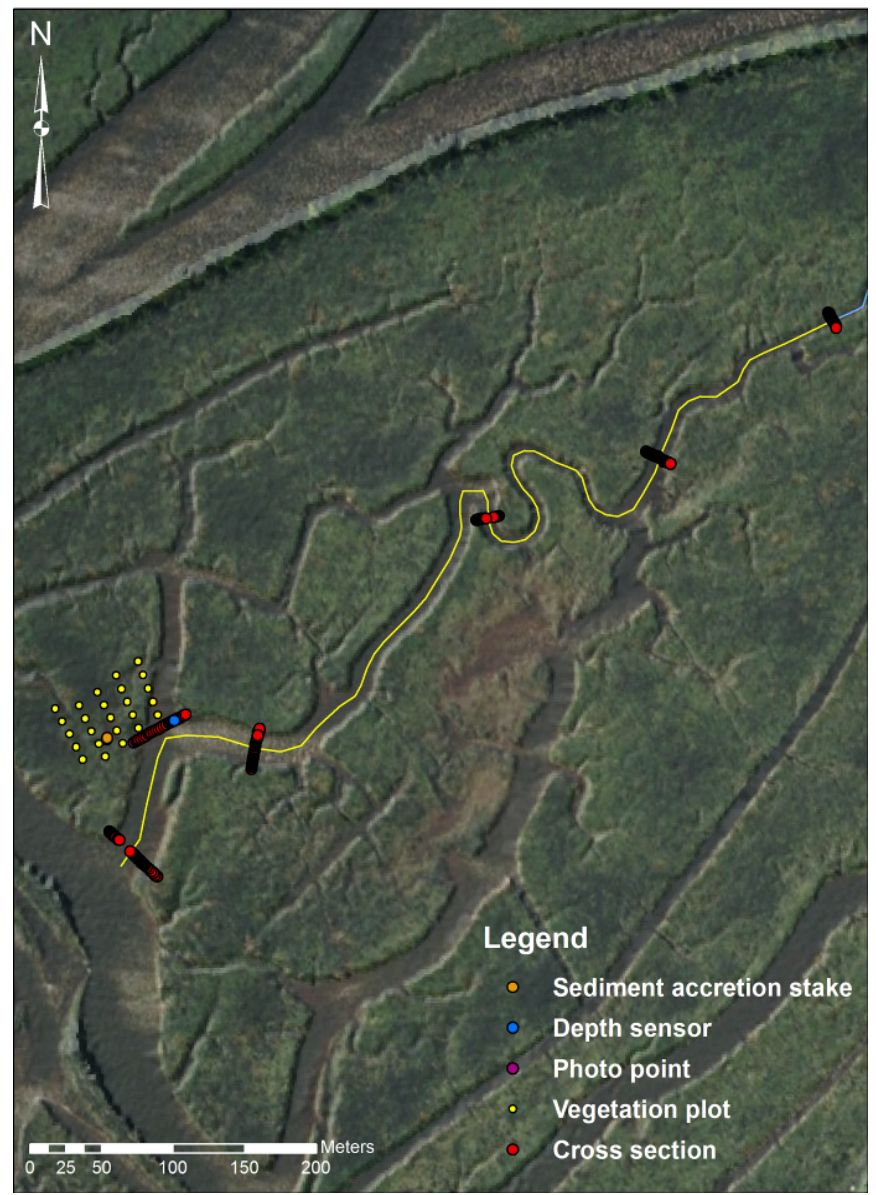

Figure C.3. Location of Monitoring Parameters at Karlson Island (LiDAR hillshade courtesy of Jen Burke, University of Washington [UW]; aerial image courtesy of ESRI World Imagery).

\section{C.1.2 Fort Clatsop}

This site, located on the Lewis and Clark River, is just downstream from a tidal restoration project at Fort Clatsop and is being used as a reference site for the project. The dike was likely built in the early 1900s and was breached during a storm in 1961, making the time since breach approximately 47 years. The location of monitoring actions is shown in Figure C.4. 


\section{Fort Clatsop Natural Breach Site}

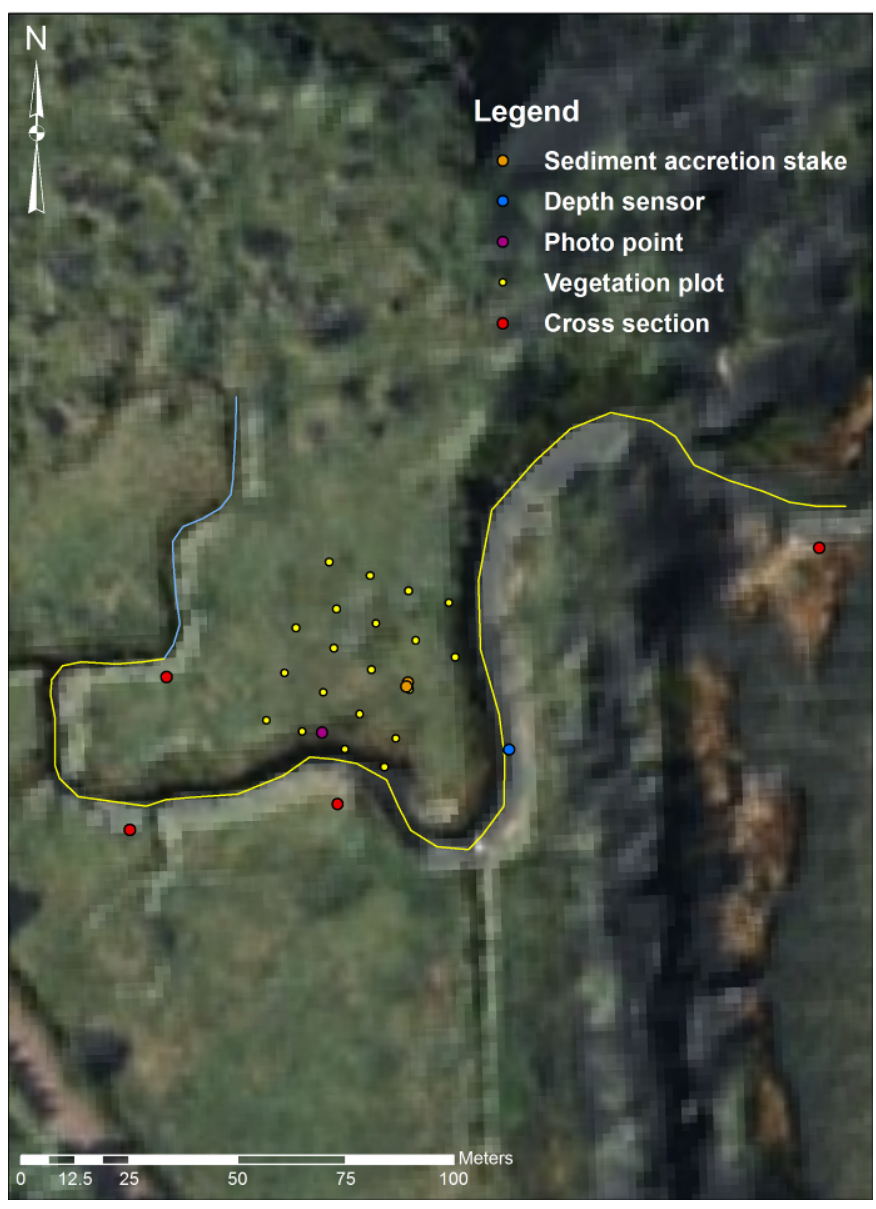

Figure C.4. Location of Monitoring Parameters at Fort Clatsop (LiDAR hillshade courtesy of Jen Burke, UW; aerial image courtesy of ESRI World Imagery).

\section{C.1.3 Trestle Bay}

Trestle Bay (Figure C.5) was created in the late 1800s with the construction of the south jetty at the mouth of the Columbia River. A small jetty was placed across the bay to protect the railroad trestle. In $1995,152 \mathrm{~m}$ of the rock jetty across the bay were breached to improve tidal flow and fish access (Hinton and Emmett 2000). Fish monitoring occurred pre- and post-breaching in 1994, 1996, and 1997. Those breach results will be evaluated in conjunction with the current study, which will evaluate vegetation, channel morphology, and fish use 13 years after breaching. 


\section{Trestle Bay Natural Breach Site}

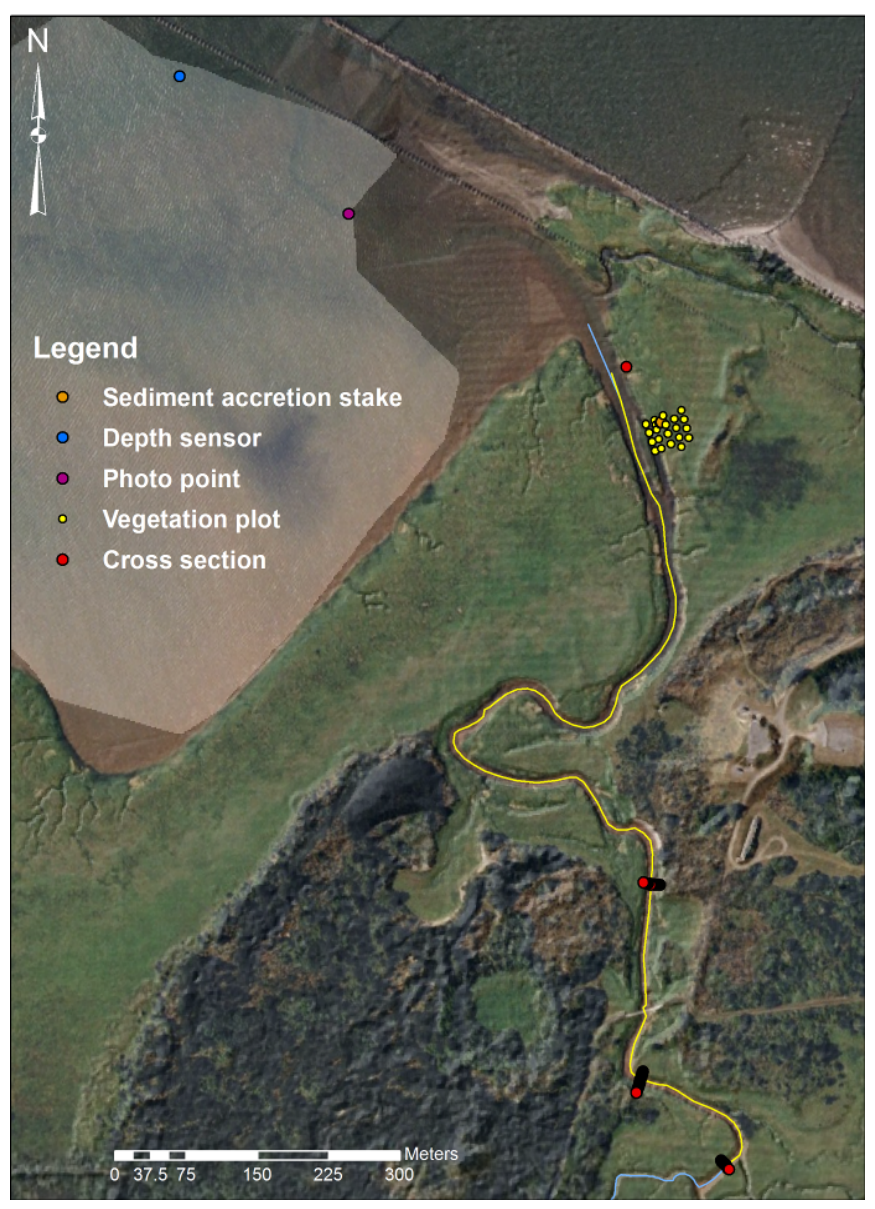

Figure C.5. Location of Monitoring Parameters at Trestle Bay (LiDAR hillshade courtesy of Jen Burke, [UW]; aerial image courtesy of ESRI World Imagery).

\section{C.2 Results}

This section contains results for vegetation, channel cross-section, and sediment.

\section{C.2.1 Vegetation}

At Trestle Bay, the dominant plants in terms of percent cover were Carex lyngbyei (46\%) and Glyceria spp. (GLST) (23\%) (Figure C.6). At Fort Clatsop, Carex obnupta and Phalaris arundinacea dominated at 45\% and 16\% cover, respectively. At Karlson Island, Myosotis (13\%) and Lythrum salicaria (12\%) were most common. Marsh vegetation elevation ranges as sampled at Trestle Bay, Fort Clatsop, and Karlson Island were 1.0-2.1 m, 1.0-2.8 m, and 1.3-2.1 m, respectively (Figure C.6). As an example, the average marsh elevation at Karlson Island was inundated $24 \%$ of the time (Table C.1). 
Reach A

Reach A
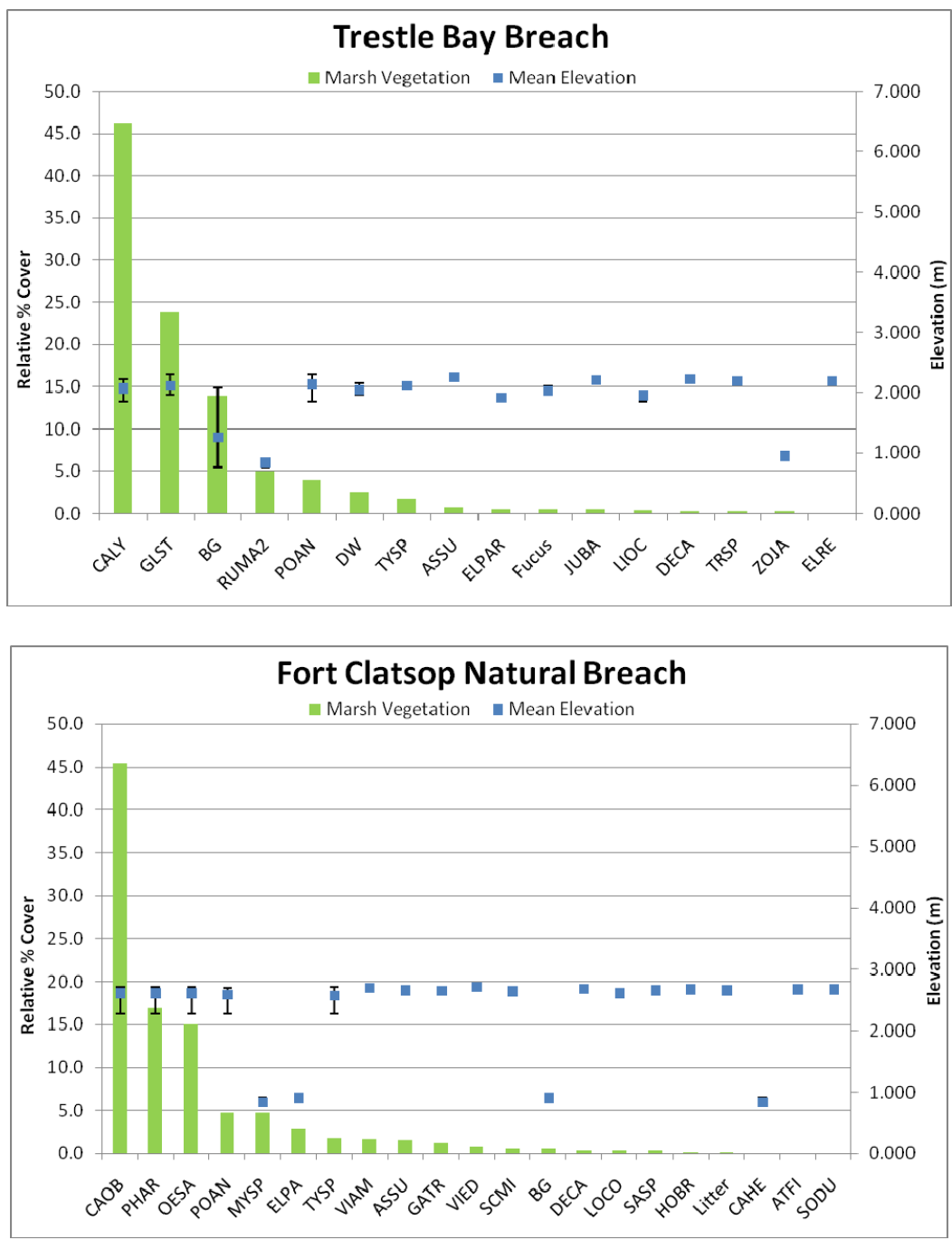

Reach B

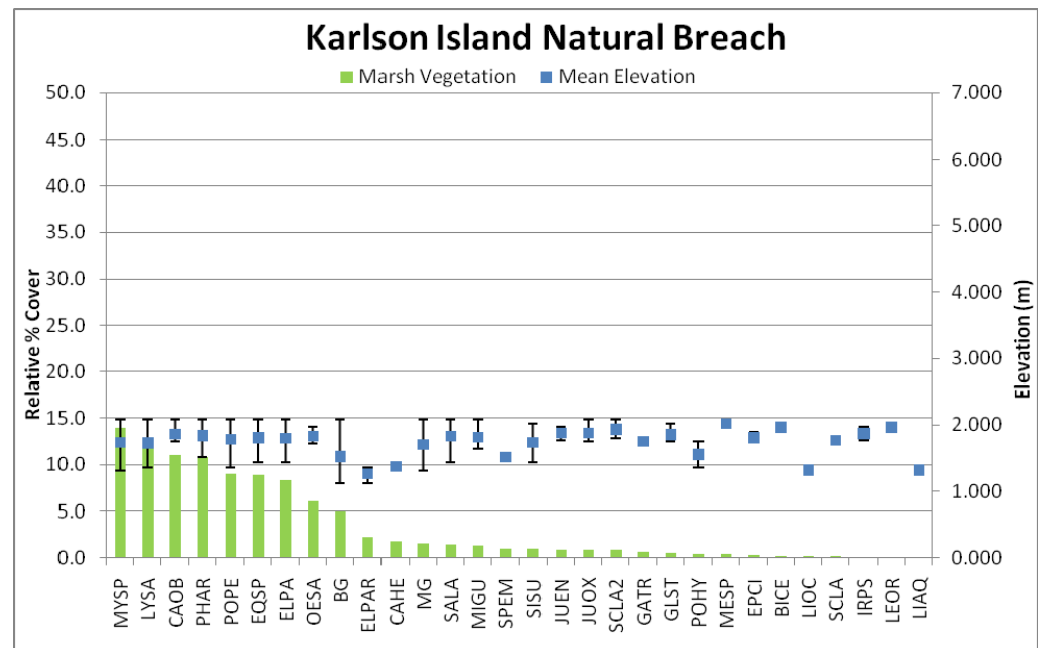

Figure C.6. Relative Percent Cover and Elevation for Vegetation Species in Previously Breached Marshes. Plant codes are in Appendices A and B (Johnson and Diefenderfer 2008). 
Table C.1. Inundation Times at the Average Marsh Elevation at Karlson Island

\begin{tabular}{|c|c|c|c|c|c|c|}
\hline & \multicolumn{3}{|c|}{ Total Deployed Time } & \multicolumn{3}{|c|}{ Growing Season } \\
\hline & Count & $\begin{array}{l}\text { Time } \\
\text { (h) }\end{array}$ & $\begin{array}{l}\% \text { Time } \\
\text { Deployed }\end{array}$ & Count & $\begin{array}{l}\text { Time } \\
\text { (h) }\end{array}$ & $\begin{array}{l}\% \text { Time } \\
\text { Deployed }\end{array}$ \\
\hline Sensor Elevation & 5975 & 2987.5 & 36.7 & 920 & 460.0 & 30.3 \\
\hline >Avg Marsh Elevation & 4968 & 2484.0 & 30.5 & 720 & 360.0 & 23.9 \\
\hline$>$ Avg Marsh Elevation $+15 \mathrm{~cm}$ & 433 & 216.5 & 2.66 & 23 & 11.5 & 0.76 \\
\hline$>$ Avg Marsh Elevation $+1 \mathrm{~m}$ & 5975 & 2987.5 & 36.7 & 920 & 460.0 & 30.3 \\
\hline
\end{tabular}

\section{C.2.2 Channel Cross Sections}

Channel cross-sectional area broadens and deepens as elevation decreases (Figure C.7 and Table C.2). Similar patterns were observed at all three sites.

Trestle Bay Natural Breach

Channel Cross Sections

Reach A

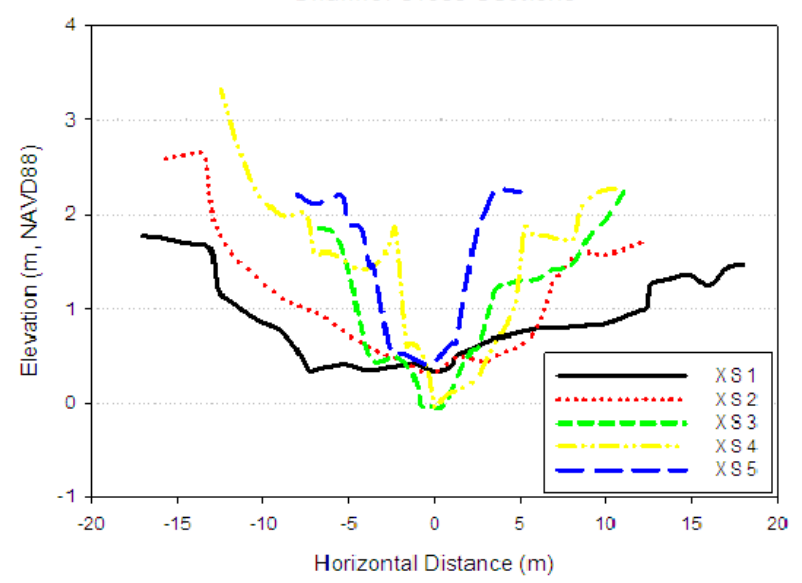

Reach A

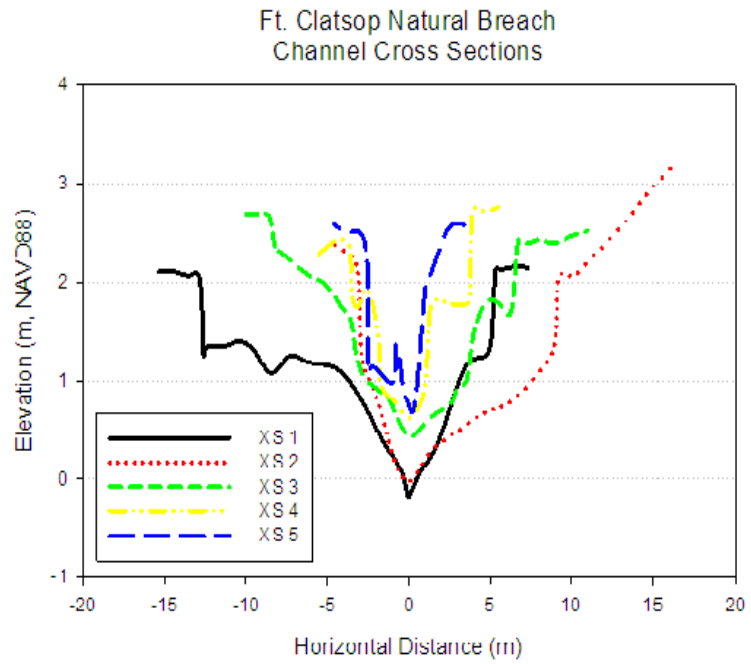

Figure C.7. Channel Cross Sections in Previously Breached Marshes from Reaches A and B 


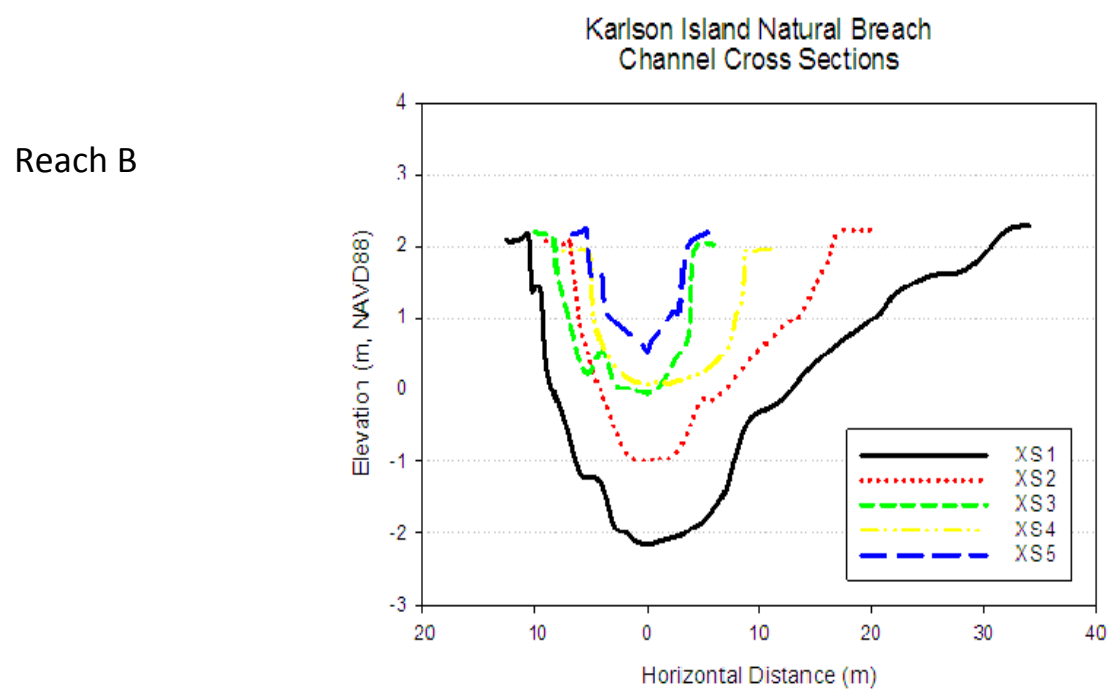

Figure C.7. (contd)

Table C.2. Channel Cross Section Characteristics and Inundation Frequencies for Previously Breached Marsh Sites.

\begin{tabular}{|c|c|c|c|c|c|c|c|c|c|}
\hline & & \multicolumn{5}{|c|}{ Physical Metrics } & \multicolumn{3}{|c|}{ Inundation } \\
\hline $\begin{array}{l}\text { Site } \\
\text { Code }\end{array}$ & $\begin{array}{c}\text { Cross } \\
\text { Section }\end{array}$ & $\begin{array}{l}\text { Bank } \\
\text { Elev } \\
(\mathrm{m})\end{array}$ & $\begin{array}{l}\text { Thalweg } \\
\text { Elev (m) }\end{array}$ & $\begin{array}{l}\text { Channel } \\
\text { Depth } \\
\text { (m) }\end{array}$ & $\begin{array}{c}\text { Cross- } \\
\text { Section } \\
\text { Area } \\
\left(\mathrm{m}^{2}\right) \\
\end{array}$ & $\begin{array}{l}\text { Channel } \\
\text { Width } \\
\text { (m) }\end{array}$ & $\begin{array}{l}\text { Width: } \\
\text { Depth } \\
\text { Ratio }\end{array}$ & $\begin{array}{l}\text { Time } \\
\mathrm{WL}> \\
15 \mathrm{~cm} \\
\text { in } \\
\text { channel } \\
\end{array}$ & $\begin{array}{c}\% \text { Time } \\
\text { WL }>\text { top } \\
\text { channel } \\
\text { bank }\end{array}$ \\
\hline \multicolumn{10}{|c|}{ Previously Breached Marsh } \\
\hline \multirow{5}{*}{ TBB } & 1 (mouth) & 1.466 & 0.331 & 1.135 & 21.20 & 30.89 & 27.22 & NA & NA \\
\hline & 2 & 1.689 & 0.309 & 1.380 & 18.25 & 24.16 & 17.51 & NA & NA \\
\hline & 3 & 1.859 & -0.043 & 1.902 & 14.95 & 16.51 & 8.68 & NA & NA \\
\hline & 4 & 2.273 & -0.040 & 2.313 & 19.13 & 21.00 & 9.08 & NA & NA \\
\hline & 5 & 2.205 & 0.434 & 1.771 & 9.89 & 11.38 & 6.43 & NA & NA \\
\hline \multirow{5}{*}{ FCB } & 1 (mouth) & 2.106 & -0.174 & 2.280 & 21.36 & 19.92 & 8.74 & NA & NA \\
\hline & 2 & 2.026 & -0.029 & 2.055 & 16.86 & 12.28 & 5.98 & NA & NA \\
\hline & 3 & 2.371 & 0.436 & 1.935 & 14.98 & 14.94 & 7.72 & NA & NA \\
\hline & 4 & 2.347 & 0.622 & 1.725 & 7.12 & 7.45 & 4.32 & NA & NA \\
\hline & 5 & 2.015 & 0.760 & 1.255 & 3.31 & 3.67 & 2.93 & NA & NA \\
\hline \multirow{5}{*}{ KIB } & 1 (mouth) & 2.089 & -2.153 & 4.242 & 91.26 & 41.75 & 9.84 & 100 & 14 \\
\hline & 2 & 2.038 & -0.978 & 3.016 & 44.14 & 23.50 & 7.79 & 100 & 14 \\
\hline & 3 & 2.050 & -0.055 & 2.105 & 20.28 & 13.26 & 6.30 & 88 & 8 \\
\hline & 4 & 1.831 & 0.084 & 1.747 & 19.93 & 13.69 & 7.84 & 71 & 5 \\
\hline & 5 & 2.156 & 0.536 & 1.620 & 10.00 & 10.26 & 6.33 & 64 & 8 \\
\hline \multicolumn{10}{|c|}{$\begin{array}{l}\text { WL }=\text { Water level } \\
\text { NA }=\text { not applicable } \\
\text { TBB }=\text { Trestle Bay Breach } \\
\text { FCB }=\text { Fort Clatsop Breach } \\
\text { KIB }=\text { Karlson Island Breach }\end{array}$} \\
\hline
\end{tabular}




\section{C.2.3 Sediment}

Sediment grain size, as measured from two sample locations at Karlson Island, was dominated by silt (Figure C.8). Very fine sediments were present at the sample locations. Total organic carbon was less than $5 \%$ of total sediment composition.

\section{Karlson Island Natural Breach Grain Size and TOC}

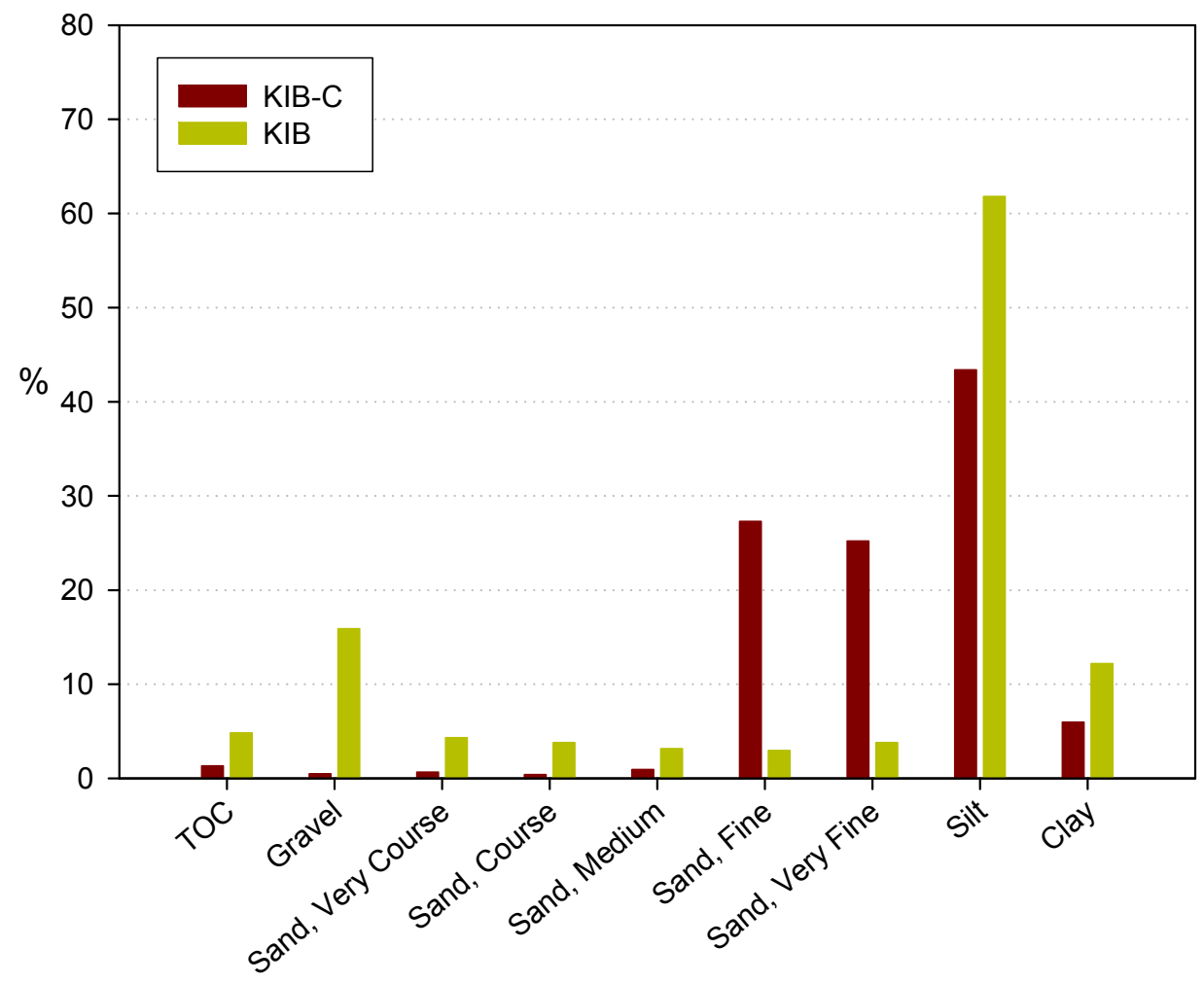

Figure C.8. Grain Size in Sediment Cores Taken from Historic Swamp Sites $(T O C=$ total organic carbon)

\section{C.3 Literature Cited}

Borde, AB, SA Zimmerman, and KL Sobocinski. 2008. "Crims Island - Monitoring Data Summary." Appendix A, in: Evaluating Cumulative Ecosystem Response to Restoration Projects in the Columbia River Estuary, Annual Report 2007, eds. GE Johnson and HL Diefenderfer. PNNL-17437, prepared by Pacific Northwest National Laboratory, Richland, Washington, and the National Marine Fisheries Service, Seattle, Washington, for the U.S. Army Corps of Engineers, Portland District, Portland, Oregon; pp. A1-A19.

Christy, JA and JA Putera. 1992. "Lower Columbia River natural area inventory." The Nature Conservancy, Seattle, Washington. 
Hinton, S and R Emmett. 2000. "Biological surveys of the Trestle Bay enhancement project 1994, 19961997." National Oceanic and Atmospheric Administration Technical Memorandum NMFS-NWFSC39, final report by the National Marine Fisheries Service, Seattle, Washington.

Johnson, GE and HL Diefenderfer (eds.). 2008. "Evaluating Cumulative Ecosystem Response to Restoration Projects in the Columbia River Estuary, Annual Report 2007." PNNL-17437, prepared by Pacific Northwest National Laboratory, Richland, Washington, and the National Marine Fisheries Service, Seattle, Washington, for the U.S. Army Corps of Engineers, Portland District, Portland, Oregon.

Simenstad, CA and BE Feist. 1996. "Restoration Potential of Diked Estuarine Wetlands: Inferring Fate and the Recovery Rate of Historically-Breached Sites.” EPA 910/R-96-005, U.S. Environmental Protection Agency Office of Ecosystems \& Communities, Seattle, Washington. 


\section{Appendix D}

\section{Wetted Area - Analysis Summary}





\title{
Appendix D
}

\section{Wetted Area - Analysis Summary}

\author{
Heida L. Diefenderfer, André M. Coleman, and Amy B. Borde
}

One purpose of tidal reconnection restoration is to increase wetted area thereby potentially increasing habitat opportunity and habitat capacity for juvenile salmonids (Simenstad and Cordell 2000). The purpose of this appendix is to describe the relationship between water surface elevation and wetted area given land surface elevations at two sites: Kandoll Reference and Kandoll Farm.

\section{D.1 Methods}

To document changes in water levels before and after restoration, $\mathrm{HOBO}{ }^{\circledR}$ model U20 water-level logger absolute pressure sensors were installed in reference and restoration channels prior to culvert installation, tide gate replacement, and dike breaching, as described in previous annual reports. Bi-hourly pressure data recorded by level loggers between July 2005 and March 2008 were summarized for this analysis. These data were corrected for atmospheric pressure and measured water level and are reported in the North American Vertical Datum of 1988 (NAVD88) to provide continuity with the light detection and ranging (LiDAR) data.

An area-time inundation index was calculated for two sites, Kandoll Reference and Kandoll Farm, for the water year 2006 (1 October 2005-30 September 2006), which immediately followed hydrological reconnection. The areas of inundation corresponding to water surface elevations were determined using a geographic information system (GIS)-based LiDAR elevation extraction and channel connectivity algorithm, and extracted at 10-cm increments and 0.5-hour time steps for the period of record (see Diefenderfer et al. [In Press] for a complete description of LiDAR extraction methods). Evaluating the resulting data, the point of inflection between water surface elevation and inundated area was determined to indicate overbank elevation and hence the beginning of floodplain inundation. The area-time inundation index was calculated as the number of hectare-hours of inundation, including both in-channel and floodplain area, summed at $10-\mathrm{cm}$ increments and divided by the total possible hectare-hours for each site.

\section{D.2 Results}

Soon after dike breaching and culvert installation, the muted tidal signals on channels inside the dikes were replaced by tidal dynamics comparable to the reference site (Diefenderfer et al. 2006). However, the frequency of inundation and area-time inundation index remained much different on adjacent restoration and reference sites.

LiDAR data indicate that the mean floodplain elevation of the restoration site on Seal Slough was $2.2 \mathrm{~m}($ s.d. $=0.5)$ compared with a mean of $2.9 \mathrm{~m}($ s.d. $=0.3)$ at the adjacent reference swamp (Figure D.1a). As measured by a topographic roughness index (Blaszczynski 1997; Riley et al. 1999), the microtopography was greater at Kandoll Reference swamp than on the neighboring diked agricultural 
land prior to restoration (Figure D.1b). The mean topographic roughness index in the swamp was 2.63 $(\mathrm{n}=586,404$, s.d. $=2.26, \min =0.03, \max =31.12)$, while in the pasture it was $1.40(\mathrm{n}=4,902,577$, s.d. $=$ $1.44, \min =0.02, \max =49.45)($ Diefenderfer et al. 2008).

Due to these topographic conditions, floodplain inundation at Kandoll Farm, as determined from the area-time extractions, began at the $1.65-\mathrm{m}$ water surface elevation (Figure D.2a), while at Kandoll Reference it began at $2.35 \mathrm{~m}$ (Figure D.2b); this $0.7-\mathrm{m}$ difference is identical to the difference of mean floodplain elevations (Figure D.1a). During water year 2006, following culvert installation on the Kandoll Farm restoration site, the area-time inundation index was 34\%, while at Kandoll Reference it was $9 \%$. The frequency of floodplain inundation at Kandoll Farm was 54\% compared with $18 \%$ at Kandoll Reference. The ordinary progression of inundation at Kandoll Reference, a tidal freshwater forested wetland site, is depicted in Figure D.3.

\section{D.3 Implications}

Based on these conclusions, in the early years after hydrologic reconnection, the area inundated on a particular recurrence interval will change as land surfaces rise. Thus the typical use of wetted area as an indicator of the effective size of tidal floodplain restoration projects, for the purpose of measuring available fish habitat, is likely to overestimate the areal extent of the inundation that will be seen some decades after implementation. The 34\% area-time inundation index seen at Kandoll Farm in the year following hydrological reconnection, for example, may be expected to decline toward the $9 \%$ seen at Kandoll Reference, as sediment accretes at a mean rate of $2.4 \mathrm{~cm} / \mathrm{yr}-1$ (Diefenderfer et al. In Press). Inundation frequency, too, would be expected to decline from $54 \%$ toward $18 \%$. However, projected rates of sediment accretion are based on measurements taken early after the implementation of restoration projects. A long-term dataset is needed to 1) verify whether the sediment accretion rates decrease over time; 2) understand the spatial patterns and variability of accretion rates; and 3) determine whether accretion through natural processes will continue until land elevations become similar to those found in the reference swamps. Additionally, some restoration designs may call for active modification of elevation during implementation. 

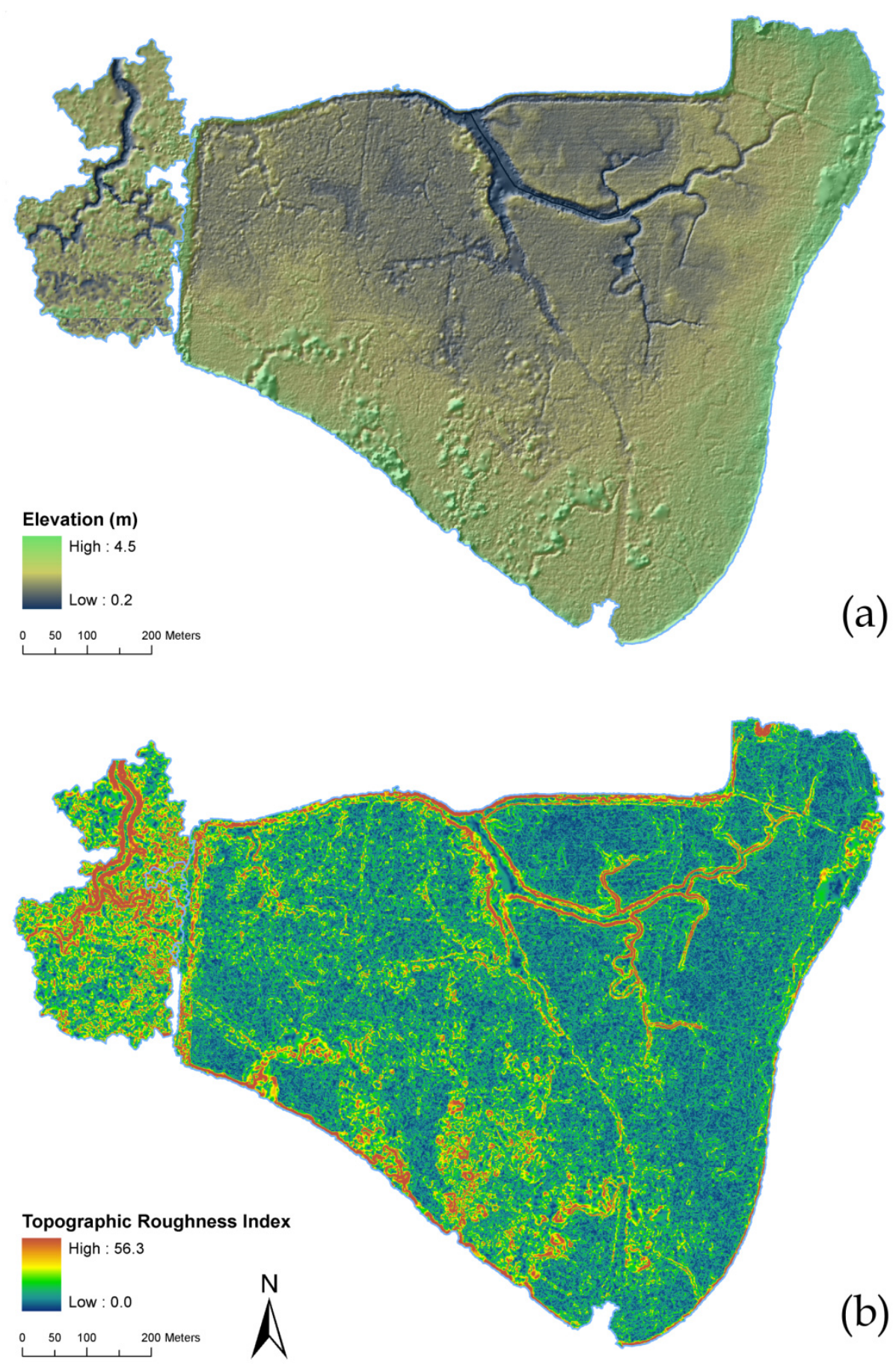

Figure D.1. Images of Kandoll Farm and Kandoll Reference Sites Derived from 2005 LiDAR Data. (a) Elevation and (b) topographic roughness index contrast the tidal forested wetland reference west of the road with the diked pre-restoration site east of the road. 


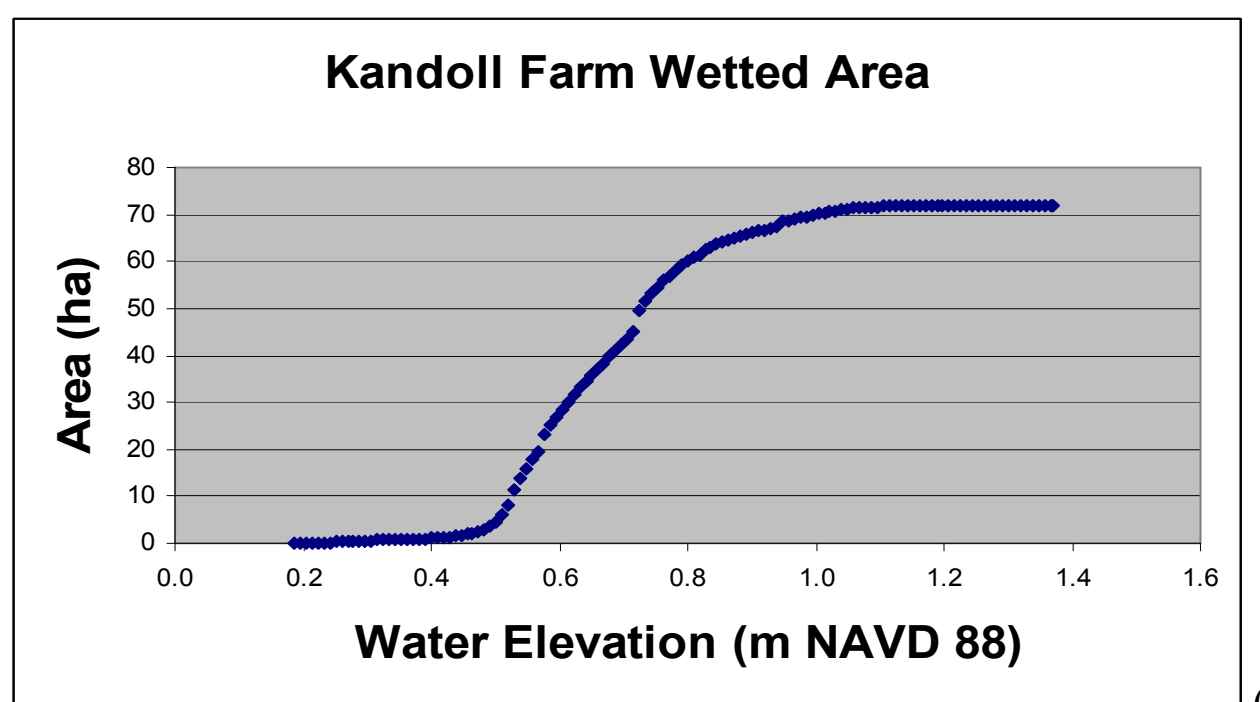

(a)

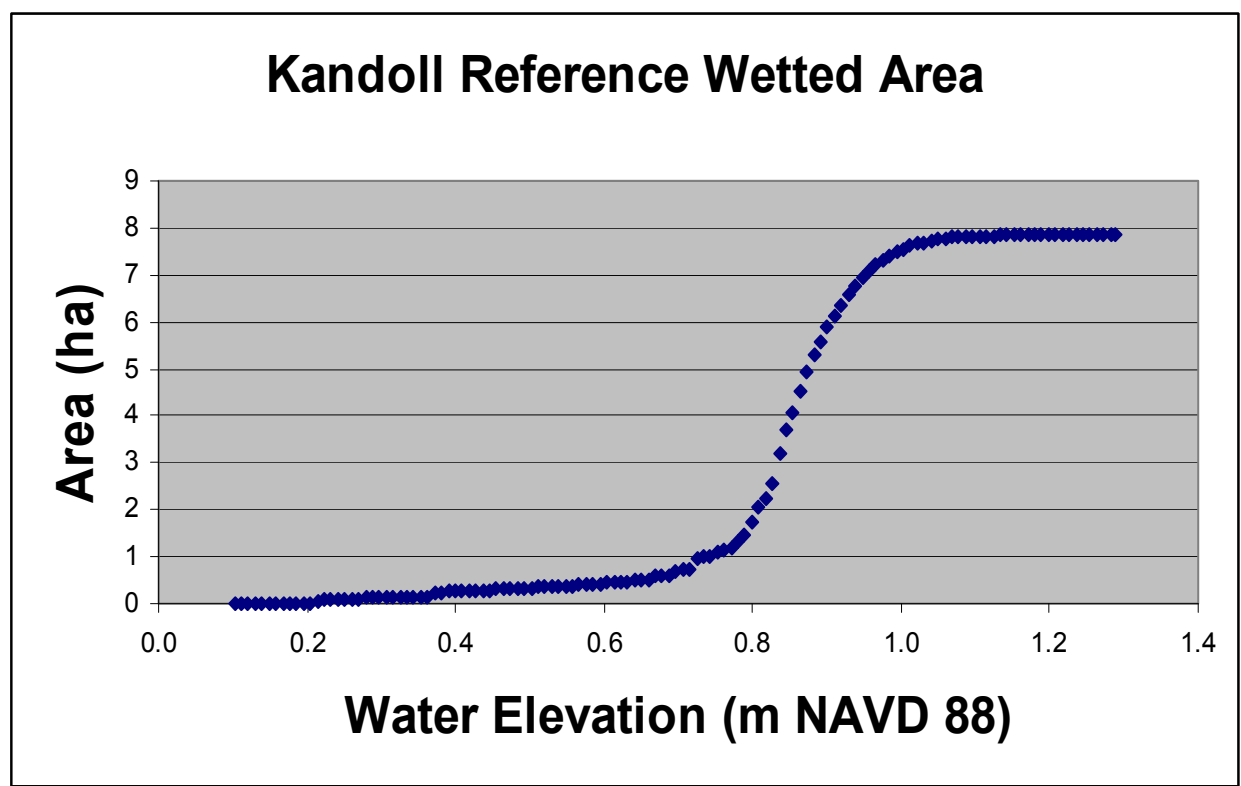

(b)

Figure D.2. Total Wetted Area Produced by Water Levels at (a) Kandoll Farm and (b) Kandoll Reference 


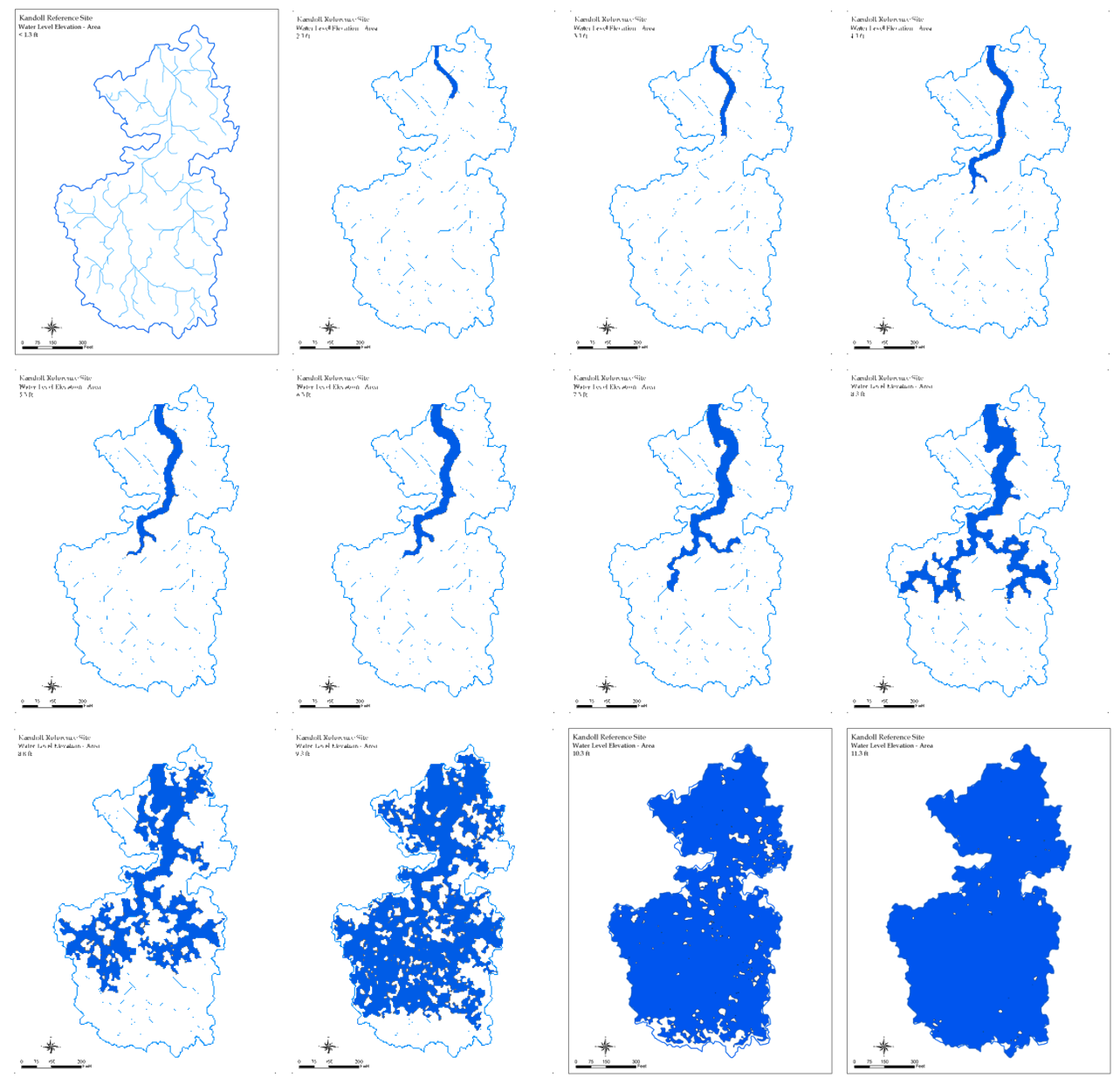

Figure D.3. A Typical Inundation Pattern. Pattern shown as the tide rises in a forested wetland, beginning at the top row left position with zero wetted area at $<1.3-\mathrm{ft}$ NAVD88, and continuing to the right with $2.3 \mathrm{ft}, 3.3 \mathrm{ft}$, etc. at 1 - $\mathrm{ft}$ water-level intervals through $11.3 \mathrm{ft}$. One 0.5 - $\mathrm{ft}$ increment is shown (bottom row, left position, $8.8 \mathrm{ft}$ ) due to the large change in wetted area between water elevations of 8.3-ft and 9.3-ft NAVD 88.

\section{D.4 Literature Cited}

Blaszczynski, JS. 1997. "Landform characterization with geographic information systems." Photogrammetric Engineering and Remote Sensing 63, 183-191.

Diefenderfer, HL, AM Coleman, AB Borde, and IA Sinks. 2008. "Hydraulic geometry of freshwater tidal forested wetlands and early channel morphological responses to hydrological reconnection, Columbia River, U.S.A.” Appendix G, pp. G1-G34, in Evaluating Cumulative Ecosystem Response to Restoration Projects in the Columbia River Estuary, Annual Report 2007, eds. GE Johnson and HL Diefenderfer. PNNL-17437, prepared by Pacific Northwest National Laboratory, Richland, Washington, for the U.S. Army Corps of Engineers, Portland District, Portland, Oregon. 
Diefenderfer, HL, AM Coleman, AB Borde, and IA Sinks. In Press. "Hydraulic geometry and microtopography of tidal freshwater forested wetlands and implications for restoration, Columbia River, U.S.A.” International Journal of Ecohydrology and Hydrobiology.

Diefenderfer, HL, Thom, RM, Borde, AB, Roegner, GC, Whiting, AH, Johnson, GE, Dawley, EM, Skalski, JR, Vavrinec, J, Ebberts, BD. 2006. Evaluating Cumulative Ecosystem Response to Restoration Projects in the Columbia River Estuary, Annual Report 2005. PNNL-15934, prepared by Pacific Northwest National Laboratory, Richland, Washington, for the US Army Corps of Engineers, Portland, Oregon.

Riley, SJ, SD DeGloria, and R Elliot. 1999. "A terrain ruggedness index that quantifies topographic heterogeneity." Intermountain Journal of Sciences 5:23-27.

Simenstad, CA and JR Cordell. 2000. "Ecological assessment criteria for restoring anadromous salmonid habitat in Pacific Northwest estuaries." Ecological Engineering 15:283-302. 


\section{Appendix E}

\section{Hydrology and Fish -}

Analysis Summary 



\title{
Appendix E
}

\section{Hydrology and Fish - Analysis Summary}

\author{
G. Curtis Roegner, Micah Russell, and Earl Dawley
}

The research focus from 2005 through 2007 was to document salmonid use in newly reconnected wetland sites. For the Grays River system, this work has been summarized in previous Annual Reports and a publication in review (Roegner et al. In Review). Our interest for 2008 and 2009 is to determine a more accurate integration of the spatio-temporal distribution of salmon within Kandoll Farm by measuring fish abundance and hydrographic parameters at several sites (two in 2008). This appendix summarizes the 2008 stage of this research conducted by NMFS, CREST, and E. Dawley.

\section{E.1 Kandoll Restoration Site}

The hydrography, fish spatial distribution, and diet at the Kandoll restoration site are described in the following sections.

\section{E.1.1 Hydrography}

Streamflow measurements in the Grays River were acquired from https://fortress.wa.gov/ecy/wrx/ wrx/flows/station.asp?sta $=25 \mathrm{~B} 060$. We also monitored hydrography with a network of pressure/temperature sensors (HOBO model U20-001-04, Onset Corp) or temperature-light sensors (HOBO model U20-001-04, Onset Corp) established at stations within and surrounding restoration sites in the Grays River system. At each station, instruments were secured to vertical poles or on bottom weights. The temperature-light sensors monitored temperature at the Kandoll Farm trap net sites. The time series are used to evaluate periods of suitable water-quality conditions for rearing salmonids. We calculated the 7-day average maximum daily temperature (7-DAM) and refer to a critical threshold of $16{ }^{\circ} \mathrm{C}$ as the upper criteria for optimum thermal conditions (EPA 2003; Richter and Kolmes 2005). For the available data, we compare temperature time series from inside Kandoll Farm and from the trap net sites, and from sites upstream (GRUpstream) and downstream (GRMouth) of the restoration site. (Data for the 2008 temperature-pressure sensors are unavailable at the time of this writing.)

Streamflow measurements in the Grays River during 2008 suffered from sensor malfunctions during four flood periods in January through April. However, overall flow patterns appeared to be dissimilar to the hydrography of 2005-2007 (Figure E.1). Flow in 2008 consisted of a relatively constant base flow of 10 to $30 \mathrm{~m}^{3} / \mathrm{s}$ with short-term pulses exceeding $50 \mathrm{~m}^{3} / \mathrm{s}$. This contrasts the more episodic and prolonged high flow periods in 2006 and 2007 (the 2005 time series is incomplete). The Columbia River experienced a very strong freshet during mid-May through June 2008. Flow-related analyses will be completed once the 2008 data are acquired. 

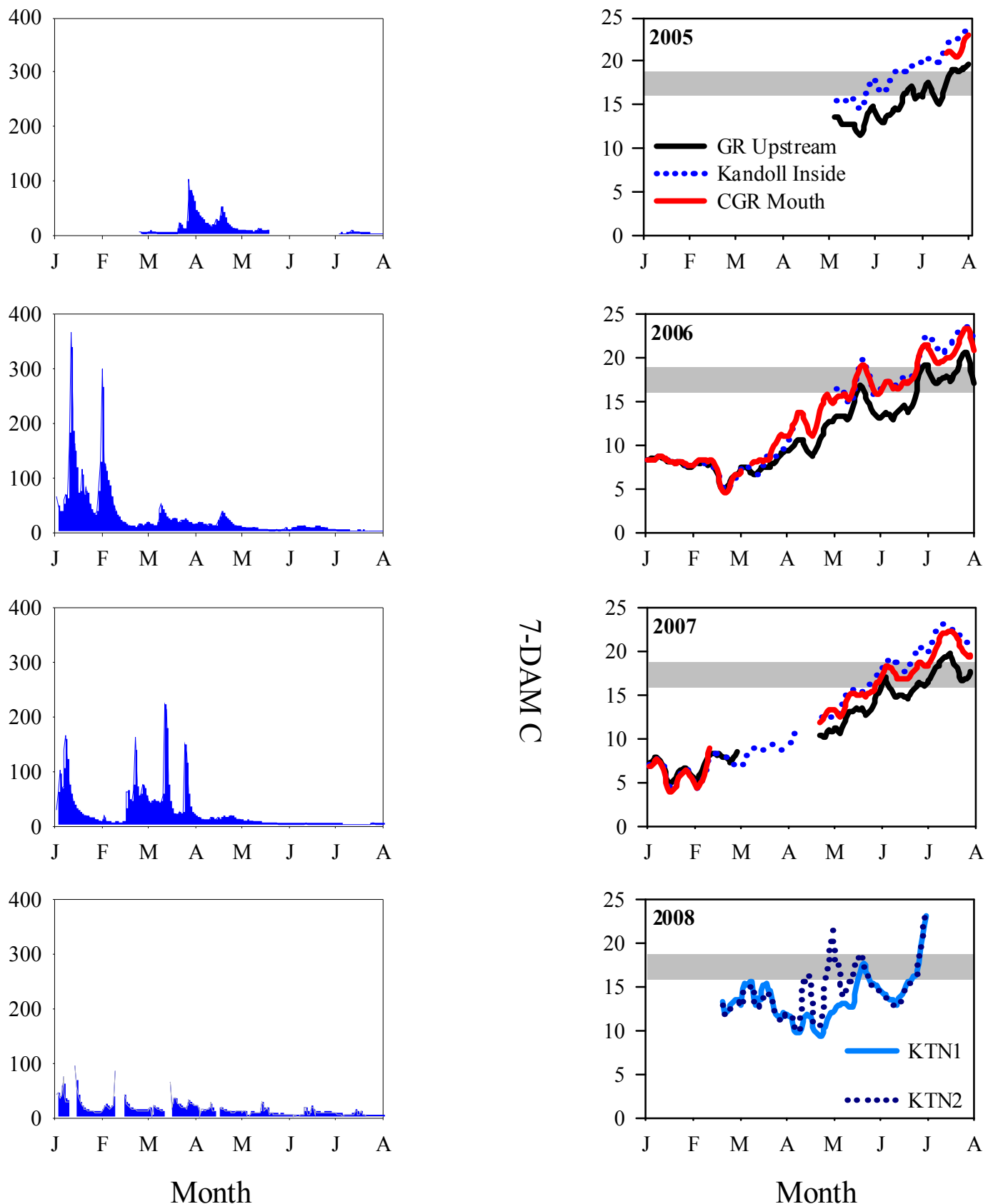

Figure E.1. Streamflow and Temperature Time Series in the Grays River System, 2005-2008. Left column: streamflow $\left(\mathrm{m}^{3} / \mathrm{s}\right)$ recorded at the Grays River hydrostation. Note gaps in the 2008 time series caused by senor malfunction during flood events. Right column: 7-day average maximum temperature time series (7-DAM). The 2005 through 2007 time series for stations GRMouth, Kandoll Inside, and GRUpstream. The 2008 plot shows temperature time series measured at Kandoll Trap No. 1 and No. 2 (KTN1 and KTN2, respectively). Gray band indicates temperature range of 16 to $19^{\circ} \mathrm{C}$. 
The 7-DAM temperature time series are for the January to July period each year from 2005 through 2007. This is typically the annual period of relatively high salmonid abundance. The data exhibited similar temporal trends within and across years but varied in magnitude between stations (Figure E.1). Temperature time series at GRUpstream diverged in spring and remained 3 to $5{ }^{\circ} \mathrm{C}$ lower than temperatures downstream at the GRMouth and Kandoll stations throughout summer (Figure E.1); these lower river locations had more similar temperatures. Each year, 7-DAM temperature exceeded the $16{ }^{\circ} \mathrm{C}$ criterion earlier at the lower stations (May versus June) and remained above $16{ }^{\circ} \mathrm{C}$ for a longer period (usually through September) than at GRUpstream. Maximum daily temperature regularly exceeded $20{ }^{\circ} \mathrm{C}$ at the GRMouth and within the restoration site, but only occasionally at the upstream site. The 7-DAM temperature time series from trap net sites in 2008 were anomalous compared with previous years. Both sensors recorded much warmer temperatures during March and April than expected. The time series deviated from each other from April to May, with KTN1 tracking a more expected seasonal trajectory while KTN2 had many days exceeding the $16{ }^{\circ} \mathrm{C}$ threshold. The two time series re-aligned in mid-May, and exhibited a rapid increase in June. These higher temperatures are likely due to sensor placement in shallow water where atmospheric heating is greater than the at the deeper pressure-temperature deployment sites. We will reexamine temperature trends once the 2008 data loggers are acquired.

\section{E.1.2 Fish Spatial Distribution}

The goal of the 2008 fish sampling was to explore the spatial distribution of salmonid habitat use in the Kandoll Farm restoration site. Data from a preliminary study initiated in 2007 are also presented. We used paired deployments of trap (fyke) nets deployed in developing intertidal channels. TN1 was located at our long-term sampling site and extends that time series to 3 years. TN2 was located approximately $100 \mathrm{~m}$ from TN1 on an adjacent tidal channel. The trap nets were comprised of two 15-x-2.4-m net leads connected to a $0.75-\mathrm{m}^{2}$ throat and $1.8-\mathrm{m}$ long cod end. The nets were set at high water and fished for 4 to 5 hours during the outgoing (ebb) tide to catch fish moving toward the river as the water within the channel drained.

All fish were identified to species, enumerated, and measured to nearest millimeter. Salmonids were anesthetized with a 50-mg L-1 solution of tricaine methane sulfonate (MS222) before measurement. We closely examined salmon for any external marks indicating hatchery production. Suitably sized juvenile coho and Chinook salmon (chum being too small) had their stomach contents sampled by gastric lavage to determine prey use. This nonlethal method uses filtered water flushed into the stomach to evacuate the contents into a sample jar fixed with $10 \%$ formalin.

We plotted salmon catch per unit effort (CPUE) by day of year to generalize temporal trends (Figure E.2). Few Chinook salmon were captured in 2007 or 2008. Chum tended to be present for 2 to 3 weeks in March-April and numbers declined sharply by 1 May. Coho had a more variable pattern extending from March through June (and occasionally in July) with peak abundance usually in May or June. Overall abundance patterns of chum and coho were similar between years and TN2 generally had a higher CPUE. In 2008, catches were 4 to 5 times higher at the TN2 site. We will be standardizing these counts by area to determine if fish densities differ between sites.

We plotted salmon CPUE by 7-DAM temperature to investigate salmon distribution based on thermal regime (Figure E.3). Chinook abundance was too low in 2007 and 2008 for analysis, but data from previous years indicate that abundance was greatest at 7-DAM temperatures between 11 to $16{ }^{\circ} \mathrm{C}$ 
(Roegner et al. In Review). However Chinook salmon were found in water as high as $23{ }^{\circ} \mathrm{C}$. Chum salmon peaked at temperatures of 9 to $12{ }^{\circ} \mathrm{C}$ (in 2007), and a few individuals were found at 7-DAM temperature $>16^{\circ} \mathrm{C}$, unlike previous years. Note that these 7-DAM temperature readings are based on the anomalously high in situ measurements. Coho salmon abundance peaked at 12 to $18^{\circ} \mathrm{C}$.
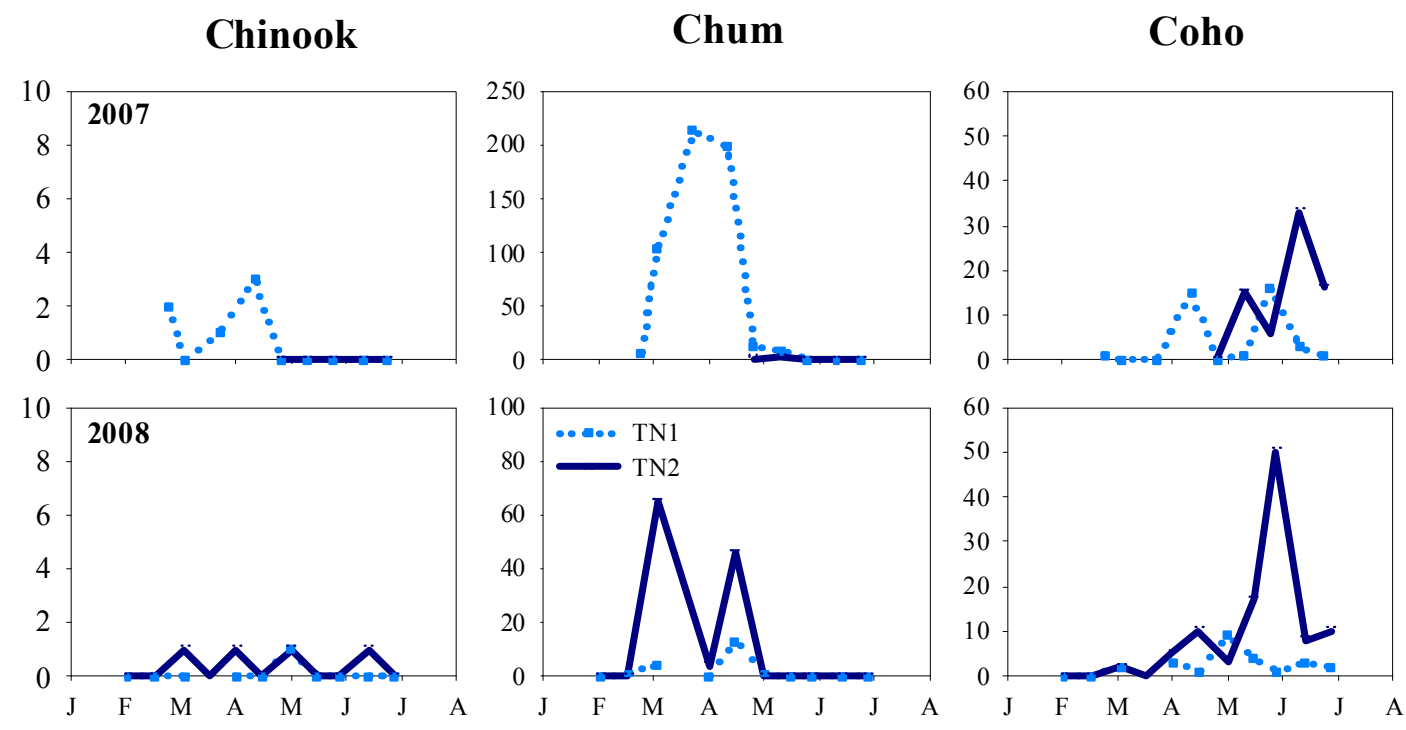

\section{Month}

Figure E.2. CPUE Time Series for Salmon Species Captured at Kandoll TN1 and TN2 During 2007 and 2008. TN2 measurements in 2007 were not initiated until May.
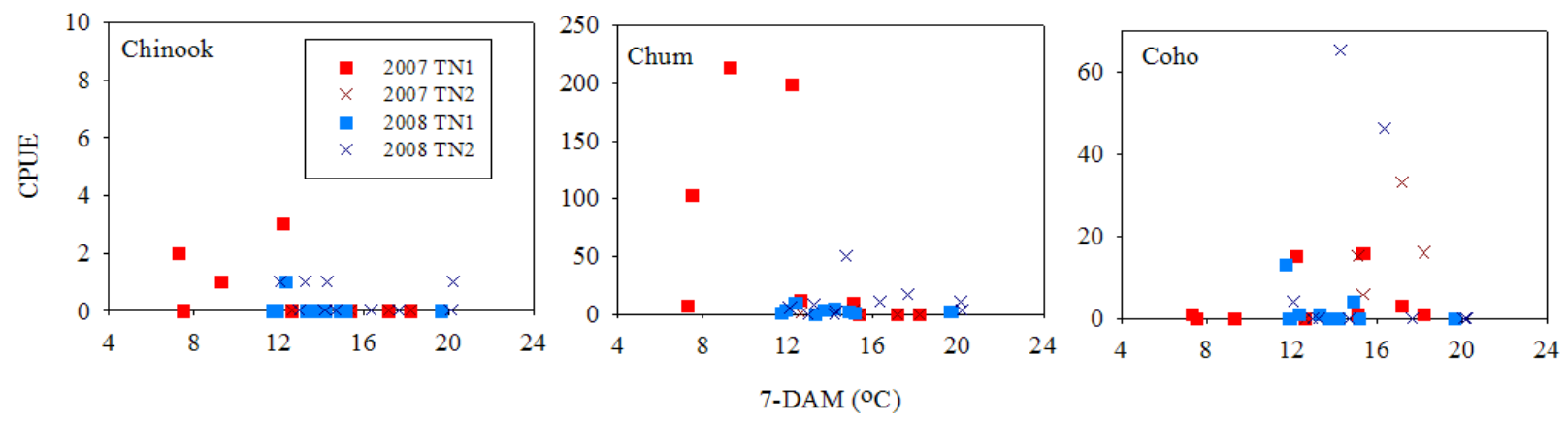

Figure E.3. Scatterplot of Salmon CPUE and 7-DAM

Chum and especially Chinook salmon abundance appeared to be lower in 2008 than in previous years. This may reflect decreased production in the Grays River system. Table E.1 lists the return and passage of salmonids to the Grays River hatchery. As can be seen, very few Chinook adults were sampled, although all were released to continue upstream. Chum numbers were higher but all were harvested for eggs, leaving none for natural production. Coho numbers were more robust. 
Table E.1. Salmon Adult Returns to the Grays River Hatchery, 2004-2007

(Source: http://wdfw.wa.gov/hat/ escape/04-05-e-report.pdf)

\begin{tabular}{llrrr}
\hline & & \multicolumn{2}{c}{ Trapped } & Total \\
\cline { 2 - 5 } & & Adult & Jack & Released \\
\hline \multirow{2}{*}{$2004-05$} & Chinook & 10 & 0 & 5 \\
& Chum & 308 & & 0 \\
& Coho & 2221 & 173 & 1893 \\
\multirow{2}{*}{$2005-06$} & Chinook & 11 & 0 & 11 \\
& Chum & 128 & & 0 \\
& Coho & 4834 & & 3994 \\
& Chinook & 29 & 5 & 29 \\
$2006-07$ & Chum & 118 & & 0 \\
& Coho & 859 & 15 & 184 \\
\hline
\end{tabular}

\section{E.1.3 Fish Diet}

Stomach contents were wet-weighed and then sorted and identified to the lowest taxonomic level possible (depending on the extent of digestion and taxonomic authority) under a dissection microscope. For analysis, we grouped the data into major taxa categories to emphasize dominant prey groups by count and weight, and examined the data for monthly trends. Diet data metrics include percent numerical and gravimetric prey composition, which were used to calculate an index of relative importance (IRI). IRI is calculated as $\% \mathrm{O} \times(\% \mathrm{~N}+\% \mathrm{~W})$, where $\% \mathrm{O}$ is the proportional occurrence and $\% \mathrm{~N}$ and $\% \mathrm{~W}$ were the proportions by number and weight, respectively (Shreffer et al. 1992). \%IRI for each salmon species and location was computed as IRI / $\sum$ IRI.

The gut contents of 70 subyearling Coho salmon were analyzed in 2008. Coho diets were relatively uniform over time, with insects comprising the primary prey (numerical abundance and \%IRI). However, annelids though few in number scored high in \% weight. Amphipods and isopods were a minor part of the diet. These data agree with our previous results and other studies that indicate insects produced in wetlands are the dominate prey type for salmon foraging in many habitats, including fluvial, tidal freshwater, and estuarine environments. However, comparisons between restoration wetlands and channel habitats in the Grays River system have shown that restoration sites provided greater diet diversity than did sampling stations in Grays River. Fish inside restoration sites ate more annelids and fish, and although the abundance of these prey items in stomachs was relatively low, the prey items were large and likely of high caloric value. Previous studies and our data indicate that restoring wetland habitats benefits salmonids by providing varied food items compared to adjacent aquatic systems. 

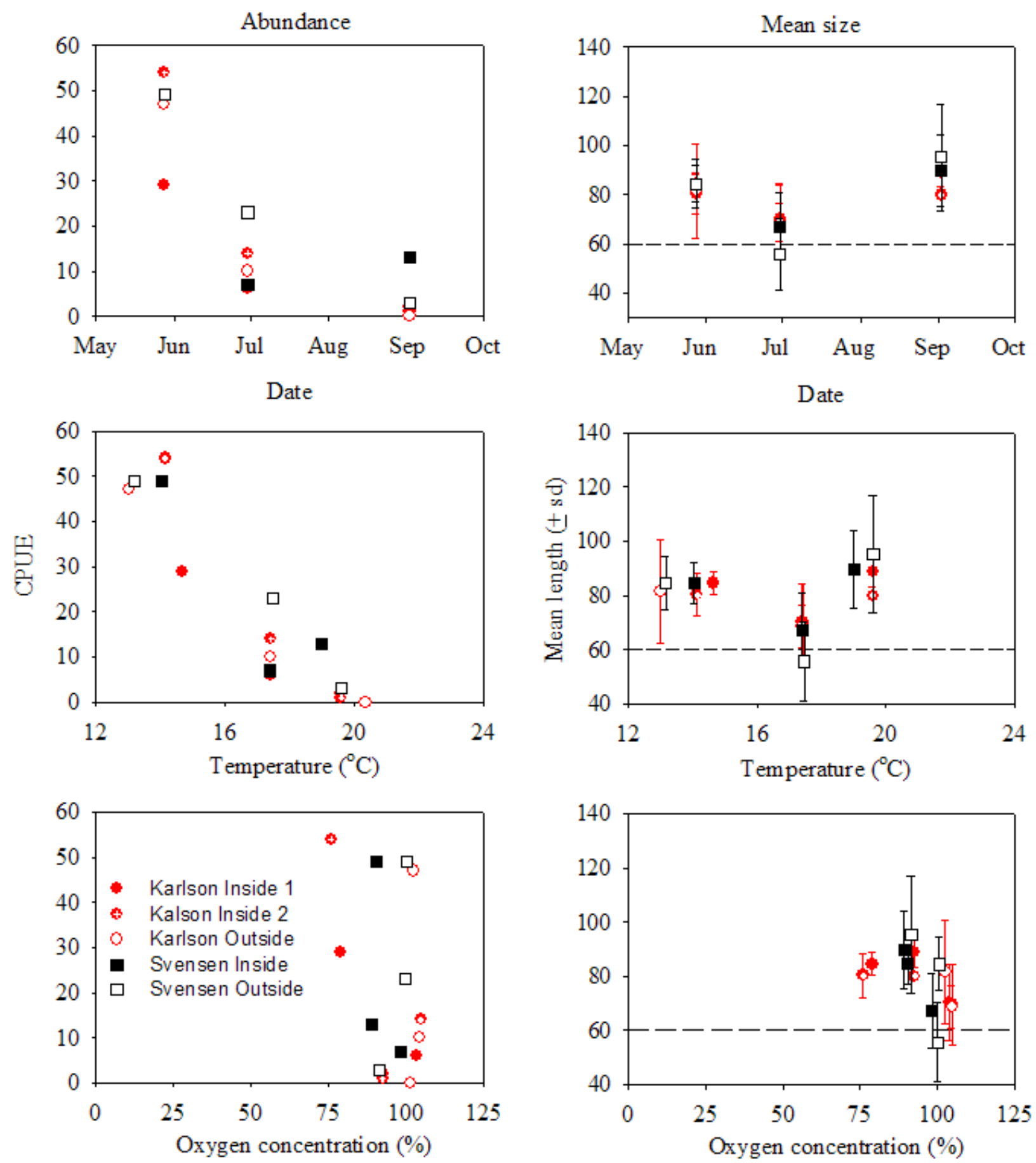

Figure E.4. Chinook Salmon CPUE and Mean Size in Relation to Time, Temperature, and Percent Oxygen Concentration. Water data were measured at the $1.5 \mathrm{~m}$ depth, which is the middle of the seine net. 


\section{E.2 Natural Breach Sites}

\section{E.2.1 Hydrography}

Conductivity-temperature-depth (CTD) casts made during the fish sampling revealed water-quality parameters of concern. All sites were within the tidal freshwater zone. Temperatures were generally isothermal with depth (Figure E.5) and increased from 13 to $15^{\circ} \mathrm{C}$ in May to between 18 and $20{ }^{\circ} \mathrm{C}$ in September (Figures E.5 and E.6). These later temperature can cause stress in salmonids (EPA 2003) and may explain the low abundances found at all sites in September (Figure E.5). Dissolved oxygen concentrations generally remained above $75 \%$ saturation, and levels inside the breach sites tended to be lower than levels found outside the breaches (Figures E.5 and E.6). These oxygen levels are not limiting to salmonids. Mean sizes of Chinook salmon exhibit no obvious trend with time, temperature, or oxygen concentration (Figure E.7).

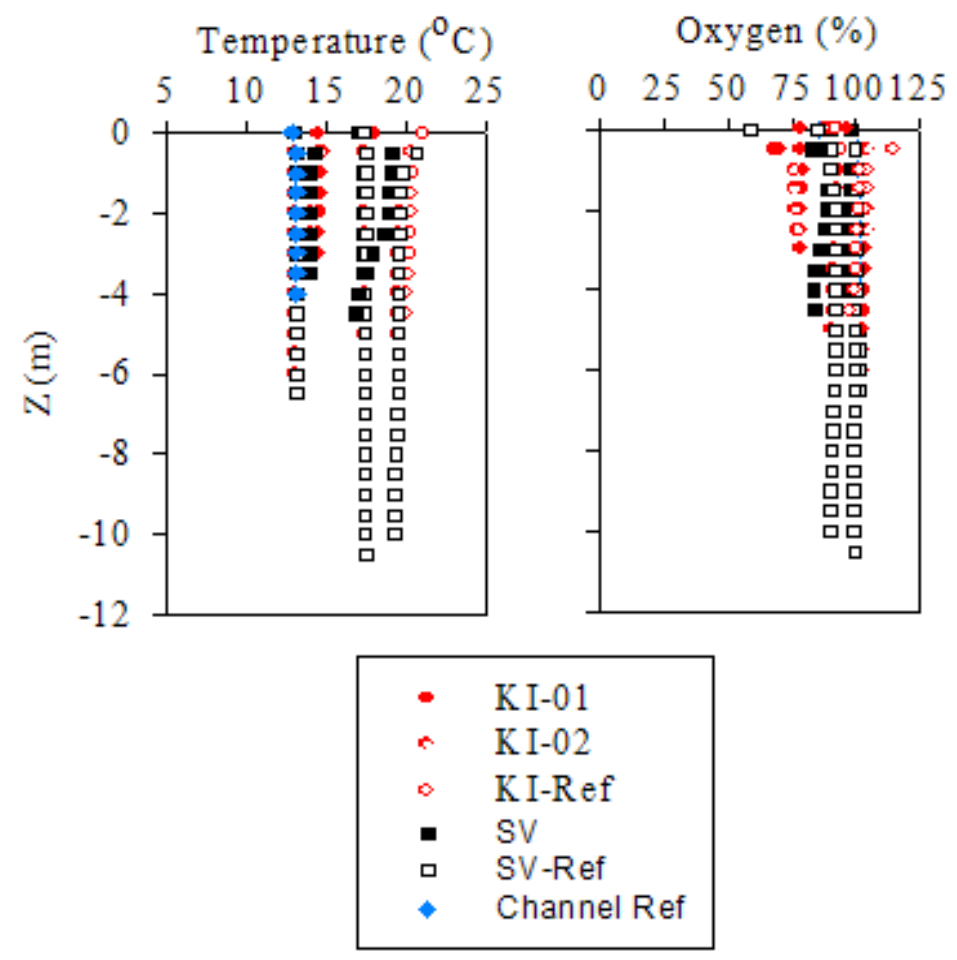

Figure E.5. Vertical Distribution of Temperature and Dissolved Oxygen at Natural Breach Sites in May, June, and September 2008 

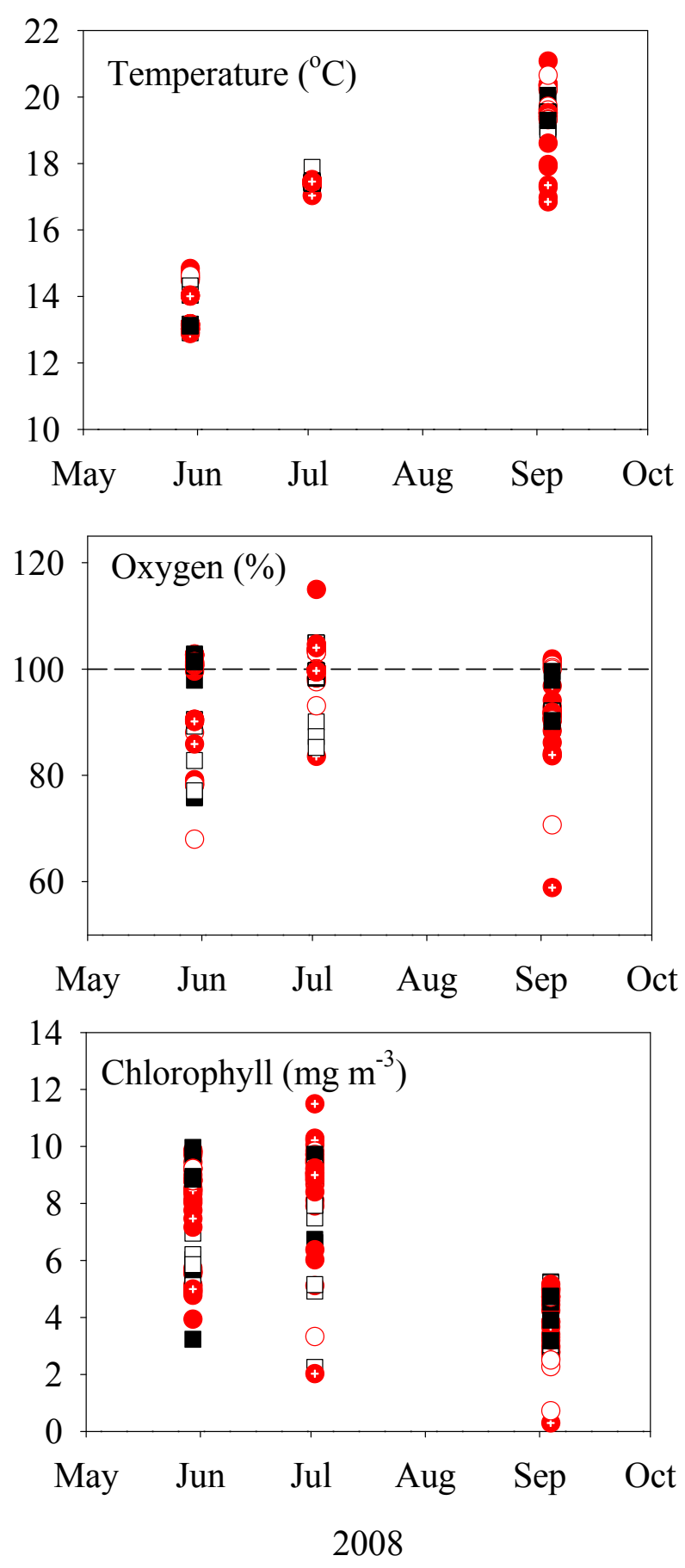

Figure E.6. Time Series of Temperature, Oxygen, and Chlorophyll During May, June, and September 2008 


\section{E.2.2 Fish}

We surveyed for salmon and hydrographic conditions at two sites in Cathlamet Bay that have experienced dike failure and a return to tidal inundation. Beach seine and CTD samples were made in channels within (in) and outside (out) the breached area on 28 May, 30 June, and 2 September. Fish stomach contents were sampled in June and September. We captured 307 Chinook salmon, 2 chum, and 1 coho. Abundances were highest in May, moderate in June, and low in September (Table E.2). Within each month, we caught similar numbers of salmon between inside and outside the breached areas, except for Seal Island outside in June, which had a relatively higher abundance. In May, a high percentage of fish at all sites were adipose fin-clipped, indicating a hatchery origin, and these fish tended to be in the 80 to 95-mm range (Table E.2). Fewer clipped fish were found later in the season. We examined sizefrequency plots to ascertain life-history stage of the salmon (Figures E.7 and E.8). The percentage of fry (fork length $<60 \mathrm{~mm}$ ) was highest in June and we found no fry in September. Fry are likely of natural origin (not produced in hatcheries). The larger fish were fingerling-sized; no yearling Chinook salmon were sampled. Fry were present in the breached areas, but higher percentages were occupying sites outside the breaches. During September, a group of 95- to 105-mm-long hatchery-reared fish was caught in Svensen Island inside, and few fish were captured elsewhere. Fish diet composition was similar between natural breach and reference sites (Figure E.9).

Table E.2. Chinook Salmon Within and Outside Natural Breach Sites

\begin{tabular}{lrrrrrrrr}
\hline Station & Date & CPUE & Fry & \% fry & Adipose & \%Ad & mean & s.d. \\
\hline Karlson in01 & $5 / 28 / 2008$ & 29 & 0 & 0.0 & 27 & 93.1 & 84.6 & 4.0 \\
& $6 / 30 / 2008$ & 6 & 3 & 50.0 & 2 & 33.3 & 70.2 & 14.0 \\
& $9 / 2 / 2008$ & 2 & 0 & 0.0 & 0 & 0.0 & 89.0 & 5.7 \\
\hline \multirow{5}{*}{ Karlson in02 } & $5 / 28 / 2008$ & 54 & 3 & 5.6 & 44 & 81.5 & 80.4 & 8.1 \\
& $6 / 30 / 2008$ & 14 & 5 & 35.7 & 2 & 14.3 & 69.6 & 14.7 \\
& $9 / 2 / 2008$ & 1 & 0 & 0.0 & 0 & 0.0 & 80.0 & \\
Seal -Out & $5 / 28 / 2008$ & 47 & 10 & 21.3 & 33 & 70.2 & 81.7 & 19.1 \\
& $6 / 30 / 2008$ & 10 & 1 & 10.0 & 5 & 50.0 & 68.6 & 7.7 \\
& $9 / 2 / 2008$ & 0 & 0 & & & & & \\
Svensen In & $5 / 28 / 2008$ & 49 & 1 & 2.0 & 40 & 81.6 & 84.5 & 7.4 \\
& $6 / 30 / 2008$ & 7 & 2 & 28.6 & 2 & 28.6 & 67.1 & 13.8 \\
& $9 / 2 / 2008$ & 13 & 0 & 0.0 & 5 & 38.5 & 89.8 & 14.3 \\
Svensen Out & $5 / 28 / 2008$ & 49 & 2 & 4.1 & 43 & 87.8 & 84.4 & 9.8 \\
& $6 / 30 / 2008$ & 23 & 18 & 78.3 & 3 & 13.0 & 55.7 & 14.5 \\
& $9 / 2 / 2008$ & 3 & 0 & 0.0 & 2 & 66.7 & 95.3 & 21.5 \\
& & 307 & 45 & 14.7 & 208 & 67.8 & & \\
\hline
\end{tabular}


In summary, both hatchery-derived and wild (presumably) fish were present in the breached sites. As with other sites in the Columbia River, abundance levels peaked in spring and decreased as summer progressed. Temperature and oxygen levels were generally similar between inside and outside breach sites on a given date.

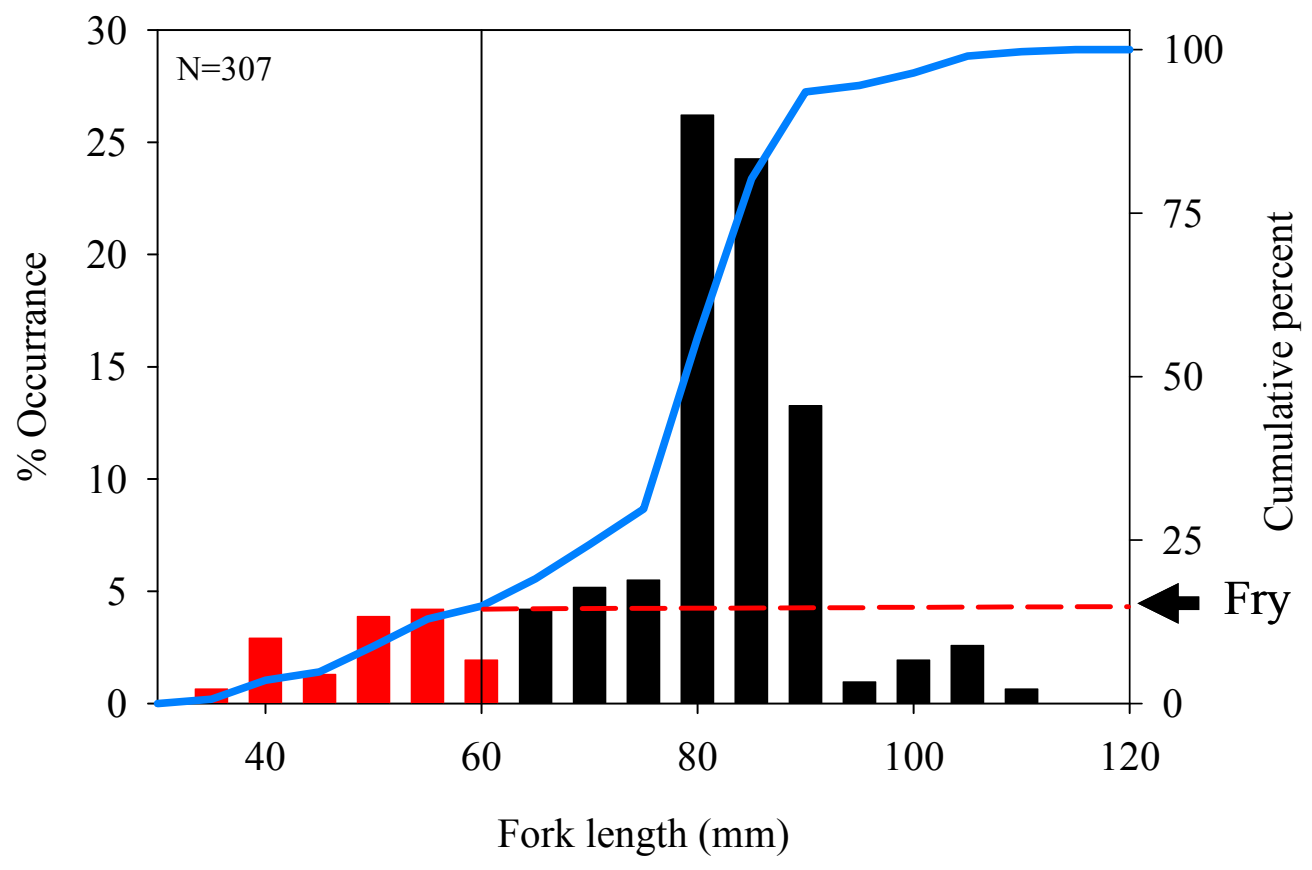

Figure E.7. Composite Size-Frequency Histogram of Salmon Sampled During Surveys of Karlson Island and Svensen Island Breach Sites. Red bars designate fry. Blue line traces the cumulative percent occurrence curve. 

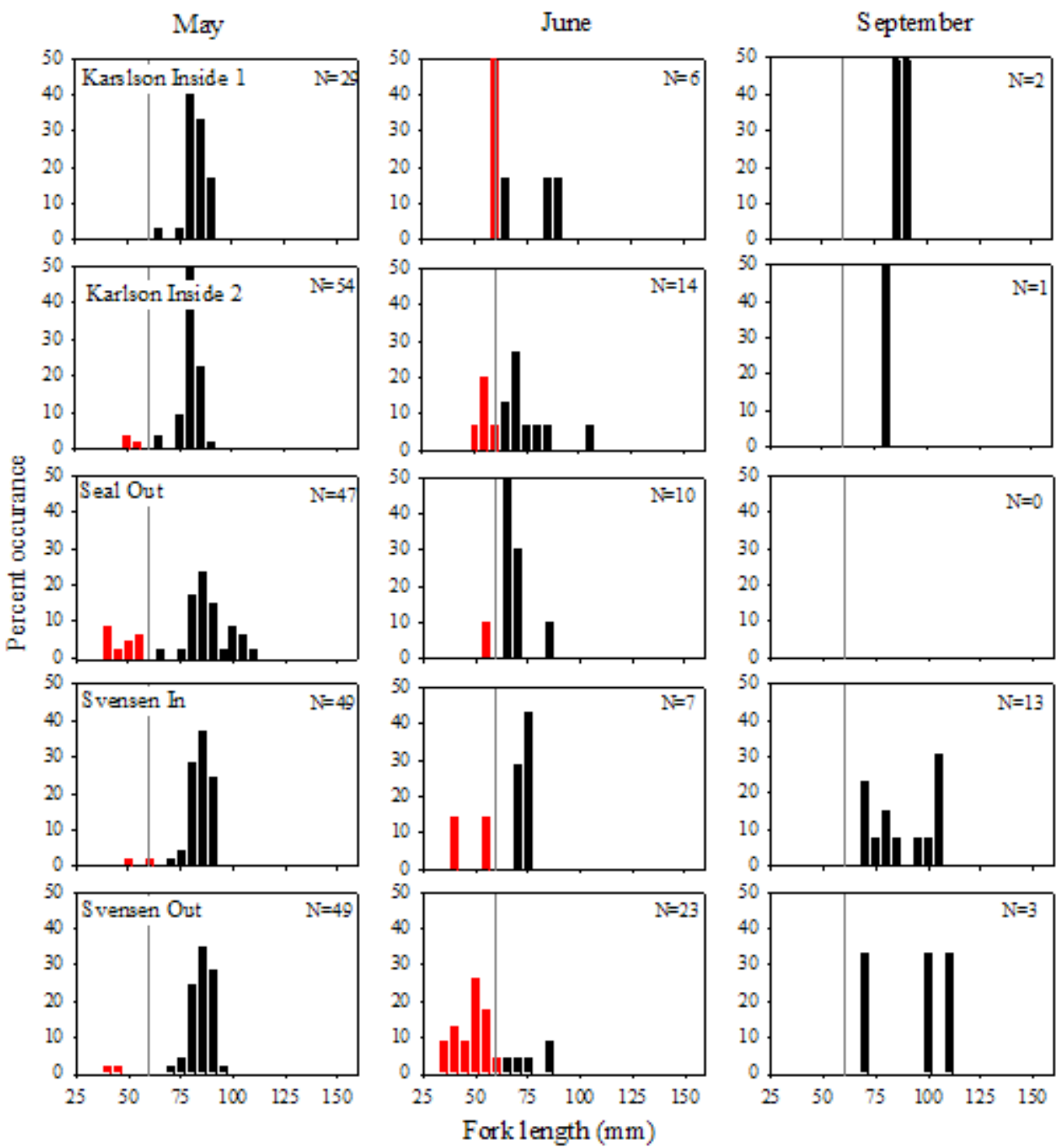

Figure E.8. Size-Frequency Histogram of Salmon Sampled During Surveys of Karlson Island and Svensen Island Breach Sites in May, June, and September 2008. Red bars designate fry. 


\section{Subyearling Chinook 2008}
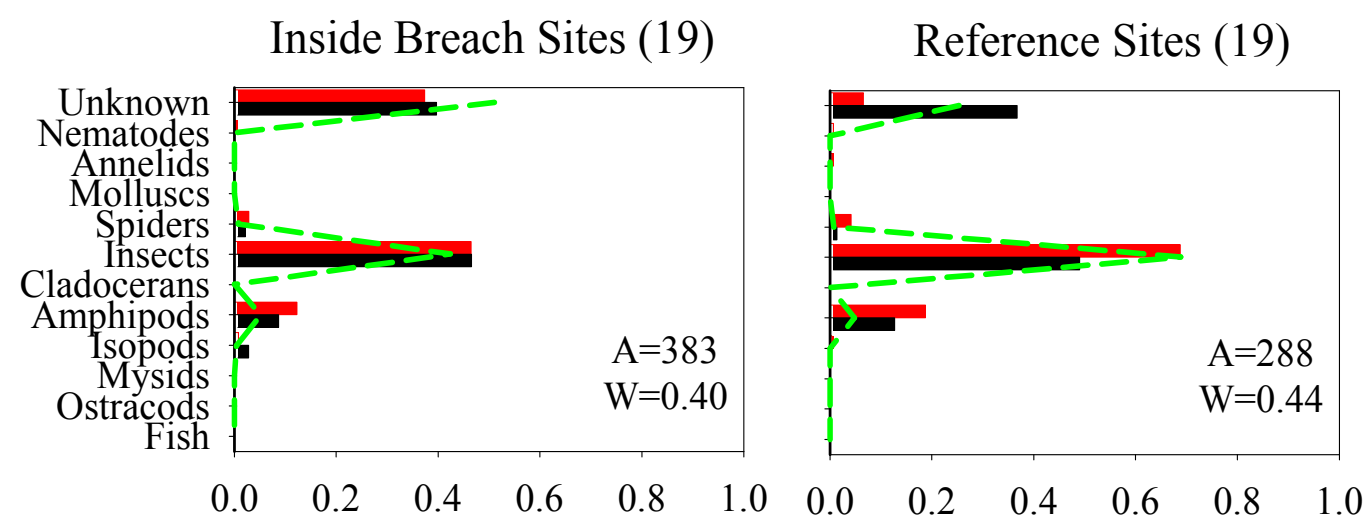

\section{Proportion}

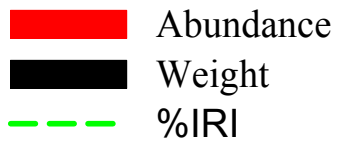

Figure E.9. Subyearling Diet at Breach Sites

\section{E.3 Literature Cited}

Richter, A and SA Kolmes. 2005. "Maximum temperature limits for Chinook, coho, and chum salmon, and steelhead trout in the Pacific Northwest." Reviews in Fisheries Science 13: 23-49.

Roegner, GC, EW Dawley, M Russell, A Whiting, and DJ Teel. 2008. In Review. "Juvenile salmon use of newly reconnected tidal freshwater wetland habitats in the Grays River tributary of the lower Columbia River." Transaction of the American Fisheries Society.

U.S. Environmental Protection Agency (EPA). 2003. EPA Region 10 Guidance for Pacific Northwest State and Tribal Temperature Water Quality Standards. EPA 910-B-03-002, Region 10 Office of Water, Seattle, Washington. 


\section{Appendix F}

\section{Julia Butler Hansen Wildlife Refuge - Monitoring Data Summary}





\title{
Appendix F
}

\section{Julia Butler Hansen Wildlife Refuge - Monitoring Data Summary}

\author{
Amy B. Borde, Heida L. Diefenderfer, and Shon A. Zimmerman
}

\section{F.1 Introduction}

Baseline monitoring of tide gate replacement and installation project sites at the Julia Butler Hansen National Wildlife Refuge (JBH) was initiated in 2007 and continued at additional sites in 2008 as reported in this appendix. The CENWP is implementing construction of multiple tide gates on this U.S. Fish and Wildlife Service site in phases, beginning in 2009. Baseline monitoring was conducted in 2007 on Ellison Slough and Duck Lake Slough, as well as an unnamed channel with a previously replaced tide gate for comparison (reported by Borde et al. 2008). Baseline monitoring of Hampson Slough and Winter Slough was conducted in 2008 (Figure F.1).

A reference site was as also monitored in 2008. The reference site is located on the refuge and is located in a similar landscape as the restoration sites (i.e., it is located within the diked area of the mainland and is affected by the hydrology of the watershed above it); however the site has been "connected" to Columbia River tidal flows through a nonfunctioning tide gate and therefore provides some indication of tidally restored conditions over time. This reference site does not receive hydrologic flows overland from other sloughs within the confines of the dike- a condition that can confound the evaluation of the results from restored tidal flows. In addition, the site has a forested riparian areaanother intended result of the restoration actions.

Monitored indicators at all sites included landscape features, elevation, and vegetation. Water properties flux monitoring was monitored in 2007-2008 as well, on a four-season sampling plan and will be presented in future reports of the Cumulative Effects Study.

\section{F.2 Methods}

Monitoring was conducted July 14-18, 2008, following methods described in the standard monitoring protocols for the region (Roegner et. al. 2009). The specific methods are detailed further below. 

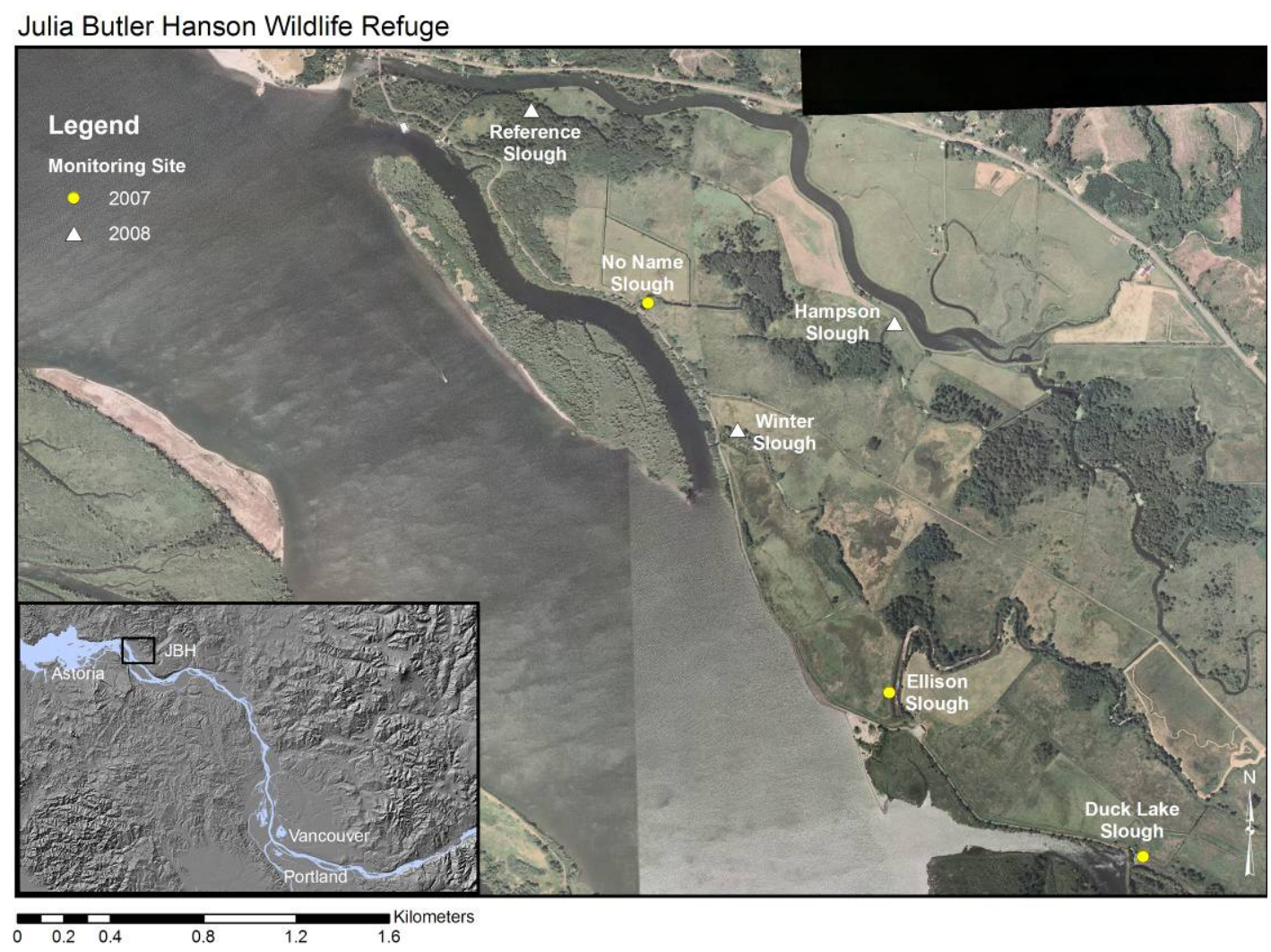

Figure F.1. 2007 and 2008 Monitoring Sites at JBH

\section{F.2.1 Sediment Accretion}

Sediment accretion stakes were installed to track changes in substrate elevation. Polyvinyl chloride (PVC) stakes (approximately $1.5 \mathrm{~m}$ in length) were installed to equal heights in a north-south direction exactly $1 \mathrm{~m}$ apart (Figure F.2). The height from the substrate surface to the top of the stakes was measured at $10-\mathrm{cm}$ intervals between the stakes and averaged. The elevation of the top of the stakes was also measured using the methods described in the Elevation section below.

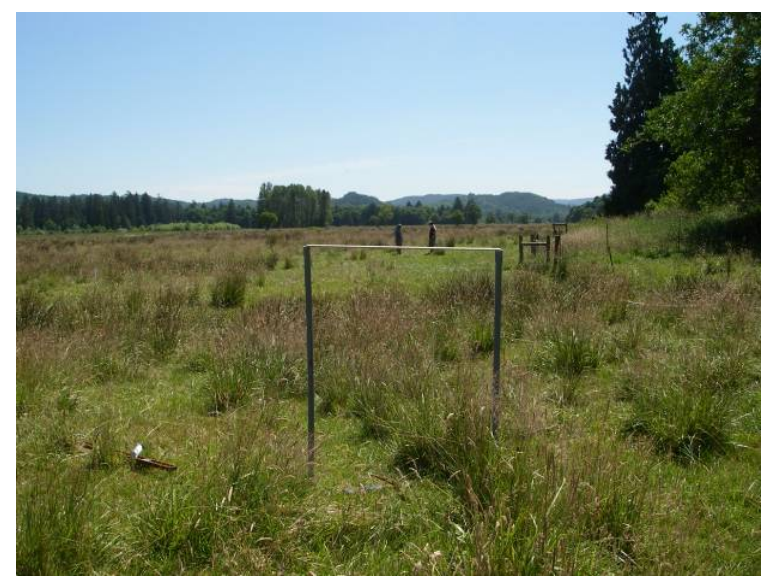

Figure F.2. Sedimentation Stakes at Winter Slough 


\section{F.2.2 Elevation}

Elevations were measured at the using a Trimble 5700 real-time kinematic (RTK) global positioning system (GPS) relative to the NAVD88 datum (North American Vertical Datum of 1988). The base station was located on a benchmark of known position and elevation and a Trimble 5800 receiver (rover) was used to determine elevations at each sample location. The elevations of the vegetation sample points, sedimentation stakes, and channel cross sections were measured at the restoration and reference sites using the RTK GPS. The elevation was measured at the centerpoint of each vegetation sample quadrant. The RTK GPS was also used to obtain elevations for the channel cross sections located at Hampson and Winter Sloughs, while at the Reference Slough an auto-level and survey rod were used based on a known elevation at one of the endpoints as described in the Channel Cross section below.

\section{F.2.3 Vegetation}

Vegetation sampling was concentrated proximal to expected changes - in this case, near the mouth of the main channel at the sites. A 50-m-x-50-m systematic grid was established, with a baseline tape running perpendicular to the channels at Hampson and Winter and parallel to the channel at the Reference Slough. Sample locations were evenly spaced (10 m apart) along perpendicular transects with a random start. The number of vegetation sample plots and their locations are shown in Table F.1 and Figure F.3.

Herbaceous species were identified and their percent cover was visually estimated in $1-\mathrm{m}^{2}$ quadrats in $5 \%$ increments for each species. At the restoration sites, which were primarily herbaceous, shrubs if present were included in the percent cover estimates. A "trace" amount of cover was given a score of 1\%. Bare ground was also noted if present in each quadrat. At the restoration sites, a randomly selected subset of five vegetation plots was marked as permanent plots for trends-analysis subsequent to restoration. At the Reference site, trees were identified and their basal area and relative density estimated in $10-\mathrm{m}-$ diameter plots spaced $15 \mathrm{~m}$ apart. In addition, shrubs were identified and counted in a 1-m- -0- plot within a subset of the tree plots.

Table F.1. Number (N) of Vegetation Sample Plots and Number of Species Identified at Each Site

\begin{tabular}{lcccccc}
\hline & \multicolumn{2}{c}{ Reference } & \multicolumn{2}{c}{ Winter } & \multicolumn{2}{c}{ Hampson } \\
\hline Metric & N & \# Species & N & \# Species & N & \# species \\
Herbaceous & 36 & 23 & 25 & 20 & 25 & 30 \\
Shrub & 10 & 4 & -- & -- & -- & -- \\
Tree & 29 & 4 & -- & -- & -- & -- \\
\hline
\end{tabular}



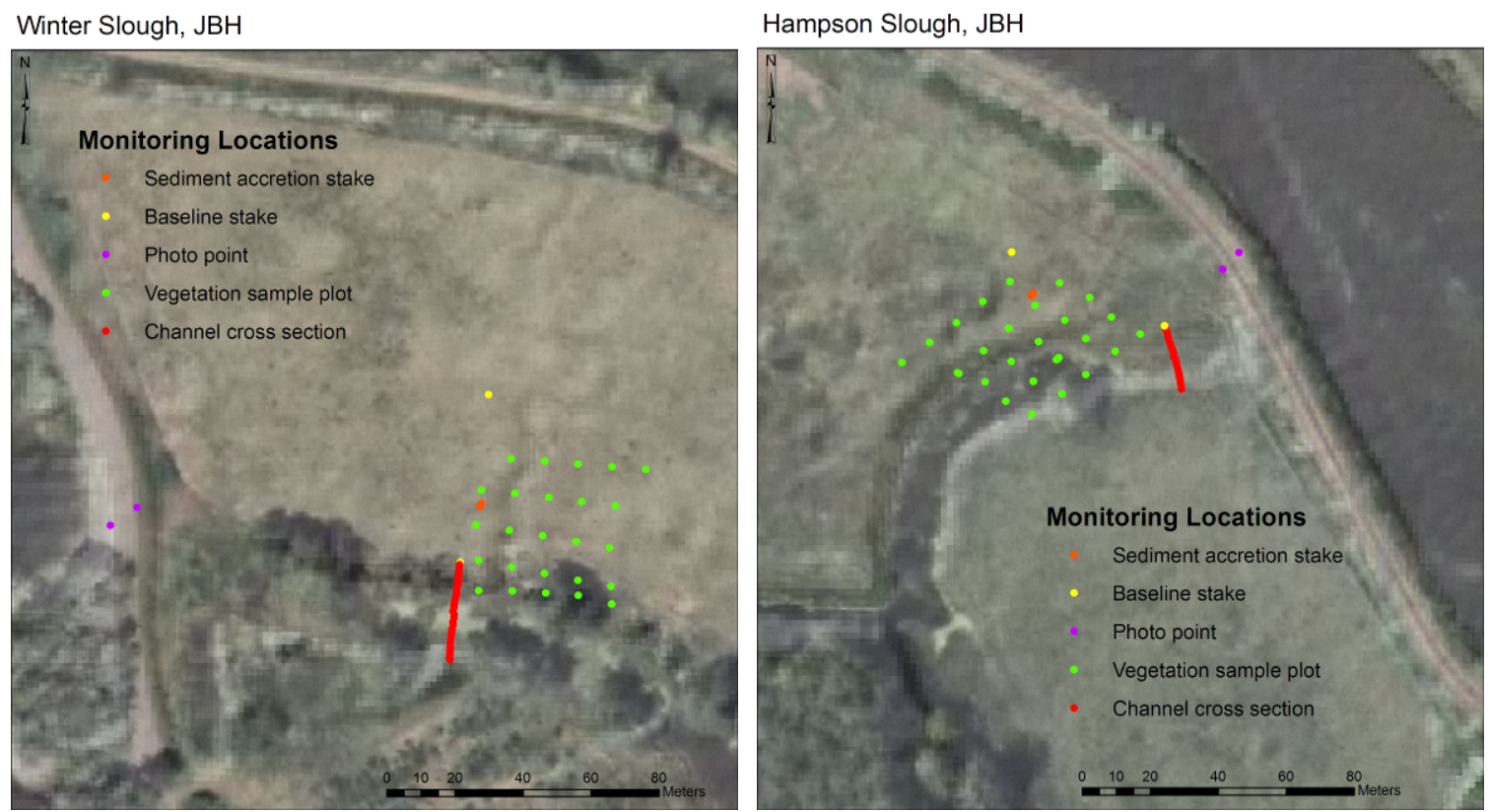

\section{Reference Slough, JBH}

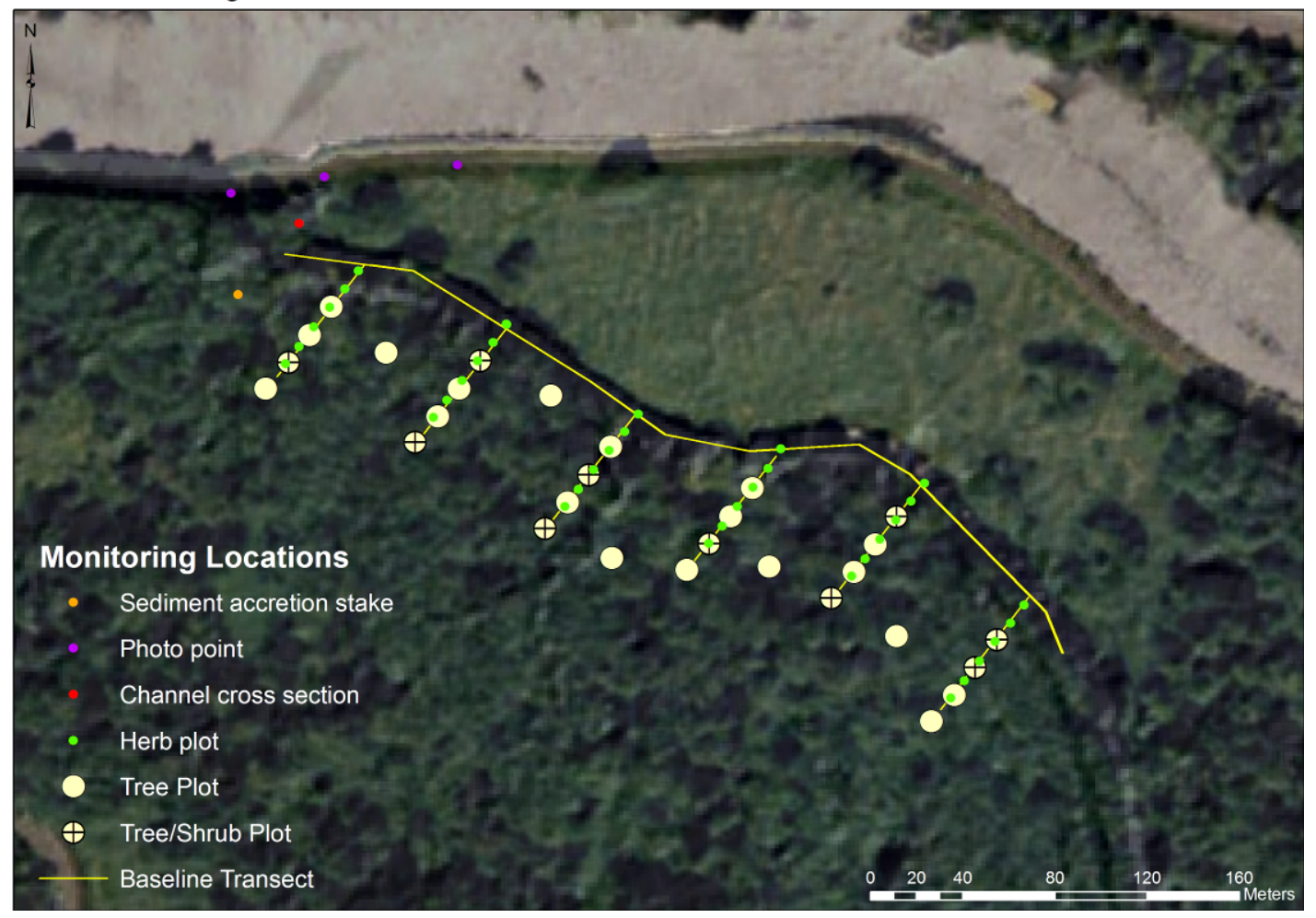

Figure F.3. Location of Vegetation Sampling at Monitoring Sites

\section{F.2.4 Channel Cross-Section Survey}

One channel cross section was measured at each of the monitoring sites in 2008. The surveys were conducted near the mouth of each channel (Figure F.3). Channel cross sections were measured by determining elevations along a permanent horizontal transect perpendicular to the channel. Endpoints 
were marked with a permanent marker (PVC pipe) at a distance far enough from the bank to ensure they would not be washed out by erosive forces. The transect endpoint locations and elevations were recorded using the RTK GPS as described above. At the Reference Slough a measuring tape was attached to the fixed endpoints, the stadia rod was leveled at each predetermined interval, and the interval and horizontal distance were recorded, and the height was measured with the autolevel. The horizontal interval used was greater (e.g., 1-2 m) in areas of low slope and smaller $(0.5 \mathrm{~m})$ in areas of steeper slope. At Winter and Hampson Slough the entire cross section was measured with the RTK GPS using intervals as described above.

\section{F.3 Results and Discussion}

\section{F.3.1 Sediment Accretion}

The distance from the top of the sediment accretion stakes to the sediment surface was measured in 2008 at the three monitoring sites. These measurements will be conducted in subsequent monitoring years to determine any changes in surface elevation.

The sediment accretion stakes at Duck Lake Slough and Ellison Slough were deployed in 2007 and measured again in February 2008. Preliminary results indicate that the accretion rates at these sites are approximately $-0.87 \mathrm{~cm} / \mathrm{yr}$ and $+0.62 \mathrm{~cm} / \mathrm{yr}$ at Duck Lake and Ellison, respectively.

\section{F.3.2 Vegetation}

\section{F.3.2.1 Percent Cover}

Percent cover at the pre-restoration sites was dominated by a few species (Table F.1). Winter Slough (WS) is dominated by mixed grasses, reed canary grass (Phalaris arundinacea), and Juncus effusus in the upper portion, with no dominant species present in the lower portion. Hampson Slough (HS) was dominated by a combination of mixed grasses, $P$. arundinacae, and Cirsium arvense at the higher elevations of the site, with Lemna minor and Nuphar lutea at the lower elevations. Carex obnupta was also present at Hampson in a large circular patch within the pasture area. Overall, the number of species identified at Winter Slough and Hampson Slough was 20 and 30, respectively. Species diversity was fairly low in the upper portion of the sites, with 10 species present above 2.0 -m elevation at Winter Slough and only 5 at Hampson Slough. Mixed grasses in this situation were thought to be primarily pasture grasses and were not identified to species at this time. Species diversity was highest in the lower, channel portion of Hampson Slough, with 15 species.

P. arundinacae, Polystichum munitum, and Urtica dioca were the dominant herbaceous species at the Reference site, with litter (detritus) also accounting for $20 \%$ of the cover. A total of 23 herbaceous species were identified at the Reference Site. The dominant tree and shrub species were Alnus rubra and Rubus spectabilis, respectively (Table F.3 and F.4). Most of the species at the Reference site had a wetland status indicative of nonwetland species with the exception of $P$. arundinacae and the species which occurred in the channel and on the banks.

Invasive species were present at both of the pre-restoration sites; however, they were primarily present in the higher (pasture) portions of the sites. At Winter Slough, the dominant species was the 
category mixed grass, which was given for primarily pasture grasses and likely were non-native species. All the obligate wetland species at Winter Slough (nine species) were native species and a combination of emergent, submerged aquatic, and floating species. At Hampson Slough, the two most common species were again mixed grass species and $P$. arundinacea, however several native obligate species were also common at the site (C. obnupta, $N$. lutea, and L. minor). In total, 17 obligate species were present at Hampson Slough. Only two of these were non-native species. This higher number of species may be in part due to the greater number of sample plots in the channel area (less than $2.0 \mathrm{~m}$ relative to NAVD88) at Hampson than in Winter Slough (14 versus 3 plots).

\section{F.3.2.2 Elevation Ranges}

The elevations of the restoration sites are very similar to those in the reference site; indicating that the reference site is an appropriate comparison for elevation. The resulting vegetation at the restoration sites will depend on the hydrology post-restoration and whether the sites are planted with woody vegetation. If the post-restoration hydrology is similar to the reference site, then woody species should be planted to reduce the likelihood of invasion by $P$. arundinacae.

Table F.2. Percent Cover of Herbaceous Vegetation Species During 2008

\begin{tabular}{|c|c|c|c|c|c|c|}
\hline Code & Scientific Name & Common Name & $\begin{array}{l}\text { Wetland } \\
\text { Status }\end{array}$ & Reference & Winter & Hampson \\
\hline ATFI & Athyrium filix-femina & Lady fern & FAC & 3.4 & & \\
\hline CACO & Carex comosa & Bearded sedge & OBL & & & 0.7 \\
\hline CADI & Carex disperma & Soft-leaved sedge & FACW & 0.7 & & \\
\hline CAOB & Carex obnupta & Slough sedge & OBL & 1.3 & & 7.4 \\
\hline CAST & Carex stipata & Sawbeak sedge & FACW & & & 0.04 \\
\hline CEDE & Ceratophyllum demersum & Coontail & OBL & 0.6 & & 0.6 \\
\hline CIAR & Cirsium arvense & Canada thistle & FACU+ & & 0.2 & 6.7 \\
\hline CLSI & Claytonia sibirica & Candy flower & FAC & 0.9 & & \\
\hline ELSP & Eleocharis spp. & Spikerush & OBL & 1.5 & 0.2 & 0.6 \\
\hline EPCI & Epilobium ciliatum & Willow herb & FACW- & & 0.2 & \\
\hline EQSP & Equisetum spp. & Horsetail & mixed & & & 0.2 \\
\hline GAAP & Gallium aperine & Cleavers bedstraw & FACU & 1.6 & & \\
\hline GATR & Galium trifidum & Pacific bedstraw & FACW & 0.1 & & 1.3 \\
\hline HELA & Heracleum lanatum & Cow-parsnip & $\mathrm{FAC}+$ & 0.7 & & \\
\hline HYRA2 & Hydrocotyle ranunculoides & Water pennywort & OBL & & 0.1 & 1.1 \\
\hline IMSP & $\begin{array}{l}\text { Impatiens capensis, Impatiens } \\
\text { noli-tangere }\end{array}$ & $\begin{array}{l}\text { Spotted touch-me-not, } \\
\text { Common touch-me-not }\end{array}$ & FACW & 1.2 & & 0.4 \\
\hline IRPS & Iris pseudacorus & Yellow iris & OBL & 0.1 & & 0.6 \\
\hline JUEF & Juncus effusus & Soft rush & FACW & & 6.0 & 5.4 \\
\hline LEMI & Lemna minor & Duckweed & OBL & & 2.2 & 10.6 \\
\hline LOCO & Lotus corniculatus & Birdsfoot trefoil & FAC & & & 0.4 \\
\hline LUPA & Ludwigia palustris & False loosestrife & OBL & & & 0.4 \\
\hline LYAM & Lysichiton americanum & Skunk cabbage & OBL & & & 0.4 \\
\hline
\end{tabular}


Table F.2. (contd)

\begin{tabular}{|c|c|c|c|c|c|c|}
\hline Code & Scientific Name & Common Name & $\begin{array}{l}\text { Wetland } \\
\text { Status }\end{array}$ & Reference & Winter & Hampson \\
\hline MIAL & Mimulus alsinoides & $\begin{array}{l}\text { Chickweed monkey- } \\
\text { flower }\end{array}$ & OBL & 0.1 & & \\
\hline MITR & Mitella trifida & Three-toothed mitrewort & na & 0.6 & & \\
\hline MYAQ & Myriophyllum aquiticum & Parrot-feather milfoil & OBL & & & 0.3 \\
\hline MYSP & Myosotis laxa, M. scorpioides & $\begin{array}{l}\text { Small forget-me-not, } \\
\text { Common forget-me-not }\end{array}$ & mixed & & 0.2 & 0.1 \\
\hline MYSP2 & Myriophyllum spp. & Milfoil & OBL & & 0.4 & 2.2 \\
\hline NULU & Nuphar lutea & Yellow pond-lily & OBL & & & 12.2 \\
\hline OXOR & Oxalis oregana & Redwood sorrel & UPL & 0.3 & & \\
\hline PHAR & Phalaris arundinacea & Reed canary grass & FACW & 35.3 & 9.2 & 13.4 \\
\hline POCR & Potamogeton crispus & Curly leaf pondweed & OBL & 4.4 & & \\
\hline POMU & Polystichum munitum & Sword fern & FACU & 23.2 & & \\
\hline PONA & Potamogeton natans & $\begin{array}{l}\text { Floating-leaved } \\
\text { pondweed }\end{array}$ & OBL & 0.6 & & \\
\hline POPU & Potamogeton pusillus & Small pondweed & OBL & & 0.6 & 0.2 \\
\hline POZO & Potamogeton zosteraformis & Eelgrass pondweed & OBL & 0.8 & & \\
\hline RACY & Ranunculus cymbalaria & Alkali buttercup & OBL & & 0.04 & \\
\hline RARE & Ranunculus repens & Creeping buttercup & FACW & 0.2 & & \\
\hline ROPA & Rorippa palustris & Marsh yellow-cress & OBL & & & 0.4 \\
\hline RUDI & Rubus discolor & Himalayan blackberry & FACU & & 3.0 & \\
\hline RULA & Rubus laciniatus & Evergreen blackberry & FACU+ & & 1.6 & 0.2 \\
\hline RUUR & Rubus ursinus & Trailing blackberry & FACU & & & 0.4 \\
\hline SCSP & Scirpus microcarpus & Small-fruited bulrush & OBL & & & 0.2 \\
\hline SODU & Solanum dulcamara & Bittersweet nightshade & FAC + & & & 0.7 \\
\hline SPEM & Sparganium emersum & Narrowleaf burreed & OBL & & 0.2 & 0.2 \\
\hline STCR & Stellaria crispus & Curled starwort & FAC + & 1.4 & & \\
\hline TRSP & $\begin{array}{l}\text { Trifolium pratense, T. repens, } \\
\text { T. dubium }\end{array}$ & $\begin{array}{l}\text { Red clover, white } \\
\text { clover, small hop-clover }\end{array}$ & mixed & & 0.7 & 0.4 \\
\hline URDI & Urtica dioica & Stinging Nettle & FAC + & 6.0 & 2.2 & \\
\hline UTVU & Utricularia vulgaris & Common bladderwort & OBL & & 1.0 & \\
\hline WOSP & Wolffia spp. & Watermeal & OBL & & 1.2 & 3.2 \\
\hline Moss & & Moss & & 5.0 & 0.2 & \\
\hline MG & & Mixed grass & & 1.4 & 65.2 & 28.9 \\
\hline UID & & Unidentified spp. & & 0.3 & & \\
\hline BG & & Bare ground/mud & & & 0.2 & \\
\hline DW & & Drift wrack & & & 6.8 & \\
\hline Litter & & Litter & & 21.4 & & \\
\hline LWD & & Large woody debris & & 4.9 & 1.8 & 0.6 \\
\hline
\end{tabular}


Table F.3. Number, Area, and Density of Tree Species in the Reference Slough

\begin{tabular}{lccccccccc}
\hline & $\begin{array}{c}\text { No. } \\
\text { Trees }\end{array}$ & Frequency & $\begin{array}{c}\text { Frequency } \\
\%\end{array}$ & $\begin{array}{c}\text { Basal } \\
\left(\mathrm{m}^{2}\right)\end{array}$ & $\begin{array}{c}\text { Density } \\
(\text { trees/ha) }\end{array}$ & $\begin{array}{c}\text { Dominance } \\
\left(\mathrm{m}^{2} / \mathrm{ha}\right)\end{array}$ & $\begin{array}{c}\text { Frequency } \\
\%\end{array}$ & $\begin{array}{c}\text { Relative } \\
\text { Density } \\
\%\end{array}$ & $\begin{array}{c}\text { Relative } \\
\text { Dominance } \\
\%\end{array}$ \\
\hline $\begin{array}{l}\text { Alnus } \\
\text { rubra }\end{array}$ & 51 & 15 & 52 & 9.55 & 224 & 41.92 & 44.1 & 64.6 & 68.7 \\
$\begin{array}{l}\text { Thuja } \\
\text { plicata }\end{array}$ & 6 & 5 & 17 & 2.57 & 26 & 11.30 & 14.7 & 7.6 & 18.5 \\
$\begin{array}{l}\text { Picea } \\
\text { sitchensis }\end{array}$ & 21 & 13 & 45 & 1.73 & 92 & 7.59 & 38.2 & 26.6 & 12.4 \\
$\begin{array}{l}\text { Rhamnis } \\
\text { purshiana }\end{array}$ & 1 & 1 & 3 & 0.05 & 4 & 0.22 & 2.9 & 1.3 & 0.4 \\
\hline
\end{tabular}

Table F.4. Number and Density of Shrub Species in the Reference Slough

\begin{tabular}{|c|c|c|c|c|c|c|}
\hline Species & $\begin{array}{l}\text { No. } \\
\text { Shrubs }\end{array}$ & Frequency & $\begin{array}{c}\text { Frequency } \\
\%\end{array}$ & $\begin{array}{c}\text { Density } \\
\text { (shrubs/ha) }\end{array}$ & $\begin{array}{c}\text { Relative } \\
\text { Frequency } \\
\%\end{array}$ & $\begin{array}{c}\text { Relative } \\
\text { Density } \\
\%\end{array}$ \\
\hline Ribes bracteosum & 38 & 2 & 20 & 3800 & 18.2 & 44.2 \\
\hline Rubus parviflorus & 1 & 1 & 10 & 100 & 9.1 & 1.2 \\
\hline Rubus spectabilis & 69 & 7 & 70 & 6900 & 63.6 & 80.2 \\
\hline Rubus ursinus & 16 & 3 & 30 & 1600 & 27.3 & 18.6 \\
\hline
\end{tabular}



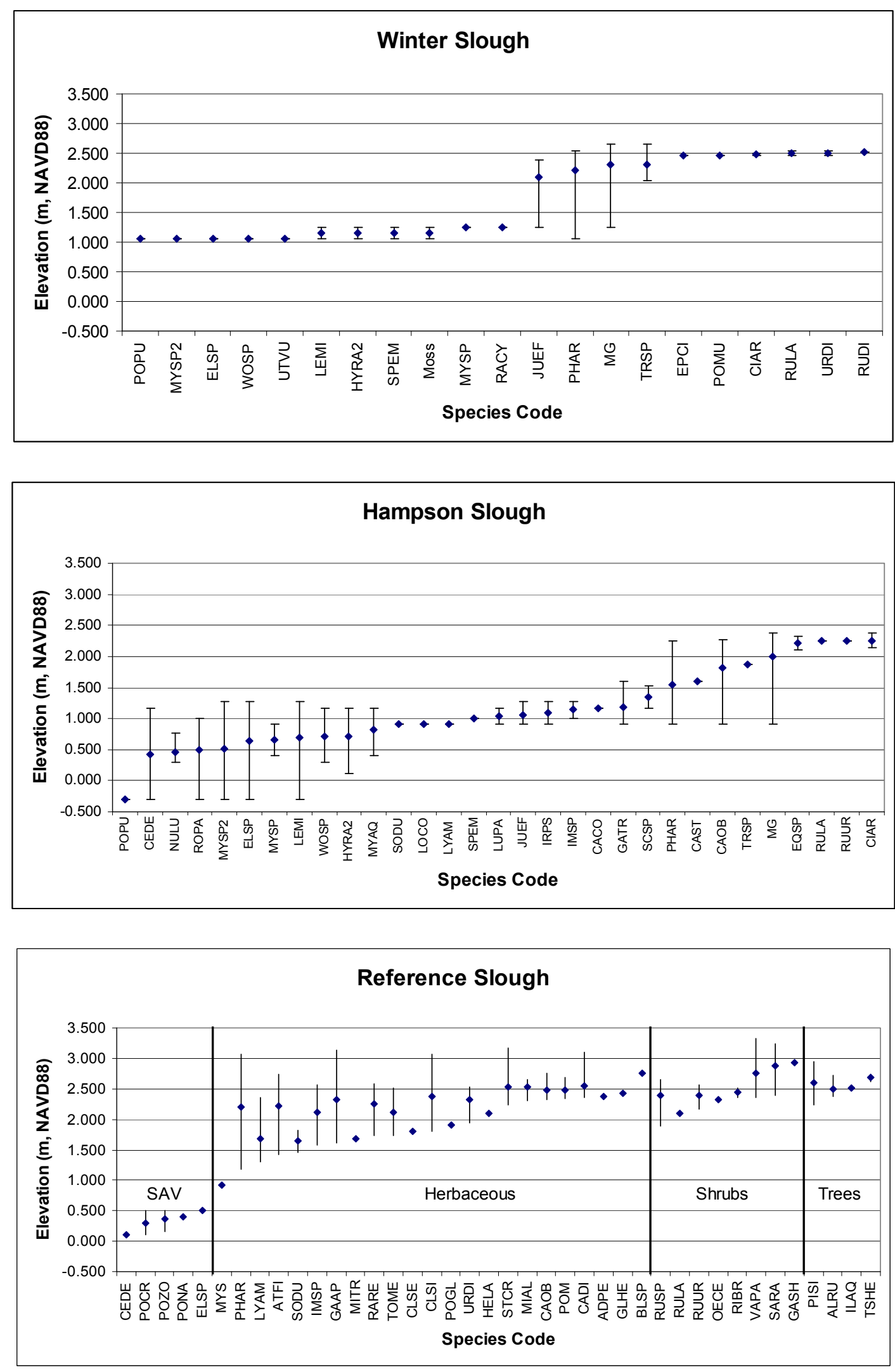

Figure F.4. Elevation Ranges in Plots at JBH 


\section{F.3.3 Cross-Section Survey}

The channel cross sections at Hampson and Reference Sloughs are wide and relatively shallow (Figure F.5). The channel cross section at Hampson Slough was located near the dead-end portion of the slough (near the road) and was therefore shallower than other parts of the slough where the vegetation plots were sampled (approximately $2.5 \mathrm{~m}$ deeper; see Figures F.3 and F.4). However, this area of the slough is likely to change the most after reconnection to tidal flows and is therefore a good location to monitor change over time. The cross section at Winter Slough was deeper, with floating mats near the banks.
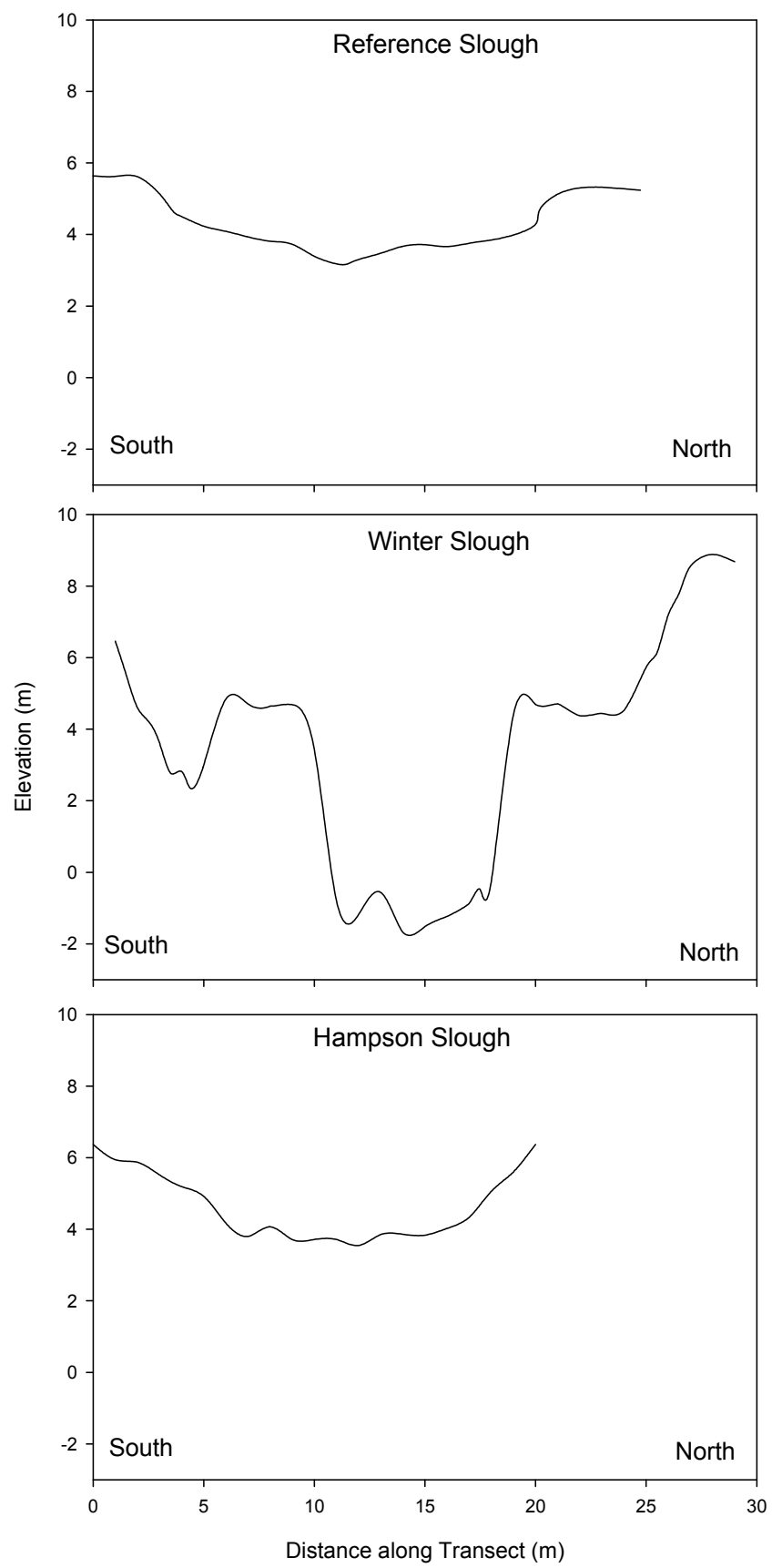

Figure F.5. Cross-Section Survey at JBH 


\section{F.4 Future Work}

Future monitoring at the site should include post-restoration monitoring and evaluation of hydrology data collected by CENWP as relevant to monitoring parameters (Table F.5).

Table F.5. Recommended Monitoring

\begin{tabular}{|c|c|c|c|c|c|}
\hline Site & Task & 2007 & 2008 & 2009 & 2010 \\
\hline Reference Slough & Monitoring & & $\mathrm{X}$ & & $\mathrm{X}$ \\
\hline \multirow[t]{2}{*}{ Ellison Slough } & Baseline Monitoring & $\mathrm{X}$ & & & \\
\hline & Post-Restoration Monitoring & & & & $\mathrm{X}$ \\
\hline \multirow[t]{2}{*}{ Duck Lake Slough } & Baseline Monitoring & $\mathrm{X}$ & & & \\
\hline & Post-Restoration Monitoring & & & & $\mathrm{X}$ \\
\hline \multirow[t]{2}{*}{ Hampson Slough } & Baseline Monitoring & & $\mathrm{X}$ & & \\
\hline & Post-Restoration Monitoring & & & & $X$ \\
\hline \multirow[t]{2}{*}{ Winter Slough } & Baseline Monitoring & & $\mathrm{X}$ & & \\
\hline & Post-Restoration Monitoring & & & & $\mathrm{X}$ \\
\hline
\end{tabular}

\section{F.5 Literature Cited}

Borde, AB, HL Diefenderfer, and SA Zimmerman. 2008. "Julia Butler Hansen National Wildlife Refuge - Monitoring Data Summary." Appendix B, in: Evaluating Cumulative Ecosystem Response to Restoration Projects in the Columbia River Estuary, Annual Report 2007, eds. GE Johnson and HL Diefenderfer. PNNL-17437, prepared by Pacific Northwest National Laboratory, Richland, Washington, and the National Marine Fisheries Service, Seattle, Washington, for the U.S. Army Corps of Engineers, Portland District, Portland, Oregon; pp. B1-B6.

Roegner, GC, HL Diefenderfer, AB Borde, RM Thom, EM Dawley, AH Whiting, SA Zimmerman, and GE Johnson. 2009. Protocols for monitoring habitat restoration projects in the lower Columbia River and estuary. Prepared by NOAA Fisheries and Pacific Northwest National Laboratory for the U.S. Army Corps of Engineers, Portland District. NOAA Technical Memorandum NMFS-NWFSC-97. Seattle, Washington. 



\section{Appendix G}

\section{Crims Island - Monitoring Activities Summary}





\title{
Appendix G
}

\section{Crims Island - Monitoring Activities Summary}

\author{
Amy B. Borde and Shon A. Zimmerman
}

\section{G.1 Introduction}

Crims Island was the location of a restoration project implemented by the U.S. Army Corps of Engineers, Portland District, in 2005. The restoration action included breaching a dike in two locations, removing material to the correct elevation for tidal wetland development, and excavating tidal channels. Prior to restoration, the site was primarily covered with reed canary grass (Phalaris arundinacea) with a small percent of other wetland species (Stockhouse 2004) and drained by straight drainage channels (Figure G.1). Monitoring of this project provides an opportunity to assess habitat improvement at the site and, in conjunction with other restoration project evaluation, to assess the cumulative ecosystem response to habitat restoration.

The information presented in this appendix summarizes post-restoration monitoring activities conducted by Pacific Northwest National Laboratory (PNNL) from 2006 to 2008. Additional monitoring efforts were conducted by PNNL on flux of ecosystem components in and out of the restored site; these data are also presented in this appendix. Monitoring plans for 2009 are also discussed.

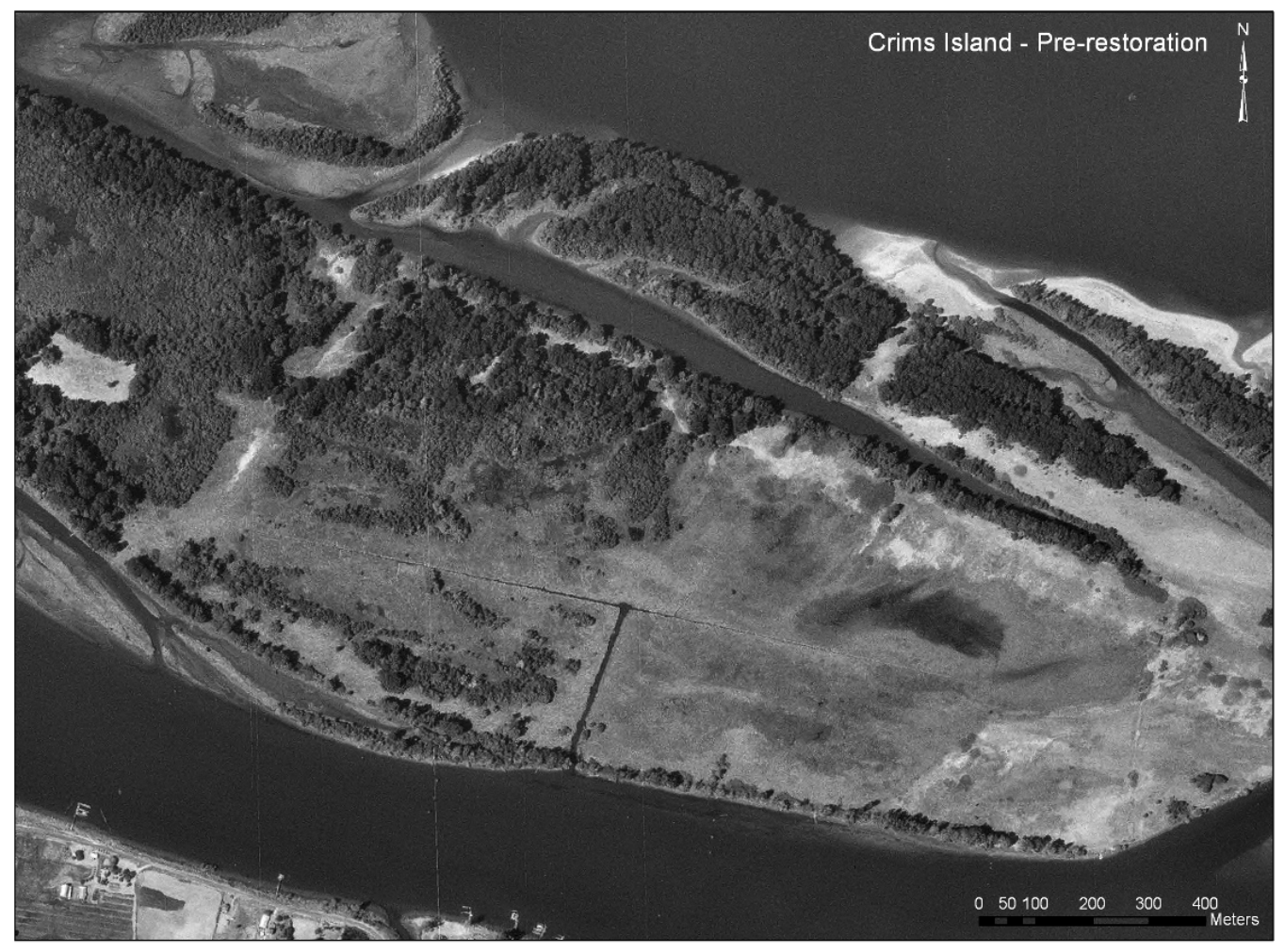

Figure G.1. Crims Island Prior to Restoration (aerial photo 2000) 


\section{G.2 Methods}

Monitoring methods were implemented in accordance with the standard monitoring protocols for the region described by Roegner et al. (2008). Detailed methods are also described by Borde et al. (2008). Sampling locations are shown in Figure G.2.

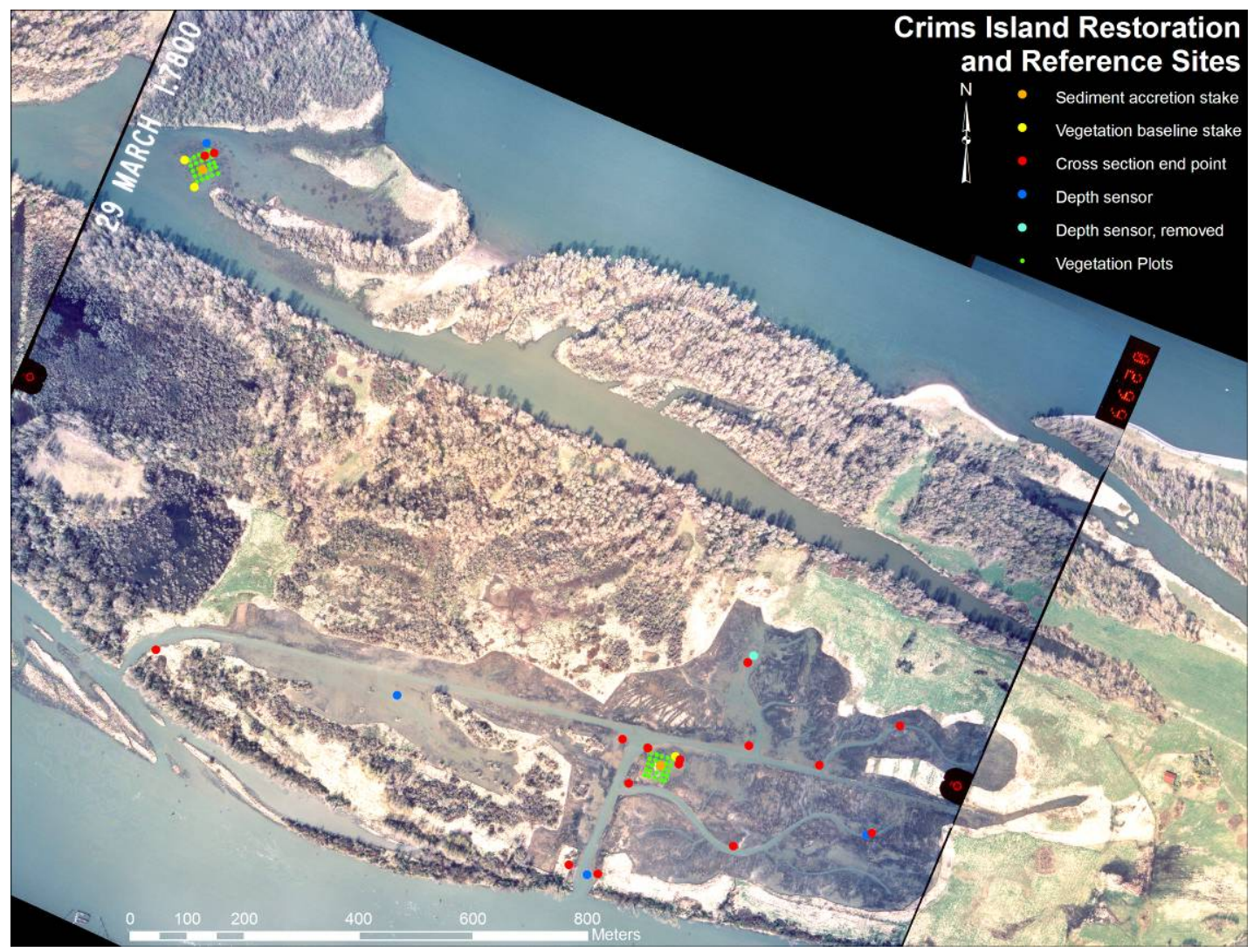

Figure G.2. 2006 to 2008 Sampling Locations at the Restoration Site (Crims Island) and Reference Site (Gull Island) (Aerial Photo 2007).

\section{G.2.1 Sediment Accretion}

Sediment accretion stakes were installed in 2006 to track changes in substrate elevation and elevations were measured in 2006, 2007, and 2008. The elevation of the top of the stakes was also measured using the methods described in the Elevation section below. The sedimentation stakes at the reference site were discovered to be missing in 2008 during a visit to the site. New stakes were deployed in 2008 and will be re-measured in 2009.

\section{G.2.2 Elevation}

Elevations were measured at the site in September 2006 and September 2007. A Trimble 5700 realtime kinematic (RTK) global positioning system (GPS) was located on a benchmark of known position and elevation and two Trimble 5800 receivers (rovers) were used to determine elevations at each sample location. The benchmark onsite had been established prior to this study and was based on a local 
benchmark in the region. Based on this benchmark, we established a second temporary benchmark on the south side of the Columbia River for ease of access.

In September 2006, the elevations of the vegetation sample points, sedimentation stakes, and channel cross sections were measured at the restoration and reference sites using the RTK GPS. An elevation survey of the restoration site was completed 6-8 September 2007. Elevation at the same monitoring locations will be re-surveyed in 2009.

\section{G.2.3 Vegetation}

Vegetation was sampled at Crims Island and Gull Island (reference site) 6-8 September 2006. A 50-m-x-50-m systematic grid was established, with a baseline tape running west-east at each site. Sample locations were evenly spaced along perpendicular transects with a random start. Vegetation sampling was concentrated proximal to expected changes - in this case, near the mouth of the main channel at the sites. The vegetation sample plot locations are shown in Figure G.2. The vegetation plots will be re-surveyed in 2009.

\section{G.2.4 Channel Cross-Section Survey}

Two channel cross sections were measured in 2006 and 2007. An additional nine channel cross sections were measured in 2007 on all the major channels at the mouth and upper extent of the channels (Figure G.2). All channel cross sections will be re-surveyed in 2009.

\section{G.2.5 Aerial Photo Interpretation and GPS Survey}

Aerial photos were acquired by the CENWP in Spring 2007. The photos were georeferenced by PNNL using existing orthoquads for the region from 2000, then corrected using higher-resolution imagery from 2005 and ground control points collected at the site with the RTK GPS. Channels were delineated from the aerial imagery to determine the ability to discern channel extent from remote data. In the field, channel ends and small channels (not excavated) were documented using a differential GPS. These points were compared to the information delineated from the aerial imagery.

\section{G.2.6 Hydrology}

Four water-level sensors were deployed at the site in February 2008. They are located at the mouth of the main channel, at the upper end of the southeast channel, in the west channel, and in the upper end on the first northeast channel (Figure G.2). In July 2008, the depth sensor in the northeast channel was moved to the Reference site to provide comparative information on the hydrology at that site. The information from both sites will be used with the elevation and channel data to evaluate inundation times, wetted area, and potential fish access to the site.

\section{G.3 Future Monitoring}

The following will be monitored at the site in 2009 (4 years post-restoration) in reference and restoration areas: 
- vegetation plots

- photo points

- channel cross sections

- sediment accretion stakes

- download depth sensors.

\section{G.4 Literature Cited}

Roegner, GC, HL Diefenderfer, AB Borde, RM Thom, EM Dawley, AH Whiting, SA Zimmerman, and GE Johnson. 2009. Protocols for monitoring habitat restoration projects in the lower Columbia River and estuary. Prepared by NOAA Fisheries and Pacific Northwest National Laboratory for the U.S. Army Corps of Engineers, Portland District. NOAA Technical Memorandum NMFS-NWFSC-97. Seattle, Washington.

Stockhouse, RE and S Love. 2004. "Final Crims Island Wetland Monitoring 2004." Pacific University, Forest Grove, Oregon. 


\section{Appendix H}

\section{Effectiveness Monitoring Data - Preliminary Meta-Analysis}





\section{Appendix $\mathrm{H}$}

\section{Effectiveness Monitoring Data - Preliminary Meta-Analysis}

Gary E. Johnson, Ron M. Thom, Amy B. Borde and Heida L. Diefenderfer (PNNL) and Krista Jones and Catherine Corbett (Estuary Partnership)

\section{H.1 Introduction}

Compiling, merging, and analyzing data derived from monitoring the effectiveness of various restoration projects (hereafter called effectiveness monitoring ${ }^{1}$ ) is fundamental to the evaluation of success or failure of ecosystem restoration. The challenge is to integrate multiple site-scale monitoring results to make inferences at an estuary-wide scale. Pre- and post-restoration monitoring data have been collected at restoration and reference sites in the lower Columbia River and estuary (LCRE). These data were used in a preliminary meta-analysis to gauge the success to date of tidal reconnection restoration. The method for the meta-analysis was to 1) review literature and contact monitoring practitioners, 2) identify and select study sites, 3) determine response variables, 4) compile data, and 5) select and apply an analysis model(s). The response variables (i.e., metrics) of interest were water temperature, sediment accretion rate, and juvenile salmon presence. We also compared photo points before and after the restoration action at several sites. Lessons learned in the meta-analysis process are described in this appendix. The methods and preliminary results from this analysis will help inform decision-makers in the Federal LCRE Habitat Restoration Program, as well as other ecosystem restoration programs nationwide. The objective was to perform a preliminary meta-analysis of effectiveness data from tidal reconnection restoration projects in the LCRE to determine the proportion of projects that were successful ${ }^{2}$.

\section{H.2 Methods}

The steps for the preliminary meta-analysis were as follows:

1. Search the literature and contact monitoring practitioners. Ecosystem restoration activities in the LCRE are a recent occurrence, beginning in earnest about 5 years ago ( 2004). Because effectiveness monitoring only occurs at a subset of the restoration sites, the literature base for effectiveness monitoring in the LCRE is relatively small, but growing. We contacted all project managers conducting effectiveness monitoring in the LCRE.

2. Identify and select study sites. We identified nine possible restoration sites and selected five of them for further examination (Table H.1). Sites were not selected for analysis because the restoration may have been delayed, the restoration action was not a true tidal reconnection, or there were no prerestoration monitoring data. Four of the five sites that were selected are located in tidal freshwater areas of tributary rivers in Reaches A and B of the LCRE; the fifth site is located on a main stem island in Reach C (Figures H.1 and H.2). The years of restoration project implementation range from

\footnotetext{
${ }^{1}$ Effectiveness monitoring specifically pertains to monitoring at restoration and reference sites for the purpose of evaluating the effects of the restoration action.

${ }^{2}$ By definition, success is when the response variable(s) trend in the desired direction when compared between preversus post-restoration conditions or between restoration versus reference site conditions.
} 
1995 to 2008. Seven different agencies and nongovernmental organizations implemented effectiveness monitoring at the selected sites. Furthermore, there are almost as many types of tidal reconnection restorations (e.g., dike breach, culvert replacement) as there are sites. Because of the diversity of organization and restoration types, replication of results is an issue. However, this is an initial effort at meta-analysis, which lays the foundation for future expanded analyses as more site restoration actions are implemented and monitored.

3. Decide on response variables. Pre- and post-restoration and reference sites data have been collected for numerous response variables at the selected study sites (Table H.2). Based mostly on the availability of data, we decided to analyze data for four response variables: vegetation cover (i.e., from photo points), water temperature, sediment accretion rate, and juvenile salmon presence. These response variables are recommended for assessing restoration site performance by Roegner et al. (2009), and provide both structural (i.e., vegetation cover, temperature) and functional metrics (i.e., sediment accretion, fish presence).

4. Compile data. The four response variables represent four types of data: descriptive (photo point), continuous (water temperature), discrete (sediment accretion rate), and binary (fish presence). For the descriptive photo points, the data are photographs of the pre- and post-restoration and reference sites. For the continuous data on water temperature, the data are in the form of frequency of occurrence from which we generated cumulative distributions for each comparison, e.g., pre- versus postrestoration water temperature at Vera. For the discrete data on sediment accretion rate, the data are numerical. For salmon presence, the data are binary, $0=$ no and $1=$ yes.

5. Select and apply an analysis model(s). For this preliminary analysis, we qualitatively compared preand post-restoration or restoration and reference site conditions. For the descriptive photo points, we compared pre- and post-conditions visually, looking for noticeable changes in the appearance of the site toward becoming a wetland. For the continuous water temperature data, we compared cumulative frequency distributions at the restoration and reference sites. For the discrete data on sediment accretion rates, we compared restoration and reference sites. For the binary fish presence data, we compared pre- and post-restoration. Future analyses will include quantitative comparisons of the proportional success rate for site effectiveness in terms of water temperature, sediment accretion rate, and salmon presence/absence. 
Table H.1. Descriptive Data About Restoration Sites. Shading indicates sites used in the preliminary meta-analysis.

\begin{tabular}{|c|c|c|c|c|c|}
\hline Site & $\begin{array}{l}\text { Col. River } \\
\text { Kilometer }\end{array}$ & Year & Implementers & Restoration Type & Comment \\
\hline $\begin{array}{l}\text { Crims } \\
\text { Island }\end{array}$ & 88 & 2005 & USGS/PNNL & $\begin{array}{l}\text { Dike breach and } \\
\text { excavation }\end{array}$ & $\begin{array}{l}\text { Intensively } \\
\text { monitored }\end{array}$ \\
\hline Ft. Clatsop & $\begin{array}{l}24 \\
\text { (Lewis \& } \\
\text { Clark R.) }\end{array}$ & 2007 & EP/CREST & Culvert replacement & Ibid. \\
\hline $\begin{array}{l}\text { Johnson } \\
\text { Property }\end{array}$ & $\begin{array}{l}35 \\
\text { (Grays R.) }\end{array}$ & 2004 & CLT/CREST & Dike breach & \\
\hline $\begin{array}{l}\text { Julia Butler } \\
\text { Hanson }\end{array}$ & 55 & Planned & USFWS/PNNL/NMFS & $\begin{array}{l}\text { Tide gate } \\
\text { replacement }\end{array}$ & $\begin{array}{l}\text { Restoration } \\
\text { delayed }\end{array}$ \\
\hline $\begin{array}{l}\text { Kandoll } \\
\text { Farm }\end{array}$ & $\begin{array}{l}36 \\
\text { (Grays R.) }\end{array}$ & 2005 & PNNL/NMFS/CREST & Culvert replacement & $\begin{array}{l}\text { Intensively } \\
\text { monitored }\end{array}$ \\
\hline Mirror Lake & 205 & 2007 & EP/NMFS/PI & $\begin{array}{l}\text { Culvert, stream, and } \\
\text { riparian habitat } \\
\text { improvements }\end{array}$ & $\begin{array}{l}\text { Intensively } \\
\text { monitored but not } \\
\text { a tidal } \\
\text { reconnection }\end{array}$ \\
\hline $\begin{array}{l}\text { Scappoose } \\
\text { Bottoms }\end{array}$ & 142 & $\begin{array}{l}2005 \\
2007 \text { to } \\
\text { present }\end{array}$ & EP/SBWC/CREST & $\begin{array}{l}\text { Riparian } \\
\text { improvements } \\
(2007+) \text { and cattle } \\
\text { exclusion }(2005)\end{array}$ & Ibid. \\
\hline Trestle Bay & 11 & 1995 & PNNL/NMFS/CREST/EP & Dike breach & $\begin{array}{l}\text { No pre-restoration } \\
\text { data }\end{array}$ \\
\hline Vera Slough & 19 & 2005 & PNNL/NMFS/CREST & $\begin{array}{l}\text { Tide gate } \\
\text { replacement }\end{array}$ & $\begin{array}{l}\text { Intensively } \\
\text { monitored }\end{array}$ \\
\hline $\begin{array}{l}\text { CLT }=\text { Colun } \\
\text { NMFS = Nati } \\
\text { Bay Watershe }\end{array}$ & $\begin{array}{l}\text { bia Land Tru } \\
\text { onal Marine F } \\
\text { d Council; U }\end{array}$ & $\begin{array}{l}\text { CREST }= \\
\text { eries Ser } \\
\text { S = U.S. }\end{array}$ & $\begin{array}{l}\text { lumbia River Estuary Stud } \\
\text {; PNNL = Pacific Northwe } \\
\text { logical Survey. }\end{array}$ & $\begin{array}{l}\text { Taskforce; EP = Estu } \\
\text { National Laboratory; }\end{array}$ & $\begin{array}{l}\text { Partnership; } \\
3 \mathrm{WC}=\text { Scappoose }\end{array}$ \\
\hline
\end{tabular}




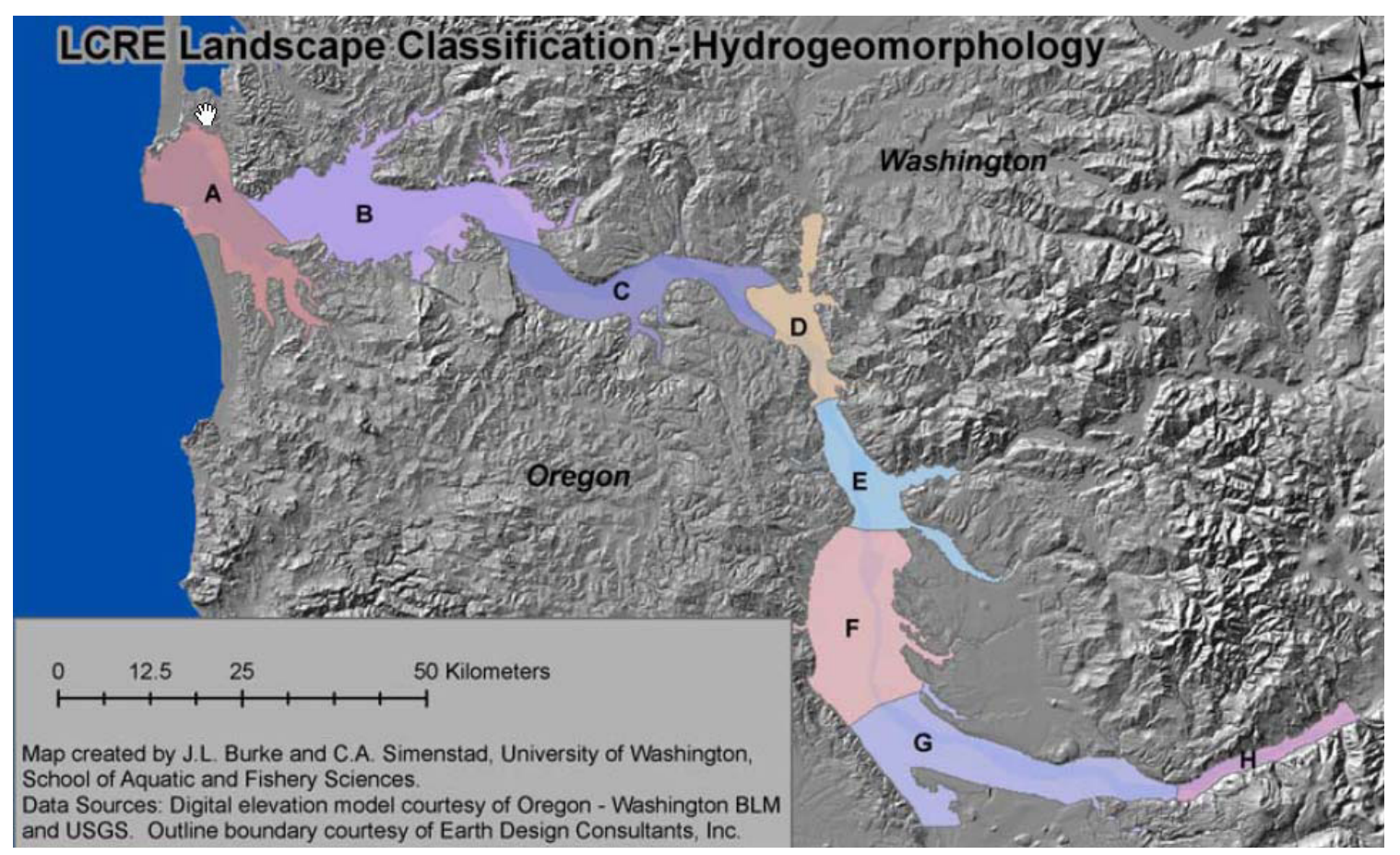

Figure H.1. The LCRE Showing the Eight Hydrogeomorphic Reaches (LCREP 2004a). The tidally influenced freshwater portions of the estuary include reaches $\mathrm{C}-\mathrm{H}$. (Image courtesy of Jen Burke, University of Washington).

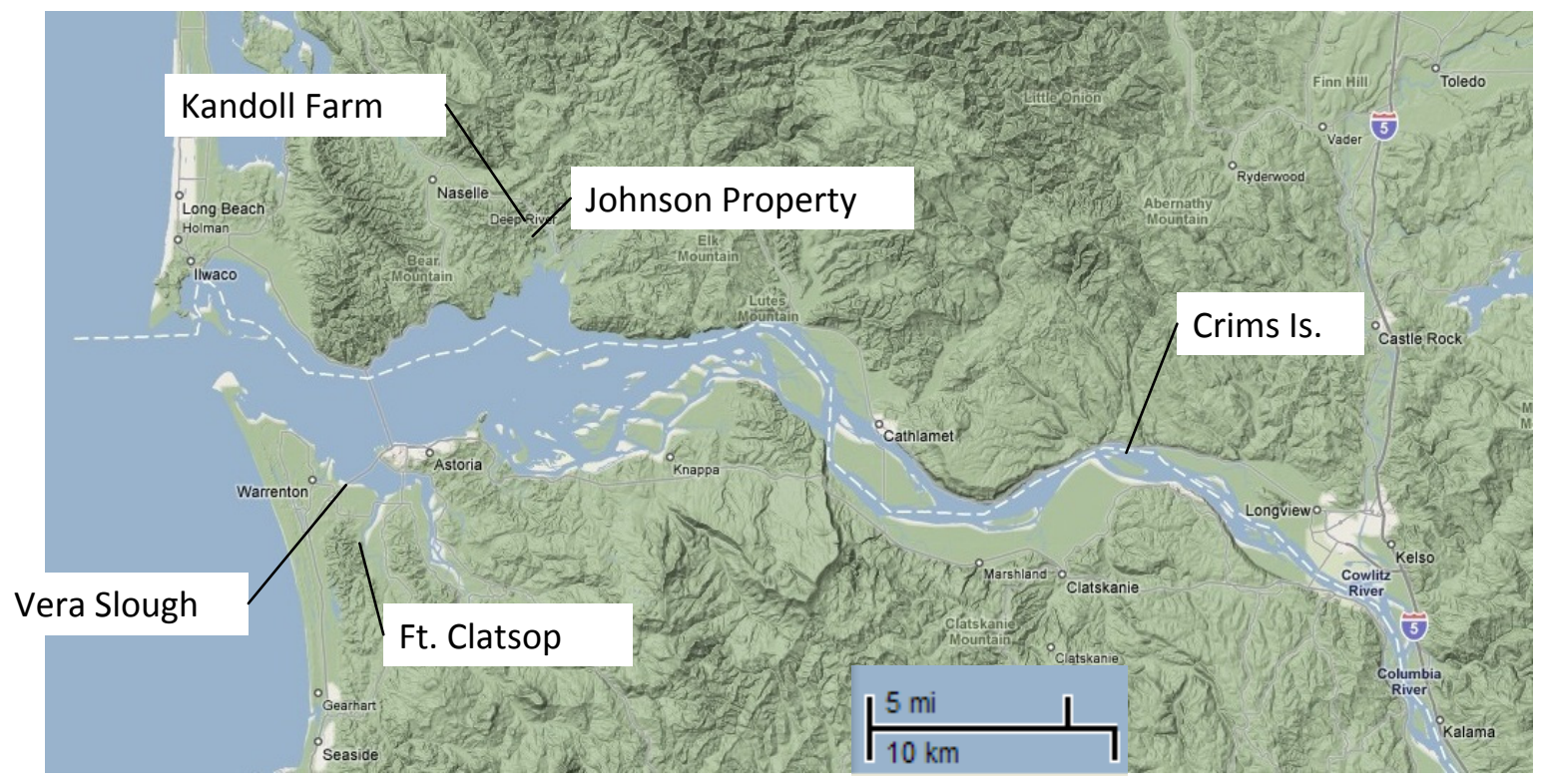

Figure H.2. Location of Meta-Analysis Study Sites in the LCRE (from Google Maps). 
Table H.2. Data Availability $(Y=y e s ; N=$ no) at the Five Sites Selected for Meta-Analysis

\begin{tabular}{|c|c|c|c|c|c|c|c|c|c|}
\hline & & $\begin{array}{l}\text { Photo } \\
\text { Point* }\end{array}$ & $\begin{array}{l}\text { Water } \\
\text { Depth }\end{array}$ & $\begin{array}{l}\text { Water } \\
\text { Temp.* }\end{array}$ & $\begin{array}{c}\text { Sediment } \\
\text { Accretion* }\end{array}$ & $\begin{array}{l}\text { Vegetation } \\
\text { Similarity }\end{array}$ & $\begin{array}{c}\text { Fish } \\
\text { Presence* }\end{array}$ & $\begin{array}{l}\text { Fish } \\
\text { Diet }\end{array}$ & $\begin{array}{c}\text { Biomass } \\
\text { Flux }\end{array}$ \\
\hline \multirow[t]{3}{*}{ Crims Is. } & Pre & $\mathrm{Y}$ & $\mathrm{N}$ & $\mathrm{N}$ & NA & $\mathrm{N}$ & $\mathrm{Y}$ & $\mathrm{N}$ & $\mathrm{N}$ \\
\hline & Post & $\mathrm{Y}$ & $\mathrm{N}$ & $\mathrm{N}$ & Y & $?$ & Y & Y & $\mathrm{N}$ \\
\hline & Ref & $\mathrm{Y}$ & $\mathrm{N}$ & $\mathrm{N}$ & $\mathrm{Y}$ & $\mathrm{Y}$ & Y & $\mathrm{N}$ & $\mathrm{N}$ \\
\hline \multirow[t]{3}{*}{ Ft. Clatsop } & Pre & $\mathrm{N}$ & Y & $\mathrm{Y}$ & NA & $\mathrm{N}$ & $\mathrm{Y}$ & $\mathrm{N}$ & $\mathrm{N}$ \\
\hline & Post & $\mathrm{Y}$ & Y & $\mathrm{Y}$ & $\mathrm{Y}$ & $\mathrm{N}$ & $\mathrm{Y}$ & $\mathrm{Y}$ & $\mathrm{N}$ \\
\hline & Ref & $\mathrm{N}$ & $\mathrm{N}$ & $\mathrm{N}$ & Y & $\mathrm{N}$ & Y & $\mathrm{Y}$ & $\mathrm{N}$ \\
\hline \multirow{3}{*}{$\begin{array}{l}\text { Johnson } \\
\text { Property }\end{array}$} & Pre & $\mathrm{Y}$ & $\mathrm{Y}$ & $\mathrm{N}$ & NA & $\mathrm{N}$ & Y & $\mathrm{N}$ & $\mathrm{N}$ \\
\hline & Post & $\mathrm{Y}$ & Y & $\mathrm{N}$ & $\mathrm{Y}$ & $\mathrm{N}$ & Y & $\mathrm{Y}$ & $\mathrm{N}$ \\
\hline & Ref & $\mathrm{Y}$ & Y & $\mathrm{N}$ & $\mathrm{N}$ & $\mathrm{N}$ & $\mathrm{N}$ & $\mathrm{N}$ & $\mathrm{N}$ \\
\hline \multirow{3}{*}{$\begin{array}{l}\text { Kandoll } \\
\text { Farm }\end{array}$} & Pre & $\mathrm{Y}$ & $\mathrm{Y}$ & $\mathrm{Y}$ & NA & $\mathrm{Y}$ & $\mathrm{Y}$ & $\mathrm{N}$ & $\mathrm{N}$ \\
\hline & Post & $\mathrm{Y}$ & $\mathrm{Y}$ & $\mathrm{Y}$ & $\mathrm{Y}$ & $\mathrm{Y}$ & $\mathrm{Y}$ & $\mathrm{Y}$ & $\mathrm{Y}$ \\
\hline & Ref & $\mathrm{Y}$ & $\mathrm{Y}$ & $\mathrm{N}$ & $\mathrm{Y}$ & $\mathrm{N}$ & $\mathrm{N}$ & $\mathrm{N}$ & $\mathrm{Y}$ \\
\hline \multirow{3}{*}{$\begin{array}{l}\text { Vera } \\
\text { Slough }\end{array}$} & Pre & $\mathrm{Y}$ & $Y$ & $\mathrm{~N}$ & NA & $\mathrm{Y}$ & $\mathrm{Y}$ & $\mathrm{N}$ & $\mathrm{N}$ \\
\hline & Post & $\mathrm{Y}$ & Y & $\mathrm{N}$ & $\mathrm{Y}$ & $\mathrm{Y}$ & $\mathrm{Y}$ & $\mathrm{Y}$ & $\mathrm{Y}$ \\
\hline & Ref & $\mathrm{Y}$ & $\mathrm{Y}$ & $\mathrm{N}$ & $\mathrm{Y}$ & $\mathrm{Y}$ & Y & $\mathrm{N}$ & $\mathrm{Y}$ \\
\hline
\end{tabular}

Yes cells are shaded for emphasis. Availability is only for the purposes of this meta-analysis. A "no" does not necessarily mean data were not collected. Pre, post, and ref are abbreviations for the existence of data pre- and postrestoration and at reference sites, respectively. The response variables included are not necessarily exhaustive of all data collected at the sites.

* An asterisk indicates response variables used in the preliminary meta-analysis.

$\mathrm{NA}=$ not applicable

\section{H.3 Results}

\section{H.3.1 Photo Points}

Pre- and post-restoration photo points indicated changes in vegetation and inundation of water, especially for Kandoll Farm and Vera Slough (Figure H.3). Additional photo points are being sought. 
Site

Crims Is.

Ft. Clatsop (looking south)

Johnson

Property

Kandoll

Farm

Vera Slough

\section{Pre-Restoration}

(early post)

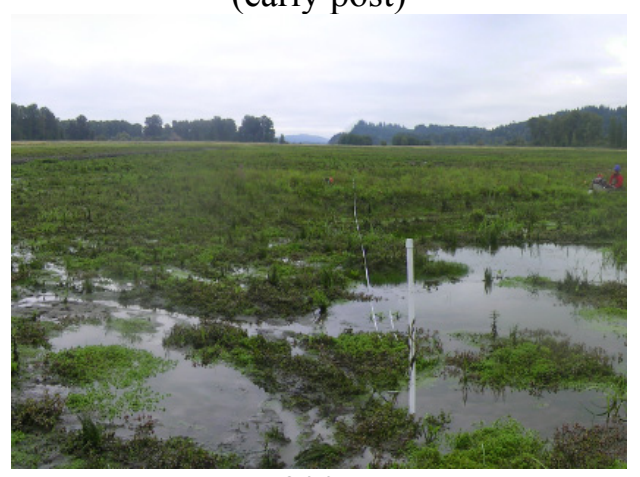

2007

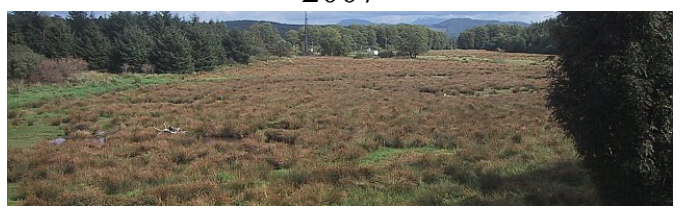

October 2004

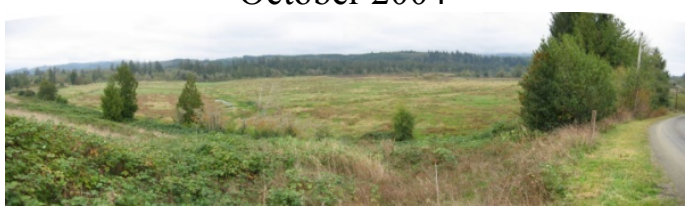

July 2005

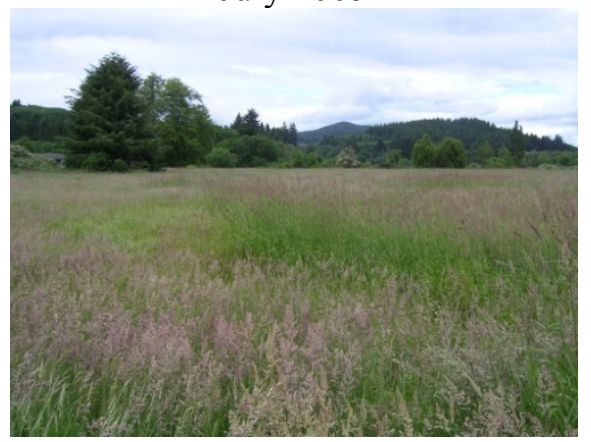

June 2005

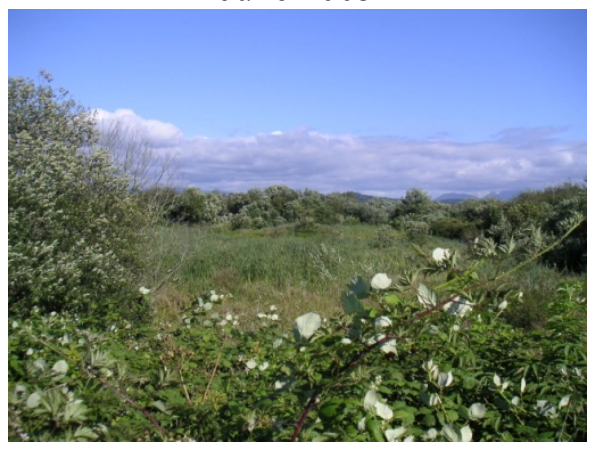

Post-Restoration

(later post)

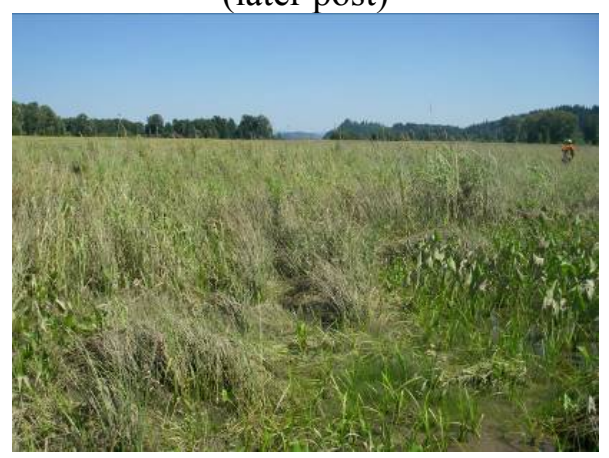

2008

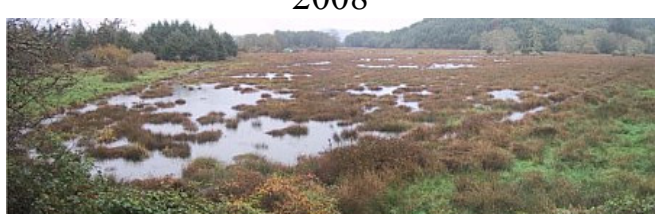

Not Available

July 2007

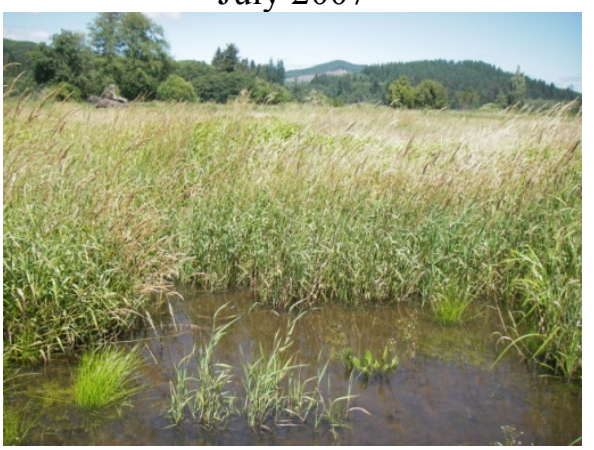

June 2009

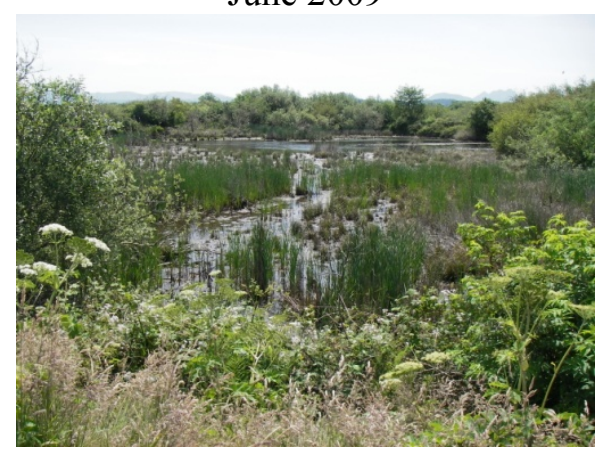

Figure H.3. Pre- and Post-Restoration Photo Points 


\section{H.3.2 Water Temperature}

At Fort Clatsop, water temperatures during June were lower after the restoration action (June 2008) than before (June 2007) (Figure H.4). Since no temperature data were available from the reference site for Fort Clatsop, we used temperature data from the Tansy Point sensor in the CORIE network (http://www.ccalmr.ogi.edu/CORIE/) as a comparison for the results at the restoration site. On average, water temperatures were cooler in Columbia River at Tansy Point in June $2008\left(12.73{ }^{\circ} \mathrm{C}\right)$ than in June $2007\left(14.10^{\circ} \mathrm{C}\right)$. Therefore, water temperatures at the restoration site and surrogate reference site at Tansy Point showed the same trend from June 2007 to June 2008

At Kandoll Farm, $10 \%$ of the water temperature observations were greater than $18.2^{\circ} \mathrm{C}$ in the prerestoration period in August-September 2005, whereas $10 \%$ were greater than $19.7^{\circ} \mathrm{C}$ during the same period 2007 post-restoration (Figure H.4). At the reference site, mean water temperatures for the August-September period were $17.6^{\circ} \mathrm{C}$ before tidal reconnection in 2005 . After tidal reconnection, mean water temperatures were $17.2^{\circ} \mathrm{C}$ in 2006 and $17.1^{\circ} \mathrm{C}$ in 2007 . Water temperatures tended to be cooler following restoration than before restoration. For example, $80 \%$ of temperatures were at or below $20{ }^{\circ} \mathrm{C}$ in pre-restoration as compared to $80 \%$ of temperatures at or below $18{ }^{\circ} \mathrm{C}$ post-restoration. This is probably explained by the greater water exchange with Seal Slough afforded by the open culverts. 


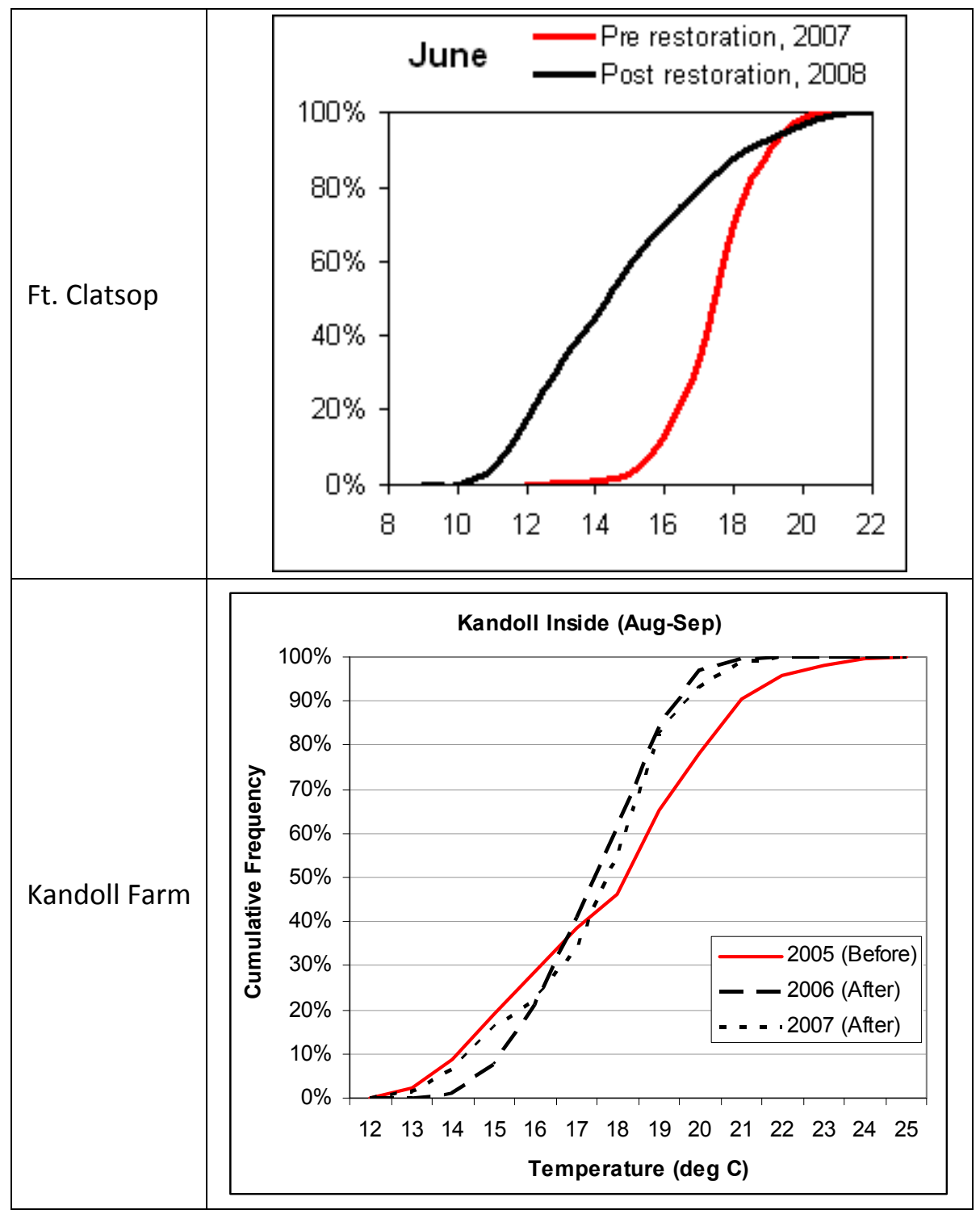

Figure H.4. Pre- and Post-Restoration Water Temperature Data

\section{H.3.3 Sediment Accretion Rate}

In the year(s) following the restoration activity of hydrologic reconnection, sediment was actively accreting at restoration sites (Table H.3). At some reference sites, however, sediment was not accreting, or accreting very slowly (Table H.3). For example, Kandoll reference site showed net loss. Although this site contains some emergent wetland plants and shrubs, the surface of much of the swamp is unvegetated; this condition limits sediment trapping capacity. 
Table H.3. Sediment Accretion Rates $\left(\mathrm{cm} / \mathrm{y}^{-1}\right)$ at Paired Restoration and Reference Sites

\begin{tabular}{lcc}
\hline & Restoration Site & Reference Site \\
\hline Crims Island $^{(\text {(a) }}$ & 1.1 & 0.1 \\
Fort Clatsop $^{(\mathrm{b})}$ & -- & 1.0 \\
Johnson Property $^{(\mathrm{c})}$ & 2.1 & - \\
Kandoll Farm $^{(\mathrm{d})}$ & 2.6 & -0.1 \\
Vera Slough $^{-}$ & -- & - \\
\hline (a) Crims Island measurements were taken September 2006 and February 2007 (Table A.2; Borde et al. 2008). \\
(b) Ft. Clatsop measurement taken July 24, 2008 (restoration) 8/15/08 (reference). Second measurement scheduled \\
for summer 2009 (restoration) 6/25/09 (reference). \\
(c) Johnson Property measurements taken 2005 and 2007 (reported in Diefenderfer et al. 2008). \\
(d) Kandoll Farm measurements taken 2005 and 2007 (reported in Diefenderfer et al. 2008). \\
\hline
\end{tabular}

\section{H.3.4 Juvenile Salmon Presence}

At three of the five sites, juvenile salmon were not present before the restoration action but were present after it (Table H.4). At Fort Clatsop, small numbers of juvenile salmon were present before restoration. In contrast, numbers of salmon increased by an order of magnitude after construction. Vera Slough is located on the west side of Young's Bay. Our sampling at the Vera Slough reference site indicated that few fish seemed to migrate into this area along the western shoreline of the bay. We suspect that this factor may explain the lack of fish presence in the Vera Slough site.

Table H.4. Pre- and Post-Restoration Juvenile Salmon Presence

\begin{tabular}{lcc}
\hline & Pre-Restoration & Post-Restoration \\
\hline Crims Island & No & Yes \\
Fort Clatsop & Yes (sparse) & Yes (abundant) \\
Johnson Property & No & Yes \\
Kandoll Farm & No & Yes \\
Vera Slough & No & No \\
\hline
\end{tabular}

\section{H.3.5 Site Evaluation Cards}

The purpose of Site Evaluation Cards (SEC) is to succinctly summarize the performance of restored sites relative to key response variables, as shown in the SEC template (Table H.5). Example SECs are provided in Tables H.6, H.7, and H.8. The SEC reports short-term performance of restored sites, from which data can be easily summarized and extracted, and often represents the basic set of information needed to report back to project sponsors and supporting programs. The concept is to use the SEC to report information in support of the cumulative effects analysis, including direct input into the calculation of the net ecosystem improvement (NEI) and cumulative net ecosystem improvement (CNEI). Critical to the meta-analysis is clearly identifying the linkage between the metrics used to assess performance at individual sites and the metrics used for extensive sampling and the higher-order metrics. Future work will include a meta-analysis of the data in the SECs. The overall report card for the projects will prove to be a simple way to communicate basic effectiveness data. However, this would only be useful if practitioners faithfully prepare the report cards based on their monitoring results. 
Table H.5. Template for a Site Evaluation Card

\begin{tabular}{|c|c|c|c|}
\hline Parameter & \multicolumn{3}{|l|}{ Result } \\
\hline \multicolumn{4}{|l|}{ Site name/location } \\
\hline \multicolumn{4}{|l|}{ Sponsor/contact } \\
\hline \multirow{2}{*}{\multicolumn{4}{|c|}{$\begin{array}{l}\text { Monitoring } \\
\text { practitioner(s)/contacts(s) }\end{array}$}} \\
\hline & & & \\
\hline \multicolumn{4}{|l|}{ Link to project and sites description } \\
\hline \multicolumn{4}{|l|}{ SEC date, author(s) } \\
\hline Project type(s) & \multicolumn{3}{|c|}{ Action } \\
\hline Vision & \multicolumn{3}{|c|}{ Describe what the site would look like if restoration is successful. } \\
\hline Goal & \multicolumn{3}{|c|}{ Statement of the expected outcome. } \\
\hline Objectives & \multicolumn{3}{|c|}{ Specific actions to be taken to meet the goal. } \\
\hline Performance criteria: & \multicolumn{3}{|c|}{ Target values for the various monitoring metrics } \\
\hline Physical change predicted & \multicolumn{3}{|c|}{$\begin{array}{l}\text { Describe how the action will affect physical controlling factors and the target } \\
\text { value }\end{array}$} \\
\hline Habitat change predicted & \multicolumn{3}{|c|}{ Describe the expected condition of habitat and the value. } \\
\hline Function change predicted & \multicolumn{3}{|c|}{ Describe the expected functional change and the target value. } \\
\hline \multicolumn{4}{|l|}{ Pre-Survey } \\
\hline Photo Point & \multicolumn{3}{|c|}{$\begin{array}{l}\text { Digital photograph from the chosen point and orientation, time of year, and } \\
\text { tide stage. Take a picture of the chosen point as a reference. }\end{array}$} \\
\hline $\begin{array}{l}\text { Condition of physical metrics } \\
\text { (water depth; water temperature; } \\
\text { sediment accretion) }\end{array}$ & \multicolumn{3}{|c|}{$\begin{array}{l}\text { List physical controlling factors and describe each one. Basically summarize } \\
\text { the major stressors on the site. Provide summary data (values). }\end{array}$} \\
\hline $\begin{array}{l}\text { Condition of habitat metrics } \\
\text { (vegetation) }\end{array}$ & \multicolumn{3}{|c|}{$\begin{array}{l}\text { Describe the key results of the vegetation survey. Provide summary data } \\
\text { (values). }\end{array}$} \\
\hline $\begin{array}{l}\text { Condition of functional metrics } \\
\text { (fish presence) }\end{array}$ & \multicolumn{3}{|c|}{$\begin{array}{l}\text { Assess or sample whether juvenile salmonids are present in the area. Provide } \\
\text { summary data (values). }\end{array}$} \\
\hline Construction Date & \multicolumn{3}{|c|}{ Insert date (time period) of construction. } \\
\hline $\begin{array}{l}\text { Was the construction performed as } \\
\text { planned? If not, why not? }\end{array}$ & \multicolumn{3}{|c|}{ Self-explanatory. } \\
\hline Actual physical changes realized & \multicolumn{3}{|c|}{ Describe what was actually done to the site, including elevations and sizes. } \\
\hline Post-Survey and Assessment & 1-Yr Results & $\begin{array}{ll}1-y r \text { Grade } & \sim 5-Y r \\
& \text { Results }\end{array}$ & $\begin{array}{l}\sim 5-y r \\
\text { Grade }\end{array}$ \\
\hline Photo point & See above for definition. & $\mathrm{n} / \mathrm{a}$ & $\mathrm{n} / \mathrm{a}$ \\
\hline $\begin{array}{l}\text { Condition of physical metrics } \\
\text { (water depth; water temperature; } \\
\text { sediment accretion) }\end{array}$ & See above. & Performance scale: & \\
\hline $\begin{array}{l}\text { Condition of habitat metrics } \\
\text { (vegetation) }\end{array}$ & See above. & Ibid & \\
\hline $\begin{array}{l}\text { Condition of functional metrics } \\
\text { (fish presence) }\end{array}$ & See above. & Ibid & \\
\hline $\begin{array}{l}\text { Unanticipated Effects (site or } \\
\text { landscape scales) }\end{array}$ & Self explanatory & & \\
\hline Actions for adaptive management & $\begin{array}{l}\text { Recommend any actions } \\
\text { or adjustments necessary } \\
\text { to meet the project goals. }\end{array}$ & & $\mathrm{n} / \mathrm{a}$ \\
\hline Final Assessment ( 10-year) & TBD & & \\
\hline $\begin{array}{l}\text { Was the project successful in } \\
\text { meeting its goals? }\end{array}$ & $\begin{array}{l}\text { State conclusions regardin } \\
\text { vision. }\end{array}$ & whether the project met its goal a & realized the \\
\hline $\begin{array}{l}\text { If not, what should be changed for } \\
\text { future projects of this type? }\end{array}$ & Describe lessons learned. & & \\
\hline Final Performance Grade & Performance scale: low, $\mathrm{m}$ & derate, high & \\
\hline
\end{tabular}


Table H.6. Site Evaluation Card for Crims Island

\begin{tabular}{|c|c|}
\hline Parameter & Result \\
\hline Site name/location & Crims Island/Lower Columbia River, rkm 88 \\
\hline Sponsor/contact & USACE/Blaine Ebberts (503 808 4763) \\
\hline Monitoring practitioner(s)/contacts(s) & $\begin{array}{l}\text { USGS/Ken Tiffan (509 } 538 \text { 2299); PNNL/Amy Borde ( } 360 \\
681 \text { 3663) }\end{array}$ \\
\hline Link to project and sites description & www.xxxx.gov \\
\hline SEC date, author(s) & July 2, 2009 (GEJ) \\
\hline Project type(s) & Tidal reconnection \\
\hline Vision & $\begin{array}{l}\text { New tidal wetland, with native vegetation communities and } \\
\text { tidal channels }\end{array}$ \\
\hline Goal & Connect tidal wetland to the main stem Columbia River \\
\hline Objectives & Excavate, grade, and build channels to intertidal elevations \\
\hline Physical change predicted & $\begin{array}{l}\text { Intertidal flats are formed at elevations that can support tidal } \\
\text { wetlands with natural tidal channels }\end{array}$ \\
\hline Habitat change predicted & $\begin{array}{l}\text { Emergent native tidal wetland vegetation species is intersected } \\
\text { with natural tidal channels }\end{array}$ \\
\hline Function change predicted & $\begin{array}{l}\text { Wetland primary productivity is restored; system is used by } \\
\text { juvenile salmon }\end{array}$ \\
\hline \multicolumn{2}{|l|}{ Pre-Survey } \\
\hline \multicolumn{2}{|l|}{ Photo Point } \\
\hline \multicolumn{2}{|l|}{$\begin{array}{l}\text { Condition of physical metrics (water depth; water } \\
\text { temperature; sediment accretion) }\end{array}$} \\
\hline \multicolumn{2}{|l|}{ Condition of habitat metrics (vegetation) } \\
\hline \multicolumn{2}{|l|}{ Condition of functional metrics (fish presence) } \\
\hline \multicolumn{2}{|l|}{ Construction Date } \\
\hline \multicolumn{2}{|l|}{$\begin{array}{l}\text { Was the construction performed as planned? If } \\
\text { not, why not? }\end{array}$} \\
\hline \multicolumn{2}{|l|}{ Actual physical changes realized } \\
\hline \multicolumn{2}{|l|}{ Photo point } \\
\hline \multicolumn{2}{|l|}{$\begin{array}{l}\text { Condition of physical metrics (water depth; water } \\
\text { temperature; sediment accretion) }\end{array}$} \\
\hline \multicolumn{2}{|l|}{ Condition of habitat metrics (vegetation) } \\
\hline \multicolumn{2}{|l|}{ Condition of functional metrics (fish presence) } \\
\hline \multicolumn{2}{|l|}{ Actions for adaptive management } \\
\hline Final Assessment ( 10-year) & TBD \\
\hline \multicolumn{2}{|l|}{ Was the project successful in meeting its goals? } \\
\hline \multicolumn{2}{|l|}{$\begin{array}{l}\text { If not, what should be changed for future projects } \\
\text { of this type? }\end{array}$} \\
\hline Final Performance Grade & \\
\hline
\end{tabular}


Table H.7. Site Evaluation Card for Kandoll Farm

\begin{tabular}{|c|c|}
\hline Parameter & Result \\
\hline Site name/location & Kandoll Farm, Lower Grays River \\
\hline Sponsor/contact & Columbia Land Trust/Ian Sinks (503 808 4763) \\
\hline Monitoring practitioner(s)/contacts(s) & $\begin{array}{l}\text { CREST/April Cameron (503 } 325 \text { 0343); NOAA/Curtis Roegner } \\
\text { (503 } 861 \text { 1212); PNNL/Heida Diefenderfer ( } 3606813663)\end{array}$ \\
\hline \multicolumn{2}{|l|}{ Link to project and sites description } \\
\hline SEC date, author(s) & August 3, 2009 (GEJ) \\
\hline Project type(s) & Tidal reconnection \\
\hline Vision & $\begin{array}{l}\text { New tidal wetland, with native vegetation communities and tidal } \\
\text { channels }\end{array}$ \\
\hline Goal & Connect tidal wetland to the main stem Columbia River \\
\hline Objectives & $\begin{array}{l}\text { Replace old tide gates with two } 14-\mathrm{ft} \text { diameter culverts and breach } \\
\text { dikes. }\end{array}$ \\
\hline Physical change predicted & $\begin{array}{l}\text { Intertidal wetlands are formed at elevations that can support tidal } \\
\text { wetlands with natural tidal channels }\end{array}$ \\
\hline Habitat change predicted & $\begin{array}{l}\text { Emergent native tidal wetland vegetation species is intersected with } \\
\text { natural tidal channels }\end{array}$ \\
\hline Function change predicted & $\begin{array}{l}\text { Wetland primary productivity is restored; system is used by } \\
\text { juvenile salmon }\end{array}$ \\
\hline \multicolumn{2}{|l|}{ Pre-Survey } \\
\hline \multicolumn{2}{|l|}{ Photo Point } \\
\hline \multicolumn{2}{|l|}{$\begin{array}{l}\text { Condition of physical metrics (water depth; } \\
\text { water temperature; sediment accretion) }\end{array}$} \\
\hline \multicolumn{2}{|l|}{ Condition of habitat metrics (vegetation) } \\
\hline \multicolumn{2}{|l|}{$\begin{array}{l}\text { Condition of functional metrics (fish } \\
\text { presence) }\end{array}$} \\
\hline \multicolumn{2}{|l|}{ Construction Date } \\
\hline \multicolumn{2}{|l|}{$\begin{array}{l}\text { Was the construction performed as planned? } \\
\text { If not, why not? }\end{array}$} \\
\hline \multicolumn{2}{|l|}{ Actual physical changes realized } \\
\hline \multicolumn{2}{|l|}{ Photo point } \\
\hline \multicolumn{2}{|l|}{$\begin{array}{l}\text { Condition of physical metrics (water depth; } \\
\text { water temperature; sediment accretion) }\end{array}$} \\
\hline \multicolumn{2}{|l|}{ Condition of habitat metrics (vegetation) } \\
\hline \multicolumn{2}{|l|}{$\begin{array}{l}\text { Condition of functional metrics (fish } \\
\text { presence) }\end{array}$} \\
\hline \multicolumn{2}{|l|}{ Actions for adaptive management } \\
\hline \multicolumn{2}{|l|}{ Final Assessment ( 10-year) } \\
\hline \multicolumn{2}{|l|}{$\begin{array}{l}\text { Was the project successful in meeting its } \\
\text { goals? }\end{array}$} \\
\hline \multicolumn{2}{|l|}{$\begin{array}{l}\text { If not, what should be changed for future } \\
\text { projects of this type? }\end{array}$} \\
\hline Final Performance Grade & \\
\hline
\end{tabular}


Table H.8. Site Evaluation Card for Vera Slough

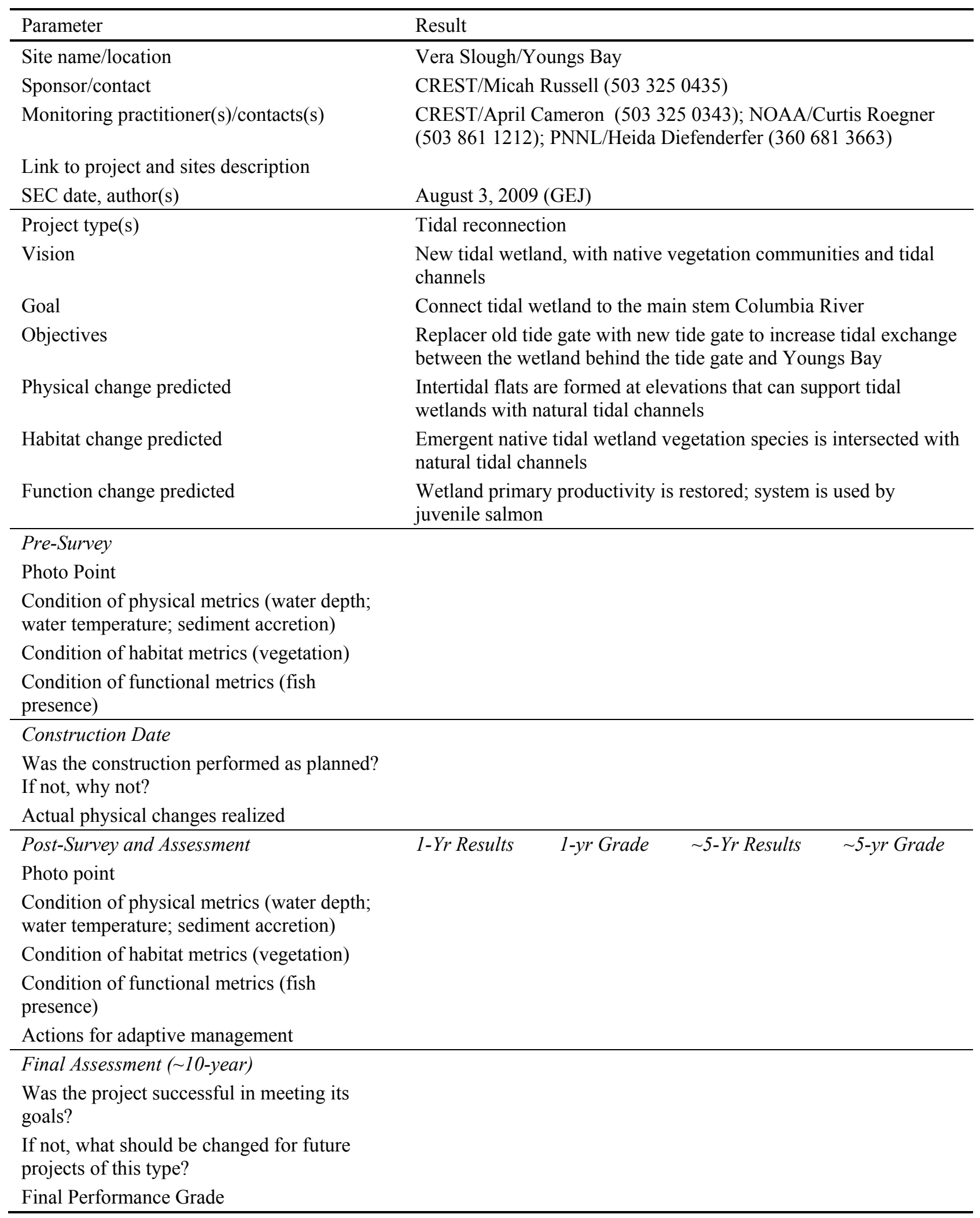




\section{H.4 Data Synthesis}

The data indicate that the restored sites are responding measurably to the restoration actions (Table H.8). The fact that water temperature, sedimentation, vegetation, and fish access have changed since prior to restoration verifies that the actions have restored ecological processes that form and maintain habitats, and that biological resource species are able to benefit from any processes like prey production and refuge afforded by these newly opened habitats. These changes have been detectable within 2 years following restorative actions.

Differences in responses among sites, for example temperature and accretion rates, can likely be explained by differences in geomorphology, elevation, and location of the sites. Kandoll Farm, being located on a side slough of Grays River is probably not receiving as cool a water mass in summer as Fort Clatsop. Yes, the direction of the change in temperature is the same at both sites. Fish presence was almost universal. Vera Slough was the exception, which may be due to its location on the west shoreline of Young's Bay. Fish apparently do not use this side of the bay for migration.

Table H.9. Summary Meta-Analysis Table

Is the response variable trending in the desired direction?

\begin{tabular}{lcccc}
\hline & Photo Point & $\begin{array}{c}\text { Water } \\
\text { Temperature }\end{array}$ & $\begin{array}{c}\text { Sediment } \\
\text { Accretion Rate }\end{array}$ & $\begin{array}{c}\text { Juvenile Salmon } \\
\text { Presence }\end{array}$ \\
\hline Crims Island & Yes & -- & Yes & Yes \\
Fortt Clatsop & -- & Cooler in Summer & -- & Yes \\
Johnson Property & Yes & -- & -- & Yes \\
Kandoll Farm & Yes & Cooler in Summer & Yes & Yes \\
Vera Slough & Yes & -- & -- & No \\
\hline
\end{tabular}

\section{H.5 Summary and Discussion}

To summarize, the preliminary meta-analysis indicated:

- Fish use of some sites will be a function of the location of the site. Do not expect sites far from salmon migratory corridors to be used by young migratory salmon.

- Water temperature changes should be expected, but they will be a function of the temperatures in the adjacent waterbodies. Predictions of the quantitative changes in water temperature must consider adjacent waterbodies.

- At least initially, sedimentation rate can be much higher in restored systems than in reference sites, perhaps due to the differences in vegetation and elevation. Establishing vegetation (e.g., by planting) may enhance the rate at which sediment is initially accreted.

- Using quantitative data on salmonids, in addition to qualitative data, might help resolve fish habitat preferences.

- Effectiveness monitoring protocols should be more widely applied.

- The SEC should be applied to all appropriate projects. 
- As the effectiveness monitoring database grows, a central data management and access system will need to be established.

This first attempt at summarizing the results from a suite of projects illustrated several points. First, variability in level of effort, lack of pre-restoration sampling, and other factors significantly reduced the number of sites that could be compared. That said, sites that were excluded here do have data that can be used for planning and evaluation purposes, but are less useful in drawing general inferences about the success or failure and direction of response of the restored sites. Second, level of effort in terms of the metrics sampled limited comparisons to four metrics. However, these metrics were relatively robust for determining the response in processes and functions. Having a greater number of metrics commonly collected and sampled would improve the power of comparisons. Third, the duration of assessment was probably not as long as needed to more fully evaluate the long-term (e.g., $>10$-year) condition of the site. We expect the vegetation the change rapidly over at least 5 to 6 years following tidal reconnection. Channel morphology should change due to sedimentation and erosion, and this may affect temperature and fish access.

In closing, as data are developed, the analysis of effects will become more robust. When effectiveness monitoring data on a set of common metrics from 15 to 20 sites of various types and locations of tidal reconnection restoration projects are available, it will be possible to perform a logistic regression to determine which metrics work and which ones do not by type and location. In addition, we expect to be able to identify temperature ranges relevant to salmonid life-history stages and determine what actions are needed to increase the chances of creating these optimal ranges. We will also incorporate ancillary data such as climate, flooding, and fisheries information to help explain interannual or longer-term results from the restoration sites. Further, as the data become more widely developed and robust we will be able to initiate estimates of the net ecosystem improvement in the estuary, which will quantify the cumulative effects of multiple restoration projects.

\section{H.6 Literature Cited}

Borde, AB, SA Zimmerman, and KL Sobocinski. 2008. "Crims Island - Monitoring Data Summary." Appendix A, pp. A1-A19, in Evaluating Cumulative Ecosystem Response to Restoration Projects in the Columbia River Estuary, Annual Report 2007, GE Johnson and HL Diefenderfer (eds.). PNNL17437, prepared by Pacific Northwest National Laboratory, Richland, Washington, and the National Marine Fisheries Service, Seattle, Washington, for the U.S. Army Corps of Engineers, Portland District, Portland, Oregon.

Diefenderfer HL, RM Thom, GE Johnson, JR Skalski, KA Vogt, BD Ebberts, GC Roegner, and EM Dawley. (In Review.) "Assessing Cumulative Ecosystem Response to Estuary and River Restoration Programs Using a Levels-of-Evidence Approach.” Ecological Restoration.

Roegner, GC, HL Diefenderfer, AB Borde, RM Thom, EM Dawley, AH Whiting, SA Zimmerman, and GE Johnson. 2009. Protocols for monitoring habitat restoration projects in the lower Columbia River and estuary. Prepared by NOAA Fisheries and Pacific Northwest National Laboratory for the U.S. Army Corps of Engineers, Portland District. NOAA Technical Memorandum NMFS-NWFSC-97. Seattle, Washington. 



\section{Distribution}

No. of

Hard Copies

10 Blaine D. Ebberts

USACE Portland District

CENWP-PM-E

333 SW First Avenue

Portland, OR 97208-2946

1 G. Curtis Roegner

NOAA Fisheries

Pt. Adams Field Station

520 Hecata Place

Hammond, OR 97121-0155

1 Earl M. Dawley 651 Grand Ave.

Astoria, OR 97103

1 Micah T. Russell

Columbia River Estuary Study

Taskforce

750 Commercial Street, Room 205

Astoria, OR 97103

1 John R. Skalski

University of Washington

1325 Fourth Avenue, Suite 1820

Seattle, WA 98101
No. of

$\underline{\text { Hard Copies }}$

\section{Internal Distribution}

1 Pacific Northwest National Laboratory

P.O. Box 999

Richland, WA 99352

Steve Schlata

K6-83

Susan Ennor

K6-86

4 Marine Sciences Laboratory

1529 West Sequim Bay Road

Sequim, WA 98382

Amy Borde SEQUIM

Heida Diefenderfer SEQUIM

Ron Thom

SEQUIM

John Vavrinec

SEQUIM

10 Battelle Portland Operations 620 SW $5^{\text {th }}$ Avenue, Suite 810 Portland, OR 97204

Gary Johnson

BPO 